
S.A. Schwary 
1 


\title{
Entomologis che
}

\section{Monographie en}

von

\author{
Dr. Fr. Klug,
}

Königl. Preufs. Geh. Medicinal-Rath und Professor, Mitdirector des Königl. zoologischen Museums der Universität und Mitglied dèr Königl. wissenschaftl. Deputation für das Medicinalwesen, ordentl. Mitgl. d. Gesellschaft naturf. Freunde in Berlin und der märkischen ökonomischen in Potsdam, auch Mitgl. d. Kaiserl. Leopold. Akademie d. Naturforscher, der Wetterauischen Gesellschaft f. d. gesammte Naturkunde, der physiographischen Gesellschaft in Lund, der naturforschenden Gesellschaften in Halle und Moskau.

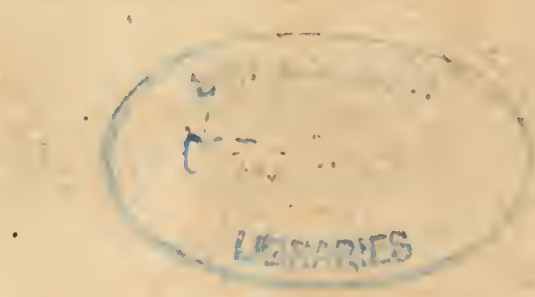

Mit 10 illuminirten Kupfertafeln.

$$
\text { Berlin, } \quad 1824 \text {. }
$$

$$
\text { Gedruckt und verlegt }
$$

bei G. Reimer. 



\title{
Seiner Excellenz
}

\author{
$\mathrm{dem}$
}

$\mathrm{Herr}$

\section{Freiherrn Stein von Altenstein}

Königl. Preufs. wirklichen Geheimen Staats - Minister, Chef des hohen Ministerii der Geistlichen-, Unterrichts - und Medicinal - Angelegenheiten, Ritter des rothen Adler-Ordens erster Klasse etc.

dem hohen Gönner und Beförderer jedes wissenschaftlichen Strebens 
che Lücke selbst nach längerer Zeit angemessen zu fiillen.

Wenn hiernach eine Rechtfertigung meines Unternehmens, wodurch wieder nur die Zahl der kleinen Monographicen vermehrt wird, kaum möglich ist, so düfte doch zu meiner Entschuldigung dienen, dafs bei der täglichen Zerstreuung durch Berufsgeschäfte sehr verschiedener Art, wo bei der Nolhwondigkeit, eine grofse, durch reiche Sendungen fortwährend sich vermehrende Sammlung sicher zu stellen und allmählig zu ordnen, zu gröfseren Arbeiten Zeit zu gewinnen, fast unmöglich ist, ich lieber mich dahin bestimmte, die Beschreibungen von Arten und Gattungen und die beim Ordnen der Sammlung gleichsam von selbst entstandenen Monographieen bekannt zu machen, als sie unbenutzt zuriickzulegen. Ersteres habc. ich hauptsächlich darum vorgezogren, weil es mir eine passende Gelegenheit schien, für den Reichthum der hiesigen selten richtig geschätzten Insectensammlung einen, wenn auch unrollkommenen Maafsstab zu geben und derselben wo möglich diejenige Aufmerksamkeit und Theilnahme zu gewinnen, welche die ihr zum Grunde gelegte Hellwig-Hofrmannseggsche in so hohem G'rade genossen hat. Und wenn zu gleichem Zweck eine Zusammenstellung der Veränderungen, welche seit jener Vereinigung im Anfange des Jahres 1820 die hiesige Königliche Sammlung erfahren hat, hier am rechten Orte 


\section{- VII}

sich finden möchte, so habe ich auch diese hicr folgen lassen.

Vorher enthielt das Museum der Universitït keine bemerkenswerthe Sammlung von Insecten. Durch die Verbindung einer kleinen von dem Kapitän von Malinow sky erkaúten Sammlung Europäischer Käfer, der, zum Theil exotischen Insecten aus dem früher erkauften Kabinet des verstorbenen Ober-Medicinalraths Dr. Riemer, der Sammlung Europäischer Schmetterlinge unsers verewigten $L$ aspeyres, so wie verscliedener Capschen Insecten, welche mein verehrter Kollege Professor Dr. Lichtenstein dem Museum geschenkt hatte, war immer noch nichts Erhebliches zu Stande gekommen, so dafs der auffallendste Unterschied zwischen diesem und den übrigen schon reichlich ausgestatteten Theilen des Königl. Musei bis dahin herrschte, wo diese Iü̈cke durch den Ankauf der Hoifmannseggschon Sammlung gefiillt wurde. Letztere enthielt damals gegen 19000, unter ihnen beinahe 9000 exotische, mehrentheils Brasilische Arten, worunter die Zahl der Coleopteren auf nah an 7500, der Orthopteren auf etwa 500, der Neuropteren auf 550, der Lepidopteren gegen 5000, der Hymenopteren etwas uber 2000, der Hemipteren auf etwa 1400 , der. Dipteren nah an 2000 sich belief. Fast gleichzeilig wurde die in Herbsts Schuiften oft erwähnte, mit manchem seltenen Käfer des 11olthuysenschen Kabi- 
nets prangende Salingre'schen Sammlung von ihrem Eigenthümer dem Museum überlassen. Zwei kleine hiesige Sammlungen, des HofChirurgus Collignon und des Kriegsrath Kirstein wurden, erstere als Geschenk, letztere durch Vermächtnifs ihm einverleibt. Auch die Gelegenheit, die bekannte Knoch'sche Sammlung um einen billigen Preis zu kaufen und dadurch die Zahl unserer Nord-Amerikanischen Insecten, vornemlich der kleineren Käfer, bedeutend zu vermehren, blieb nicht unbenutzt; endlich aber wurde im verflossenen Jahre meine eigene beträchtliche Sammlung von Hymenopteren mit der Königlichen verbunden und namentlich lierdurch eine bisher sehr mangelhafte Abtheilung jeder andern wenigstens gleichgebracht, wo nicht über dieselben erhoben. Wie aber ganz vorzüglich durch die reichen Sendungen unserer Reisenden die Sammlung der Insecten in kurzer Zeit ansehnlich und allgemein vermehrt worden, verdient mit wenigen Worten noch eine besondere Erwähnung.

Die grörste Ausbeute hat bis jetzt auch für uns Brasilien geliefert. Die ersten minder beträchtlichen Sendungen waren aus Bahia von Freireifs. Doch sehr bald wurden sie entbehrlich durch die reichen Beiträge Sellow's, welcher, aufs thätigste von der Königl. Preulsischen Gesandtschaft am Hofe von Brasilien, Herrn Grafen von Flemming und dem eifrigen Naturkundigen Legationsrath Dr. von 
Olfers unterstiitzt, zum Theil in des letztern Gesellschaft, mit ausgezeichnetem Glück in den Districten von Bahia und Minas Geraes, um Rio Janeiro und Montevideo, in ganz anderen Gegenden und Riclitungen, als früher Sieber, des Grafen von Hoffmannsegg Kammerdiener, sammelte. Mit mancher neuen Art von Rio Janeiro hatten aufserdem der verstorbene Feldner und der Gärtner Beyrich, mit wichiigen Beiträgen daher der für Entomologie so thätige Bescke aus Hamburg und mit einer Menge der schönsten und seltensten Arten, besonders aus den Ordnungen der Coleoptera und Lepidoptera mit-seltener Uneigennützigkeit Herr von Langsdorff die hiesige Sammlung bereichert. Dafs von keiner Seite die Mittheilung einzeln gefundener Stücke verweigert worden, erschien ron gröfserem Belang in Hinsicht der von Langsdorffschen Sammlung, wegen der grofsen Menge darin enthaltener nur einmal gefundener Seltenheiten, die nach der ausdriicklichen Bestimmung des Besitzers der Königl. Sammlung einverleibt und nur durch eben so viele in der letztern mehrfach vorhandene Arten wieder ersetzt werden sollten.

Wenn so auf verschiedenem Wege mehrere Tausend neue Brasilische Arten dem schon Vorhandenen sich zugesellten, so war doch nicht Amerika allein die Quelle der Bereicherungen unsers entomologischen Kabinets. Was 
Afrika betrifit, so erbielt das Museum durch die rastlosen Bemühungen des allzu früh verstorbenen Bergius eine ausgesuchte und ungemein schön erhaltene Sammlung Capscher Insecten. In Bergius Stelle trat Krebs. Jede Sammlung, welche derselbe am Kap und besonders in dern entfernteren District von Vitenhagen veranstaltete, vermehrte bedeutend die Anzahl der neuen Arten, so dafs jene Verbindung in entomologischer Hinsicht unstreitig als eine der wichtigsten erscheinen mufs. Endlich war unter dem, was Mund und Maire in naturhistorischer Beziehung am Kap gesammelt hatten, auch für Entomologie manches seu und bemerkenswerth.

Die Sendungen unserer Reisenden in Egypten und Nubien, des Dr.Hemprich und Dr. Ehrenberg trugen durch iliren iiberraschenden Reichthum ebenfalls nicht wenig zur Erweiterung der Insectensammlung bei. Dennoch ist erst der geringere Theil des dort Gesammeiten, in unsern Händen, da die Reisenden die Absiclit haben und es für sicherer halten, ilsre entomologischen Schätze mitzubringen, wenn sie selbst am. Ende des künftigen Jalires nach Eiuropa zurückkehren. - Was auf den verschiedensten Punkten der Erde Dr. von Chamisso bei Gelegenheit der Russischen Entdeckungsreise an Insecten gesammelt hatte, wurde ebenfalls dem Museum zugetheilt. - Endlich aber bleibt noch der Reise des Dr. Eversmann von Oren- 


\section{$-\quad \mathrm{XI}-$}

burg nach Buchara zu ersähnen, die auch in entomologischer Beziehung cine keineswegs unwichtige Ausbeute gegeben hat.

Wenn dicse verschiedenen Sendungen das Museum zu dem Besitz einer grofsen Menge sonst nirgend vorhandener und nur auf solchem Wege zu erlangender Seltenheiten verholfen haben, so bestand ein anderer nicht geringerer Vortheil solcher Verbindungen in dem sich hierdurch zugleich bildenden Vorrath brauchbarer Doubletten, wodurch allein ein lebhafter Umtausch nach allen Richtungen hin und die Vervollständigung der Sammlung sowohl durch neuentdeckte Europäische Arten, als deren Ausstattung mit Insecten der entlegensten Länder, ohne auf den Ankauf. solcher Gegenstände bedeutende Kosten verwenden zu dürfen, möglich wurde. In der Sammlung, welche auf diese Weise eine mannigfache und mehrseitige Ausbildung gewonnen, findet sich nach ihrer ursprüglichen Einrichtung bei allen nicht ganz'gemeinen Insecten neben der Bezeichnung der Art und der Angabe des Vaterlandes, auch der Name des Einsenders, so dafs, wo jetzt oder später der Reichthum unserer: Sammlung crkannt wird, zugleich bemerkt werden kann, wodurch es möglich geworden ist diesen Grad der Vollständigkeit zu erreichen. So werden die von jedem Freunde des entomologischen Studiums hochgeschätzten Namen: C. F.C. und C. H. Bescke, Banon, Bonfils, v. Charpentier, Dahl, Gr. Dejean, Escher 
der Beschreibung mancher Arten der Gattungen Agra und Chlamys nur zu wohl eingesehen. Ich wünsche auf eine nachsichtsvolle Aufnahme und Beurtheilung von Denen, die sich mit mir in gleichem Fall befunden, rechnen und hoffen zu dürfen, billigen Forderungen mehrentheils genügt zu haben.

Berlin, im September 1824.

\section{Der Verfasser.}


C $t$ e n o s t o m a. 


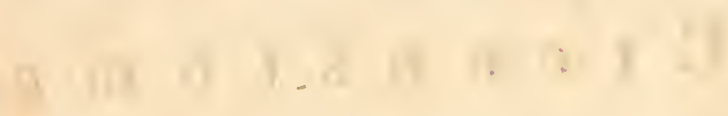




\section{Cte nostoma.}

Ctenostoma Klug (Nova acta physico-medica Acad. Caes, Leop. Nat. Curios. x.). Latreille, Déjean (Histoire natur. et Iconographie des Insectes Coléopterès d'Europe I.). Caris $\mathbf{F}$ ischer (Entomographia Imperii Russici). Collyris $\mathbf{F}$ abr. (Sysi، Eleuth.). Schönherr (Synonymia Insect.).

$\mathrm{B}_{\mathrm{ei}}$ der gegen wârtigen Bearbeitung von Ctenostoma habe ich nicht die Feststellung dieser an sich ausgezeichneten and nun auch von Andern angenommenen Gattung, sondern vielmehr die Unterscheidung der Arlen, auf welche es allein noch anzukommen schien, vor Angen gehabt. Herr Baron Déje a n äufsert die Vermuthung, dafs Collyris formicaria Fabr, mein Ctenostoma formicarium, eigentlich nicht unterschieden, sondern hüchstens Varietät der von ihm beschriebenen und aborebildeten Art sey und mit dieser bis auf den gelben, vielleicht von Fabricius und mir übersehenen Flecli am hintern Ende der Deckschilde übereinstimme. Ich habe aber drei verschiedene Arten von Ctenostoma vor mir, und unter die. sen auch die Déjeansche Art, welche lieineswegs einerlei mit derjenigen ist, welche ich in den Ver 
handlungen der Leopoldinischen Alsademie beschrieben und für Fabricius's Collyris formicaria, wahrscheinlich nicht mit Unrecht, gchalten habe, dic aber wohl mit $F$ is che $r$ Caris trinotata übereinzustimmen scheint. Die Auseinandersetzung dieser direi Arten macht den Inhalt dieses bleinen monographischen Versuchs aus, und bemerke ich hier beiläufig, daf's die hierzu gehörenden Insecten wirklich ungeflügelt sind.

Dafs Herr Prüsident v. Fischer in den sciner Entomographia Imperii russici angehängten Generibus Insectorum diese Gattung bereits unter cinem andern Namen: Caris aufgestellt hatte, war mir, als ich theine Abhandlung für dic Verhandlungen der Leopoldinischen Akadenie niederschrieb, noch unbekannt, indem damals noch kein Exemplar der $\mathbf{F}$ ischerschen Entomographie hierher gckommen war. Fischer's Benennung hat jedoch aus der von Herrn Baron Déjean (Hist. natur. p. 55.) angefülırten Ursache nicht beibehalten werden können.

\section{Ctenostoma formicarium.}

Ctenostoria nigrum, nitidum, elytris punctatis fuscis, macula media transversa flava. Long. lin. $5 \frac{x}{2}$.

Ctenostoma formicarium $\mathrm{K} l \mathrm{ug}$, Verhandlungen der Kaiserl. Lcop. Carol. Akadenie d. Naturf. II. p. 304. Tab. XXI. f. 7 .

Collyris formicaria Falbr. Syst. Eleuth. I, p. 226 . n. 3. S chönher Synon. Insect. I. x. p. 236. n.43. 4.

Patria: Parà in Brasilia; ex Museo Comito de Hof $\mathrm{m}$ annsegg.

Caput cum palpis nixrum nitidum mandibulis apice ferrugineis. Antennae ferrugincae articulo pri- 
no fusco-nigro. Thorax nitidissimus niger. Elytra sparsim punctata, basi densius foveolata, pilifera, apice emarginata fusca, macula magna media s. fascia abbreviata pallida. Pedes pilusi picei femoribus anticis subincrassatis, posterioribus basi pallidis.

Vou Parà in Brasilien; Länge: $5 \frac{T}{2}$ Linien. Kopf und Bruststück glänzend schwarz, dịe Mandibeln mit braunen Spitzen. Die langen borstenförmigen Fühler braun mil schwarzbraunem Grundgelenk. Die Deckschilde bräunlichschwarz, einzeln punktirt und mit steifen Härchlıen besetzt, an der Wurzel mit tief eingedriichten Grübchen, an der Spitze etwas heller und ausgerandet. Die Mitle ziert ein blafsselber Fleck, der in Gestalt einer Quecrbinde von dem Aufsenrande bis gegen die Nath sich erstreckl. Die Beine sind mit IIaaren besetzt, pechbraun, die vordersten Schenkel dicker als die hinteren, letztere an der Wurzel blafsgelb.

Auf einen Druckfehler in meiner in den Schriften der Leopoldinischen Akademie befindlichen $A b$ handlung , wo es statt Ct. formicarum, Ct. formicarium heilsen soll, mache ich um so mchr aufmerlisam, als auch Hr. Baron Déje an veranlafst worden ist, diese unrichtige Benenungyg als Citat anzuffihren. Uebrigens leidet es wohl keinen $Z Z_{\text {vieifel, dafs die }}$ Gattungुsbeneunung Ctenostoma als Neutrum gुebraucht werden mufs.

\section{Ctenostoma trinotatum.}

Ctenostoma nigrum, elytris punctatis, basi trans-. versim rugosis, fuscis, fascia ante apicem apiectue pallidis. Long. lin. $5 \frac{\mathrm{T}}{2}$. 
Ctenostoma formicaria, Latreille et Déjean Histoire naturelle et: Iconographie des Insectes Coléopterès d'Europe I. p. 26. Tab. II. Fig. 1.

Caris trinotata $\mathbf{E}$ is oher genera Insect. systematice exposita etc. I. p. 99. Caris fasciata Tab. I. Fir. 3.

Patria: Rio Janeiro Brasiliae; Misit Sello et communicavit de Langsdorff.

Differt a Ctenostom. formicario F. praesertim elytris ad basin transversim rugosis, macula baseos obsoleta, apice obtuse tridentato, fasciaque semilunari infra medium pallidis. Caput nigrum nitidum, fronte plana foveolis rugisque inaequali. Antenņae testaceae, articulis supra nigris, Thorax niger nitidissimus. Elytra sparsim punctata, basi rugosa seu transversim plicata apice obtuse tridentata, nigro-fusea, nitida, macula transversa baseos obsoletiori, fascia semilunari infra medium apiceque pallidis, Pedes pilosi picei, femoribus basi testaceìs.

Von Rio Janeiro, Kaum merklich grörser und eben so gestaltet als die vorhin beschriebene Art, jedoch vornehmlich in Hinsicht der Declischilde von ihr unterschieden. Der Kopf glänzend schwarz, die Stirn voller Grübchen, dịe Fühler blafs geḷbbrïunlich, jedoch die obere Seite der Glieder schwärzlich. Das Rüclsenschild schwarz, glatt und glänzend. Die Decksshilde zum Theil einzeln punktirt, die vordere Hälfte dicht und stark in die Queer gerunzelt, die Spitze dreifach stumpf gezahnt. Die gelben $\mathrm{Ab}$. zeichen auf den Deckschilden bestehen in einem dunkleren und nicht so dentlich begränzten Fleck unweit dem Grundtheil, in einer hell und lebhaft gefärbten haibmondförmigen Binde, die unter fler 
Mitte, melir als bei dem Ctenostoma formicarium, der Spitze genähert und dieser die eingebogene Seito zugekehrt, sich befindet und endlich in den blarsgelblichen Spitzen der Decken selbst. Dic Beine sind mit Haaren besetzt, bräunlich, die Schentiel au dor Wurzel gelblich.

Die Abbildung in Fischer's Entomographio pafst zwar keineswegs genau, auch mangelt eine Beschreibung, doch ist die grörste Wahrscheinlichkeit vorhanden, dafs keine als die hier Leschriebene Art vou ihm geneint sey.

\section{Ctenostoma rugosum.}

Tab. Ili. Fig. 3 .

Ctenostoma nigrum, fronte scabra, elytris dimidiatis transversion-rugosis, nacula baseos apicequo late pallidis. Lung. lin. 6.

Habitat in Brasilia; Misit Dr. de Olfers.

Distinctissima species. Caput nigrum pallidopilosum, fronte plana, scabra. Antennae nigrae, articulis tribus prioribus testaceis, dorso fuscis. Thorax aterrimus, sparsim pilosus. Elytra ultra inedium rugosa nigra, macula magna baseos flava, apice glabra obtusa vixque emaroinata, flava. Pedes nigropicci linc inde pilosi, femoribus posterioribus basi testaceis.

Ais Brasilien. Sechs Linien lang. Gestalt der vorigen Arten. Kopf und Rïckenschild tiefschwarz, glänzend, hin und wieder belaart. Die Stirn breit, flach, durch eingedrückte Punkte und zackenförmige Erhabenheiten ungleich. Die Fühler lang, schwarz, die drei ersten Glieder blafsgelb, oben schwarz. Dio 
Deckschilde von ihrer WVurzel an bis über die Hälfte stark queer gerunzelt, hiernächst glatt; die gerunzelte HäIfte bräunlich schwarz, mit einem grofsen, einer breiten Binde ähnlichen, braungelblichen Flügelfleck, der nicht gerunzelte Theil blafs strohgell; die Spitze gerundet, in der Mitte kaum merklich ausgerandet. Die Beine schwarzbraun, mit einzeln stehenden Haaren. Die Schenkel der hinteren Beine an der Wurzel gelblich. 
A g r a. 


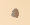




\section{A $g r a$.}

Agra Fabricii (Syst. Eleuth.). Latreille Histoire natur, etc. Gen. Crust, et Ins. Considerations gener. I Regne animal) Olivier (nouveau diction. d'histoire naturelle). , Dumeril (Diction. des sciences natur.). Illiger (May. f. Insect.) Schönherr (Synonymia Ins.). Germar (Ersch u. Grube Encycl.). Klug (Verhandlungen der Kaiserl. Leopold. Carol. Akademie d. Naturf.). Carabus Olivier (Entomolog. Encycl. method.) Cicindela Fabr. (entomol, syst, emend.) Drypta Schönherr (1. c.).

Eine bekannte, deutlich in ihrem ganzen Körper. bau unterschiedene und jetzt allgemein angenommene Gattung, deren Kennzeichen daher hier nicht weiter zu erörtern seyn werden. Im zweiten Bande der Verhandlungen der Kaiserl. Leopoldiniscien Akademie der Naturforscher (dem 1 oten der Nova ącta Physico medica) habe ich die weit schwierigere Auseinandersetzung der Arten von Agra verssucht, und jene Abhandlung ist es, welche der gegenwärtigen Arbeit zum Grunde gelegt worden. Uebes cinige der mir damals nech zweifẹthaften Arten, namento lich Agra aenea und rufipes $\mathrm{E}$. habe ịch mị seitdem nähere Kenntnifs und $\Delta$ ufklärung verschaffen lsünnen. Auch sind noch einige neue $A_{g}$ ra denı hiesigen Mu. seum zugekummen, so dafs ich es dor Mtihe. werth 
hielt, mit einer wiederholten Beleuchtung der genannten Gattung hier aufzutreten. Iclt habe hierbei die Schwierigkeiten gefühlt, bei einander mehrentheils sehr ähnlichen und wenig ausgezeichneten Arten durch blofse Beschreibungen hinreichend deutlich zu werden und halte in dieser Hinsicht, namentlich was gegrenwärtige Gattung betrift, sowohl die Beschreibungen in deutscher Sprache für ein Mittel die lateinischen hin und wieder verständlicher zu machen, als auch die beigefügten Abbildungen zur Erläuterung der Beschreibungen nützlich.

Ich habe die Arten mit an der Spitze dreigezahnten Deckschilden denen, welche nur zwèi ZZ̈̈hne an den Spitzen der Deckscliilde haben, folgen lassen.

Unbekannt ist mir geblieben, aufser der Agra caycnnensis 01., welche ich nicht mit Sicherheit zu deuten wage, desselben Verfassers Agra tridentata (Entomologic III. p. 53. n. 61. Pl. XI. F. 129. Encyclopédie méthod. Pl. 180. F. 18. Drypta tridentala Schönlaer Synon. Ins. I. 1. 1. 237. 11. 4, )。

\section{Agra aenea.}

Tab. I. Fig. 1.

Agra aenea, capite elongato nitido, thorace elongato impresso - punctato, elytris punctato - rugosis, apice oblique truncatis bidentatis. Long. lin. $10 \frac{1}{2}$.

Agrat acrea Fabricii System. Elentl. I. p. 224. w. x. Sehünher Synonymia Insect. 1. 1. p. $25^{6}$. 11. $42, x$.

Habilat in America meridionali. Mus. Reg Mavn. ex Museo Di. de Sehestedt.

Magna, depressa. Caput laevissimum, clypeo, habroque una cum mandibulis palpisque nimro-piceis. 
Antennae vix elytris breviores, subpilosae, rufae, articulis ante apicem nigricantibus. Thurax capite longior, elongatus, ante apicem parum angustatus dorso vage impresso - punctatus lineolaque longitudinali media impressa divisus. Scutellum laeve. Elytra cupreo micantia thorace plus duplo longiora ad apicem latiora, apice acute bidentata, ubique impresso-punctata et punctato-rugosa, punctis magnis inaequalibus irregularibus. Venter piceus, aeneo-micans. Pedes picei tibiis femoribusque aeneis, tarsis fuivo-pilosis.

Vaterland: Siidamerika. Länge $10_{2}^{T}$ Linien. Glänzend erzfarben. Kopf sehr glatt, Schildchen, Lefze, Frefszangen und Frefsspitzen glänzend braun. Die Füllerglieder braun, an der Spitze schwarz. Das Bruststück fast noch einmal so lang als der Kopf, oben punktirt, die Punkte eingedrückt, grofs, einzeln stehend, cinigermarsen in Längsreilien geordnet. Rückenschild sehr kleiu. Deckschilde noch einmal so lang als das Rückenschild, an den Spitzen schräg abgeschnitten, izu beiden Seiten in einen spitzen Zahn auslaufend. Fläche stark punlitirt. Punkte grofs, eingedrückt, kanm in Reihen geordnet. Der Raum zwischen den Punkten ungleich erhöhet. Bauch bräunlich mit Erzglanz. Beine erzfarben, Fufschlicder melır bräunlich, Sohlen mit goldgelben Haaren besetzi.

Beschreibung und Abbillung nach dem Exemplar der ehedem Lund-Sehestedschen, jetzı Königl. Dänischen Sammlung in Kopenhagen.

Wahrscheinlich gehürt hierher: Carabus cayennensis Olivier (Entomologie III. p. 53. n. 6o. Taf. 
XII. F. 133.). Dryptą cayennensis Schünherr (Synonymia Ins. I. 1. p. 237 . 12.3.)。

\section{Agra rufescens.}

Tal, I. Fig. 2.

Agra piceo-sub-aenea, antennis pedibusque rufo-piceis, capite ovali laevi, thorace elongato, punctato-rugoso, elytris impresso-punctatis, apice oblique truncatis bidentatis. Long. lin. 10.

Agra infescens Klug Verh. d. Leopold. Alkad. II. p. $281 . n . x$.

Patria. Bahia in Brasilia. Misit Sello.

Magna, subdepressa. Caput thorace vix angustius, ovale, laeve, marginibus sparsim punctatum rufo-piceum, clypei apice, labro palpisque dilutioribus. Mandibulae piceae, apice nigrae. Antenuae elytrorum fere longitudine, subpilosae, rnfo-piceae. Thorax capite vix longior, ad apicem parum angustatus, supra punctis impressis, saepius confluentibus, inaequalis, subtus vix punctatus. Scutellam concolor. Elytra thorace plus duplo longiora, capite duplo fere latiora, subaequalia, marginata, marginibus rufescentia apice oblique truncata, acute bidentata, picea, aeneo-submicantia, punctata, punclis magnis inaequalibus inpressis, saepius confluentibus, in seriebus novem longitudinalibus positis. Venter piceus segmentis apice ferrugineo-subpilosis. Pedes rufo-picei, femoribus subincrassatis, tibiis rarius, tarsis densius falvo-ciliatis. Plantae fulvo-tumentosae.

Mas tibiis posticis subincurvatis, intus fusco - subtomentosis differt.

Von Bahia in Brasilien. Beinah eben so grofs, doch im Verhältuifs breiter als die vorhergehende 


\section{$-\quad 15$}

Art. Die Farbe pechbraun, nur an den Deckschilden mit schwachem Erzschimmer. Der Kopf glänzend. am Rande einzeln, punktirt, das Schildchen und die Spitze der Lefze hellröthlich gefärbt. Fühler und Frefsspitzen, erstere etwas kürzer als die Deckschilde und überall mit Härchen besetzt von braunrother Farbe. Das Brustschild, etwas länger als der Kopf, ist oben durch unregelmärsig umhergestreute grubenfïrmig vertiefte Punkte ungleich; das Schildchen ist. sehr klein. Die Deckschilde sind im Verhältnifs zum Rückenschilde mehr als noch einmal so lang und ungefähr noch einmal so breit, vor der Spitze breiter, an der Spitze schräg abgeschnitten und in jedem der Endwinkel in einen scharfen Zahn auslaufend. Sie haben einen helleren deutlich erhabenen Rand und reihenweis tief eingedrückte Punkte, die theilweise, besonders an der Nath in Linien zusammenfliefsen. Die untere Fläche des Körpers ist sammt den Beinen rothbraun. Die Sohlen sind mit goldgelbem Filz bedeckit.

5. Agra infuscata.

Tab. 1. Fig. 3 .

Agra, capite angusto laevi, thorace elongato punctato, nigro-aenea, elytris aeneo-punctatis apice bidentatis. Long. lin. 9 .

Agra infuscata, KI ug Verh. d. Leopold. Akad. II. p. 283. n. 2.

Patria: Parà in Brasilia. Misit Sieber. Ex Museo Comit. de H off mansegg.

Agrae -rufescenti simillima; differt praesertim colore non rufescenti-sed nigro-aeneo, capite thoraceque angustioribus, antennis brevioribus, elytris 
apice, vix tamen oblique truncatis, dentibus elytrorum minoribus, tarsis angustioribus.

Caput thorace angustius, laevissimum et nitidissimum, piceo-aeneum, punctulis utrincue binis minutissimis impressis. Labrum palpique ferruginea, Mandibulae ferrugineae, apice nigrac. Antennae capite thoraceque simul sumtis fere longiores, elytris breviores, rufescentes, subpilosae. Thorax elongatus, ad apicem angustatus, dorso punctis impressie, saepius confluentibus, inaequalis, subtus vage punctatus, nigro-aeneus. Scutellum nigro-piceum. Elytra thorace plus duplo longiora, capite duplo fere latiora; medio subangustiora, marginata, apice truncata, bidentata, nigro-aenea, aeneo - punctata, punctis impressis distinctis, in seriebus longitudinalibus novem dispositis. Abdomen fusco-aeneum, nitidum. Pedes picei, tibiis tarsisque dilntioribus rufo - subpilosis, plantis aurato-tomentosis.

Variat antennis nigro-annulatis.

Vaterland: Parà in Brasilien. Länge 9 Linien. Die gegenwärtige Art ist der vorhergehenden nah verwandt, unterscheidet sich jedoch hinreichend theils durch die Farbe, die fast allgemein dunkelschwarz mit ziemlich lebhaftem Metallglanz ist, theils durch die Gestalt, namentlich einen schmaleren Kopf, nicht so breites Rïckenschild, kürzere Fühler, nicht so schräg abgeschnittene schwächer gezahnte Deckschilde und schwächere Fufseglieder.

Der Kopf ist nicht so breit als das Rückenschild, selır grlatt nnd glïnzend, fast pechloraun mit roth. braunen Schildchen und Frefsspityen. Am Rande stehen zu beiden Seiten zwei vndeutliche eingestochene Punkte. Die Frefszangen sind braunroth mit schwar- 
zen Spitzen, die Fühler ungefähr so lang als Kopf und Rückenschild zusammengenommen, doch kürzer als die Deckschilde, braunroth und mit Härchen besetzt. Das Rückenschild ist länglich, an der Spitze enger, von der allgemeinen Körperfarbe, oben voll eingedrückter Punkte, die zum Theil in einander laufen. Das Schildchen ist schwärzlich; die Deckschilde sind in Verhältnifs zum Rückenschilde mehr als doppelt so lang, fast noch einmal so breit als der Kopf, vor der Spitze breiter, am Ende ziemlich schräg abgeschnitten und an beiden Seiten gezahnt. Sie haben die Farbe des Rückenschildes und neun deutlich unterschiedene Peihen eingedrückter metallglänzender Punkte. Die untere Seite des Körpers ist braur und metallglänzend. Die Beine sind rothbraun, Schienen und Fufsglieder heller, röthlich behaart, die Sohlen mit goldgelbem Filz bedeckt.

Zuweilen sind die Fühlerglieder an der Spitze dunkelschwarzbraun.

\section{Agra aterrina. \\ Tab. I. Fig. 4.}

Agra capite angustissimo laevi, thorace valde angustato punctato, elytris punctato-striatis apice acute bidentatis tota nigerrima. Long. lin. 7.

Agra aterrima $\mathrm{K} l \mathrm{ug}$ Verh. d. Leop. Akad. II. p. 284. n. 3.

Pația: Bahia. Misit Sello.

Angusta, nitida. Caput elongatum, laevissimum, labro palpisque concoloribus. Mandibulae nigro-piceae. Antennae elytris breviores, nigrae, subpilosae. Thorax vix capite latior, elongatus, ad apicem coarctatus, dorso profunde, sed irregulariter, impresso- 
punctatus. Scutellum conculor. Elytra thorace plus duplo longiora, angusta, subaequalia, marginata, apice oblique truncata, bidentata, centibus, interno praesertin, productis, acutis; supra punctata, punctis profunde impressis, irregularibus vixque in sericbus distinctis dispositis. Venter sparsim pilosus. Pedes concolores, tibiis tarsisque nigro-subpilosis. Plantae cinereo-tomentosae.

Vun Bahia in Brasilien. Sieben Linien lango. Schmal gebaut, tiefschwarz und glänzend. Der Kopf ist lang und schmal mit dunkelpechbraunen Frefszangen. Die Fühler sind kürzer als die Deckschilde, schwarz und behaart, vor der Spitze verengt. Das längliche Rückenschild erscheint kaum breiter äls der Kopf. Auf der oberen Seite ist es ziemlich tief unregclmäfsig; doch unzusammenhängend punktirt. Das Schildchen ist, wie gewöhnlich nur klein. Die Deckschilde sind noch einmal so lang als das Rüclsenschild, schmal, überall so ziemlich von gleicher Breite, deutlich gerandet, an der Spitze schräg abgeschnitten, beide Endwinkel in einen scharfen Zahn vorgezogen; die Fläche ist mit grubenförmig einggedrücliten Punkten besetzt, die zienlich unregelmälsig gestellt sind. Der Bauch ist theilweise behaart. Die beine sind schwarz, Schienen und Fufsolieder schiwarz behaart, Die Sublen mit weirslichgrauem Filz bedeckt.

\section{Agra variolosa. Tab. I. Fig. 5 .}

Agrra fuscu-aenea, pilosa, capite ovato, basi excavato, thorace elongato, punctato, elytris punctatostriatis, plicato-rugosis, apice truncatis bidentatis. Long. lin. 5. 


\section{$-19$}

Agra variolosa. K $\operatorname{lug}$ Verh. d.'Leop. Akad. Il. p. 285. n. 4.

Patria: Bahia. Misit Sello.

Praecedentibus brevior. Caput vix productum, thorace haud angustius, laeve, nigro - piceum, labro, palpis mandỉbulisque ferrugineis. Antennae elytris ferè longiores, ferruginineae, pilosae. Thorax capite vix duplo longior, fusco-aeneus, suprä profunde, sed irregulariter, punctatus, punctis partim confluentibus, subtus punctatus, dorso lateribusqué cano = pilosus. Scutellum laeve. Elytra fusco-aeneá, margínata, äpice truncata, acute dentata, cano-pilosa, foveolata et punctatá; foveolis' irregularibus, obiter impressis, oblique transwersis coháerentibus, punctis in seriebus novem lungitudinalibus dispositis. Veno ter nigro-picéus. Pedes pilosi, picei, femoribus niz gro-piceis, plantis cinereo-tómentosisis.

Von Bahia in Brasilien. Länge 5 Linien. İm Verhältnifs kürzer als die vorhergehenden Arten. Dunkel Mretallfarbèn. Der Kopf nicht so lang; ; sondern mehr eifürmig, dunkel pechibraun, glïnzend, am IUinterkopf eine deutlich eingedrückte Grube. Ĺefée, Fref̂́spitżen, Frefszangen, sind rolhbraun, die Fühler roth, fast längér als die Deckschilde und ziemlich dicht behaart. Das Rückenschild ist kaunt noch einmal so lang als der Kopf, oben voll eingedrückter, unregelmäfsig stehender Punkte, überall, dock dichter zu beiden Seiten, mit feinen weifsgrauen Haaren beseizt. Die untere Fläche ist unbehabart, aber dicht punktirt. Das Schildehen ist glatt. Die an der Sjitze gerade aboscstużten, zwei geżahnten Deckschilde bieten die gewöhnlichen Verhälthisse der Länge und Breite zu Kopf und Rüclienschilde dår. 
Sie sind reihenweis und ziemlich regelmäisig punktirt, doch sind die Punlitreiher durch wellenförmig schräg eingedrückte Vertiefungen überall unterbrochen. Auch ist die Fläche mehr als bei den andern Arten mit einzeln stehenden, ziemlich langen, weifslich granen Haaren besetzt. Der Unterleib ist dunkel pechbraun. Dieselbe Farbe haben die Beine. Sie sind ebenfalls behaart, Schienen und Fufsglieder heller gefärbt und die Sohlen mit einem grauen, schwach goldglünzenden Filz bedeckt.

\section{Agra excavata.}

Tab. I. Fig. 6.

Agra nigro-aenea, capite ovato, basi excavato, thorace elongato, punctato, elytris punctato - striatis, apicibus truncatis bidentatis. Long. lin. 5.

Agra excavata, Klug Verh. d. Leop. Akad. II. p. 285. n. 5.

Patria Parà. Misit Sieber: ex Museo Com. de $H$ off mannsegg.

Similis Agrae variolosae. Caput ovatum, laeve; nitidum; nigro-piceum, labro, mandibulis palpisque piceis, vertice foveola media orbiculari impressa. $\mathbf{\Lambda n}$ tennae longitudine elytrorum, piceae, pilosae. Thorax vix capite latior, modice elongatus, sulcis laterálibus punctisque impressis, saêpius confluentibus, inaequalis, nigro-subaeneus. Scutellum nigrum. Elytra thorace duplo fere latiora, duploque longiora, marginata, apice truncata, bidentata, nigro-aenea, punctato-striata, punctis confertis, distinctis, in seriebus novem, versus elytrorum apices per paria junctis, dispositis. Venter nigro-piceus. Pedes picei, plantis cinerascentibus tomentosis. 
Von Parà in Brasilien und fünf Linien lang. In der Gestalt der vorhergehenden $\Delta$ rt schr ähnlicl, doch nicht wie jene bchaart. Dunkel metallfarben. Der Kopf eirund, glatt und glänzend, dunkel pechbraun mit etwas lieller gefärbten Lefze, Frefsspitzen und Zangen. Am Iinterkopf eine eingedrïckte Grube. Die Fühler eben so lang als die Deckschilde, braun und mit Haaren besetzt. Das Halsschild in Verhältnifs zum Kopf von geringer Länge, ist dunkel, fast schwarz mit schwachem Metallglariz. und dicht voll eingedrückter Punkte, die besonders an den Seiten in Furchen zusammenlaufen. Das Rükkenschildchen ist dunkelschwarz. Die Declsscliilde fast noch einmal so breit und etwa noch einmal so lang als der Halsschild, sind an der Spitze ziemlich gerade abgeschnitten, zweizahnion, metallglänzend. Die eingedrückten Punkte stehen regelmälsiger und dichter in Reihen geordnet, die mittleren Reihen sind da wo sie die Spitzen der Deckschilde erreichen, paarweise verbunden. Der Unterleib ist dunkel pechbraun. Die Beine sind braun, die Sohlen mit grauen Filz bedeckt.

\section{Agra immersa.}

Tab. I. Fig. 7.

Agra capite excavato laevi, thorace elongato, punctato, sigro-aenea, subpilosa, elytris cupreis punctato-striatis apice truncatis bidentatis. Longit. lin. 4.

Agra immersa, Kl ug Verh. d. Leopold. Alad. II. p. 286. n. 6 .

Patria: Parà. Misit Si e ber; ex Museo Comit. de Hoffmannseg $g$. 
Similis Agrae excavatae; differt imprimis capite thoraceque angustioribus subpilosis, antennis longioribus, elytris discoloribus.

Caput ovatum nigro - piceum, nițidum, occipite foveola media. Os piceum. Antennae elytris lon= giores, piceae, pilosae. Tho an angustatus, punctis confluentịbus inaequalis, lateribus subpilosis, dorso lineola media; subtus confertim et distincte punctatus. Scutellum laeve ${ }_{2}$ concolor. Elytra thorace duplo fere latiora, vix duplo longịora, marginata, apice trunçata, obtuse bidentata, viridi-aeneo medio cupreo-micantia, passim pilifera, punctato-striata, striis intermedịis per paria junctis, sparsim foveolata, foveolis in strịis ipsis positis, interstitiis laevissimis. Venter nigro-piceuse Pedes sparsim pilosi, picei, tịbiis tarsisque dilutioribus, plantis cinerascentibus,

Von Parà, Länge 4 I Lịnien. Ganz andere Körperverhältnisse, wie bei der voṛhergehenden Art, der sie beim ersten Anblick ähnlich erscheint. Der Kopf ịst eiförmig, dunkel pechbrạn, glatt und glänzend mit hellẹ gefärbten Mundtheilen und einer Grubenförrmigen Vertiefung am Hinterhaupt. Die Fühler sind im Verhältnils länger als bei den vorhergehenden Arten und länger als die Deckschilde, braun und behaart. Der Ifalsschild ist nur sclimal, dunkel und beinąh schwarz mit sçhwachem Metallglanz, auf der obern Fläche und an den Seiten leicht hehaart, In dẹx Mitte ist oben eine schwach eingedrückte Linịe, neben derselben stehen tief eingedrückte Punkte, nach den Seiten hin in Reihen geordnet. Unten ist der Halsschild dicht und deutlich punktirt. Das Rückenschildchen ist glatt. Die Deckschilde fast noch einmal so breit, doch weniger als noch einmal so lang 
als der Halsschild sind lebhaft grünlich, in der Mitte kupferroth ğlänzernd, selir regelmäfsig punlitirt-gestreift, doch finden sich in den Punktreilien selbst hin und wieder klcine grubenfürnigge Vertiefungen. Die mittleren Punktrciken sind wie bei der vorhergehenden Art paarweis verbunden. An der Spitze sind die Deckschilde gerade abgeschnitten, und jederseits mit einem Zalın verschen. Unterleib und Beine sind pechbraun, einzeln behaart, die Schienen und Fufsglieder etwas heller gefïrbt und die Solılen mit einem grauen Filz bedeckt.

\section{Agra chalcoptera.}

Tab. I. Fig. 8.

Agra capite basi excavato, nigro, thorace elongato, punctato, nigro-acneu, snbpiluso, elytris viridiaencis punctalo - ștriatis, passim excavatis, apicc truncatis subbidentitis. Long. lin, $5 \frac{\mathrm{r}}{2}$.

Agra chalcoptera, KI ug Verh. d. Leopold. Aliad. II. p. $287 \cdot \mathrm{n} \cdot 7$.

Patria: Parà. Iix Museco Comit. de II offmannsegg. Misit Sieber.

Simillima Agrae immersac; differt statura magis elongata et elytrorum sculptura. Caput ovatum, thorace vix angustiụs, laevissinum, nigrum, occipite impresso, labri apice, mandibulis palpisque piceis. Antennae elytris multo longiores, pilosae, rufescentes, articulis baseos obscurioribus. Thorax lineola longitudinali divisus, subpilosus, dorso punctis magnis impressis, passim confluentibus, inaequalis, subtus subtilius et confertius distincte punctatus, totus nigro-aeneus. Scutellum nigrum. Elytra thorace duplo fere latiora, vix tamen duplo longiora, margi- 
nata, apice truncata, obtusa, bidentata, viridi-aenea, micantia, passim pilosa, istriata et foveolata; striis novem e punctis distinctis confertis, per paria versus apicem, ut in antedecentibus, junctis; foveolis transversis, leviter impressis, striis et interstitiis passim immixtis. Venter piceus. Pectrus medio pu. bescens. Pedes picei, subpilosi, tibiis tarsisque dilutioribus rufescentibus, plantis tomentosis subauratis.

Von Parà in Brasilien. Länge $5 \frac{x}{2}$ Linien. Aelnnlich der A. immersa. Der Kopf cirund, glänzend schwarz, eine einǵedrückte Grube, am Hinterkopf. Rand der Lefze, Frefszangen und Frefsapitzen sind pechbraun, die Fühler länger als die Deckschilde, röthlich mit dunkleren Wurzelgliedern, sind ziemlich behaart. Der verlängerte Halsschild, durch eine leichte Längsfurche getheilt, ist schwärzlich erzfarben, leicht behaart, oben grob punktirt, die Punkte ineinanderlaufend, unten regelmäfsiger punktirt; das Rückenschildchen ist klein, fast schwarz. Die Deckschilde grün erzfarben, glänzend, sind fast nock einmal so breit als der Falsschild, an der Spitze abgestutzt und zweimal gezahnt. Sie haben neun deutliche Reihen aus eingedrückten Punkten, die zum Theil an der Spitze paarweis vereinigt sind. Min und wieder sind sie in die Queer etwas eingedrückt und stehen dergleichen grubenförmige Verticfungen sowohl in den Punktreihen als den Zwwischenräumen. Brust, Hinterleib und Beine sind pechbraun, Schieven und Fufsglieder hell röthlich, die Sohlen mit hell goldglänzendem Filz bedeckt. 


\section{$-25-$}

\section{Agra brevicollis.}

Tab. I. Fig. 9.

Agra capite angustato, basi excavato, thorace elongato punctato, nigro-aenea, elytris punctatostriatis, apice bidentatis cupreis. Lono. lin. $5 \frac{x}{2}$.

Agra brevicollis, Kl ug Verh. d. Leop. Alkad. II. p. 288. n. 8.

Patria; Parà. Ex Mus. Comit. de Hoffmannsegg. Misit Sieber.

Affinis Agrae immersae; differt praesertim capite angustiori, thorace crassiori pilis destituto, elytris apice pone dentem exteriorem subsinuatis. Subdepressa. Caput vix thorace brevius, porrectum, laevissimum, nigrum, mandibulis apice piceis, occipite foveola impressa, antennis piceis, articulis tribus prioribus nigris, reliquis apice obscurioribus. Thorax supra lineola longitudinali media impressa divisus punctisque, saepius confluentibus, inaequalis, subtus distinctius punctatus, nigro subaeneus. Scutcllum nigrum. Elytra thorace duplo longiora vix tamen duplo latiora, marginata, striata, striis novem e punctis confertis, eodem modo, ut in praecedentibus, iunctis; margo elytrorum externus violaceo-subaeneus, apex truncatus, dentatus, dente externo acuto distincto, interno obtuso. Venter nigro-violaceus, medio per totam longitudinem cinereo-tomentosus. Pectus subhirtum. Pédes nigro-violacei, ungulis piceis, plantis cinerco-tomentosis. -

Von Parà. Fünf und eine halbe Linie lang. Der A. immersa ähnlich, doch schon durch einen schlanlieren Kopf und kürzeren unbehaarten Halsschild unterschieden. Die Gestalt ist flach, die Fasbe mir Aus- 
nahme der Deckschilde dunkel erzfarien, fast schwarz mit cinem bläulichen Glanz. Der Kopf ist glatt mit einem Eindruck am Hinterkłopf." Die Frefşangen haben braune Spitzen. \Dịe Fühler sind nuur unvollstündiog, nemlich nicht mehr als sechs Glieder, vorhanden, von diesen sind die ersten drei schwarz, die folgenden braun mit dunlleren Spitzen. Den Rüçken des Halsschildes theilt eine leicht eingedrïckte Längslinnie. Aufserdem ist dieser Theil voll eingedrüclster Punkte, die auf der untern Seite regelmäfsigner gestellt sind, auf der obern hingegen melir in einander laufen. Brust und Bauch sind in der Mitte mit einem gelllichgrauen zieunlịch dichten Haạrfilz hedeclit. Das Rụ̈ckenschilldchen hat die Farbe des Halsschilildes. Die Deckschilde schillern in verschiedenen Richtungen bald mit rothem Kupfer - bald mit grïnem Messsingglanz, sind selhr glatt und mit regelmälsigen, gegen dịe Spitze hin paarweis verbundenen Punktreilien geziert. Die Spitzen sind gerade abgeschnitten und an dem äufseren wie dem inneren Winkel gezahnt. Der äufsere Zahn tritt um so deutlicher hervor, als vor demselben eine leichte Einbiegung, wodurch nach innen zu ein abermaliges, doch schwaches Hervortre1 en entsteht, bemerklich ist. Der innere Zahn ist un- qerklich rorragond und nur durch das Zusammentrefton dẹ biden Rïnder in einem rechten Wiukel gebilslot. Die Beine sind wie der Körper gefärbt, die Sohlen mit blạsgrauen Filz bedeckt, dic Klauen braun.

\section{Agra attenuata. Tab, II. Fig. 1.}

Agra capite postice punctato thoraceque nigris, *lytrig punctato-striatis apice bidentatis cupreis. Long. lin. 6. 
Habitat in Brasilia, Dedit Bescke.

Corpus valde angustum. Caput nigrum, nitidum, occipite punctis plurimis inpressis. Mandibulae apice piceae. Antennae vix thorace longiores subpilosae, fuscae, primo arliculo piceo. Thorax vix capite latior, subcylindricus, ubique punctatus, utrinque sulcatus, totus niser, opacus. Scutellum minimum nigrum. Elytra cuprea thorace plus duplo longiora, punctato - striata, punctis passim confluentibus, apice truncata, bidentata, dente externo producto acuto, interno obtuso. Pectus abdomenque nigra nitida. Pedes graciles nigro-picei, tarsis pallidioribus rufescenti-subpilosị, plantis tomento aureo tectis.

Aus Brasilien. Sechs Linien lang: Sehr schmal, Grundfarbe schwarz. Der Kopf glänzend. Der Hinterkopf deutlich punktirt. Die Frefszangen mit bräunlichen Spitzen. Die Fühler nicht viel länger als das Rückenschild, wenig behaart, schwärzlich, mit braunem Grundgelenk. Das Rückenschild nịcht breiter als der Kopf, überall dicht punktirt, mattschwarz, zu jeder Seite eine Längsfurche. Das Schildchẹn sehṛ klcin. Die Deckschilde viel länger als das Rücken= schild, und mehr als noch einmal so lang, kupferroth, mit deutlichen Punktstreifen, die Punkte hị und wieder verlaufend, an der Spitze abgeschnitten zyveigezalınt, der äufsere Zahn spitzig, der innere stumpf und gerundet. Untere Seite schwarz und gläuzend. Die Beine dünn, glänzend braunschwarz, die Fuৎse glịeder hellbräunlich mit röthlichen Härchen spar san besetzt, dis Sohlen mit goldfarbigem Filz be deckt. 
11. Agra gemmata.

Tab. II. Fig. 2.

Agra capite angusto laevi, thorace excavato punctato pedibusque rufescentibus, elytris rufo-testaceis, aeneo-punctatis, nigro-submaculatis, apice bidentatis. Long. lin. $7 \frac{\pi}{2}$.

Habitat in Brasilia. Misit Dr. de OIfers.

Corpus subelongatum rufum. Caput nitidissimum, glaberrimum, antennis concoloribus, palpis mandibulisque apice obscurioribus, oculis nigris. Thorax subconicus, dorso aeneo nitidulus, sparsim excavato - punctatus. Elytra thorace duplo longiora, nitida, rufo - testacea, excavato - punctata, nigro - maculata, punctis, maculis nigricantibus intermixtis in seriebus novem dispositis. Apex elytrorum truncatus, bidentatus, dentibus brevibus, externo acuto, interno rotundato, obtuso. Pectus abdomenque rufescentia, aeneo submicantia glaberrima, medio rufo-subpilosa. Pedes rufi; plantae subauratae.

Ans Brasilien. Länge $7 \frac{x}{2}$ Linien. Im Verhältnifs lang gestreckt, von Farbe bräunlich roth und glänzend. Der Kopf sehr glatt, Palpen und Mandibeln an der Spitze dunkler, die Augen schwarz. Das Rüklisenschild beinah kegelförmigo, dunkel metallglänzend, voll eingedriickter einzeln stehender Punkte, die unten schwächere, oben stärkere und gröfsere Vertiefungen bilden. Das Schildchen sehr klein. Die Deckschildo noch einmal so lang als das Rückenschild, blafs gelbbräunlich, glatt und glänzend, an der Spitze schräg abgeschnitten, die Winkel in kurze Zähnchen auslaufend, deren äufserer scharf, der innere stumpf und gerundet ist. Die Oberfläche zie- 
ren neun Reihen punktförmiger Grübchen, die in der Tiefe hellgrünlich wie Metall glänzen und zwischen sich strichförmige schwarze Flecken haben. Die Unterseite des Kürpers ist etwas heller gefärbt. Der Bauch ist in der Mitte roth behaart. Die Beine sind wio der Kopf, doch heller, gefärbt, die Sohlen mit einem goldfarbigen Filz bedeckt.

\section{Agra catenulata.}

Tab. II. Fig. 3.

Agra rufa, cupreo-nitida; capite laevi, thorace punctato - rugoso, elytris excavato - punctatis, unidentatis. Long. lin. $5 \frac{x}{4}$.

Habitat in Brasilia. Misit Sello.

Affinis praecedenti, at minor et angustior. Caput laeve, ferrugineum, nitidum. Antennae thorace longiores, rufescentes, articulis apice obscurioribus. Mandibuląe ferrugineae. Palpi ferruginei, maxillares majores articulo ultimo subfusco. Thorax conicus, ferrugineus, subcupreus, dorso punctis irregulariter impressis, saepius confluentibus inaequalis. Scutellam minimum. Elytra thorace duplo longiora, angulo postico externo unidentato, interno rotundato, rufa s. rufo-testacea, cupreo-nitida, foveolata, foveolis in series dispositis punctatis, punctis impressis approximatis aeneo - subviridibus. Pectus abdomenque ferruginea, aeneo - nitida. Fedes ferruginei.

Vaterland: Brasilien. Länge 5 $\frac{x}{4}$ Linien. Nicht nur kleiner, sondern in Verhältnifs auch schmaler, als die vorbeschriebene $\Lambda$ rt. Die Farbe dunkel braunroth mit lebhaftem Kupferglanz. Der Kopf glatt und glänzend, die Fühler märsig lang, heller gefärbt als der Kopf, nur die Spilzen der Glieder dunkler. Die 


\section{- 30}

Frefsspitzen braun. Das letzte Glied der Kinnladen. taster fast schwarz. Das Rückeuschild ziemlich kurz, kegelförmiğ, ungleich durch stírk eingredrückte hin und wieder zusammenlaufende Punkte. Das Schildchen sthr klein. Die Deckschilde noch einmal so lang als das Rückenschild, sehr glänzend mit purpurfarbenem Schein, voller Gruben, die grünlich glänzend $_{3}$ in der Tiefe punktirt und in Längsreilien geordnet sind, wogegen die glatte nnd erhàbene Umgegend als kettenähnliche Bildung in schräger Richtung dem Innenrande zu und bis nahe an dènselben abwä̀rts steigt. Die Nath ist hell gelbbräunlich. An der Spitze sind die Deckschilde ziemlich gerade abgeschnitten, am innern Winkel gerundet, am äufsern in eine kurže doch scharfe Spitze auslaufend. Brust und Bauch sind rotbbraun, mit erzfarbnem Schimmer; der Bauch etwas heller gefärbt. Die Beine haben die nämliche Färbung.

\section{Agra geniculata. \\ Tab. II. Fig. 4.}

Agrà fusco - nigra, capite angusto laevi, thorace elongato punctato, elytris excavato-punctatis apice 'subtridentatis; pedibus luteis, femoribus apice fuscis. Long. lin. $6 \frac{\pi}{2}$.

Agra geniculata. Klug gerh. d. Leop. Akád. II. p. 288, n. 9.

Patria: Parà. Ex Museo Comit, de Hoffmannsegg. Misit Sieber.

Elongata, subdepressa. Caput laeve, nigrum, labro, mandibulis palpisque piceis. Antennae longitudine feré elytrorum, pilosae, piceae, articulis baseos obscurioribus. Thorax elongatus, niger, impresso- 


\section{- 31}

punctatus, punctis in dorso majoribus, ad latera confluentibus, subtus perpaucis. Scutellum concolor. Elytra thorace duplo fere latiora, duplo longiora, nigra, punctata, punctis magnis aeneis impressis in seriebus longitudinalibus novem dispositis, apice trüncata, tridentata, dente externo brevi acuto, reliquis obtusis. Venter nigrossubaeneus, lateribus piceis. Pedes lutei, femoribus apice fuscis, tibiis apice tarsisque piceis. Coxae nigro-piceae.

Von Pard̀. Länge $6 \frac{x}{2}$ Linien. Grundfarbe dunkel braunschwarz nit schwachem Metallglanz. Kopf sehr verlängert, glatt. Am Hinterkupf lieine Grube. Lefze, Frefszangen und Frefsspitzen pechbraun. Fühler so lang als die Decken, behaart, rothbraun, die ersten Glieder dunkler. Rückenschild lang gestreckt, voll tief eingedrückter Punkte, die an den Seiton in einander flief'sen und unterhalb seltner werden. Deckschilde ungefähr noch einmal so breit und noch cinmal so lang' als das Ríckenschild, vor der Spitze breiter, an der Spitze abgestrzt und mit drci Zähnchen bewaffnet, von welchen jedoch nur der äufscre spitzig ist, der vorhergehende aber so wie der innere kaum merklich hervortreten. Die Puukte auf den Deckschilden sind in Reihen geordnet, tief eingedrückt, mit bläulichem Metallglanz. Die untere Flïche ist nicht ander's gefärbt. Die Beine sind rothgelb, die Schenkel im Kniegelenke schwarz, die Spitzen der Schienen und die Fuf́sglieder bräunlich.

\section{Agra rufipes.}

Tab, II. Fig. 5.

Agra thorace varioloso, elytris punctato-striatis apice tridentatis, fusca; antennis pedibusque rufis. Long. $\operatorname{lin} .6 \frac{x}{2}$. 


\section{$-32-$}

Agra rufipes Fab r. Syst. Eleut. p. 225. n. 2. $\mathrm{Sch}$ önherr Synonymia Insect. I. 1. p. 236. No.42.2.

Habitat in America meridionali; Mus. Reg. Havn. ex Museo Lundii.

Caput laeve, labro mandibulis palpisque rufo-piceis. Antennae elytris breviores, rufae. Thorax brevis dorso punctato-rugosus, subtus sparsim punctatus. Scutellum parvum. Elytra thorace duplo longiora, punctato. striata, sparsim impresso-punctata, apice truncata, tridentata, dente intermedio obtuso, externo et interno productis acutis. Pectus 'et abdomen aeneomicantia. Pedes rufi, femoribus apice nigris. Plantae tomento pallide-aureo tectae.

Die Beschreibung ist nach einem Exemplar aus der ehemaligen Lund'schen Sammlung. Das Vaterland: Südamerika. Die Länge $6 \frac{x}{2}$ Linien. Von der vorhergehenden Art ist diese hinreichend verschieden. Die Grundfarbe dunkelbraun. Der Kopf verlängert, glatt und ohne Grube. Lefze, Frefszangen und Frefsspitzen röthlich pechbraun. Fühler liürzer als das Rückenschild, ganz braunroth. Der Rückenschild im Verhältnifs viel kürzer als bei der vorhergehenden Art, oben unregelmäfsig und stark, unten feiner, einzelner und regelmärsiger punktirt. Schildchen sehr klein. Deckschilde noch cinmal so lang als das Rükkenschild, an der Spitze abgestutzt und dreigezahnt. Der inwendige und äufsere Zahn sind ansehnlich verlängert und spitzig, der "mittlere sehr stumpf. Auf den Deckenschilden sieht man regelmärsige Reihen aus fein eingedrückten Punkten, und hin und wieder flach grubenförmig eingedrückte Punkte. Brust und Unterleib haben einen bäulichen Metallschimmer. Die Beine sind rothgelb, die Schenkel 
an den Spitzen schwarz, die Sohlen mit hell goldfarbenem Filz bedeckt.

\section{Agra ruficornis.}

Tab. II. Fig. 6.

Agra capite angustato laevi, thorace elongato rugoso-punctato, elytris punctato-striatis apice truncatis subtridentatis, nigro-aenea, ore, antennis pedibusque rufo-piceis. Long. lin. $6 \frac{x}{2}$.

Agra ruficornis Klug Verh. d. Leop. Alkad. II. p. 289. n. 10.

Patria: Parà. Misit Sieber. Ex Museo Comit. de $\mathbf{H}$ offmannsegg.

Valde attenuata, omnium facile angustissima. Caput perangustum, valde elongatum, in rostrum quasi productum, laevissimum, nitidissimum, piceonigrum, clypeo, labro, mandibulis palpisque rufopiceis. Antennae elytris breviores, rufo - piceae, subpilosae. Thorax elongatus, nigro-aeneus, dorso sulculo longitudinali divisus, profunde et irregulariter punctatus, subtus glaber, nitidus. Scutellum concolor. Elytra thorace latiora, duplo fere longiora, marginata, punctata, punctis magnis, profunde impressis, violaceo-aeneis in seriebus longitudinalibus novem dispositis, apice truncata, dentata, dentibus tribus, externo acuto, secundo approximato obtuso, interno obtusissimo. Venter nigro - piceus, violaceomicans, glaberrinus, nitidus. Pedes unicolores rufo-picei, tibiis tarsisque subpilosis, tarsorum articulo quarto subtus albido - sericeo.

Vaterland: Parit. Länge: $6 \frac{x}{2}$ Línien. Im Verhältnifs sehr schmal. Grundfarbe dunkelbraunscliwarz mit schwachem Metallglanz. Der Kopf schmal, fast 
linienförmig verlängert, glatt und glänzend. Schildchen, Lefzen, Frefszangen und Trefsspitzen sind rothbraun, die Fühler etwas kürzer als die Deckschilde, braunroth mit Härchen besetrl. Das Rükkenschild ist verlängert, in der Mitte der Längc nach schwach gefurcht, oben lief und unregelmäfsigs punktirt, unten glatt. Das Schildchen trägt die Farbe des übrigen Körpers. Die Declsschilde sind etwas breiter und fast noch einmal so lang als das Rückenschild, gerandet und punktirt. Dic Punkte sind grofs, tiéf eingestochen, mit blïulichem Erzschimmer, ziemlich regelmärsig in neun Reihen auf jedem Schilde vertheilt. Die Spitzen der Dechen sind gerade abgestutzt und mit drei Zähnen bewaffnet, von welchen der äufsere schmaler und hervorsiehend, der miltlere dieșem nahe stehend and stumpf, der innere kaum wahrzunehmen ist. Die untere Seite ist hochbraun mit ziemlich lebhaftem ins Blaue fallenden Metallglanz. Die Beine sind einfarbig braunroth. Die untere Seite des vierten Fufsgliedes ist mit einem weifslichen Filz bclkleidet.

16. Agra attelaboides.

Tab. II. Fig. 7 .

Agra capitc postice foveolato, thorace punctatoragoso, elytris punctato-striatis, transversim subplicatis, apice acute tridentatis, fusco nigra, antennis pedibusque rufo-piceis. Long. In. :

Agra attelaboides Fabricii Syst. Eleuth. I. p. 225. n. 3. Schönherr Synon. Ins. I. 1. p. 236. Nr. 42. 3. Klug Verh. d. Loop. Akad. II. p. 293. n. 16. Cirindela attalaboides Fabr. culom. Syst. emend. IV. p. 445. n. $2-3$. 
Mabitat in India orientali. Mus. Reg. ex Museo \$. Salingre.

Caput elongatum, glabrum occipite foveola parva sublineari. Labrum mandibulaeque picea. Palpi rufo-picei. Antennae passim pilosae, rufo-piceae. Tliorax capite haud duplo longior ad apicem attenuatus aeneo-nitidulus, dorso linea longitudinali impressa divisus, iuppresso-punctatus, punctis ad latera confertioribus et confluentihus. Scutellum parvum concolor. Elytra thorace duplo longiora, aeneomicantia, dorso punctato-striata, apice tridentata, dente interno acutissimo; striae elytrorum plicaturis transversis foveolisque longitudinalibus saepius interruptae. Abdomen nigro-violaceum. Venter medio cinereo-pilosus. Pedes rufo-picei, anteriores capitulis, postici coxis una cum fulcro femorali nigro-acneis. Plantac tomento griseo subinauratu tectae.

Vaterland: angeblich Ostindien. Länge: sieben Linien. In der Gestalt nichts Abweichendes. Farbe dunkelbraun, fast schwarz mit schwach röthlichem Metallschimmer. Der Kopf nicht besonders verlüngert. Arn Hinterhaupt ein schwacher linienförmiger Eindruck. Lefze, Kinubacken, Frefsspitzen und Fühler braunroth. Das Riiclienschild in Verhältnifs weniger lang als bei den meliresten anderen Arten, nicht viel länger als der Kopf, wenigstens bei weitem nicht noch einmal so lang, wird nach dem Kopf hin deutlich schmaler, ist oben reihenweis unordentlich punlitirt, in der Mitte durch eine eingedrückte feine Läugslinie getheilt, unten fein und dicht punktirt. Das Schildchei ist nicht anders gefärbt. Die Deckscliilde etwa noch cinnal so lang als das Rül. kenschild, sind reihenweis punktirt, die Punbtreihen 
theils durch kleine Queerfalten, thcils durch längliche Grübchen oft unterbrochen. Die drei Zähne an den schrïg abgeschnittenen Spitzen der Deckschilde sind besunders deutlich, und namentlich ist der innere Zahn lang und scharf vorgezogen. Brust und Bauch haben einen dunkelbläulichen Glanz, die Mitte ist mit einem leichten graubräunlichen Haarfilz bedeckt. Die Beine sind braunroth, die Hïftglieder und die Schenkelanhänge der hintersten Beine schwarz, die Sohlen mit einem gelblich grauen Filz von sehr mattem Goldschimmer bedeckt.

Da alle übrigen Agra-Arten im südlichen Amerika einheimisch sind, so ist es nicht wahrscheinlich, dafs die gegenwärtige aus Ostindien stammt, und kann der Angabe des Vaterlandes leicht ein Irrthum zum Grunde liegen. Das Exemplar, in dessen Besitz unser Museum ist, befand sich früher in der II ol thu y sen schen Sammlung.

\section{Agra femorata.}

Tab. II. Fig. 8.

Agra nigro-aenea; capite ovato laevi, thorace elongato punctato-rugoso, elytris punctato-striatis, apice truncalis tridentatis, femoribus incrassatis. Long. lin. 7 .

Agra femorata Klug Verh. der Leopold. Akad. II. p. 2 go. n. 11 .

Patria Parà. Misit Sieber. Ex Museo Comit. de Hof fmannsegg.

Corpus elongatum, aterrimum, aeneo-violaceopunctatum. Caput angustatum, porrectum, lacve, nitidissimum, nigro-subpiceum, clypei apice, labro, mandibulis palpisque piccis. Antennac elytrorum fere 


\section{$-37$}

longitudine, piceae, subpilosae. Thorax elongatus, aterrimus, nitidus, subtus fere impunctatus, dorso lineola longitudinali media, punctisçue ad latera in sulcos profundos confluentibus inaergualis. Scutellum glabrum. Elytra thorace vix duplo longiora, paullo latiora, marginata, apice truncata, distincte tridentata, punctata, punctis violaceo-aeneis profunde impressis, distantibus, in seriebus novem longitudinalibus positis. Venter glaberrimus, nigro-piceus, violaceo-aeneo-nitidus. Pedes nigro-picei, aeneo-nitidi, tarsis piccis, femoribus insigniter incrassatis, tibiis tarsisque rufescentibus densius ciliatis, plantis cinereo-micantibus.

Von Parà. Sieben Linien lang. Dunkelschwarz mit schwachem Metallglanz. Der Kopf sehr schmal, glatt, und glänzend, olne Eindruck, Kopfschild, Lefze und Frefszangen sammt Frefsspitzen pechbraun. Die Fühler kürzer als die Deckschilde sind pechbrann, fein behaart, die Glieder an der Spitye clunkler. Das Rückensclild ist im Verhältnirs lang, oben der Länge nach punktirt, unten glatt und glänzend, die Punkte als Gruben in der Mitte einzeln stehend, in der nächsten Rishe zum Theil zusammengeflossen. Das Schildchen klein und länglich. Die Deckschilde nicht ganz noch einmal so lano als das Rückenschild, ziemlich breit mit aufgeworfenem Seitenrande, sind an der Spitze fast gerade abgestutzt und deutlich dreigezalnt; der mittlere Zahn ist dem äufsern genähert. Auf ihren Flächen sind die Deckschilde in regelmäfsigen Reihen stark und tief punktirt, dic Pmukte mit dun. kel blaugrä̈nlichem Metallglanz. Der Bauch ist gglatt, pechschwarz, metallschillernd. Die Beine elsen so šefärbs, sehr grlatt und glänzend, haben stark ver- 
dickte Schenkel, hellere, dicht schwärzlich behaarte Schiencn und Eufsoglieder, braune Klauenglieder uud einen hell bräunlich-grrauen Filz an den Sohlen.

\section{Agra exarato.}

Tab. II. Fig. 3 .

Agra Jigro-aenea, capite ovato, occipite leviter impresso, thorace elongato punctato-rugoso, clytris punctato-striatis apice truncatis tridentatis. Long. lin. 8 .

Agra exarata Klug Verh. d. Leop. Akad. II. p. 291, 11. 12 .

Patria: Part. IMisit Sieber, Ex Museo Comilis de Hoffinannsegg.

Magna, elongata, subdepressa, elytrorum sculpluma disinclissima, nitida, nigro-aenea. Caput ovalum, clongatum, postice levissime impressum, nitidissimum, nigrum. Labrum margine piceo. Mandibulae piceae, apice nigrae. Palpi anteriores picei, postici nigro-picei. Antennae elytris bieviores, subpilosae, piceae, basi obscuriores, apice rufescentes. Thorax elongaius, subtus passin et leviter, dorso profundius et confertius irregulariter impresso-punctatus, lineolaque media longitudinali impressa divisus. Seutellum glabrum, planum. Elytra thorace plus duplo longiora, marginata, apice truncata, distincte tridentata, dorso plana, nigerrima, aeneo-subcyanca, punctata, punclis impressis plerumque conferlissimis partimque conflucutibus in sericbus noven distinctis, passim interruptis, dispositis. Venter nigerrimus, aeneo nilidus, sparsiu rufo pilosus. Pedes nigro-cyanei, nitidi. Tarsi picei, rufo-ciliati, plantis fulvotomentosis, 
Variat nigro-picea; elytris virescentibus.

Von Parì. Acht Linien lang. Etwas fach, glänzend dunkelschwarz, die Deckschilde mit blïulichen, der übrige Körper nit diisterem Metallschcin. Der Kopf länglich eirund, sehr glänzend. Am Hinterhaupt ein Grübclien. Die Lefze ist am Rande, die Kinnbacken sind an der VVurzel, die vorderen Frefsspitzen überall röthlichbraun. Die Fühler, kürzer als die Deckschilde, sind rothbraun, röthlich behaart, die ersten Glieder dunliler. Das Rüclsenschild von lärnglich kegelfürmiger Gestalt ist unten überall deutlich, oben theilweis, jedoch stärker punktirt. Die Dunlice sind in Längsstreifen zusammengedrïngt und durch die Mitte länft eine fein eingedrïckte Linie. Das Rückenschildchen ist glatt. Die Deckschilde sind grlatt und glïnzend, der Lïnge nach dnichzogen ron neun Rihen mehrentheils dicht gestellter einge. drückter Punlite oder Grübchen, hin und wieder durch eine leichte einer kleinen Queerfalte äinliche Verliefung unterbrochen. Das Ende der Dechschilde ist schräg abgescinitien und dreigezahot. An Brust und Bauch finden sich einzelne röthliche Härchen. Die Beine sint gefärbs und glänzend wie der übriga Körper, die lufsglieder pechbraun, rüthlich behaart, dis Suhlen mit gelbrothen Filz bedeclit.

\section{Agra minitiplicata.}

Tab. III. Fig. 1.

Agra nigro-aenea occipite subimpresso, thorace. subelongato, punctato, elytris punctato-striatis, apice tridentatis, purpurascentibus. Long. lin. $6 \frac{3}{4}$.

Patria: Part. Misit Sieber; ex Museo Comit. de Hoffmannsegr. 


\section{$-40$}

Statura minori et praesertim thorace breviori, elytris cupreo-nitidulis transversim plicatis pedibusque gracilioribus a praecedentibus differt. Caput attenuatum elongatum nigrum, occipite leviter impresso, labri apice, mandibulis, maxillis palpisque piceis, antennis elytris brevioribus rufo piceis, ubique subhirtis, articulis apice subpilosis, prioribus ante apicem obscurioribus. Thorax capite cum palpis paullo longior, conicus, nigro-aenens, subtus glaber nitidus, ad latera confertim impresso - punctatus, supra irregulariter foveolatus, foveolis longiludinaliter conglomeratis. Scutellum parvum obscurum. Elytra fusco-subcuprea, punctato-striata, striis passim interruptis, transversim plicata, apice tridentata. Pectus abdomenque nigroviolacea. Pedes nigro-picei, aeneo-nitiduli, coxis ferrugineis, tarsis piceis fulvo-pilosis, plantis fulvotomentosis.

Vaterland: Parà. Länge : $6 \frac{3}{4}$ Linien. Im Bau durch einen kürzeren Halsschild und dünnere Beine von den vorhergehenden Arten, vornemlich der A. femorata, der sie im übrigen ähnlich ist, unterschieden. Der Kopf glänzend schwarz, glatt, nit einer leichten Vertief ung am Hinterhaupt. Die Lefze ist am Rande, Kinnbacken, Laden und Palpen sind überall pechbraun. Nur das letzte Glied der Lippentaster ist dunkler. Die Fühler kürzer als die Deckschilde sind röthlich braun, mit kurzen feinen Härchen bedeckt, die Glieder an den Spitzen länger behaart, die ersten vor der Spitze dunkler, das Grundgelenk fast sclıwar\%. Das Rückenschild nur etwas länger als der ausgestreckte Kopf, ist fast kegelförmig, dunkal erzfarben, unten mil blauem Schiller, in der Mitte glatt, an den Seiten aber dicht punktirt, oben voller Gruben, die in vier Längsseihen 
zusammengedrängt stchen. Das Schildchen ist klein und von dunkler Färbung. Die Deckschilde schwärzlich mit röthlichem oder dunkel kupferfarbigem Glanz, tragen neun Punktreihen, in welchen die Punlite mehrentheils sehr dicht stehen, nur hin und wieder fehlen, so dafs die Reihen unterbrochen erscheinen. Auch finden sich aufserdem, und vornehmlich in den Punktreihen selbst viele seichte Vertiefungen die da, wo sie aufhören, leichte Queerfalten bilden. Am Ende sind die Deckschilde fast gerade aboeschnitten, und mit drei kurzen, doch scharf zugespitzten Zähnchen bewaffnet. Die Unterseite hat am Hinterleibe, wie am Halse, einen dunkelblauen Schein, hier und da einzeln stehende, lange, rostbraune Haare. Dic Beine sind dunkel pechbraun, mit schwach bläulichem Metallschein. Die Gelenkköpfe sind rothbraun, die Fufsolieder pechbraun, mit rostfarbenen Haaren, und einem gelbröthlichen, goldglänzenden Filz der Sohlen.

\section{Agra cuprea.}

Tab. III. Fig. 2.

$\Lambda$ gra capite postice foveolato, thorace elongato, punctato, violaceo - nigerrima, elytris punctato - striatis apice tridentatis cupreis. Long. lin. 7 .

Agra cuprea Klug Verh, der Leop. Akad. II. p. 291 . n. 13.

Patria: Parà. Misit Sieber. Mus. Reg. ex Mus. Comit. de $H$ of fmannsegg.

Caput angustum, porrectum, laeve, nigrum, nitidum, occipite foveola parva sublineari. Mandibulae obscure piceae. Palpi picei, labiales articulo ultinı obscuriori. Antennae elytris breviores, subpilosae, rufescentes, articulis tribus prioribus obscurioribus. Thorax vix ca- 
pite longior, nigerrinus, subtus nigro-violaceus, punctulatus, dorso lineola longitudinali divisus, sparsim excavato-punctatus. Scutellum nigrum. Elytra thorace plus duplo longiora, viridi-taened, cupreo-micantia, nitidissima, punctato-striata, apice tridentata, dentibus distinctis, externo acuto, interntedio obtuso, interno in spinam acutissiman producto; mar viridi-cyaneo. Venter violaceo-nigerrimus, passim pilosus. Pedes nigro-picei, femoribus nigrro-cyaneis, tarsis rufo-piceis, plantis rufeseentibus inauratis hirtiz.

Von Parà. Liingne 7 Linien. Grundfarbe oben tief schwarz, auf der untern Seite blïulich schwarz und glänzend. Der Kopí ziemlicla schmal. Das Grübchen am Hinterhaupt klein und fast linienförmig. Dic Kinnbacken dunkel pechbraun, die Frefsspitzen eben so gefärbt, das letzte Glied der Lippentaster jedoch dunkler und fast schwarz. Die Fühler auffallend luürzer als dic Deckschilde sind röthlich gefürbt, doch sind die drei ersten Glieder dunller und fast schwarz. Das Rückenschild ist kürzer als gewöhnlich, unten fein, oben stärker, aber einzeln punktirt. Eine feine Längsiinie ist in der Milte bemerklich. Das Schildchen ist wie das Rückenschild gefärbt. Die Deckschilde sind metallfârben, nach den verschiedenen Richtungen bald grün, bald liupferroth schillernd, auf glattem, glänzendem Grunde regelmärsig punktirt, dic Punkte reihenweis gestellt. Dio Spitzen der Deckschilde sind dentlich ưreigezahnt, kleiner und stumpfer ist der mittlere, besouders lang and scharfspitzig der inwendige Zahn. Der umgeschlagene $\Lambda$ ufsenrand ist blaugrün abgeseizt. Der Bauch ist hin und wicder behart. Die Schenkel sind. blauschwarz, dịe Schienen bräunlich, die Fr:ssğlieder röthlich, die Sohlen mit goldfarbenem Filz bedeckt. 
M e $\quad \begin{array}{lllllll}g & \text { a } & 1 & o & p & \text { u } & \text { s. }\end{array}$ 



\section{M e g a lop us.}

Megalopus F a br. (Syst. Eleuth.): L a treille (gen. crust. et ins. Consid. gen., regne animal). Olivier (Entomologie). Kirby (Linn. Transact. XII.). Dalman (Analecta entomol.). Germar (Insect. Spec.). Clythra Fabr. (Syst, Eleuth.). S c hö nherr (Synonymia Insect.).

Fabricius und Latreille Bezeichnungen dieser Gattung, obschon nach wenigen Arten entworfen, scheint im Wesentlichen kaum etwas hinzuzufügen. Der Körper ist jedoch nicht bei allen Arten flach, bei manchen vielmehr gewölbt, im letzłern Fall länglich, selbst sehr schmal, im ersteren ziemlich breit.

Der Kopf ist angedrüclit, der Hinterkopf wulstig hervorragend. Die Augen sind grofs, gewölbt, ausgerandet; die eilfgliedrigen Fühler jederzeit, wenn auch nicht immer, bedentend länger als das Rückenschild, bei einigen noch einmal so lang, bald mehr bald weniger an der Spitze verdickt, zuweilen gesägt, bei vielen zusammengedrückt. Die Lefze ist gerundet; die Kinnbacken sind braun, spitzig, inwendig ohne Zahn; die Kinnladen flach, beinah hornartig, an der Spitze schräg, gekïmmt und gespalten. Die Lippe ist nur schwach ausgerandet. I) Taster sind behaart, die Kinnladentaster vier - die Lippen- 


\section{$-46$}

taster dreiglielnig. Bei beiden ist das erste Glied sehr lurz, das letzte länglich und zugespitzt. Das zweite Glied der Lippentaster ist länger als die übrigen. Das Rückenschild (thorax) ist fast vierecliog, dessen vorderer und hinterer Rand bei einigen stark, bei andern kaum merklich aufgeworfen, bei noch andern findet eine deutliche Einschnürung statt. Die Winliel sind mehr, oder weniger vorgezogen. Die Brust ist bei einigen flach oder mälsiog gewölbt, bei andern in der Mitte (sternum) als Höcker hervorragend. Die Beine sind von mäfsiger Länge; vier Fufsglieder an allen, die beiden ersten herzförmig, das dritte an den vordern Beinen gespalten, an den hintersten schräg abgeschnitten, das Klauenglied, besonders au den hintersten Beinen, lang, die Klauen gekrümmt, einfach, d:e Afterklauen linienförmig mit borstenähnlichen Härchen an den Spitzen, die Sohlen mit einem Haarfilz bedeckt. Die hintersten Beine, grofsen und breiten länglichrunden Hüftstücken eingefügt, haben mehr oder weniger verdiclite Schenkel, die zuweilen vor der Spitze gezalunt sind. Es finden hierin sowoll bei verschiedenen Arten als bei derselben Art Abweichungen statt, und haben im letztern Falle allein die gröfseren Individuen, welche man dem $\mathrm{An}$ sehen nach für Weibchen halten sollte, die verdickten Hinterschenkel. Die Schienen sind zusammen. gedrückt, oft stark zuweilen nur wenig gekrümmt, im letztern Falle dicht behaart, im ersten auf der obern Fläche gefurcht, d. h. es begränzt die lläche zu jeder Seite eine erhabene Lciste oder Län grslinie. Das Rückenschildchen ist klein und dreieckig. Die Declsschilde sind fast überall gleich breit, die Spitzen abgerundet. 
Eine bunte Färbun ist bei Allen wahrzunchmen. Rückenschild und Decliscinilde sind gewühnlich glatı und haben einzcln stehcnde eingedrückte Punkte.

Zur Unterscheidung der Familien scheint das Sternum der passendste Körpertheil, je nachden diescs nemlich entweder flach und als eigentlicher Brusthöcker nicht vorhanden ist, oder im Gegentheil als Höcker stark hervortritt. Die Arien bei welchen letzteres wahrzunehmen, bilden die zweite Familie und zeichnen sich gleichzeition durch den fachen, im Verhältnifs breiteren Körper und lï̈rzere nach der Spitze zusammengedrückte Fühler aus.

Ls sind im Folgenden ein und dreifsio Arten beschrieben, die bis auf eine Afrilianische Art, Bewohner des südlichen Amerilia sind. Von diesen sind nur sechs, welche aus der grofsen Copenliagner Sanmiung entlehnt worden, nicht in Brasilien einheinisch, letztere aber bis auf den IM. egregius Germ. befinden sich im hiesigncn Miseum. Aufserdem führen noch Olivier (Entomologie VI. p. 920. n. 1. Pl. I. Fig. 1. a. b.) als Megalopus dorsalis und Kirby (im 12ten Bande der Linuean Transactions p. 144. n. 90.) unter der Benennung Megalopus sexmaculatus, jeder eine hier nicht gesenene Art auf, so dafs überhaupt drei und dreifsig Megalopen jetzt beuannt und beschrieben sind.

\section{Erste Familie.}

Kein Brusthöcker: Sternum planum.

$$
\text { 1. Megalopus sellatus. }
$$

Megalopus testaceus, coleoptrorum disco, antennis tibiisque nigris. Long. liu. $4 \frac{\pi}{2}-6$. 
Megalopus sellatus Germar Insect. Species I. p. 524.11 .704 .

Patria: Rio Janciro Brasiliae. Misit Dr. de Olfers.

Caput macula occipitali duplici punctoque utrinque ante antennas nigris. Vertex impressus punctatus, niger. Oculi testacei. Labrum nigrum. Mandibulae apice nigrae. Palpi testacei. Thorax antice posticeque marginatus immaculatus. Pectus abdomenque omnino testacea. Scutellum testaceum. Elytra testacea, dorso punctata late nigra, cano-pilosa. Alae fuscescentes. Femora testacea, postica (non tamen in omnibus) incrassata. Tibiae nigrae, anteriores cano - pilosae, posticae compressae, incurvae. Tarsi nigri subtus cinereo-tomentosi.

Von Rio Janeiro in Brasilien. Länge von $4 \frac{T}{2}$ bis 6 Linien. Kürper fahlgelb. Am Hinterhaupt dicht an einander zwei schwarze Punlite. Der Scheitel eingedrüclt, punktirt, schwarz. Dicht vor der Einlenkung der Fühler jederseits ein schwarzer Punkt. Augen bräunlich. Fühler und Lefze schwarz. Frefszangen mit schwarzen Spitzen. Rückenschild vorn und hinten mit aufgeworfenem Rande, so wie das Schildchen ungefleckt. Brust und Hinterleib einfarbig blafsgelb. Decirschilde blafsgelb, in der Mitte schwarz, punktirt, durch feine dicht anliegende Härchen grauschillernd. Flügel schwärylich. Schenkel blafsgelb, oft (ob allein bei den grö̈fseren Weibehen?) ansehnlich verdickt, Schienen und Fufsglieder schwarz, die hintersten Schienen gelsümmt und zusammengedrückt. 
2. Megalopus discoideus,

Tab. III. Fig. 5 .

Megalopus testaceus, caleoptris dorso viridi-coeruleis. L Long. lin, $4 \frac{x}{2}-5$.

Patria Brasilia. Misit Dr. de Olfers.

Statura praecedentis. Caput testaceum macula occipitali nigra. Vertex punctatus, puncto medio nigro. Antennae nigrae. Mandibulae apice nigrae. Palpi testacei. Oculi testacei. Thorax antice posticeque marginatus, testaceus puncto nigro. Punctulum utrinque ad pedum anticorum originem nigricans. Pectus testaceum ad pedum posteriorum insertiones nigro punctatum. Abdomen testaceum immaculatum. Scutellum nigrum. Coleoptera margine exteriore apiceque testacea, medio confertim punctata, viridi-caerulea; Alae fuscescentes. Pedes testacei, postici femoribus incrassatis, tibiis compressis incurvatis; Tarsi postici nigri.

Aus Brasilien. Länge $4 \frac{x}{2}$ bis 5 Linien. Dem Vorhergehenden älnnlich. Körper fahlgelb. Am Hinterkopf ein schwarzer Fleck. Scheitel punktirt mit schwarzem Mittelfleck. Fühler schwarz. Frefszangen mit gelben Spitzen. Augen bräunlich. Rückenschild vorn und hinten mit aufgeworfenem Rande, oben mit einem scluwarzen Punkt, zu den Seiten an der Wurzel der vordersten Beine schwarz punktirt. Brust an der Einlenkung beider. Fufspaare schwarz punktirt. Hinterleib ungefleckt. Rückenschildchen schwarz. Deckschilde am Aufsenrande und der Spitze blafsgelb, in der Mitte dicht stark punktirt und grünblau. Flügel schwärzlich. Beine blarsgelb, an dem hintersten Paar die Schenkel verdickt, die Schie. 
Ben zusammengedrüucht und gelsrümmt, die Fufsglieder schwarz.

\section{Megalopus egregius.}

Tab. III. Fis. 4 .

Megalopis niger, capite thoraceque sanguineis, antennis apice albis, elytris cyaneis margine externo apiceque pallidis. Long. lin. 4.

Megalopus egregius, Germar Insect. species etc. i. p. $525 \cdot 21.706$.

Habitat in Brasilia. Mus, Germar.

Praecedentibus angustior. Caput pone oculos punctatum, sanguineum, oculis mandibulisque nigris. Labrum nigrum apice testaceum. Palpi testacei. Antennae elytris breviores nigrae, articulis 5. 6. 7.8. et 9. subtus, ultimis duobus omnino albis. Thorax transversus basi apiceque marginatus, marginibus subreflexis, sanguineus, glaberrimus. Scutellum sanguineum. Pectus abdomenque aterrima nitida. Segmenta ventralia albido-ciliata. Elytra pailida, basi punctata late cyanea, margine externo reflexo pallido. Pedes nigri. Femora postica incrassata. Tibiae subincurvae. Plantae tonento cinerascente tectae.

Aus Brasilien; vier Linien lang. Kleiner und schlanker ais beide vorbeschriebene Arten. Kopf, Rizckenscliild und Schildchen sind lebhaft roth und glatt, ausgenommen einige eingedrückte Punkte zu beidén Seiten der Stiru dicht vor den Augen. - Die Lefze ist schwarz, mit blafsgelber Spitze. Die Mandibeln sind schwarz. Die Frefsspitzen blafsgelb. Die Fühler sind lürrzer als die Declischilde, die vier prsten Glieder schwarz, die fünf fol o enden schwarz, nnten weirs, die letzten beiden ganz weils. Kopf und 
Hinterleib sind schwarz, der Bauch weifslich behaart. Die hintere Hälfte der Deckschilde ist glatt und blafsgelb, die vordere punktirt und stahlblau, der $\mathrm{Au}$ fsenrand gells. Die Beine sind schwarz, die Hinterschenkel märsiog verdickt, die Schicnen etwas gekrümmt, die Sohlen mit einem weifsgrauen Filz bedeckt.

\section{Megalopus marginatus.}

Tab. III. Fig. 6."

Megalopus niger, thoracis et coleoptrorum margine omni, elytrorum fasciis duabus, anteriori obliqua, testaceic. Long. lin. $5 \frac{\pi}{2}$.

Patria: Brasilia. Misit Dr. de Olfers.

Caput nigrum clypeo testaceo. Vertex utrinque punctatus. Labrum testaceum basi fuscum. Mandibulae antennaeque nigrae. Oculi fusci. Thorax antice posticeque marginatus, marginibus reflexis, medio niger. Jugulum nigrum. Pectus nigrum. Abdomen testaccum. Elytra punctata nigra testaceo-marginata et bifasciata. Fascia altera-baseos a scutello versus marginem exteriorem oblique descendit, altera transversa pone medium marginem ipsum attingit. Alae nigricantes. Pedes nigri, Femora postica parum incrassata. Tibiae compressae incurvae.

Vaterland: Brasilien. $5 \frac{T}{2}$ Linien lang. Aehnlich den zuerst beschriebenen Arten. Kopf schwarz. Scheitel an den Seiten punktirt. Schildchen gelb. Lefze im Ursprunge schwärzlich. Frefszangen und Fühler schwarz: Augen dunkel. Das Rückenschild mit aufgeworfenern Vorder - und Hinterrande in der Mitlo schwarz, an den Seiten überall gelb. Brnst schwarz. Hinterleils fahlgelb. Bückenschildchen schwary. Deck- 
schilde punktirt, schwarz, am Rande gelb, mit zwei gelben Queerbinden, deren erste schräg vom Schildchen gegen den Aufsenrand herabsteigt, die andere gerade und durchgehend ist; die Flügel schwärzlich. Beine schwarz, die hintersten Schenkel wenig verdickt, die Schienen gelsrümmt und zusammengedrückt.

\section{Megalopus subfasciatus.}

\section{Tab. III. Fig. 7 .}

Megalopus testaceus, thorace macula "nigricanti subtriloba, elytris macula axillari, fascia transversa abbreviata, apiceque fuscis. Long. lin. $5 \frac{x}{4}$.

Megalopus subfasciatus Germar Insect. Spec. I. p. 525 . n. 705 .

II a bitat in Brasilia. Dedit amicissimus de Winthem.

Simillimus M. marginato, vix tamen mera varictas. Caput punctatum nigrum clypeo testaceo, maculaque utrinque occipitali ferruginea. Labrum testaceum basi ferrugineum. Mandibulae fuscae basi testaceae. Palpi subfusci. Antennae compressae nigrae. Oculi testacei. Thorax basi apiceque marginatus, marginibus subreflexis, antice atienuatus, sparsim punctatus, testaceus, subtus niger, supra macula subtriloba, litteram MI quodammodo referente, fusca. Pectus subpunctatum nigrum. Abdumen testaceum fasciis transversis nigris. Scutellum testaceum, basi fuscum. Elytra vage punctata, subpilosa, testacea, apice late obscuriora, macula axillari transversa, fasciacque obliqua media utrinque abbreviata fuscoferrugineis. Pedes nigri, fenoribus basi apiceque ferrugineis. Tibiae angulatac, posteriores com- 
pressae, incurvatae, subpilosae. Femora postica incrassata.

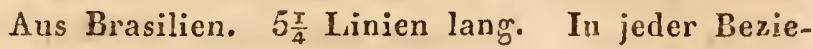
hung dem Megal. marginatus sehr ähnlich. Grundfarbe blafsröthlich gell,. Der Kopf punktirt, schwarz, hinten zu jeder Seite mit einem bräunlichen Fleck, unter den Augen blafsgelb. Lefze gelb mit schwïrzlichem Wurzelfleck. Frefszangen gelblich mit schwarzbraunen Spitzen. Frefsspitzen bräunlich. Fühler zusammengedrückt, schwarz. Augen blafsbräunliclı. Der Rückenschild vorn ein wenig verengt, und hier, wie am hintern Ende, gerandet. Die untere Seite schwarz, die obere gelbröthlich, mit einem grofsen braunen, beinah wie ein M gestalteten Mittelfieck. Brust schwarz. Bauch gelblich, mit schwärzlichen Queerbinden. Rückenschildchen schwarz an der Spitze gelblich. Deckschilde punktirt, schwach behaart, an der Spitze dunliler, bezeichnet am Schulterwinliel mit einem schrär abwärts steigenden Fleck und in der Mitte mit einer ebenfalls schräg laufenden, auf beiden Seiten abgekürzten Binde von durkelbrauner Färbung. Die Beine sind dunkel, beinah schwarz, schwach behaart, die Schenkel an beiden Enden braun, die hintersten Schentel fast keulenförmig verdickt, die Schienen zusammengedrüekt, gekriimmt und eckig.

\section{Megalopus bifasciatus.}

Tab. III. Fin. 8.

Megalopus niger, thorace utrinque, elytris fasciis duabus, teslaceis. Long. lin. $4-4 \frac{1}{2}$.

Patria: Brasilia. Misit Dr. de Olfers.

Praecedenti sinilis. Caput nigrum vertice ad oculos impresso-punctato, clypeo testaceo. Oculi 


\section{$-54$}

fusci. Thorax marginibus parum reflexis, niger, utrinque testaceus (rarius margine omni testaceo). Pectus nigrum. Abdomen testaceum. Scutelluın nigrum. Elytra punctata, nigra, fasciis duabus transversis, altera baseos, altera pone medium, axillis apicibusque testaceis. Alae nigricantes. Pedes nigri. Femora postica parum incrassata.

Aus Brasilien. Länge 4 bis $4 \frac{x}{2}$ Linien. Der vorhergehenden Art sehr ähnlich. Gewöhnlich kleiner. Der Kopf schwarz mit fahlgelbem Schildchen. Die Scheitelgegend vor den Augen punktirt. Die Lefze schwärzlich. Frefszangen und Fühler schwarz. Au . gen schwärzlich. Am Rückenschild der vordere Rand wenig, der hintere merklicher aufgeworfen. Farbe schwarz, nur an den Seitentheilen gelb. Brust schwarz. Hinterleib fahlgelb. Rückenschildchen schwarz. Declsschilde punlitirt, schwarz, mit zwei blafsgelben Binden, eine hleinere an dem Grundtheil, eine gröfsere dicht hinter der Mitte. Aufserdem sind die Achselgegend und die Spitzen der Deckschilde gelb. Die Flügel schwärzlich. Die Beine einfarbig schwarz. Die hintersten Schenkel kaum stärker als die übrigen.

\section{Megalopus signatus.} Tab. IlI. Fig. 9.

Megalopus testaceus elytris punctatis linea marginali maculaque obliqua media, thorace macula triloba, capite pedibusque nigris. Long. lin. 5 .

P'atria: Brasilia. Misit Dr. de Olfers.

Stalura pracedentium. Caput nigrum, occipito utrinque ferruginco. Vertex lateribus punctatus. Clypeus testaccus. Labrum nigrum apice testaceum. 
Mandibulae antennaeque nigrae. Oculi nigri. Thorax antice posticerue marginatus, testaceus, dorso niger, postice testaceo-bimaculatus, maculis linearibus, obliquis, basi approximatis. Jugulum pectusque nigra. $\Delta$ bdomen testaceum, segmentis prioribus utrinque, ultimo basi nigris. Scutellum nigrum.' Elytra distincte et profunde impresso-punctata, testacea, ad marginem exteriorem nigra, margine ipso tamen testaceo, medio nigro-maculata, macula lineari subarcuata obliqua a sutura mạginem exteriorem versus provecta. Alae infuscatae. Pedes nigri coxis testaceis. Femora postica parum incrassata, testaceomarginata.

Aus Brasilien. Gestalt der Vorhergehenden. Kopf schwarz, am Hinterkopf jederseits ein bräunlicher halb verloschener Fleck in ähnlicher Weise wie bei den beiden vorhergehenden Arten. Scheitel an den Seiten punktirt. Schildchen gelb. Lefze schwarz, an der Spitze gelb. Frefszangen, Fühler und Augen schwarz. Raiclenschild mit aufgeworfenem Vorderund Hinterrande, blafsrelb, oben in der Nitte schwarz, hinterwärts mit gelbem Doppelfleck, der im Ursprung voreinigt ist, und wo er sich endigt, gabelförmior abweicht. Kelsle und Brust schwarz. Hinterleib blarsgelb, die ersten Abschnitte zu joder Seite, der letzte an seinem ganzen Ursprunge schwarz. .Rück enschildchen schwarz. Deckschilde einzeln, aber tief punk. tirt, fallgelb. In der Milte ein linienförniger geschlungener. Fleck, der von der Natik gegen den $\mathrm{Au}$ fscnrand hin abwairts steigt, doch wedor diesc nocin jenen berührt. Vor dem Aufsenrande von der Wurzel der Deckschilde bis zur Spitze hin eine schwarze Linie. Der Aufsenrand selbst gelb. Beine schwarz. 
mit gelben Hüftstücken. Die hintersten Schenkel wenig verdickt, unten gelb gerandet.

\section{Megalopus testaceus.}

Tab. IV. Fig, 2.

Megalopus niger, elytris, thoracis margine, maculaque postica duplici testaceis. Long. lin. $4 \frac{\frac{T}{2}}{2}$.

Patria: Brasilia. Misit Dr. de Olfers.

Similis praecedenti. Caput nigrum vertice lateribus punctato. Clypeus testaceus. Labrum apice testaceum. Mandibulae antennaeque nigrae. Oculi nigro - fusci. Thorax antice vix, postice parum marginatus, testaceus, dorso macula magna triloba nigra, subtus niger. Pectus scutellumque nigra. Abdomen testaceum, segmentis prioribus utrinque, ultimo basi macula fusca. Elytra punctata, punctis leve impressis, testacea, unicoloria. Pedes nigri.

Aus Brasilien. Aehnlich der vorhergehenden Art. Länge $4 \frac{x}{2}$ Linien. Kopf schwarz. Am Hinterliopf keine Spur von bräunlichen Flcclien. Scheitel zu beiden Seiten puntirt. Schildchen ganz, Lefze an der Spitze blafsgelb. Frefszangen, Fühler und $\Lambda \mathrm{u}$ gen schwarz. Rückenschild kaum gerandet, sehr glatt, blafsgelb, geschmückt mit cinem grofsen glänzend schwarzen Fleck, ähnlich einer umigekehrt stehenden dreiblättrigen Blume, deren starlser Sticl den vordern Rand und das mittlere Blatt den linteren erreicht. Kehle, Brust und Rückenschildchen schwarz. Hinterleib blafsgelb, die beiden crsten $A$ bschnittc zu jeder Seite, der letzte in der Mitte mit braunschwarzem Grundflecke. Deckschilde leicht punkirt, einfarbig fahigelb. Beine schwarz. Dic lintersten 


\section{$-57-$}

Schenkel nicht mehr als bei der vorhergehenden Art verdickt.

9. Megalopus flavo-maculatus.

Tab. IV. Fig. 2.

Megalopus niver, elytris róseis, flavo-bimaculatis, thorace testaceo, nigro signato. Long. lin.4-5. Habitat in Brasilia. Misit Dr. de Olfers. Rio Janeiro. Mus. Di. de Langsdorff.

Praecedentibus angustior. Caput nigrum, vertice lateribus punctato, cano-subpiloso. Clypeus labrumque subpilosa testacea ad basin fusca. Mandibulae antennaeque nigrae. Palpi testacei, anteriores articulo primo basi fusco. Oculi fusci. Thorax parum marginatus testaceus, dorso macula nigra bisinuata, litteram M referente ornatus. Pectus abdomen et pedes nigra cano-pubescentia. Scutellum testaceum, basi subfuscum. Elytra vage punctata rosea, maculis duabus testaceis, altera pone medium altera ad apicem, ornata.

Aus Brasilien: Vier Linien lang. Schmaler als die Vorhergehenden. Kopf schwarz, Scheitel an den Seiten punktirt, dünn weifslich behaart. Schildchen und Lefze blaissgelblich, nach dem Grunde hin schwärzlich, überall leicht weifslich behaart. Frefszangen und Fühler schwarz. Frefsspitzen gelblich. Augen braun. Rückenschild kaum gerandet, blafsgelb, oben mit einer schwarzen MI förmigen Zeichnung. Brust, Hinterlcib und Beine schwach weifslich behaart. Riiclienschildchen gelblich, nach oben etwas schwärzlich. Deckschilde schwach punktirt, rosenroth, jedes mit zwei gelben runden Flecken, den einen in der Mitte, den andern unweit der Spitze. 


\section{$-38$}

10. Megalopus fasciatus.

Tab, IV. Fig. 3.

Megalopus aterrimus, coleopteris sanguineis, fascia media atra. Long. lin. 4.

Megalopus fasciatus Dalman analecta entomol. p. 72. n. 65.

$\mathrm{H}$ a bit at in Brasilia. Dedit Bes clse.

Brevis, validus. Caput magnum, occipite subgibboso punctato, verlice plano, lateribus punctato. Oculi magni prominentes. Orbitae postice argenteociliatae. Antennae breves apice dilatatae, compressae. Thorax antice posticeque marginatus, margine antico utrinque argenteo-ciliato, lateribus subtuberculatus, dorso punctatus. Pectus et abdomen, anus densior, albido-ciliata.' Scutellum punctatum. Elytra basi apiceque vage punctata, sanguinea, medio confertius punctata nigra, nigro-subtomentosa. Pedes punctati, atro-villosi. Femora postica incrassata, subtus me• dio unidentata.

Aus Brasilien. Vier Linien lang. In der Gestalt abweichend. Der ganze Körper, die Declischilde ausgenommen, tiefschwarz. Der Kopf grofs, das Hintcrhaupt gewölbt, erhaben und punktirt; die Seheitelgegend flach, seitwärts punktirt. Die Âugen grofs, hervorstehend, an hintern Rande mit einem silberfarbenen Haarsaum. Die Fühler lürzer, als bei den vorhergehenden Arten, an der Spitze breiter, zusammengedrückt. Das Riuchenschild vorn und hinten mit aufgeworfenem Rande, an den Seiten in cinen stumpfen Höcker crhaben, oben panktirt, der vordere Rand an den Seiten nit silberweifsem Haarsaum. Brust und Hinterleib weifslich, die Afterge- 


\section{- 59 -}

gend dichter behaart. Das Rück̉enschildchen deutlich punktirt. Deckschilde punktirt, hochroth. Durch die Mitte eine dichter punktirte schwarze Binde mit schwarzem Haarfilz bedeckt. Die Beine stark, mit aufliegenden schwarzen Härchen besetzt. Die hintersten Schenkel sehr dick, am untern Rande in der Mitte mit einem kurzen Dorn bewaffnet.

\section{Megalopus analis.}

Tab. IV. Fig. 4.

Megalopus elongatus luteus, elytris apice, capite cum antennis, abdomine pedibusque posticis nigris. Long. lin. 4 .

\section{Habitat in Brasilia. Misit Dr. de Olfers.}

Praecedentibus multo angustior. Caput thorace latius, vertice punctato, nitidum, nigrum, oculis magnis prominentibus, tostaccis. Antennac capite duplo longiores subcompressae, nec tamen dilatatae. Clypeus elevatus labrumque nigra. Mandibulae testaceae apice fuscae. Palpi testacei. Thorax cylindricus, marginibus antico posticoque parum elevatis, luteus immaculatus. Pectus scutellumque lutea. Abdomen nigrum, nitidum. Elytra attenuata, punctata lutea, luteo pilosa, apicibus nigris, nigro-villosis. Pedes anteriores lutei, postici nigri, ungulis luteis. Femora parum incrassatae, tibiae elongatae, subincurvae, cinereo subpilosae.

Aus Brasilien. Vier Linien lang. Körper sehr schmal. Der Kopf breiter als das Rücclinschild, am Scheitel punltirt, glänzend schwarz. Augen hervorstehend, blafsbräunlich. Fühler etwas zusammengedrïclst, schwarz. Frefszangen gelblich mit dunkileren Spitzen. Frefsspitzen blafsgrelb. Das Rücken- 
schild vorn und hinten ein wenig aufgeworfen, cylyndrisch geformt, röthlichgelb. Brust und Rückenschildchen eben so gefärbt. Hinterleib schwarz und glänzend. Deckschilde schmal, punlitirt, röthlichgelb, eben'so behaart, an der Spilze schwarz und scliwarzhaarig. Die vordern Beine röthlichgelb. Die hintersten schwarz mit gelbrothen Klauen, Die SchenkeI laum merklich verdickt, die Schienen etwas verlängert, wenig gelrümmt, mit weifslichen Härchen leicht besetzt.

\section{Megalopus rufscornis.}

Tab. IV. Fig. 5 .

Megalopus elongatus testaceus, capitis vertice thoracisque dorso fuscis. Long. lin. 4.

Megalopus ruficornis Fabricii Syst. Fleuth. II. p. 367. n. 1.

Habitat in America meridienali. D. Smidt. (Fabr. 1. c.). Ex Museo Regio Havniensi.

Caput pusctatum fuscum inter antennas laeve, impressum, testaceum, macula fusca. Clypeus labrumque testasea basi flava. Mandibulae ferrugineae basi testaceae. Palpi ferruginei. Oculi 'magni globosi emarginati glauci. Antennae vix thorace longiores, compressae, ferrugineae, articulo primo testaceo. Thorax cylindricus, antice posticeque marginatus, punctatus dorso fuscus. Scutellum rufo-testaceum. Elytra attenuata testacea punctata sulpilosa, apice argenteo-micantia, nargine externo obscuriori. Pectus obscure testaceum, argenteo-sericeum. Pleurae macula fusca. Abdomen testaceum, argenteo-sericeum, segmentis basi utrinque ferrugineis, ullinu ferrugineo, dorso flavo. Pedes testacei, femoribus an- 
terioribus basi, tibiis tarsisque obscurioribus. Pedes postici elongati. Femora incrassata. Tibiae subincurvae.

Aus dem südlichen Amerika und 4 Linien lang. Schmal, blafsalbelblich, der Kopf grofs, am Scheitel punktirt und dunkelbräunlich, die Stirn zwischen den Fühlern platt eingedrückt mit dunkelm Fleck. Frefszangen und Frefsspitzen braun. Augen grofs. Fühler kaum länger als das Rückenschild, zusammengedrückt, bräunlich, das erste Glied blafsgelb. Rülkenschild rund, punktirt, in der Mitte schwärzlich. Das Schildchen röthlicbgelb. Die Deckschilde eng, röthlich blafsgelb, punktirt und mit dunklen Härchen besetzt, an der Spitze silberweifs schimmernd, ain Aufsenrande dunkel. Brust punktirt mit silberweifsen Härchen bedeckt. Brustseiten mit schwarzbraunem Fleck. Bauch gelb, die Abschnitte seitwärts braun, der letzte unten braun, oben gelb. Die Beine blafsgelblich, die vordern Schenkel von ihrem Ursprunge an zur grö̊sern Hälfte dunkler bräunlich, sämmtliche Schienen und Fufsglieder bräunlich. Die hintersten Beine verlängert, deren Schenkel verdickt und die Schienen gelrümmt.

\section{Megalopus inscriptus.}

Tab. IV. Fig. 6.

Megalopus elongatus, testaceus, capite maculis, thorace signo litteram MI referente, ferrugineis. Long. lin. $3 \frac{\mathrm{T}}{2}$.

Patria: Parà Brasiliae. Misit Sicber. Ex Museo Com. de Hoffmannsegg.

Statura praecedentis. Capul thorace latius, punctatum, testaceum, vertice macula occipiteque fer- 
rugineis, macula verticali litura angulata aurea terminata. Antennae ferrugineae, apice incrassatae, dilutiores, articulo primo testaceo. Oculi magni prominentes, testacei. Mandibulae testaceae, apice ferrugineae. Palpi testacei. Thorax cylindricus, marginibus parum reflexis, testaceus, dorso littera M, lateribus punctulo, ferrugineis notatus. Pectus testaceum ferrugineo-maculatum. Abdomen testaceum, segmentis basi ferrugineis. Scutellum testaceum. Elytra punctata, testacea, cano-pilosula-, marginibus axillisque ferrugineis. Alae fuscescentes. Pedes testacei femoribus fascia ferruginea. Femora postica parum incrassata.

Von Parà in Brasilien und $3 \frac{x}{2}$ Linien lang. Körperbau schmal, wie bei der vorhergehenden Art. Kopf breiter als das Rückenschild, punktirt, blafsgelb, aí Scheitel und dem Hinterlsopf braun. Ueber dem Scheitelfleck eine eckige goldfarbige Linie. Augen grofs, hervorstehend, blafsbräunlich. Frefszangen blafs, an der Spitze dunlelbraun. Frefsspitzen gelblich. Fühler an der Spitze verdiclit, das erste Glied gelb mit einigem Goldglanz, die zunächst folgenden dunkel-, die übrigen hellbraun. Rückensckild schmal mit wenig aufgeworfenen Rändern, blafsgelb. Auf dem Rücken ein grofses lateinisches $M$ von brauner Farbe, an den Seiten ein brauner Punlt. Brust blafsgelb mit braunem Fleck. Hinterleib blafsgelb, die Abschnitte nach vorn braun. Rückenschildchen blafsgelb. Deckschilde punktirt, blafsgelb, leicht weifslich behaart, mit braunem Rande und eben solchem Schulterfleck. Flügel hellbräunlich. Beine blafsgelb. Schenkel von einer brauner Binde in der Mitte durch- 
zogen. Die hintcrsten Schenkel etwas verdickt, die Schienen verlängert.

\section{Megalopus nigricornis.}

Tab. IV. Fig. 7.

Megalopus elongatus, testaceus, capite, elytrorum margine, pedumque posticorum tibiis tarsisque nigris. Longr. lin. 4.

Megalopus nigricornis Fabr. Syst. Eleut. II. p. 368. n. 2. Olivier Entomologie VI. p. 920. n. 2. Pl. I. Fig. 2. Latreille geń. Crust. et Ins. III. p. 45. sp. 1. Tab. XI. Fig. 5.

Habilat in America meridionali. D. Smidt. Ex Museo Regio Havniensi.

Affinis II. ruficorni. Caput punctatum, fronte impressa laevi. Clypeus labrumque testacea, basi nigra. Mandibulae elongatae, testaceae, apice fuscae. Palpi testacei. Antennae vix thorace longiores, compressae nigrae. Oculi magni prominentes emarginati glaucescentes. Throrax globesus, rufo-testaceus, antice posticeque marginatus, sparsim punclatus, duabus maculis, altera baseos, altera media, dorsalibus nigris. Scutellum testaceum. Elytra attenuata, punctata, testacea, linea suturali baseos abbreviata, humeris, margineque externo nigris, vitta suturali ad apicem, apicibusque ipsis ferrugineis. Pectus testaceum macula media triangulari nigra. Abdomen testaceum. Pedes testacei, postici elongati, femuribus parum incrassatis, basi nigro-lituratis, tibiis incurvatis, intus fulvo - ciliatis.

Aus dem südlichen Amerika. 4 Linien lang. Gestaltet wie Megalopus ruficornis. Kopf schwarz punktirt, zwischen den $\Lambda$ ugen glatt. Schildchen und Lefze 
schwarz, an der Spitze gelblich. Frefszangen blafsgelb mit braunen Spitzen. Frefsspitzen blafsgelb. Fühler zusammenged:ückt, kaum länger als das Rükkensclild und schwarz. Augen grofs und hervorstehend. Rückenschild rund, einzcin und schwach punktirt, röthlichgelb mit schwarzem Mittel - und einem ähnlichen Fleck in der Mitte des vordern Randes. Rückenschildchen blafs röthlichgelb. Deckschilde blafs gelbbräunlich, punktirt, der Aufsenrand, die Schultern und ein Drittheil dor Nath unmittelbar vom Schildchen abwärts schwarz, die Spitzen und im Zusammenhang mit ihnen ein länglicher Nathfleck braun. Die Brust blafs röthlichgelb mit einem dreieckigen schwarzen Mittelfleck. Der Bauch blafs röthlichgelb. Die Beine von der nemlichen Farbe, mit Ausnalime der hintersten Schienen und Fufsglieder, welche schwarz sind. Die Hinterschenkel sind ein wenig verdickt mit einem schwarzen Strich unterhalb an ider Einlenkung. Die Hinterschienen sind etwas verlängert und gelsrümrnt, am inwendigen Rande mit goldgelben Härchen besetzt.

\section{Megalopus cruralis.}

Tab. IV. Fig. 8 .

Megalopus thorace subgloboso niger, elytris testaceis; femoribus posticis ferrugineis, macula flava. Long. lin. 4.

Patria Bahia Brasiliac. Misit Sello.

Caput aterrimum. Occiput gibbun. Antennae mediocres, apice compresse. Oculi ovati fusci. Mandibulae nigrac. Maxillae testaceae. Thorax subglobosus, antice posticeque marginatus, punctatus, aterrimus. Pectus nigrum. Abdomen nitidum nigrum macula 
macula magna baseos flava. Scutellum nigrum. Coleoptra attenuata, punctata testacea, nigro - subpilosa, basi, axillis, maculaque subscutellari triangulari communi Perrugineis. Pedes fusci, genubus tarsisque testaceis. Femora postica subincrassata, medio ferruginea, macula flava. Tibiae posticae apice crassiores nigro - subhirtae.

Von Bahia in Brasilien. Vier Linien lang: Kopf ticf schwarz. Hinterkopf stark gewölbt. Augen wenig hervorstehend, dunkelbraun. Fülller von mäfsiger Länge, etwas zusammengedrüclit. Kinnbacken schwarz. Laden gelllich. Rückenschild rundlich, gerandet mit stark aufgeworfenem Vorderrande, punktirt, tiefschwarz. Brust schwarz. Hinterleib glänzend schwarz unit einem grofsen gelben Grundfleck: Rückenschildchen schwarz. Deckschilde punktirt, blafsbrïunlichgelb, besetzt mit einzeln stehenden schwarzen Härchen. Braun sind die Schultergegend, der vordere Rand, und ein gemeinschaftlicher dreieckiger Fleck hinter den Schildchen. Die Beine sind dunkelbraun, beinah schwarz, mit gelbröthlichen Kniegelenken und Fufsogliedern. Die hintersten Schenliel sind märsig verdickt in der Mitte glänzend rothbraun mit einem grofsen gelben Fleck unweit der Spitze; die hintersten Schienen gegen die Spitze verdickt und mit schwarzen Haaren besetzt.

\section{Megalopus hirtipes.}

Tab. IV. Fig. 9.

Megalopus therace subgloboso, aterrinus elytris testaceis. Long. lin. $4 \frac{x}{2}$.

Patria: Parà Brasiliae. Misit Sieber; ex Museo Com. de Hoffmannsegg. 
Praecedenti affinis. Occiput gibbum. Vertex planus. Antenuae mediocres distincte articulatae fuscae, articulo primo basi testaceo, ultimo acuminato. Oculi ovati fusci. Thorax dorso punctatus antice posticeque marginatus, marginibus elevatis, antico utrinque albido-ciliato. Pectus nigrum. Abdomen nigrum macula parva baseos testacea. Anus nigro-hirsutus. Scutellum punctatum nigrum. Coleoptcra angnstata, obscure testacea, punctata, nigro-pilosa, marginibus axillisque fuscis. Pedes niori, ungulis ferrugineis; posticorum condyli tcstacei. Femora parum incrassata basi apiceque parum testacea. Tibiae incurvae carinatae nigro-hirtae, npice ferrugineo-pilosae; plantae ferrugrineae.

Aus Brasilien, $4 \frac{x}{2}$ Linien lang. Der vorhergehenden Art selır ähnlich. Kopf ganz schwarz, Hintorkopf gewölbt, Scheitel flach. Tühler braun, die Glieder deutlich abgesetz.t, das letzte zugespitzt. Rükkenschild einfärbig schwarz, kuglicht, punktirt, niit stark aufgeworfenem Vorder- und Hinterrande. Brust und Hinterleib schwarz, letzterer an der Spitze schwarz behaart, der Bauch mit einem blafsgelben Wurzelfteck. Rückenschildchen schwarz. Deckschilde blafs bräunlich gelb, punktirt, mit einzelnen schwarzen Härchen überall besetzt, braun gerandet und mit braunem Schulterfleck. Bcine schwarz, schwarz behaart. Kniegelenke gelblich. Hinterschenkel etwas verdickt, Wurzel sammt den Gelcnliköpfen und Spitzen gelblich. Mlinterschienen seln behaart mit röthlichen Haaren an der Spitze. Sümntliche Klavenglieder rothbraun, die Flächen der Fufsoglicder röthlich behaart. 


\section{$-67-$}

\section{Megalopus afer.}

Tab. VI. Fig. 7. 8.

Megalopus niger, capite thoraceque luteo - maculatis, elytris luteis, nigro-fasciatis. Long. lin. 4-5.

Patria: Prom. b. spei prope Uitenhagen. Detexit D. Krebs.

Corpus oblongum nigrum, griseo subpilosum. Caput declive punctatum, macula frontali transversa lutea; clypeo linea transversa impressa separato, cinereo-hirto apice glabro, obscure luteo; labro apice rotundato ferrugineo, ciliato. Mandibulae nigrae, validae, breves', subincurvatae, integrae. Maxillae compressae basi nigrae, corneae, apice luteac, incurvatae, pectinatac, bifidae. Mentum transversum, breve, corneum, tridentatum nigrum. Labium testaceum coriaceum crassum subconicum, apice rotundato. Palpi nigri; maxillares maxillis vix longiores quadriarticulati, articulo primo brevissimo, secundo tertioque altero dimidio breviori cylindricis, quarto longitudine secundi subulato; labiales triarticulati, articulo primo brevissimo, secundo tertio longiori. Antennae thorace vix breviores compressae serratae fuscae, basi apiceque nigrae. Thorax cylindricus convexiusculus punctatus, lateribus rotundatis maculaque dorsali subcordata luteis. Scutellum transversum nigrum apice rotundato. Elytra punctata, sparsim pilosa lutea, nigro bifasciata, fasciis obliquis ad suturam latioribus, priori ad humeros ascendente, secunda marginem externum non attingente. Pectus, abdomen, pedes griseo pilusa. Femora postica incrassata, tibiae vix incurvatae, plantae tomento subinaurato tectae, ungues valde elonga- 


\section{$-68$}

tae, unguiculis ferrugineis armatae. Variat antennis ferrugineis, coleoptris nigris, macula communi baseos, fascia media obliqua utrinque intersupta, apiceque luteis.

Von Vitenhagen in der Cap-Colonie. 4-5 Linien lang. Fast cylindrisch, schwarz, grau behaart. Der Kopf abhängend, punltirt, mit einem breiten rothgelben Stirnfleck. Mandibeln und Frefsspitzen schwarz. Die Fühler etwa so lang als das Rüclsenschild, zusammengedrückt, gesägt, dunkelbräunlich, Wurzel und Spitze schwarz. Das Rückenschild an den Seiten ab. gerundet und rothgelb, mit einem fast herzförmigen rothgelben Mittelfieck. Das Rückenschildchen breit, gerandet, schwarz. Die Deckschilde stark punktirt, einzeln behaart, rothgelb mit zwei schwarzen Oneerbinden, beide stehen an der Nath sich näher, die erste fängt von der Schulter, die andere vor dem Anfsemrande an. Die untere Seite und die Beine sind sehr hehaart, die hintern Schenliel verdickt, die Klauenglieder lang, die Sohlen mit einem hellgoldfarbenen Filz bedeckt.

Bei einer Abänderung sind die Fühler rostfarben, dio schwarzen Binden der Deckschilde sind breiter, namentlich die hintere, welche zugleich den Aufsen. rand und fast die Spitze erreicht, aufserdem aber durch einen nach der anderen Binde ausgrchenden Streifen das grelbe Mittelfeld theilt, so dafs die Deckschilde wie schwarz und mit gelben Flecken erscheinen. (Fig. 8.) 
Zweite Familie.

Brustbein als Höcker hervorragend: Sternum in tuberculum elevatum.

18. Megalopus variegatus.

Tab. V. Fig. x. 2.

Megalopus luteus nigro-maculatus, olytris fascia flava. Long. lin. 5.

Habitat in Brasilia. Misit Dr. de Oifers.

Caput luteum occipitis medio, macula clongata in vertice punctisque duobus inter antennas nigris. Clypeus punctis tribus, labrum macula magna baseos nigris. Mandibulae luteae apice nigrae. Palpi lutei. Oculi fusci. Antennac luteae, articulis quatuor prioribus dorso ferrugineis, ultimis quinque nigris, compressis. Thorax depressus, transversus luteus dorso maculis novem nigris, subtus nigro-maculatus. Pectus nigrum lateribus ferrugineo-maculatis. Abdomen luteum. Scutellum nirrum. Elytra punctata lutea nigro - cincta, basi nigro - maculata, fascia transversa media dentata flava nigro marginata. Pedés lutei, femoribus maculis, tibiis margine extcriori, tarsis dorso ungulisque nigris. Femora postica incrassata, tibiae parum incurvatae.

Variat elytris nigris, basi luteo-apice ferrugineo-maculatis, fasciaque transversa communi medio interrupta pallida. Fig. 2.

Aus Brasilien. Fünf Linien lang. Körper rothgelb. Am Kopf ein grofser Fleck am Hinterlaupt, cin länglicher Scheitelfleck und jederscits ein P'unit vor den Fühlern sclıwarz. Auf dem Schildchen drei schwarze Punkte nebon cinander. Dic Lefze uit ei- 
nem grofsen schwarzen Fleck. Die Frefszangen mit schwarzen Spitzen. Augen bräunlich. Dic vier ersten Fühlerglieder sind aufserhalb braun, die fünf letzten zusammengedrückt, mattschwarz. Das Rükkenschild, von flachgedrückter, queergedehnter Gestalt, hat oben neun schwarze Flecke, und ist auch unten schwarz gefleckt. Die Brust ist schwarz und nur an den Seiten braungefleckt, der Hinterleib durchaus rothgelb, das Rückenschildchen schwarz. Die punktirten Deckschilde haben einen feinen schwarzen Rand, in der Mitte eine gelbe gezackte Binde, welche hinten schwarz eingefafst ist. Die vordere Hälfte der Deckschilde durchziehen schwarze zackige Queerbinden, aus mehr oder weniger in einander geflossenen Flecken gebildet. Die Schenkel sind schwarz gefleckt, die hintersten verdickt, die Schienen schwarz gerandet, die Fufsglieder oben schwarz, die Klauen schwarz. Die Grundfarbe der Decken ist bei cinigen schwarz. Sie sind durch eine gelbweifse Binde, die entweder ganz, oder beinah unterbrochen ist, getheilt. Die Spitzen der Decken sind entweder hellbraun oder haben nur einen braunen Fleck, die vordere Hälfte durchziehen zwei rothgelbe geschlängelte Binden, welche vor der Nath aufhören. (Fig. 2.)

\section{Megalopus vittatus.}

Tab. V. Fig. 3 .

Megalopus testaceus, elytris flavis vitta longitudinali suturaque roseis. Long. lin. 5 .

Habitat in Brasilia. D. Bescke.

Caput testaccum, labro macula bascos, mandibulis apice nigris. Oculi fusci. Antennae apice compressac, subserratae flavescentes, articulis dorso fuscis. 
Thorax immaculatus. Pectus obscure-testaceum. Abdomen testaceum segmentis medio obscurioribus. Scutellum rufescens. Elytra punctata flava vitta longitudinali abbreviata. Pedes testacei, femoribus maculis, tibiis tarsisque dorso ferrugineis. Femora postica incrassata subtus ad apicem acute dentata. Tibiae posticae incurvatae.

Aus Brasilien. Fünf Linien lang. Blafs rüthlichgelb, Kopf und Rïckenschild ungefleckt. Nur die Lefze an der Vurzel und die Frefszangen an der Spitze schwarz. Die Fühler zusammengedrüclt, blalsgelblich, mit dunkelbraunem Rücken. Augen brïunlich. Brust und Hinterleib grelbbräunlich, die letzten Abschnitte an den Spitzen heller. Riickenschildchen blassroth. Deckschilde punlitirt, gelb. Blafsroth die Nath und dicht linter dén Schultern eine Längुsbinde bis über die Milte der Deckschilde. Beine wie der Hinterleib gुefürbt, Schenkel röthlich gefleckt, der Schienen obere Seite sammt den Fufsgliedern braun. Hinterschenkel verdickt, unten unweit der Spitze scharf gुezahnt, Schienen selır gekrümmt.

20. Megalopus clepressus.

Tab. V. Fig. 女.

Megalopus testaceus, capite nigro-maculatu, clytris marginibus, macula Iuncrali punctorue medio, tibiis dorso nigris. Long. lin. 4.

Patria: Cameta Brasiliae. Ex Musco Comit. de Hoffmannsegg.

Corpus depressum. Capul nitidum medio subtilissime punctatum, macula magna elungata media a vertice inter oculos ad frontem provecta, altera utrinque minori post oculos, punctoque arl antenna- 
rum insertionem nigris. Oculi profunde emarginati testacei. Clypeus inmaculatus. Labrum basi nigrumı. Mandibulae apice nigrae. Falpi testacei. Antennae compressae, subserratae, articulis quatuor prioribus testaceis, antice ferrugineis, insequentibus sex brunneis, ultimo ochraceo. Thorax immaculatus. Pectus postice nigrum. Abdomen obscure testaceum, segmentis pallido - marginatis. Scutellum nigrum. Elytra punctata rufo-testacea, macula magna humerali, puncto disci, sutura, margine externo tenuissimo, postico latissimo nigris. Femora immaculata. Tibiac dorso nigrae. Tarsi nigri. Femora postica parum incrassata. Tibiae vix incurvae.

Von Cametá in Brasilien. Vier Linien lang. Körper flachgedrückt, blâs bräunlichgelb, glänzend. Kopf in der Mitte schwach punktirt. Vom Scheitel bis zur Stirn ein schwarzer länglicher Fleck. Schwarz ist noch zu jeder Seite die Gegend hinter den Augen und ein Punlt an der Einlenkung der Fühler. Die Augen sind tief ausgerandet, blafsbräunlich. Die Fühler zusammengedrückt. etwas gesägt, die vier ersten Glieder gelb, vorn braun, die sechs folgenden matt blafsbraun, das letzte ockergelb. Der Kopfschild ungefleckt. Die Lefze an der Wurzel, Mandibeln an der Spitze schwarz. Frefsspitzen gelblich. Das Rükkenschild ist durchaus einfarbig. Die Brust nach hinten scliwarz, der Hinterleib dunkler als das Rückenschild, die Bauchsegmente hell gerandet. Das Rülbenschildchen, schwarz. Die Deckselilde deutlich und einzeln punktirt, röthlichgelb. Schwarz sind ein grafser Sclulterfleck, ein Punkt in der Mitte, die Nath, eine feine Linie am äuferu Rande und ein breiter Saum an der Spitze. Dic Bcine sind blars 


\section{$-73-$}

röthlichgelb, die Schenkel ungefleckt, dic Schienen oben schwarz gerandeh, dic Fufsglieder uben schwarz. Die IIinterschenkel sind nur wenig verdickt, die hintersten Schienen kaum deutlich gelrümmt.

21. Megalopus dentatus.

Tab. V. Fig. 5.

Megalopus testaceus, capite postice, thorace macula, elytris lineola maculisque nigris. Long. lin $4 \frac{x}{2}$. Habitat in Brasilia. Ex Museo $D^{i}$. de Winthem.

Affinis Megalopo depresso. Caput nigrum, sub uculis testaceum. Labrum nigrum apice testaceum. Palpi pilosi testacei. Mandibulae apice nigrae. Antennae thorace longiores, compressae, serratae, brun-. neae, basi nigrae. Thorax planus, vage punctatus, rufo testaccus, macula media, in nonnullis geminata, nigra. Scutellum nigrum. Elytra 'punctata pallida, macula lineari axillari subflexuosa aut interrupta, lineola media maculaque ad apicem nigris. Pectus nigrum, medio rufo-testaceum. $\Lambda$ bdomen pedesque testacea. Tibiae posteriơres incurvae, dorso nigrae. Femora postica dilatata subclavata basi flavá, ante apicem acute dentata aut subdentata.

Aus Brasilien. Länge $4 \frac{x}{2}$ Linien. Dem Megalopus depressus schr ähnlich. Der Kopf schwarz, unter den Augen röthlichgelb. Die Lefze schwarz nit gelblicher Spitze. Die Frefsspitzen behaart und gelblich. Dic Fühler zusammengedrückt, allmählig breiter auslaufend, sind bräunlich, die vier ersten Glicder glänzend schwarz, dic zunächst folgenden auf der obern Seite mattscliwarz. Das Rückenschild ist hin und wieder punlitirt, glänzcnd rothgelb. Nur 
in der Mitte steht ein schwarzer Doppelfleck. Das Schildchen ist schwarz. Die Decken sind punktirt, blafsgelb. Vom Schulterwinkel steigt am Aufsenrande abwärts ein länglicher, in der Mitte unterbrochener, schwarzer Fleck oder Binde. Vor diesem befindet sich in der Mitte der Deckschilde eine feine schwarze Linie und an der Spitze steht ein runder schwarzer Fleck. Die Brust ist schwarz, die vorragende Mitte aber röthlichgelb. Bauch und Beine sind röthlichgelb, dic hinteren Schienen gekrümmt, oben schwarz. Die hintersten Schenkel sind verdickt an der Wurzel blafsgelb und vor der Spitze mit einem kurzen, zusammengedrücliten, etwas geliümmten und spitzen Zahn bewaffnet.

\section{Megalopus binotatus.}

Tab. V. Fig. 6.

Megalopus depressus, testaceus, occipite, thoracis macula, elytrorum humeris lineolaque media nigris. Long. lin. $4 \frac{\mathrm{T}}{2}$.

Habitat in Brasilia. Misit Feldner.

Similis praccedenti. Caput rufo-testaccum occipite, macula frontali continua punctoque utrinque ad antennarum insertiones nigris." Clypeus medio, labrum basi, mandibulae apice nigra. Antenuae thorace longiores, compressae, brunncae, basi et dorso nigrae. Thorax planus subquadratus, vage punctatus, rufo-testaceus, macula media nigra. Scutellum nigrrum. Elytra marginata, punctata, testacea, macula hunerali subtrigona lincolaque media nigris. Pectus abdomenque testacea. Pedes testacei tibiis dorso nigris. Femora postica incrassata. 


\section{- $\quad-70-$}

Aus Brasilien; $4 \frac{\mathrm{r}}{2}$ Linien lang. Sehr ähnlich der vorbeschriebenen Art. Kopf und Rückenschild siud blafs braungelb. Hinterkopf und mittlere Stirn, ein Punkt vor den $\Lambda$ ugen, ein Mittelfleck des Kopfschildchen, die Wurzel der Lefze und die Spitzen der Frefszangen sind schwarz. Die Fühler sind zusammengedrückt und länger als das Rückenschild, bräunlich an der Wurzel und oben schwarz. Auf dem Rückenschild, welches einzeln punktirt und glänzend ist, befindet sich in der Mitte ein schwarzer Fleck. Das Schildchen ist schwarz. Die Deckschilde sind gerandet, punktirt und blarsgelblich, bezcichnet mit einem Schulterfleck und in der Mitte einer kaum merklich schräg nach innen sich neigenden, etwas gebogenen Linie von schwarzer Farbe. Dic untere Seite des Körpers ist, wie die Beine blafsgelb. Die Schienen sind oben schwarz gerandet, die lintersten etwas gelrümmt, die Hinterschenkel oben verdickt.

\section{Megalopus frontalis.}

Tab. V. Fig. 7 .

Megalopus depressus rufus, capitis macula transversa, elytrorum fascia postica, pedumque posticorum tibiis tarsisque nigris. Long. lin. $4 \frac{x}{2}$.

Patria: Cametà Brasiliac. Misit Sieber. Ex Museo Comit. de H offmannsegg.

Statura praecedentis. Caput occipite verticeque punctatis rufum fascia inter oculos latissima nigra: Antennae compressae nigrae. Mandibulae apice nigrac. Oculi prominuli fusci. Thorax planus postice utrinque subimpressus vago punctatus inmaculatus rufus. Pectus abdomenque rufa. Segmenta ventralia apice dilutiora. Anus rufescenti-pilosus. Scutellum 
rufum. Elytra marginata, punctata, rufa, ante apicem nigra. Pedes rufi, tibiis tarsisque posticis nigris. Femora parum incrassata. Tibiae incurvatae.

Von Cametà in Brasilien. $4 \frac{x}{2}$ Linien lang. Flach, wie die vorhergehende Art. Braunroth. Hinterkopf und Scheitel punktirt. Zwischen den "Augen eine breite schwarze Binde. Fühler zusammengedrückt, scliwarz. Frefszangen mit schwarzen Spitzen. Augen etwas hervorstehend blafsbraun. Bruststück hinterwärts an den Seiten ein wenig eingedrückt, überall schwach und einzeln punktirt, gleich Brust und Rückenschildchen einfarbig und ungefleckt. Die $\mathrm{Ab}$ schnitte des Hinterleibes roth, an der Spitze blars. After röthlich behaart. Deckschilde gerandet, punktirt." Vor der Spitze eine breite schwarze Binde. Beine roth. Schienen und Fufsglieder der hintersten Beine schwarz. Hinterschenkel nur wenig verdickt.

\section{Megalopus bicolor.}

Tab. V. Fig. 8 .

Megalopus depressus, rufus, capite nigro-maculato, elytris dimidiato-nigris. Long. lin. $4 \frac{5}{2}$.

II a b it at in Brasilia. Misit Dr. de OIfers.

Megalopo frontali proximus. Rufus, nitidus. Vertex utrinque punctatus, fascia inter oculos nim̧ari. Mandibulae apice nigrae. Antennae compressae nigrae. Oculi fusci. Thorax antice posticeque utrinque productus, postice subimpressus, dorso vage punctatus, immaculatus. Pectus abdomenque testacea. Scutcllum rufum. Elytra marginata impresso-punctata, nigra, basi rufa. Pedes ruf, posticorum femora subincrassata, tibiae incurvae apice nigrae, tarsi nigri, unģuli ferruğinci. 
Vaterland: Brasilien. Länge: $4 \frac{T}{2}$ Linien. Flach gedrückt, rolh, glänzend. An Kopf zwischen den Augen eine breite schwarze Binde. Frefszangen mit schwarzen Spitzen. Fühler zusammengedrückt, schwarz. Angen schwärzlich. Die Winkel des Rülkkenschildes vorgezogen, der Rücken punktirt. Brust und Hinterleib blafs gelbröthlich. Rückenschildchen roth. Deckschilde nit aufgeworfenem Seitenrande, deutlich punlitirt, die vordere Hälfte roth, die hintere schwarz. Beine roth. An den hintersten die Schenkel etwas verdickt, die Schienen an der Spitze, die Fufgoglieder gänzlich schwarz, die Klauen braun.

\section{Megalopus dimidiatus.}

Tab. V. Fig. 9.

Megalopus depressus rufus, capitc toto, elytrorum parte postica pedumque posticorum tibiis tarsisque nigris. Long. lin. 4.

Patria: Bahia in Brasilia. Misit Sello.

Affinis praecedentibus. Vertex utrinque punctatus. Antennae compressae breves. Palpi ferruginei. Oculi prominentes testacei. Thorax antice utrinque productus postice impressus, planus, glaberrimus rufas. Pectus scutellumque rufa. Abdomen pallidum. Elytra punctata, nitida, nigra, basi rufa. Pedes rufi, tibiis tarsisque posticis nigris. Femora postica parum incrassata.

Von Bahia in Brasilien. Vier Linien lang. Flach. Kopf einfarbior schwarz, glänzend. Scheitel an den Seiten punltirt. Fülıler zusammengedrückt, von geringer Länge. Frefsspitzen braunrotb. Augen hervorstehend, blafsbrüumlich. Rückenschild am vordern Rande zu jeder Seite etwas vorgezogen, hinter- 
wärts an den Seiten eingedrückt, flach und glatt, sammt Brust und Rückenschildchen einfarbig braunroth. Hinterleibssegmente blafs. Deckschilde punktirt, gelb-roth, die gröfsere hintere Hälfte schwarz. Beine roth. An den hintersten die Schenkel wenig verdickt, Schienen und Fufsglieder schwarz.

\section{Megalopus abdominalis.}

Tab. VI. Fig. x.

Megalopus depressus, niger, elytris abdomineque rufis. Long. lin. $4 \frac{\pi}{2}$.

Habitat in Brasilia. Misit Dr. de Olfers.

Caput aterrimum, nitidum. Vertex utrinque punctatus. Antennae apice compressae. Labrum fusco-marginatum. Thorax marginibus tam antico quam postico utrinque productis, postice subimpressus, totus aterrimus. Pectus scutellumque nigra. Abdomen rufum. Elytra punctata, rufa, basi inter scutellum angulumque externum nigra. Pedes unicolores nigri. Femora postica vix incrassata.

Aus Brasilien. Länge $4 \frac{x}{2}$ Linien. Kürper sehr flach, Hinterleib und Deckschilde ausgenommen, schwarz. Der Scheitel an den Seiten punktirt. Die Fühler an der Spitze zusammengedrückt. Die Winkel des Rückenschildes vorgezogen. Deckschilde punktirt, an der Wurzel zwischen den Schulterwinkel und dem Schildchen schwarz. Hinterschenkel kaum verdickt.

27. Megalopus bipunctatus.

Tab. VI. Fig. 2.

Megalopus rufus, thorace punctis duobus, elytris puncto nigris. Long. lin. 5.

Habitat in Brasilia. Misit Dr. de Olfers. 


\section{- 79}

Caput vage punctatum, rufum, clypeo, labro pal. pisque testaceis. Vertex macula media fusca. Mandibulae apice nigrae. Antennae compressae nigrae articulis duobus prioribus subtus rufis. Oculi fusci. Thorax subquadratus antice angustior, utrinque productus, dorso punctatus, niedio nigro-bipunctatus, subtus utrinque nigro maculatus. Pectus nigrum. Abdomen rufum. Anus fulvo-subpilosus. Scutellum punctalum rufum. Elytra punctata rufa, medio puncto nigro notata. Pelles nigri, femoribus anticis, tibiisque omnibus subtus rufis. Plantae fulvac. Femora postica incrassata.

Aus Brasilien. Fünf Linien lang. Kopf roth, einzeln punktirt, Schildchen, Lefze und Frefsspitzen hell röthlichgelb. Auf dem Scheitel ein dunkler Fleck. Die Frefszangen mit schwarzen Spitzen. Fühler zusammengedrückt schwarz, die beiden ersten Glicder unten roth. Augen blafsbraun. Rückenschild vorn etwas enger, an den Seiten vorgezogen oben punktirt mit zwei neben einander stehenden schwarzen Punkten, aufsen an den Seiten mit einem schwarzen Fleck. Brust schwarz. Hinterleib roth. $\Lambda$ fter gelbröthlich behaart. Rückenschildchen punktirt, roth. Deckschilde stark punktirt, schön roth, in der Mitte eines jeden ein schwarzer Punlt. Beine schwarz, die untere Seite der Schienen und der vordersten Schenkel roth; die Sohlen gelbroth. Die hintersten Schenkel verdickt.

\section{Megalopus curvipes.}

\section{Tab. VI. Fig. 3.}

Megalopus subferrugineus, fronte, thoracis macula, elytris, basi excepta, tibiisque posticis nigris. Long. lin. $4 \frac{\pi}{4}$. 
Clythra curvipes Fabr. Syst. Eleuth. II. p. 2g. n. 4. Schönlerr Synonymia Ins. I. 2. p. 344. n. 4 .

Ha bitat in America meridionali. Descr. secundum specimen Mus. Regii Havniensis.

Corpus depressum, ferrugineum, nitidum, nigromaculatum. Caput punctatum, clypeo labroque flavescentibus, mandibulis porrectis flavescentibus apice nigris. Frons inter antennas nigra. Occiput rufoferrugineum. Antennae compressae vix thorace longiores nigrae. Thorax dorso planus, punctatus, ferrogineus, medio fuscus. Scutellum ferrugineum. Elytra plana distincte impresso-punctata marginata nigra, basi ferruginea, humeris tamen obscurioribus subfuscis. Pectus abdomenque flavo - ferruginea. Pedes flavo ferruginei, posticorum femora subincrassata, tibiae incurvatae cum tarsis nigrae.

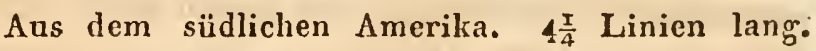
Flach, hellbrann, der Kopf vorn hell, fast gelb, hinten dunkel rothbraun, zwischen den Augen schwarz, die Frefszangen rothgelb mit schwarzen Spitzen. Die Fühler, kaum länger als das Rückenschild, flach gedrückt, nach der Spitze etwas verdickt, schwach gesägt und schwarz. Das Rückenschild flach, schwach punktirt, glänzend rothbrann, mit einem nicht deutlich begränzten dunkleren, beinah schwarzen Mittelfleck. Das Schildchen gefärbt wie der übrige Körper. Die Deckschilde stärker punktirt, sind fast bis zur Wurzel hin schwarz. Braunroth gefärbt sind der Theil zunächst am Rückenschild besonders aber die Gegend am Rückenschildchen und die Schultern. Brust und Bauch sind gelbbraun. Eben so gefärbt sind auch die Beine mit Ausnahme der hintersten Schienen und Fufsglieder, wclche schwarz sind. Die hintersten Schenkel 
sind kaum verdickt, die Schienen aber deutlich gekrümmt.

89. Megalopus tibialis.

Tab. VI. Fig. 4.

Meg. flavo-ferrugineus, fronte, thoracis dorso, elytrorum macula humerali fasciaque nigris, Long. lin. $4 \frac{3}{4}$.

Clythra tibialis Fabr. Syst. Eleuth. II. p. 29. n. 5. Schönherr Syn. Ins. I. 2. p. 344. n. 5.

II a bitat in America meridionali. Fabr. 1. c. De. scr. sec. specimen Mus. D. de Sehestedt nunc Regii Havniensis.

Statura praecedentis. Caput punctulatum ferrugineum, clypeo labroque flavescentibus, fronte inter oculos maculaque parva occipitali triangulari nigris: Mandibulae purrectae nigrae, basi flavescentes. Antennae vix thorace longiures, compressae, nigrae. Thorax sparsim punctulatus flavo-ferruginens, s. rufo-testaceus dorso niger. Scutellum rufu-testaceum medio nigrum. Elytra punctata testacea, nacula magna humerali fas. cia ante apicem margineque nigris. Pectus abdomenque flavescentia. Pedes rufo-testacei tibiis dorso tarsisque nigris. Femora postica subincrassata. Tibiae incurvatae.

Aus Südamerika. $4 \frac{3}{4}$ Linien lang. Gestalt der vorhin beschriebenen Art. Die Farlse hell gelblichbraun. Die Stirn und ein dreieckiger Fleck am Hinterhaupt schwarz. Die Mandibeln an der Spitze schwarz, an der Wurzel gelblich. Die Fühler zesammengedrückt, kaum länger als das Rückenschild, von schwarzer Färbung, dieses mit cinem grofsen, beinah viereckigen schwarzen Mittelfleck. Das Schildchen schwarz mit bräunlichem Rande. Die Deckschilde stark punktirt. Ein grofser Schulterfleck, eine breite Binde vor der 
Spitze, so wie der Rand schwarz. Brust und Bauch heller gefärbt. Dic Schienen gekrümmt, oberhalb schwarz. Die Fufsglieder schwarz. Die Hinterschenkel etwas verdickt.

\section{Megalopus curvatus.}

Tab. VI. Fig. 5.

Megalopus flavo-ferruginens, fronte, thoracis macula, elytrorum humeris, fascia apiceque nigris. Long. lin. $3 \frac{3}{4}$.

Clythra curvata F a br. Syst. Eleuth. II. p. 29. n. 3. Schönher Syn. Ins.' 1. 2. p. 544. n. 3.

$\mathrm{II}$ a bit at in America meridionali. Fabr. l. c. Descr. secundum specimen Musei Regii Havn., olim Mus. Lund et de Sehestedt.

Statura praecedentium. Caput ferrugineum, macnla parva occipitali fasciaque inter oculos nigris, clypeo labroque flavescentibus. Mandibulae apice-nigrac. Antennae vix thorace longiores subsersatae nigrae, articulo primo ferrugineo. Thorax punctulatus ferrugineus, macula magna media baseos nigra. Scutellum laeve ferrugineum. Elytra punctata flavescentia apice maculaque humerali cum fascia media transversa ante marginem exteriorem parum angustiorc cohaerente nigris. Pectus abdomenque flavo - ferruginea. Pedes ferruginei, tibiis anterioribus extus, posticis totis tarsisque nigris. Femora postica parum incrassata.

Aus Südamerika. Lünge $3 \frac{1}{4}$ Linien. Gestalt der vorhergehenden Arten. Farbe blafs gelblichbraun. Am Hinterkopf ein kleiner Flecls, zwischen den Augen eine Stirnbinde von schwarzer Farbe. Mandibeh gelblich mit schwarzen Spitzen. Fühler kaum länger als das Rückenschild, zusammengedrückt, elwas gesiiggt, 
schwarz, das erste Glied braun, das Rückenschild schwach punktirt, braun, mit einem schwarzen Mittelfleck an der Basis. Schildchen einfarbig braun. Deckschilde deutlich punktirt, heller gefärbt, mit schwarzen Spitzen. Ein Schulterfleck, zusammenhängend mit einer vor dem Aufsenrande verschmälerten, an der Nath breiteren, durch die Mitte" der Deckschilde hinlaufenden Qucerbinde, sind gleichfalls von schwarzer Farbe. Brust und Bauch sind einfarbig blafs gelblichbraun, die Beine braun, die vordern Schienen an der äufsern Seite, die hintern, so wie, sämmtliche Fufsglieder, durchaus schwarz; die Hinterschenkel etwas verdickt.

\section{Megalopus obliquus.}

Tab. VI. Fig. 6 .

Mezalopus flavescens, fronte macula media; thorace maculis quatuor, elytris fasciis tribus apiceque fuscis: Long. lin. 4.

Clythra obliqua F a br. Syst. Eleuth. II. p. 29. n. 6. Schönherr Syn. Ins. I. 2. p. 344. n. 6.

Habitat in America meridionali. Fabr. 1. c: Descriptio sec. Specimen Mus. de Sehestedt nunc Regii Havn.

Statura fere praecedentium. Color fere flavus. Caput macula media frontali fusca. Labrum pallidum, basi fuscum. Mandibulae pallidae apice nigrae. Antennae thorace longiores subserratae brunneae, dorso fuscae, articulis quatuor prioribus flavis dorso ferrugineis. Thorax punctulatus nigro-quadri-maculatus. Scutellum ferrugineum medio fuscum. Elytra punctata, nigro-marginata, macula humerali fasciaque obliqua baseos contiguis, fascia obliqua pone medium, macula transversa ante apicem apicerque fuscis. Pectus abdo- 
menque flavescentia. Pedes flavescentes, tibiis tarsisque dorso ferrugineis. Femora postica parum incrassata.

Aus Südamerika. Vier Linien lang. In der Gestalt übereinstimmend mit den vorhergehenden Arten. Farbe bräunlicligelb. Auf der Stirn ein dunkler Mittelfleck. Die Lefze blafsgelb am Grunde schwärzlich. Die Frefszangen blafs mit schwarzen Spitzen. Die Fühler lïnger als das Rückenschild, gedrückt, etwas gesägt, sind blafsbraun, nach oben dunkler. Die vier ersten Glieder sind auf der unteren Scite gelb. Auf den Rüclienschild finden sich neben einander vier runde braunschwarze Flecken. Das Schildchen ist braun, in der Mitte dunkler. Die Deckschilde sind punktirt, schwarz gerandet, mit vier braunschwar. zen Binden; die erste, verbunden mit einem Schulterfleck, steigt von diesem nach innen aufwärts und endigt am vordern Rande diclit vor dem Rückenschildchen; die zweite, etwas über der Mitte, hat dieselbe schräge Richtung; die dritte, unterhalb der Mitte, gleicht einem grofsen Fleck; die vierte nimmt die äufserste Spitze der Deckschilde ein. Brust und Bauch sind blafsgelblich, die Beine gelblich, Schienen und Fufsglieder am Aufsenrande braun. Die Schienen sind gekrümmt, die hintersten Schenkel etwas verdickt. 


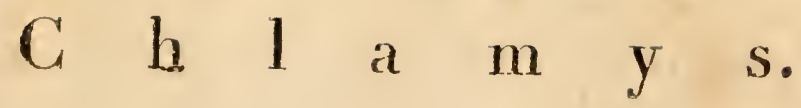



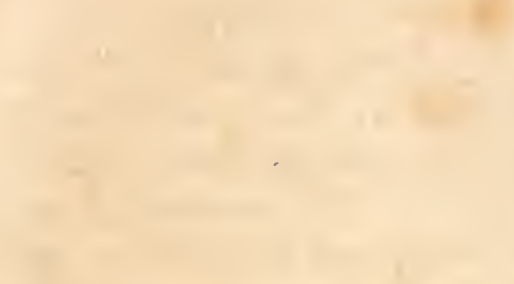


\section{C h 1 a m y s.}

Chlamys Knoch (n. Beytr. zur Insektenkunde). Lat reille (Genera Crust. et Insect. JII. Consideraions génér. clc. Regne animal). Illigger (Magazin für Inseltenk.). Olivier (Entomologie. Nouveau dict, d'hist. natur.) Schönherr (Syno. rymia Insect.). Dumeril (Dict. des Sciences natur.). Clythra Fabr. (Syst. Elcuth. Entom. syst. suppl.). Coqueloert (illustrat. iconogr.). Olivier (Encyclopédie). Bruchus Fabr. (Syst. Eleuth. Ent. syst, einend.). Olivier (Encyclupedic).

Fine ausfihhrliche Beschreibung der Gattung finden vir in den oben angeführleu neuen Beitrïgén des selir unterrichteten und genauen Beobachters, welcher zuerst die Gattung aufgrestellt hat. Zưr Ergänzung dient, was Latreille hinsichtlich der Fühler und der sie verbergenden Brustfurche (Gen. Crust. a. a. O.) gesagt hat. Zu erinnern ist noch, dafs die Palpi labiales nicht eigentlich furcati heifsen künnen und selbst die grörsten Arten dentlich sichthar nur cincn !'uecreindruck oder einen, jedoch nicht ticfen Queereinschnitt im letzlen Gliede der Taster haben. Die Mundthcile fand ich bei sehr viclen, die ich untersuchte, wie nachfolgende kurze Beschreibung sif angुivb:

Labrum quadralum, integrum. 
Mandibula e breves, crassae, intus concavae, apice oblique truncatae, emarginatae, bidentatae.

Maxillae apice membranaceae, compressae elongatae, ciliatae.

Lab rum brevissimum integrum.

Palpi breves

maxillares quadriarculati, articulo primo minimo, secundo tertioque cylindricis, quarto latiori subcompresso;

labiales breviores, triarticulati, articulo primo brevissimo, secundo cylindrico, tertio ovato.

Der innere Rand der Deckschilde ist gewöhnlich, doch nicht überall, fein gezahnt. Die Zahl der beschriebenen Arten ist durch die nachfolgende Zusammenstellung ansehnlich vermehrt worden. Chlanys impressa und cristata erhielt ich zur Ansicht aus dem Königl. dänischen Museum in Copenhagen, der ehemaligen Lund-Sehesiedtschen Sammlung. Die hiesige Sammlung verwahrt von Chlamys nicht weniger als 60 Arten von welchen 55 aus Brasilien, bei weitem die mehresten durch Herrn Legationsrath Dr. v. OIf ers und den fleifsigen Sello gesammelt, die andern aus Nordamerika sind.

Aulserdem zeichnet sich eine nerkwürdige Art, deren Vaterland nicht genau angegeben ist, und welche Sieber nach seiner Rückkehr von Brasilien in London für den Graf von $\mathbf{H}$ offmanusegg eingetauscht hat, durch verdickte Hinterschenlsel und selir lange Fühler, welche selbsl die Körperlänge übertreffen, aus. Dic Fühlerglieder sind lang, cylindrisch, und das letzte kürzer und an der Spitze etwas verdickt. Das drilte, vierte, fünftc und sechate Glied sind auf der untern Seite mil sehr feinca, etwab ge- 
krümmten Härchen dicht besetzt: $\mathrm{Ob}$ sie, wie bei Chlamys in eine Brustfurche sich einfügen, liefs sich bei dem ausgebreiteten Stück nicht melir deutlich erkennen. Graf v. Hoffmannsegg hatte dieses Insect mit dem Namen Caloscirtes testaceus vorläufio bezeichnet, mithin als eigene neue Gattung betrachtet. Ich habe aufser der schon angcgebenen Beschaffenheit der Fühler und Hinterschenkel keine unterscheidenden Nierkmale von Chlamys auffinden können, und bei der in Uebrigen der Körperbildung so auffallenden Annäherung an Chlamys sie um so weniger davon trennen mögen, als sicher auch das Vorkommen einer einzelnen springenden Galleruca die Trennung derselben und Gründung der Gattung Haltica nicht veranlafst haben würde. Abgesondert von den übrigen habe ich sie am Ende als Chlamys braccata beschrieben.

\section{Chlamys monstrosa.}

Chlamys cyanea, thorace medio elevato gibboso, gibbere plano cicatricoso, quadri-dentato, elytris punctatis plicato-rugosis, basi tuberculatis. Long. lin. $5-6$.

Clythra monstrosa rabr. entom: syst. suppl. p. x11. n. 9. Syst. Eleuth. II. 1. 33. n. 19.

Chlamy's monstrosa Olivier Fntomol. VI. 96. p. 875. n. 1. Pl. I. Fig. 1. Schünherr syn. Ins. I. 2. p. 343. n. 3.

If a bitat in Brasilia (Cayennac. Ol. Fabr. 1. c.). Naxima, subquadrata, cyanea. Caput punctatum, inter oculos planum, subtilissime striatum punctis duobus in froute impressis. Antennae scrratae, thorace breviures fuscae, basi cyaneac. Oculi fusci, sub- 
tilissime reticulati. I abrum ferrugineum. Mandibulae nigrae. Palpi nigri, articulo ultimo apice ferrugineo. Thorax subtilissime striolatus medio in tuberculum holosericeum, subquadratrm, punctis sulculisque impressis confluentibus scabrum, utrinque, antice obtusins postice acutius spinosum elevatus, postice productus, sinuatus, sinu angustissimo. Pectus abdomenque punctata cyanca unicoloria medio pilis brevibus incumbentíbus argenteis micantia. Scutellum transversum, immersum, subquadralum, laeve, basi tuberculatum, tuberculo parvo lineari thoracis sinum occupante. Elytra lineis elevatis abbrevialis longitudinalibus et transversis arcuatis concatenatis foveulisque impressis inaequalia; basi tuberculata, tuberculo medio elevatiori, distinctiori; margine interno apice serraio. Pedes cyanei, plantis fuscis.

Aus Brasiiien. Von bcinah viereckiger Gestalt. Thie grröfste der bekannten Arten ( 5 bis 6 Linien lang). Ueberall lebhaft dunkelblau, zuweilen grünlichblau. Kopf punktirt, zwischen den Augen etwas vertiefl, sehr fein gestrichelt. An der Stirn zwei cingedrückte Punlkte. Die Lefze braun, die Frefszangen schwarz, die Frefsspilzen schwarz, mit braunem Endpunkt, die Fühler gesügt, liürzer als das Rückenschild, die exsteu Glieder blau, die übrigen dunkelbraun, fast schwarz. Die Angen dunkel sehr fein gegitterl. Das Riickenschild aufs feinste gestrichelt. In der Mitte cin fast vierecliiger, sammetartiog erscheinender starIner IIöcker, uncben durch eine Menge punkt - und linionförminger in einauder laufender Vertiefungen, an den Seiten sowohl hinten als vorn zugespitzt, die vordere Spitze stumpfor und breiter, die hintere schärfes nul deutlicher. Nach hinten rart das Risk- 
kenschild hervor, ist jetoch in der Mitte mit ciner in Verhältuifs sehr schmalen Vertiefung versehen. Brust und Ilinterleib tragen vertiefte Punkte. Die Mitte des Brustheils und der Rand der Aftergrube sind nit dicht anliegenden silberfarbenen Härchen besetzi. Das Rückenschildchen ist queer gezogen, fast viereckig, etwas tief liegend, glatt. In die Bucht am hintern Rande des Rückenschildes tritt cine kleine linienförmige Erhabenheit. Dic Deckschilde sind selır uneben, besonders durch netzförmig sich verbindende sowuhl nach der Länge als Breite der Deckschilde scharf erhabene abgebrochene Linien. Zwischen ihnen liegen Vertiefungen und einzelne cingedrückte Punkte. Au der Basis finden sich Hücker, zwoi von geringer Bedeutung zu jeder Seite, einer in der Mitte, der höher und schärfer zugespitzt ist. Die Nath ist nach der Spitze hin deutlich gelierbt. Die Beine sind wie der Körper gefärbt, dio Sohlen mit braungrauem Filz bedeckt.

\section{Chlamys violacer.}

Chlamys violacea, thorace elytrisque punctatis tuberculatis. Long. lin. $5_{2}^{\frac{x}{2}}-4$.

II abitat in Parà Brasiliae. Misit Sicber. Ex Museo Comit. de Hoffman ${ }^{1} \mathrm{seg} g$.

Affinis Chlam. moistrosae. Caput inter oculos planum, cyancum, Labrum ferrugineum. MandibuJae nigrac. Antennae thorace breviores, serratae, rufae, articulo primo dorso cyanco. Oculi fusci. Thiorax cyancus, lateribus viridi-cyaneis, nitidissinus, medio in tuberem dorso planum striolatum, utrinque foveolatum et trituberculatum clevatus, postice productus, angustissime sinuatus. Pectus abdomenque 
punctata, cyanca aut viridi-cyanea, sterno et fossa anali pilis brevissimis adjacentibus argenteis micantibus. Scutellum transversum subquadratum immersum laeve, basi lineola media elevata, abbreviata. Elytra cyanea, lateribus violacea, sparsim punctata, tuberculata, tuberculis inaequalibus conicis acutis, singulis, majori ad basin intermedio, reliquis brevioribus, carinatis, et lineolis elevatis invicem junctis. Margo elytrorum internus ad apicem crenatus. Pedes cyanei, plantis tomento fuscescenti sericeo tectis.

Von Parà in Brasilien. Kleiner als die vorhergehende Art (Länge $3 \frac{x}{2}$ bis 4 Linien). Leblaft blau mit bald grün-bald violet-blauem Schiller. Die Stirn flach, die Lefze braunroth, die Fref'szangen schwarz. Die Augen erscheinen blafsbraun. Die Fühler sind kürzer als das Rückenschild, ģesägt, braunroth, das VVurzelglied auf der oberen Seite blau. Das Izïckenschild an den Seiten sehr glänzend erhebt sich in einen metallglänzenden, in der Mittc grestrichelten, an den Seiten in drei stumpfe Spitzen auslaufenden, dazwischen mit cinģedrückten Grübchen bezeichneten Hücker. Hinten ist das Rückenschild zwischen die Deckschilde lserein vorgezoger, mit einer sehmalen Bucht zur Aufnahme der linienförmigen Trhabenlseit des Rüclicnschildchen. Brust und Hinterleib haben eingedrüickte Punkto und in der Milte einen leichten schillernden Ueberzuor kurzer silberglïnzender Märchen. Die Deckschilde sind eingeh punktirt und mit kegelfürmigen Erhabenheiten von ungleicher Gröfse besetyt. Grölser ist die mittlere an dem Grundheil der Dechschilde. Dic anderu sind kleiner, an der vordern Scite lcicht ausgehölt, oft zusammenhänrend und vormemlich von dor Mitle 


\section{- 93 -}

an durch linienförmige Erhabenheiten verbunden. Die Nath ist deutlich gekerbt. Die Beine haben die Farbe des Körpers. Die Sohlen tragen einen Haarfil $z$ von hell graubrïunlicher Farbe.

\section{Chlamys bacca.}

Chlanys atra, thorace striato quadri-tuberculato elytrisque punctatis tuberculatis cupreo-auratis, femoribus cupreo-purpureis. Long. lin. 4.

Chlamys bacca Kirby transact. of the Linnean Society. Vol. XII. p. 446. n. 95 .

H abitat in Brasilia. Misit Dr, de Olfers.

Statura praecedentium. Caput planum, fronte immersa striolata, clypeo punctato. Labrum ferrugineum. Mandibulae nigrae. Antennae thorace breviores, subserratae ferrugineae articulo primo supra cupreo. Oculi fusci. Thorax dorso elevatus, gibbere subquadrato medio exarato striolato utrinque sub-trituberculato, postice nigricans, medio productus angustissime sinuatus. Pectus et abdomen punctata atra pilis incumbentibus argenteis submicantia. Scutellum subquadratum, subemarginatum, utrinque marginatum, marginibus lincolaque elevata abbreviata baseos nigris. Elytra tuberculata, inter tubercula punctata, tuberculis in singulo elytro duodecim inaequalibus, aut conicis aculis, aut subacutis antico concavis et concatenatis. Margo elytrorum internus apice crenatus. Pedes purpurei, femoribus subtus cupreo - purpureis.

Ans Brasilien. Vier Linien lang und wie die vorhergehende Art gestaltet. Oben durchaus die bronnendste Kupferfarbe, unten schwarz, ins purpurfaibene sich neigend. Der Kopf flach, die Stirn einge- 


\section{$-94-$}

drückt, gestrichelt, das Schildchen punktirt. Die Lefze rothbraun, die Frefszangen schwarz. Die Fühler kürzer als das Rückenschild und etwas gesägt, sind von braunrother Farbe. Nur das erste Glied ist oben liupfrig. Die Augen sind schwärzlich. Das Rückenschild von dunklem Feuerglanź, erhebt sich in einem breiten Buckel, dessen fein gestrichelte mittlere Verticfung an den Seiten durch einen dreispitzigen Höclier begränzt ist. Hinten ist das Rükkensclild schwärzlich, vorgezogen, schmal und nicht sehr tief ausgerandet. Brust und Hinterleib sind voll eingedrückter Punlste, die zum Theil kurze sil. berglänzende Härchen tragen. Das Rückenschildchen ist beinah viereckig, linten schwach ausgerandet, an den Seiten mit erhabenem schwärzlichem Rande. Von dem Grunde reicht bis zur Hälfte eine linien förmige ebenfalls dunkiere Erhabenheit. Die Deckschilde sind einzeln und tief punistirt, sehr höclrig, die Erhabenheiten kegelförmig, zugespitzt, die mehresten an der vurderen Seite ausgeliölt, unter einander durch auslaufende erhabene Linien verbunden.' Der innere Rand ist auch hier nach der Spitze hin deutlich gezahnt. Die Beine haben die Farbe des Hinterleibes und nur die Schenkel zeigen auf der untern Fläche einen dunkel kupferrothen Feuerglanz.

\section{Chlannys cuprea.}

Chlanys subtus violacea, dorso cuprea, thorace elytrisque tuberculatis. Long. lin. $4-5$.

Habitat in Brasilia. Misil Dr. de Olfers.

Praecedenti similis. Obscure cuprea, pectore ventreque purpurascentibus. Caprt antice excavatum, subtilissime striolatum, clypeo púnctato, emar- 


\section{$-\quad 95$}

ginato nigro - marginato. Labrum ferrugineum. Mandibulae nigrae. Antennae thorace breviores, subserratae rufae, articulo primo punctato cupreo, secundo tertiocue dorso macula nigricanti notatis, rarius immaculatis. Oculi fusci. Thorax medio gibbus, gibbere utrinque trituberculato, punctato, medio exarato laevi, postice productus, emarginatus. Pectus abdomenque punctata caprea, nonnullis purpurascentia, aliis coerulescentia. Scutellum snbquadratum impressum lacve utrinque elevatum, antice productum subcarinatum. Elytra subtilissime striolata, sparsim impresso - punctata, tuberculatit, tuberculis conicis acutis in quovis elytro sodecim aliis singulis altioribus, aliis basi exarata dilatata junctis. Margo internus nigricans ad apicem crenatus. Pedes obscure cuprei, punctati, plantis tomentosis, fuscescentibus.

Aus Brasilien. Vier bis fünf Linien lang. Sehr ähnlich der vorher beschriebenen Art, von dunkler Kupferröthe, an der untern Seite ins Purpurfarbene, bei einigen ins Blaue sich neigend. Der Kopf etwas ausgehölt und fein gestrichelt, hat ein schwach ansgerandetes, schwarz begränztes Schildchen, eine braunrothe Lefze, schwarze Treiszangen und Fühler, die kürzer als das Riückenschild, gesägt und rothgefärbt, deren erstes Glied punktirt und kupferfarben, das zweite und dritte gewöhnlich oben schwarz gefleckt sind. Die Augen erscheinen dunkel, Das. Rï̈kkenschild erhebt sich in einen Höcker, der punktirt, zu jeder Seite mit drei Spilzen versehen, in der Mitte der Länge nach gefurcht ist. Nach hinten ist das Schild vorgezogen und ausgeschnitten. Das Schildchen ziemlich viereckig, liegt ticf, ist glatl, mit auf- 


\section{- 96}

geworfenem Seitenrande, nach vorn mit einer kleinen Erhöhung in den Einschnitt des Rückenschildes verlaufend. Die Deckschilde sind liöchst fein gestrichelt, dazwischen deutlich punktirt, stark höckrig, dị Erhabenheiten kegelförmig zugespitzt, einige einzeln stehend, andere von geringerer Höhe ausgelö̈hlt, an der Grundfläche verlaufend und gegenseitig verbunden. Der Innenrand ist dunkel gefärbt, aufgeworfen und nach der Spitze scharf gekerbt. Die Beine sind punktirt, dunkel kupferfarben, die Sohlen mit hell graubräunlichem Filz bedeckt.

\section{Chlamy's hispidula.}

Chlamys cuprea, thorace elytrisque panctatis tue berculatis. Long. lin. $2-2 \frac{\mathrm{T}}{3}$.

Patria: Montevideo Brasiliac. Misit Sello.

Similis proxime praecedentibus, minor tamen et tota pallide cuprea. Caput obsolete punctatum, labro luteo. Mandibulae nigrae. Antennae thorace breviores luteae articulo primo dorso nigro. Thorax dorso subtilissime striolatus, in gibberem medio exaratum, utrinque obtuse bituberculatum elevatus, lateribus vage punctatus unituberculatus, postice emarginatus. Pectus abdomenque punctato-reticulata. Scutellum subquadratum, substriatum apice dilatatum. Elytra subtilissime strivlata vage impresso-punctata, multituberculata, tuberculis conicis, acutis. Margo internus denticulatus. Pedes cuprei, ungुuibus nigris.

Von Montevideo, Zwwei bis $2 \frac{x}{3}$ Linien lang. Die auffallend gुeringerc Gröfse und hellere Färbung abgereshnet, den beiden vorhergehenden Arten sehr ähnlicls. Der Kopf dicht, doch äufserst flach und kaum merklich punktirt, mit rothgelber lefze und 


\section{- 97 -}

schwarzen Kinnbacken. Die Fühler, kürzer als das Rückenschild, sind rothgelb, nur das erste Glied ist oben schwarz. Der Rücken des Thorax ist sehr fein gestrichelt und in einen Höcker erhoben. Dieser hat in der Mitte eine seichte aber breite Rinne, seitwärts steigt er aufwärts in eine doppelt stumpfspitzige Erhöhung. Die Seiten des Rückenschildes sind weitläuftig punktirt. Auch sieht man hier noch einen breiten kurzen, schnell zugespitzten kleinen Hücker, und nach hinten ist das Rückenschild, wo es gegen das Schildchen vortritt und sich verlängert, ausgerandet. Brust und Bauch sind flach netzförmig punktirt. Das Rückenschildchen ist schwach aber dicht gestrichelt, fast viereckig, hinten breiter. Die Deckschilde sehr fein gestreift, und gleichzeitig einzeln punktirt erheben sich vielfach in Höcker, welche kegelförmig und zugespitzt sind. Die Nath ist deutlich gezahnt. Die Beine, wie der übrige Körper gefärbt, haben schwarze Klauenglieder.

\section{Chlamys muricata.}

Chlamys subtus lutea, nigro-maculata, supra nigro-acnea multispinosa. Long. lin. $2 \frac{T}{2}$.

Habitat in Brasilia. Misit Dr. de Olfers.

Brevis, subquadrata. Caput punctatum, luteum vertice nigro-aeneo, antennis apicc-mandibulisque nigris. Oculi fusci, cantho luteo. Thorax nigroaeneus, dorso gibbus, gibbere utrinque elevato, trituberculato, medio sulcato laevi, tuberculis conicis acutis, posterioribus majoribus. Pectus punctatum luteum. Abdomen luteum ntrinque nirro-punctatum. Scutellum nigro-aencum triangulare, basi tubercula lineari. Elytra nigro-acnea tuberculata, tuberculis 


\section{- 980}

in singulo elytro duodecim conicis acutis, inter tubercula punctata, punctis sparsis impressis, margine interno denticulata. Pedes lutei, femoribus tibiisque annulo medio punctisque baseos apicisque nig̣ris.

Aus Brasilien. In Hinsicht der Gestalt den vorhergehenden Arten verwandt, $2 \frac{x}{2}$ Linien lang, dunkel erzfarben, auf der untern Seite rothgelb. Der Kopf ist punktirt, die untere Hälfte rothgelb, die obere, oder die Gegend von der Mitte der Augen an dunkel erzfarben. Die Fühler sind nicht so lang als das Rückenschild, rothgelb, die letzten Glieder schwarz. Augen und Mandibeln sind schwarz, erstere im Ausschnitt gelb. Rückenschild, Sclildchen und Decken sind von dunkeler Erzfarbe, ersteres in der Mitte erhöhet, nacb hinten vorgezogen und ausgeschnitten. Wer Höcker zu jeder Seite dreispitzig, so dafs die vorderste Spitze die kleinste ist. Zwischen den Spitzen ist eine glatte Längsfurche. Brust und Hinterleib sind punktirt, rothgelb, letzterer an den Seiten dunkel oder schwärzlich geflcckt. Das Schildchen ist fast dreicckig mit einem Höckerchen in dem Einschnitt des Rückenschildes. Die Deckschilde sind sehr höckrigt, die Höcker kegelförmig hoch und zugespitzt, etwa zwölf auf jeder Decke und zwischen ihnen in geschlängelten Reihen eingedrüchte Punkte. Die INath ist deutlich gezahnt. Die Beine sind rothgells, Schenkel und Schienen haben in der Mitte ein'en schwarzen Ring und einen dergleichen Punlst an beiden Inden. 


\section{- 99 \\ 7. Chlamys arcula.}

Tab. VII. Fig. I.

Chlamys nigro - cuprea, thorace bituberculato, confertim punctato, elytris sparsim punctatis, carinato-tuberculatis, antennis tarsisque luteis. Long. lin。 $2 \frac{x}{3}-2 \frac{t}{2}$.

Chiamy's arcula Germ. Ins. Spec. I. p. 552, n. 750 .

Habitat in Brasilia. Mus. Germar.

Brevis, subquadrata. Caput adpressum fere absconditum vage punctatum, fronte impressa laevi, clypeo oculisque nigris. Labrum emarginatum, luteuri. Mandibulae nigrae. Os ferrugineum: Antennae vix thorace breviores, compressae, serratae luteae, apice obscuriores, articulo primo dorso nigro. Thorax basi lateribus sinuatus, inedio productus emarginatus confertius punctatus, dorso gibbosus, gíbbere sulco longitudinali diviso, lateribus bituljerculatus, tuberculis vix elevatis obtusis, baseos majori. Pectus abdomenque punctato-reticulata. Scutellum subtriangulare, laeve. Elytra obscuriora vage punctata, tulerculata, tuberculis compressis arcuatis acutecarinatis, obliquis, ad latera confinentibus apice et ad suturam solitariis cupreo-violaceís: Sutura crenata. Pełes violacei; tarsis luteis.

Vaterland: Brasilicn. Länge $2 \frac{3}{3}$ l, is $2 \frac{\dot{x}}{2}$ Linien. Fast viereckig; dunkel liupferfarben. Der Kopf angredrückt, deutlich einzeln punktirt, die Stinn grubenförmig vertieft und ohne Punlitë; Kopfschild und Augeni schwarz. Die Lefze und die innern Mundtheile robthlichgelb. Die Fühler zicmlich so lang als das Rüclicnsclild, zusammengedrückt, teutlich gesägt, rühlicherelb, an der spilze ilunliler, das erste filied 
oben selswarz. Der hintere Rand des Rückenschildes ist seitwärts tief cingebogen, in der Mitte hervorstehend and ausgerandet. Auf seiner Fläche dicht punktirt ist es in einen der Länge nach getheilten Hücker erhoben, an den Seiten befinden sich aufserdem noch zwei niedrige flache, doch deutlich wahrnelmbare Höcker, von welchen der hintere einen gröfseren Umfang hat. Brust und Bauch sind grob und flach punktirt wic genctzt. Das Rückenschildehen ist glatt und fast dreieckig. Die etwas dunkleren Deckschilde sind unebea durch abgebrochene, zum Theil, besonders in einiger Fntfernung von der Nath und den Spitzen unter einander verbundene, bogig verlaufende, scharflkantige auf den Kanten leblaft violet grlänzende Erhabenheiten, zwischen welchen einzelne eingestochene Punkte sichtbar sind. 'Die Nath ist deutlich, gezahnt. Die Fufsglieder sind röthlichgelb.

In Germar's Diaguose (a. a. O.) soll, wie bald aus der Beschreibung deutlich wird, in Beziehung auf die Fühler und Fufsglieder: rufis, statt: nigris stchen.

\section{Chlamys nodosa.}

Tab. VII. Fig. 2.

Chlamys tuberculata, aenea elytris pedibusque nigris, labro antennis tarsisque luteis. Long. lin. $2 \frac{3}{4}$.

Habitat in Brasilia. Misit Dr. de Olfers.

Statura praccedentium. Caput medio impressum, punctatum, aeneum occipite nigrum. Labrum cum palpis luteum. Mandibulae nigrae. Antennae breves serratae luteae. Oculi fusci. 'Thorax postice vix cmarginatus, lateribus punctatus, dorso gibbus; gibbere 


\section{$-101$}

violaceo-aeneo sulco longitudinali laevi diviso, utrinque in cornu obtusum;, emarginatum elevato. Pectus aeneum foveolatum et reticulatum. Venter punctalus aeneus segmento ultimo truncato, glaberrimo, nitidissimo. Scatellum nigro-aeneum, lasve. Elytrá nigra, violaceo - nitida, sparsim punctata, tuberculata, tuberculis conicis, in singulo elytro duodecim, intermedio baseos altiori, reliquis subacutis basi dilatata junctis. Margo internus distincte denticulatus. Pedes nigro-viclacei, tarsis luteis.

Aus Brasilien. Gestallet wie die vorhergehenden Arten und $2 \frac{3}{4}$ Linien lang. Der Kopf ist punktirt, erzfarben, in der Mitte der Stirn eingedrückt, am Hinterhaupt schwärzlich. Lefze und Frefsspitzen sind rothgelb. Eben so gefäbt sind die Fühler, dabei sehr kurz und etwas gesägt. Die Frefszangen sind schwarz. Das Rückensclild ist erafarben, an den Seiten cinzeln punktirt, linten etwas vorgezogen und ausgerandet, in der Mitte in einen doppelten violetbläulichen IIökker crhaben. Beide sind durch cine glatte Längsfurche getrennt, sic selbst hoch, stumpf-spitzir, uneben und wic ausgerandet. Brust und Finterleib sind erzfarlicn, erstere voll eingedrückter Punkto and wie genetzt, letzterer mit, wie gewönlich, abgestutztem, sehr glattem und glïnzendem Endglied. Das Schildchen ist glatt und tiefer liegend, von schwärzlich glänzender Erzfarbe. Die Deckschilde ğlänzend schwarz und ins Blaue spielend, haben selnr deutlich einzeh stehende eingedrückte l'unkte. Dabci sind sie voll Erhöhungen, etwa zwölf auf jeder Decke, deren mittlere der Grundfäche grö̈fser und höher, auch melr zugespilat, die übrigen nichriger und in ihrem Ursprunge durch auslaufende erhabenc Linien 
verbunden sind. Der lnnenrand ist deutlich gekerbt. Die Beine sind blauschwarz nuit , rothgelben Fursgliedern.

\section{Chlamys tarsata.}

- Tab. VII. Fig. 3 .

Chlamys-elytris rugosis, thorace bituberculato, nigra (vel cuprea) antennis tarsisque luteis, Longo. lin. $2 \frac{\pi}{2}$.

Ma bitat in Brasilia. Misit Dr, de Olfers.

Praecedenti simillima. Nigra, violaceo-nitida, rae rius cuprea. Caput adpressum subtilissime striolatum. Antennae thoracis fere longitudine luteae ad apicem fuscae. Luabrum luteum., Mandibulae nigrạe. Palpi ferruginei. Oculi fusci. Thorax nitidissịnus, sparsim punctatus, lateribus inaequalis, dorso elevatus bitu= berculatus, tuberculis laevibus obtusis, postice productus, emarginatus. Pectus abdomenque nigro-violacea impresso-punctąta. Scutellam laeve. Elytrạ tuberculato-rugosa, nitidissima, sparsim z punctata, margane interno denticulato. pedes nigro-violacei, țarsis lutcis.

Aus Brasilien. Sehr åhnlich der vorhergehenden Art, $2 \frac{\pi}{2}$ Linien lang, dunkel blauschwarz und gläne zend. Der Kopf ist flach sehr fein gestrichelt. Lefze, Frefsspitzen und Füller sind rothgelb, lelztere beiṇah so lạng als das Ruickenschild und an der Spitze schẉärylich, die Frefszangen schwar\%, die Augeu, dunkel, Das Rụickenschild ist an den Sciten stellenweis erlaben, punktirt, in der Mite höckricht, Höcker sind zwei, durch eine glatte Längsfurche gefrennt, stumplef-spitzirg und gliinzend. Das Schild-

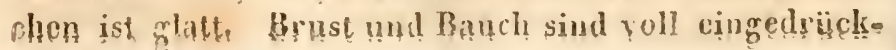




\section{$-105-$}

ter Punkte, dunkel violetschwarz. Dic Flügeldecken sind einzeln punktirt, ungleich durch in einander laufende crhabene Linien, dic sich zuın Theil in stumpfspitzige Höcker erheben. Nie Nath ist deutlich gezahnt. Dic Beine sind blauschwarz, dic Fufsglieder rothgelb. Unter den drei vorhaudenen Exemplaren ist eins mit kupferrothem Glanz.

\section{Chlamys obscura.}

Tab. VIl, Fig. 4.

Chlamys aenea, obscura, thorace biluberculato, elytris rugosis, basi tuberculatis. Long. lin, $2-2 \frac{x}{2}$.

II a il at in Brasilia. Misit Dr. de Olfers.

Statura praccedentium. Capat punctatum, labro obscure testaceo. Antennac breves ejusdem coloris. Mandibulac nigrae. Oculi fusci. Thorax punctatus, utrinque bipustulatus, dorso bituberculatus tuberculis apice truncatis, scabriusculis obtusis. Pectus abdomenque punctato reticulata, cupreo-aenea. Scutellum laeve, Elytra impressu-punctata reticulata et tuberculata, tuberculis disci minoribus vixque eleva. tis. NIargo internus denticulatus. Pedes cuprei.

Aus Brasilicn. Längge 2 bis $2 \frac{1}{2}$ I inien. Von dunkler Erzfarbe. Kopf punlitirt. Lefze und Püller dunkel rüthlichgelb. Rückenschild an den Seiten punlitirt, zweimal ein weuig erhuben, in der Mitte mit einem Doppelhücker. Beide Hucker sind dureh eine glatte, ziomlich breite Furche geschieden, dic Spitzen breil, abgestumpft umd durch hervorstehende Punkte rauh. Brust und Hinterleib haben melir Kupferglan\%, sind voll ziemlich grrofser, flach cingedrückter Punkte und erscheinen hicrdurch wie genetzt. Das Schildchen ist glatt, Dic Dechschilde 


\section{- 104 -}

punktirt mit abgebrochenen erhabenen Linien und Höckerchen besetzt, die wie gewöhnlich nach dem Rückenschilde zu, mehr hervorragen. Dic Nath ist fein gekerbt. Die Beine sind, wie der Bauch gefärbt.

\section{Chlamys rugosa.}

Tab. VII. Fig. 5 .

Chlamys elytris rugosis tubercalatis nigra, thorace dorso utrinque elevato trituberculato obscure aeneo. Long. lin. $2 \frac{x}{2}-2$.

Habit at in Brasilia. Misit Dr. de Olfers.

Praecedenti similis, 'statura tamen angustiore. Caput obscurum labro, antennis, palpisque ferrugineis. Thorax obscurus, aeneus, sparsim punctatus, lateribus pustulatus, dorso biclevatus, gibberibus trituberculatis, tnberculis aequalibus obtusis, postice emarginatus. Pectus abdomenque punctata, nigroviolacea. Scutellum immersum, laeve, nigro-aeneum. Elytra punctata, nigra, aeneo-nitida, lineis transversis elevatis tuberculisque subconicis, in elytro singulo circa decem, versus apicem majoribus, inaequalia. Sutura crenata. Pedes nigro-violacei tarsis ferrugineis.

Aus Brasilien. Länge von $1 \frac{x}{2}$ bis 2 Linien. Aehnlich der vorhergehenden Art, nur von etwas schmalerem Bau. Kopf dunkelschwarz, Lefze, Fühler und Frefsspitzen rothbraun. Das Rückenschild dunkel erzfarben, ist hin und wieder punktirt, an den Seiten in Beulen erhaben, in der Mitte mit einem Doppelhö̈cker versehen, der zu jeder Scite in drei stumpfe Spitzen sich endigt. Der hintere vorstehende Rand hat, wie gewöhnlich, in der Mitte cinen kleinen Einschnitt. Brust und Hinterleib sind punktirt, dunkel 
blauschwarz. Jas Riickenschildchen 'ist dunkel er\%farben. Die Deckschilde voll Queerlinien und kegelformig zugespitzten Erhabenheiten, von denen dic grö̈fsern sich hinterwärts befinden, sind hin und wieder punktirt, von Farbe dunkelschwarz, dic Nath gekerbt. Die Beine sind dunkelblauschwarz mit braunröthlichen Fufsgliedern.

\section{Chlamys chrysocephala.'}

Tab. VII. Fig. 6.

Chlamys thorace elytrisque tuberculato-reticulatis, atra, fronte lutea. Long. lin. 2.

Patria: Camctả Brasiliae. Misit D. Sieber. Is Museo Com. de Hoffmannsegg.

Statura praccedentis. Aterrima. Caput lutenm, vertice impresso nigro. Antennae breves luteac. Mandibulae nigrae. Oculi nigri. Thorax punctatus inacqualis, medio gibbus maltituberculatus. Pectus abdomenque punctata, punctis magnis leviter impressis, segmento ultimo postice lineato. Scutellum laeve, impressum. Elytra punctata, lincis elevatis reticulata, postice tuberculata, sutara crenata. Pedes rufi, tibiis omnibus, femoribusque posterioribus extus nigris. Tarsi lutei.

Von Cametà in Brasilien. Zwei Linien lang. Der Vorhergehenden ähnlich. Tiefschwarz. Der Kopf rothyelb, nur an Scheitel cin runder eingedrückter schwarzer Fleck. Die Fühler kurz, rothgelb. Augen und Mandibeln schwarz. Das Rückenschild durch kleine Erhabenheiten und Punkte ungleich, in der Intitte stark hüclserig, der Hücker mit viclen kegelförmigen Erhabenheiten besetzt. Brust und Unterleil sind voll flach cingedrücliter Punkte, 


\section{$-106$}

an dem letzten $\Lambda$ bschnitt Zeichnungen aus erhabenen Linien. Das Rïckenschildchen, tiefer liegend, ist glatt. Die Deckschilde sind punktirt, voll erlrabener Linien, die durch ein netzförmiges Gewebe verbunden sind, nach hinten mit kegelförmigen Erhöhungen besetzt. Die Nath ist auch hier gekerbt. Die Beine sind roth, nur die Aufsensciten an den Schienen und den hinteren Schenkeln schwarz.

\section{Chlamys anthracina.}

Tab. VII. Fig. 7 .

Chlamys thorace elytrisque lineis elevatis punctisque scabris, nigra capite ferrugineo-maculato. Long. lin. 2.

Patria: Parà Brásiliac. Misit Sieber, Ex Musco Comit. de H offmannsegg.

Statura clongata praecedentis. Nigra, nitida. Caput punctatum luteo - maculatum. Labrum luteum. Antennae breves luteae, apice nigrae. Thorax punctatus gibbosus, reticulatus et subtuberculatus, fuberculis linearibus longitudinalibus approximatis in medio binis. Pectus abdomenque punctata, punctis magnis leviter impressis. Scutellum parvum, laeve. Elytra punctata, lineis elevatis reticulatia, ad apicem subtuberculata sutura crenata, Pedes ferruginei, femoribus apice tibiisque obscurioribus. Nonnullis caput fere nigram, aliis nigrum, vertice utrinque macula fronteque ferrugineis.

Von Parà in Brasilien. Fast zwei Linien lang. Gestaltet wie die vorhergehende Art. Schwarz. Der Kopf pnuktirt, mehr oder weniger rothgefleckt, im ersien Fall ein Doppelfieck an Scheitel und eine Stirnmakel von rothgelber Farbe. Lefze und Fühler 
rothgelb, letztere sehr kurz, die Endglieder schwasz. Das Halsschild stark gewölbt, panktirt, mit netzfiirmig erhabenem Gewebe und in der Mitte einigen Höckern von geringerer Bedeutung, zwei dicht neb.en einander besonders deutlichen auf der Höhe des Hal.sschildes. Brust und Hinterleib erscheinen durch grofse, flach eingedrückte Punkte wie genetzt. Dias nückenschildchen ist klein. Wie Deckschilde sind punktirt, mit erhabenen Linien durchzogen, die sich am hinteren Ende in mäfsige Höcker erheben. Die Nath ist gekerbt. Die Beine sind gelbbraun, die Schienen und Spitzeu der Schenkel dunkler.

\section{Chlamys cruciata.}

Tab. VII. Fig. 8.

Chlamys thorace elytrisque lineis elevatis punctisque scabris nigro - brunnea, fronte thoracisque antico ic - rugineo-maculatis. Long. lin. $\mathbf{x}_{\frac{\mathrm{x}}{2}}$.

Patria: Parà in Brasilia. Misit D. Sieber. Ex Museo Com. de II of fmannsegg.

Praecedenti similis. Obscura. Caput punctatum macpla magna frontali punctisque in vertice binis ferrugineis, Labrum palpique ferruginea. Antennac preves ferrugineae, apice nigrae. Thorax gibbosus, punctatus, lineis elevatis ferruginco-reticulatus, anlice macula lineari perpendiculari alịaque transversa infera ferrugineis. Pectus abdomenque punctato-reticulata. Scutellum parvum. Elytra punctata lineis elevatis concatenatis reticulata sutura crenata. Pedes ferruginei femoribus basi obscurioribus.

Von Parà ịn Brasilien. Längre: $\mathbf{x}_{\frac{1}{2}}$ Linien. Der vorhergehenden Art ähnlich. Dunkelbraun, Der Kopf punktirt, vor der Stiru mit einem, auf dem Scheitel 


\section{$-108$}

mit zwei rostfarbenen Flecken. Schildchen, Frefsspitzen und Fühler rostfarben, letztere kurz und an der "Spitze schwarz. Das Halsschild gewölbt, punktirt, durch erhabene Linien genetzt. Die Erhabenheiten sowohl als vorn ein Queerfleck und über demsalben eine in der Mitte ihn senkrecht treffende Linie sind ebenfalls rostbraun. Brust und Hinterleiib sind voll schwach eingedrückter Punkte. Das Rückenschildchen nur klein. Die Deckschilde sind pranktirt, genetzt durch erhabene zusammenhängende Linien, die zum Theil braun gefärbt sind. Die Nath ist fein gezahnt. Die Bcine sind braun mit an der Wurzel dunkleren Schenkeln.

\section{Chlamys cyanella.}

Chlamys cyanea thorace gibboso scabro, elytris punctatis, reticulatis. Long. lin. 2.

Patria: Bahia in Brasilia. Misit Sello.

Elongata, cyanea. Caput ubique punctatum, obscurum labro rufo. Antennae breves, serratae, fuscae, basi rufae. Thorax punctatus, gibbosus, scaber gibbere sulculo longitudinali laevi laete cyaneo diviso. Pectus abdomenque punctata reticulata sutura laevi. Scutellum parvum. Elytra sparsim punetata, lineis elevatis obscurioribus reticulata. Tarsi ferruginei.

Von Bahia in Brasilien. Zwei Linien lang. Von etwas länglicher Gestalt. Tiefblau. Der Kopf stark punktirt mit rothgelber Lefze. Die Fühler ziemlich kurz, schwärzlich mit rothgelbem Wurzelglied. Dor Halssehild punktirt, der Rücken ansehnlich gewölbt, stärker punktirt, auch dunkler von Farbe, in der Mitte vou einer gilatten und helleren Längsfurche 


\section{,$\quad-109$}

durchschnitten. Die Nath glatt. Brust and Unterleib sind flach und grob punktirt. Das Rückenschildchen ist nur klein. Die Deckschildo sind hin und wieder punktirt und ungleich durch netzförmig verbundene erhabene Linien. Die Beine haben braune Fufsglieder.

\section{Chlamys diadems.}

Tab. VII. Fig. 9.

Chlanys punctata, atra, elytris reticulatis, thoracis antico, capite, pedibusque lutcis. Long. lin. $2 \frac{\pi}{3}$. Habitat in Brasilia. Bescke.

Elongata. Aterrima. Caput punctatum, luteum vertice lineola oculisque nigris. Antennae thorace breviores apice fuscae. Labrum pallidum. Mrandibulae nigrae. Thorax dórso parum elevato, vix tuberculato, scabro, ubique impresso-punctatus, margine postico utrinque sinuato, medio vix emarginato, antico, praesertim lateribus luteo. Pectus abdomenque punctata nigra. Scutellum transversum subquadratum laeve. Elytra remote punctata, lineis parum elevatis reticulata, sutura crenata. Pedes lutei, postici femoribus, tibiis basi nigris.

Aus Brasilien. $2 \frac{x}{3}$ Linien lang. Tiefschwarz und von lïnglicher Gestalt. Der Kopf punktirt, rothgelb, am Scheitel eine schwärzliche Mittellinie. Die Lefze weifs. Die Frefszangen schwarz. Die Fühler kürzer als das Rückenschild, rothgelb mit dunkeln Spitzen. Das Rückenschild ist stark punktirt, in der Mitte nur weniş erhaben und hückrigt, dic Mitte des hinteren Rande fast olne Kerb, der vordere Rand, besonders an den Seiten brcit rothoelb und bogigt gesäumt. Das Rückenschildchen ist melır in die (lucer 


\section{$-110$}

gezogen, fast viereckiog und glatt. Auf den Deckschilden stehen sehr entfernt tief eingestochene Punkte und schwach erhabene Linien bilden unter einander ein weitläuftiges Netz. Die Nath ist deutlich gekerbt. Die untere Seite voll flach eingedrückter Punkte. Die Beine sind rothgelb, und an den hintersten sind die Schenkel beinah ganz und die Schienen bis zur Mitte schwarz.

\section{Chlamys foveolata}

Chlamys thorace punctato, elytris punctato-rugosis nigra, fronte antennis pedibusque luteis, Long. lin. $1 \frac{x}{2}$.

Chlamy's foveolata K noch neue Beyträge zur In selitenkunde I. p. 150. n. 2. T. 4. f. 9. Schönherr syn. Ins. I. 2. p. 343. n. 2.

Habitat in America scptentrionali.

Statura praecedentium. Nigra. Caput luteum vertice nigro. Antennae breves luteae. Labrum luteum. Mandibulae nigrae. Thorax elevatus scaber. Pectus abdomenque punctata. Scutcllum minimum. Elytra punctata, elevato-lincato. Sutura crenata. Pedes anteriores lutei postici fusci.

Eine nordamerikanische Art. Länge $1 \frac{x}{2}$ Linien. Gestalt der vorigen Arten. Grundfarbe schwarz. Stirn, Lefze und Fïhler gelbroth, Halsschild gewölbt; stark punktirt und höckerieg. Brast nud Banch punktirt. Rückensehildehen sehr lilein. Declischilde durch zahlrcich eingedrückte Punkte und erhabené Linien ungleich. Die Nath fein gelkerbt. Die Vorderbeine rothgelb, die hintersten dunkler. 
18. Chlanys cristata.

Tab. VII. Fig. Io.

Chlamys nigra; thorace gibbo, elevato - lineato, elytris lineato - reticulatis, tuberculatis. Long. lin. $1 \frac{x}{2}$.

Clythra cristata Fabr. Syst. Eleuth. II. p. 33. n. 23.

Chlamy's cristata Schönherr Synon. Ins. II. p. 343. n. 6.

I abitat in America meridionali. Fabr. 1. c.

Descriptio secundum specimen musei Regii Havniensis.

Magnitudo et statura C. foreolatae. Nigerrimá nitida. Caput planum unipunctatum, labro ferrngineo. Antennae apice luteae. Thorax medio elevatus, quadrilineatus, lineis apice coeuntibus, lateribus subtuberculatus. Llytra reticulata, basi elevato-lineata, apice tuberculata, margine interno integro. Pectus abjdomenque punctata. Pedes unicolores.

Aus Südamerika. Gröfse und Gestalt der Chlamys foveulata. Glänzend schwarz. Kopf flach mit rothbrauner Lefze. Fühler an der Spitze rotlgelb. Rückenschild an den Seiten etwas höckerig und ungleich, in der Mitte erhöhet und durch vier scharf erhabene, nach dem Hinterrande zu vereinigte Längslinien ausgezeichnet. Dic Deckschilde überall genetzt aufserdem vorzüglich in der vorderen Hälfte mit erhabenen Linien, an der Spitze mit Höckerchen besetzt. Der innere Rand glatt. Brust und Bauch grob punktirt. Beine cinfarbig schwarz. 
19. Chlamys galeata.

Tab. VII. Fig. 21.

Chlamys thoracc medio gibboso, bicarinato, elytris punctatis rugosis, nigra, antennis tarsisque luteis. Long. lin. 2.

H a b it at in Brasilia. Ex Museo de WV in them.

Similis C. cristatae. Caput punctulatum, fronte foveola impressa. Labrum luteum. Antennac thorace brcviores luteae. Thorax sparsin punctatus, utrinque tuberculo laevi, dorso valde gibbosus gibbere ruguloso punctato, linea longitudinali elevata duplici sulcoque intermedio insigni. Elytra punctis impressis lineisque elevatis flexuosis et abbreviatis transversis inaequalia. Sutura integra. Pectus abdomenque subtilissime punctata, opaca. Tarsi lutei.

Aus Brasilien. Zwei Linien lang. Der Chlamys cristata ähnlich. Tiefschwarz. Der Kopf fein punktirt, mit einem seichten Stirngrübchen. Fühler und Lefze röthlichgelb. Das Rückenschild einzcln punktirt, zur Seite eine schwache, glatte, halbrunde Erhöhung, in der Mittc ein ansehnlicher grobpunktirter IIöcker, den eine Furche durchläuft, die seitwärts von einer kurzen, ziemlich glatten erhöheten Längslinie begränzt ist. Das Rückenschildchen, wie gewölnnlich. Die Deckschilde tief, doch einzeln punktirt, sind nach verschicdenen Richtungen, von erhöheten sowohl Bogen-als Quecrlinien durchzogen. Die Nath ist glatt. Brust und Bauch sind flach und fein punlitirt. Die Beine haben rothgelbe Fufsglieder. 


\section{$-113-$ \\ 20. Chlamiys suberosa.}

Tab. VII. Fig. 12.

Chlamys globosa cuprea, thorace elytrisque punc. tatis, tuberculatis, Long. lin. $1 \frac{x}{2}$.

Patria: Parà Brasiliae. Misil Sicber. Ex Museo Comit. de If of fmannseg g.

Statura brevis. Obscure euprea. Caput punctatum. Antennae breves, articulo primo luteo. Palpi lutei. Thorax punctatus, utrinque tuberculatus, medio elevatus gibbosus, gibbcre binodi inaequali. Pectus abdomenque punctata. Scutellum triangulare. Elytra punctata, tuberculata, tuberculis in medio transversis majoribus. Sutura crenata. Pedes unicolores.

Von Parì in Brasilien. Lünge $1 \frac{\pi}{2}$ Linien. Fast kuglicht. Dunkel kupferfarben. Der Kopf puntirt. Fühlerwurzel und Frefsspitzen gelbbrïunlich. Der Halsschild punktirt, an den Seiten höckrig, in der Mitte stärker crhaben, ungleich, buckliog. Brust und? Jinterlcib punlitirt. Rückenschillchen drcieckion, deutlich. Declischilds einzeln und stark punktirt, zum Theil höckerig, die Höcker der Mitte in die Queere gezogen und gröfser. Nath gekerbt. Being cinfarbig.

\section{Chlamys capricornis.}

Chlamys thurace gibboso, rugoso bituberculato, alytris rugosis oblique transveraim carinatis, cuprea; antennis pedibusque lutcis, Long. lin. 2.

Chilumys capricornis Germ. Ins. sp. i. 11. 55\% 1.. 751.

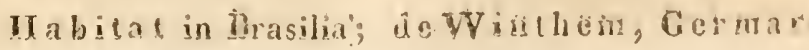


Brevis, ouscure cuprea. Caput punctatum lábro palpisque ferrugineis. Antennae thorace breviores luteae, apice obscuriures. Thorax punctatus, inacqualis, dorso rugosns, bituberculatus, tuberculis hrevibus compressis acutis. I'ectus abdomenque reticulata cuprea. Scutellum postice dilatatum. Elytra basi undato-lineata, apice reliculata foveolata, plica arcuata transversa media ab angulo antico cxteriorì ad suturam descendente divisa. Sutura denticulatil. Pedes cuprei, tarsis luteis.

Aus Brasilien. Zwei Linien lang. Durkel liupferfarben. Der Kopf voll cingedrückter I'unlite. Lefze und Frefsspitzen gelbbraun. Dic Fühler ungefälır so lang als das Rückenschild sind rothgell, mit dunklen Spitzen. Das Rücỉenschild selır ungleich, einzcln punktirt, lat in der Mitte dicht neben cinander zwci gerunzelte, ziemlich erhabene und zugespitzte Höclser. Kopf und Bauch sind genetzt, am Rückenschildchen die Hinterwinkel vorgezogen. Die Deckschilde durch cine vom Schulterwinkel nach der Mitte der Nath schräg abwärts laufende, etwas gebogene und scharfe Leiste getheilt, sind aufserdem ungleich durch verschicdene crhabene Längslinien, die sich in der vorderen Iälfte, und netzfürmig verhundene Linien, die sich in der lintern $\Lambda$ blheilung befinden, auch stehen hin und wieder, besonders in der hintern Häfte, eingedrückte Grübchen. Die Fufsglieder sind rothgelb.

\section{Chlamys plicata.}

Chlamys thorace bituherculato elytris punclatis, tuberculatis, cuprea obscura, labro antennisque testaceis. Longr. lin. 2 . 
Chlamy's plicata O livier Entomol. VI. 96. p. 876 . a. 3. Pl. I. Fir. 3. b.

Clyihra plicata Fabricii supplementum entom: yst. p. 111, n. 10. Syst. Elcuth. II. p. 33. n. 20. Cof u e b e rt illustr. iconogr. ins. III. p. 129. Tab. XXIX. ?ig. 8.

Bruchus silbosus 'Fabricii entom. syst. II. p. 77o. n. 8. Syst. Eleuth. II. p. 397. n. 10. Olivier inc. méth. V. p. 198. n. 8.

Chlamys tuberosa Knoch neue Beytr. I. p. 128. 1. 1. Tab. 4. Fig. 1. 2. Schönh. Syn. Ins. I. 2. p. i43. n. 1.

Habitat in America septentrionali.

Obscura. Caput punctatum labro antennisque liss cis. Mandibulae nigrae. Thorax striatus, medio eleatus, bituberculatus, postice emarginatus. Scutellum riangulare. Flytra tuberculata, tuberculis plurimis, utura crenata. Pedes concolores.

Aus Nordamerika. Von gewöhnlicher Gestalt und Linien !lang. Dunkel kupferfarben. Lefze und 'ühler blafs rothgelb. Der Kopf leicht punlitirt. as Halsschild cinzeln punktirt, fein gestrichelt, in er Mitte erhaben, ungleich, zweihückerig: Das Rük=enschildchen dreieckig. Die Deckschilde einzelnt unktirt, mit vielen Höckern besetzt, an der Nath ekerbt. Die Beine wie der Körper gefirbt.

\section{Chlamys affinis.}

Chlamys cuprea, thoracc medio clevato striato,

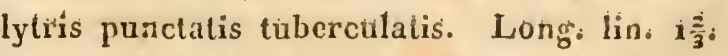

If abitat in Amcrica septentrionali.

Praeculenti similima. Caput punctatiom; labro bscurioris Antennac breves luteae. Thorat nimedie 雚 
eicvatus, subtilissime striatus. Pectus abdomenque concoloria. Scntellum laeve. Elytra punctata, tuberculata, tuberculis sulscompressis. Sutura crenata. Pedes cuprei.

Tbenfalls aus Nordamerika. Etwas kleiner als Chlamys plicata, der sic übrigens sehr ähnlich ist. Kupferroth. Der Koplf punktirt, die Lefze dunliler, die Fühler rothgelb. Das Halsschilu crhebt sich in der Mitte in einen starken fein concentrisch gestreiften Höcker, den cine kaum wahrnchmbare eingedrückte Längslinie theilt. lirust, Hinterleib und Beine sind wic der übrige Körper gefärbt. Das Rülskenschildchen klein und glatt. Die Deckschilde sind cinzeln und tief punktirt, voller Erhöhungen die etwas gedrückt und an den Kanten scharf, doch weniger, als bei der vorhergehenden Art verbunden sind. Die Nath ist gesügı.

\section{Chlamys gibber.}

Chlamys thorace elytrisque punctatis taberculatis, nigra antennis pallidis. Long. lin. $\left\{\frac{x}{2}\right.$.

Clythira gibber Fab r. Entom. syst. suppl. 1. 112. n. 11. Syst. Eleuth. II. p. 33. n.21. Coquebert illustr. iconogr. ins. III. p. 12g. Tab. XXIX. Fig. 7.

Chlamys sibbera Olivier Entomologic VI, p. 876 . 1n. 4. Pl. I. Fig. 4.

Chlamys gibher Schönherr Synon. Ins. II. p. 343. n. 4 .

Habitat in America scplentrionali. Ex Mruseo de VV in them.

Corpus parvom, elongatum, fusco-nigrum. Caput punctatum, labro fusco. Antennac vix capite 
longiores, pallidac, apice latiores, obscuriores. Thorax gribbosus, impresso-punctatus, nultitubcrculatus. Scutellún parvum immersum. Elytra impresso-punctata, tuberculata, tuberculis intermediis linearibus confluentibus. Sutura subtilissime creneta. Pęctus abdomenque punctato-reticulata. Pcies concolores.

Aus Nordamerika. Länge $1 \frac{T}{2}$ Linien. In Ver= hältnifs länger als die vorhergehenden Arten. Tiefbraunschwarz. Der Kopf punktict, mit brauner Lefze und kurzen blafsgelben, an der Spitze otwas dunkleren Fühlern. Das Rückenschild erhaben, überall voll eingedrückter Punlite mit mehreren Höckern besctzt. Das Rückenschildchen ticfliegend, von ggewöhnlicher Gestalt. Auf den Declsschilden stehen die einredrückten Punkte zwischen den Höckern des Um. కreises und den mehr linienfürmigen Erhabenheiten der ITitte regelmärsirg geordnet. Dic Nath ist schr fein gelerbt. Die Beine sind wie der Körper gofütb:

\section{Chlamys iuberculata.}

, Tab. VIIL. Fig, I,

Chlimys thorace fibboso, striato, elytris punctas tis taberculatis, atra antennis pallidis, Long. lin. $1 \frac{7}{2}$.

Chlumys huberculata Germar (in litt.).

Patria: Sarannah. Mus. Geraar.

Statura fere praccedentis, at brevior. Caput opacum, labio ferruginco. Antennae vix thorace breviores. Thorax sultilissime striolatus, dorso elevato gibboso, gibbere obtuso, sunımo apice sulculo brevi longitudinali diviso. Pectus abdomenque reticulata sermentis ultimis cupreo-nitidis. Scutellum subtrian- 
gulare, Elytra syarsim foveolata, subtuberculata, tuberculis prope basin linearibus longitudinalibus, intermediis compressis obliquis transversis, ad apicem minimis vixque elevatis. Pedes cum tarsis nigri,

Vaterland: Savamnah, Länge $1 \frac{x}{2}$ Linien. Im Verhältnifs liürzer als die vorbeschriebene Art. Dunkelschwarz. Das Kopfschildchen hellbraun, Dic Fühler etwa so lang als das Rückenschild von blafsgelber Farbe, Das Rüclseuschild, fein gestrichelt, erhebt sich in einen stumpfrunden Höcker, der nur an der Spitze durch eine kurze Lüngsfurche getheilt ist, Brust und Bauch sind genetzt, die letzten Segmente in manchen Richtungen wie Kupfer schimmernd, Die Deckschilde haben nur hin und wieder Grübchen, aufserdem kleine Höcker, die am Grundtheile linienförmig, in der Mitte zu einer vom Schulterwinkel nach der Nath herabsteigenden Quecrlinie vereinigt, in der Spitze der Decken klein und unmerklich sind. Dic Beine sind, dic Fufsglieder einbegrif fen, schwarz,

\section{Chlanys coronata.}

Tab, VIII, Fig. ?:

Chlamys thorace elytrisquo punctatis, tuberculatis cuprea, obscura, labro antennisque lutcis, Long. lin, 2 ,

Ha bitat in Brasilia Misit Dro de Olfers.

Statura praccedenlium. Caput junctatum obscurum labro anteunisuge lntcis, Therax obscurus spars sim punctatus multitulerculatus, tulerculis praesertim quatupor in media dorsi elevatioribus, distinctio- 
ribus, al marginem posticum in semicirculum dispositis. P'ectus abdomenque punctata. Scutellum subquadratum, postice utrinque productum laeve. Elytra cuprea sparsim punctata, punctis mañis impressis, basi apicerque tuberculata, tuberculis baseus majoribus, disco lineis elevatis concatenatis reticulata. Sutura crenata. Pedes cuprei.

Aus Brasilien. Zwei Linien lang. Gestalt der Chlamys plicata. Dunkel kupferglänzend. Der Kopf punlitirt, Lefze und Fühler röthlichgrelb. Der Halsschild punktirt, mit Hüclern besctzt. Deutlicher und gुröfser als die übrigen stehen vier in cinem Halbzirkel nach dem hintern Rande. Brust und Ifinterleib sind punktirt. Das Rückenschildelion ist fast viereckig, die hinteren Winkel vorgezugen. Die Deckschilde sind regelmälsig punlitirt, die Punlite deutlich und grubenfürmig cingedrückt. $\Lambda_{n}$ dem Ursprunge der Deckschilde sind cinige grö̈sere, an der Spitze mchrere klcine Erhölungen bencrlilich, in der Mitte laufen mehrere erhabene Linien netzförmigg zusammen. Dic Nath ist gekerbt. Die Beinc sind wic der Körper gefärbt,

\section{Chlamys globosa.}

Tab, VIII, Fig. 3.

Chlamys thorace quadrituberculato elytris tuberculato - rcticulatis nigerrima, labro autennisque ferrübincis. Lung. lin. $1 \frac{3}{4}$.

Il abitat in Brasilia. Misit Dro de Olfers.

brevis, subghlobosa, nitida. Capul subtilissime punciatum. Labrum luterm Anicund thorace fire-

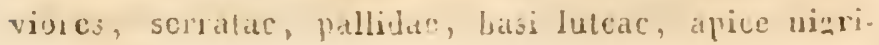


cantes. Thorax hrevis sparsim punctatus utrinque in tuberculum parvum subglobosum elevatus, nedio bituberculatus, tuberculis his majoribus carinatis, antice truncatis rugosis sulcatis. Pectus abdomenque punctis impressis lineisque elevatis inaequalis. Scutellom parvum subquadratum laeve. Elytra impressopunctata, lineis elevatis reliculata. Sutura laevis. Pedes unicolores plantis cinereis.

Aus Brasilien. Nahe an zwei Linien lang. Kürzer als die vorhergehenden Arten und fast rund. Glänzend tiefschwarz, Der Kopf braun punlitirt. Die Stirn etwas eingedrückt. Lefze und Fühlerwurzel rothgelb. Die folgenden Fühlcrglieder blafsgelb, die Endglieder schwärzlich. Das Rückenschild kurz, voll vertiefter Punkte und erhabencr Linien, zu jeder Seite eine kleine liugelförmige Frhöhung in der Mitte ein Doppelhöcker, jeder nach hinten abgeschnitten mit scharfer Kante, vorn stumpf und ungleich gefurcht. Brust und Hinterleib voll eingedrückter Punkte und erhabenor Linien. Das Schildchen irlein, fast vicreckig, glati. Die Deckschilde punktirt von erhabenen gebogenen Linien vielfach durchzogen. Dio Nath ungezalnt. Die Beine von der Farbe des Kürpers. Mit grauen Filz bodeckte Sohlen.

28. Chlninys scoriosn.

Tap. VIIT. Fig. 4.

Chlamys thorace clytrisque punctatis, reticulatis Atra kabo ferrugineo. Long, lin. I $\frac{r}{2}$.

I a pitat in Brasilia. Misit Dr. de Offers.

lifongata, atcrima, Caput punctatum, Labrum olsecurc ferrugineuryo Antennac breves serratac ni- 
grac, basi obscure luteac. Thorax subgibbosus, rugosus. Elytra lineis elevalis reticulata sparsin punctata. Sutura crenata. Pectus abdomenque impresso. punctata. Pedes compressi atri, tarsis obscure luteis.

Aus Brasilien. Längुe $1 \frac{x}{2}$ Linien. Länglich, dunkel mattscliwarz. Der Kopf punktirt mit dunkel gelbbrauner Lefze. Die Fühler kurz, zur untern Hälfte dunkelgelblich. Das Halsschild gewölbt, sehr runzlich, dazwischen flach hin und wieder punktirt. Das Rückenschildchen klein. Die Deckschilde bedeckt mit weniug erhabenen netzförmig verbundenen Linien und einzelnen eingedrückten Punkten. Dio Nath fein gekerbt. Flach eingedrückte Punlite an Brust und Ilinterleib. Die Beine gedrückt, schwarz, mit schnutzig gelbbräunlichen Fufsgliedern.

29. Chlamys favosa.

Tab. VIII. Fig. 5.

Chlamys thorace gibboso scabro elytris reticalato cavernosis brunnea, atromaculata. Long. lin. $\times \frac{3}{4}$.

Habitat in Brasilia. Misit Dr. de Olfors.

Statura praccedentis. Caput panctatum atro. maculatum. Antennac thorace breviores serratae brunneac. Thorax elevatus medio vir sulcatus punctaius, inaequalis brunneus latcribus fusco-naculatus. Scutellum brunneum, nigro-marginatum. Elylra lineis plurimis eleratis reticulata lacunosa subtuberculata, brunnea fusco-maculata. Sutura subtilissime denticulata. Peclus abdomenque punctata, punctis levissime impressis, brunnea atro maculata. Pedes hrınnei, coxis omnino, femoribus tibiisıue fascia nigris. 
Aus Brasilien. Beinah zwci Linien lang. Gestalt der vorhergehenden Art. Dunkel gelbbräunlich, überall schwarz unregelmäfsig gefleckt. Der Kopf dicht punktirt. Die Fülhler bräunlich gresägt und kürzer als das Rückenschild. Dieses kegrlicht erhaben, in der Mitte kaum deutlich geschieden, punktirt und leicht genetzt, in der Mitte lıeller gefärbt. Das Schildchen dunkelbraun mit schwarzem Rande. Dic Deckschilde in der Mitte weitläuftig, am Rande dicht genetzt, haben zwischen den Linien flache Gruben, in welchen schwärzliche Flecken und hin und wieder eingeslochene Punkte zu bcmerken sind. Die Nath solır fein gezülnelt. Brust und IInterleih sind kaum merklich punktirt und wie der übrige Körper, vornelımlich aber die Brust, dunkel gefleckt. Dic Beine sind braun, dic Beinwurzeln schwarz, Schenkel und Schienen mit einer schwarzen Binde bezcichnet.

\section{Chlaniys umbrosa.}

Tab. VIII. Fig. 6 ,

Chlamys thorace subgloboso rugoso, elytris radiato-reticulatis subspinosis, brunnea, opaca, Long. lin. $1 \frac{x}{2}$.

Habitat in Brasilia, Misit Dr, de Olfers.

Simillima praccedenti. Caput punctatum, antennis serratis, Thorax elevatus, globosus lineiserue dorso reticulatis lateribus arcuatis rugosus. Scutcllum subimmersum. Elytra subtuberculata ambitu ccllulusa.reticulata medio radiato-reliculata, radiis tubercula petentibus. Sutura lacvis. Pectus abiomenque subpunctata, punctis levissimc impressis. Pedes unicolores. 


\section{$-123$}

Aus Brasilien. Länge $1 \frac{x}{2}$ Linien. Der vorhergehenden Art selır iilnnlich, Gelbbräunlich, ungefleckt. Der Kopf punlitirt mit kurzen gesägten Fühlern. Der Rücken kuglicht crhaben, in der Mitte regelmä$\mathrm{fsig}$, an den Seiten bogigt in einander laufend genetzt. Das Schildchen etwas eingelassen. Die Deckschilde hin und wieder hückricht, an den Seiten ekkig in der Mitte strahlenähnlich genetzt, so dafs die Strahlen nach den Höckern hin und in ihnen zusammen lanfen. Die Nath ist glatt. Brust und Hinterleib sind kaum deutlich punktirt, die Punkte sehr schwach eingedrüht, Dic Beine einfarbig.

\section{Chlanlys subspinosa.}

Tab. VIII. Fig. 7 .

Chlamys thorace gibboso spinuloso, elytris punctatis tuberculatis, ferruginea immaculata. Long. lin. 2.

Habitat in Brasilia, Misit Dr, de Olfers.

Similis praccedentibus, at major. Laete ferruginea, lucida, Caput levissime punctatum. Antennae thorace breviores, serratae luteac. Mandibulae nigrae. Thorax reticulato - concatenatus, dorso gibbosus, gibbere medio diviso striato-sulcato, lateribus spinuloso obscuriore, Scutellum parvum triangulare. Elytra punctata et punctato striata, tuberculata, tuberculis in singulo elytro quatuordecim, in seriebus transversis a margine exteriori ad suturam oblique descendentibus dispositis. Sutura laevis. Pectus abdomenque reticulata, Pedes unicolores,

Aus Brasilien, Zwei Lịnien lanç, Sehṛ ähnlich der vorbeschriebenen Art. Hell lebhaft rostfarben. Der Koppe seicht punktirt. Die Füluler liüzer als das laickenselitd und rothsell, Die Frefszinuren schwarz. 
Das Rutckenschild genetzt, in einen Höcker erhoben, der in der Mitte getheilt und gestrichelt, neben der Vertiefung dunkler braun und mit kleinen spitzen Erhabeuheiten dicht bedeckt ist. Das Schildchen ist klein und dreieckig. Auf den Deckschilden bemerken wir Punkte und der Länge nach gebogene Punktreihen, aufserdem soliräg von Aufsen nach der Nath herabsteigende heihen von spitzigen Hö̈ckern, deren auf jedem Schilde iberhaupt etwa vierzchn vorhanden sind. Die Nath selust ist glatt. Brust und Bauch erscheinen renetzt. Die Beine sind einfarbig hellbraun.

\section{Chlamys tencbrosa. \\ Tab. VIII. Fig. 8.}

Chlamys thorace noduloso poroso canaliculato elytris punctatis tulserculatis reticulatis obscure cu. prea antennis tarsiscque luteis. Long. lin. $2 \frac{x}{2}$.

Nlabitat in Brasilia. Misit Dr. de Olfers.

Obscura. Caput subtilissime punctalum labro ferrugineo. Antennae thorace breviores compressae serratae luteac arliculo primo dorso macula fusci, allimis obscuris. 'ilhorax subgibbosus, punclatus, dorso canalicnlatus, ubique nodnlosus. Scutellum laeve, impressum postice dilatatum. Flytra lincis elevatis reticulata, basi tuberculata, ubique loculesit, punctata, punctis subocollaribus. Sulura crenatav Pectus abdomenige obsolete-punctata. Pedes cu. prei tarsis luteis.

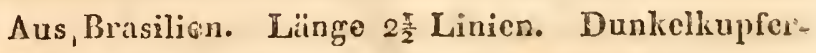
roth. Lefze, Fühler und Fufserlicier rothgelb. Der Kopf solu fein punktirt. Auf dom Rückenscliildo eingecirückte lualie, verschicdene stumpre Höoker und in der Mitte eine scichtc Längsfurchc. Das Schild- 
chen eingesenkt glatt, mit stark seitwärts gezogenem Hinterrande. Auf den Deckschilden netzeörmmiøg in einander laufende crhabene Linien, in den Zwischenräumen cinzeln stehende cingestochene urid von einem Ringe nicht undeutlich ungebene Punkte. Die Nath dentlich gezahnt: Brust und Hinterleib fcin genctzt, Die Fufsøglicder röthlichgelb.

\section{Chlamys cistella.}

Tab. vill. Fig." $g$.

Chlamys thorace ragoso canaliculato, elytrisque tuberculato-reticulatis punctatis cuprea obscura, antennis tarsisque luteis. Long. lin. $2 \frac{x}{2}$.

Chlamy's cistella Germar Ins. spec. I. p. 551. n. 749 。

Patria: Brasilia. Bescke, Germar.

Simillina praecedenti. Brevis, subquadrata, obscure cuprea. Caput punctatum, fronte subimpressa, laevi, labro palpisque ferrugineis. Antennae thorace breviores, compressae, serratae, chscure luteac, articalo primo dorso fusco. Thorax postice utrinque sinuatus, medio versus scutellum productus, emarginatus, ragosus, punctatus, punctis minutissimis ocellaribus, dorso gibbosus, canaliculatuś. Pectus, venter pedesque punctis magnis vix impressis, versus abdo. minis apicem confiuentibus inaequalia, passim reticulata. Scutellum angulis posticis productis trimngnlare lacve. Elytra tuberculis compressis lincaribus reticulata, interstitiis opacis punctatis, punctis subocellaribus. Sutura denticulata. Tarsi lntei.

Aus Brasilien. Gröfse und Gestalt der eben be schriebenen $\Lambda$ rt, doch etwas breiter und dureh bir 


\section{$-126$}

Stellung der auf den Deckschilden gebildeten Fächer und die Beschaffenheit der eingedrückten Punkte unterschieden. Der Kopf grofs, aber flach, punktirt bis auf die Stirn, dic etwas eingedrückt ist. Lefze, Frefsspitzen und Fühler rothgelb, an letztern das erste Glied oben dưnkel. Das Rückenschild runzlicht, flach senctzt und punktirt. Eine Punktreihe steht dicht am vordern Rande, die anderen Punkte stehen einzeln und zerstreut, haben einen deutlichen Ring und erscheinen als höchst kleine Augenpunkte. Der Rülsken ist erhöhet und der Höcker in eine seichte Längsfurche getheilt; der hintere Rand ist zu jeder Seite eingebogen, in der Mitte vorgezogen und ausgerandet. Das Schildchen ist von dreieckiger Form. Die Decksehilde erscheinen durch linienförmige bogigt verbundene Erhölungen genetzt. In den Verticfungen finden sich zerstreut, doch deutlicher noch wie auf dem Riickenschilde, kleine Augenpunlte. Der innere Rand ist gezahnt. Brust, Bauch und Schenkel sind voll flach eingedrïckter Punkte, die am Ende des Hinterleibes und an dessen Seiten netzförmig und zu unregelmäfsigen Flecken zasammenlaufen. Die Fứsglieder sind röthlichgelb.

\section{Chlannys diffcilis.}

Tab. vill. Fig. 10.

Chlamys thorace nodoso elytrisque oblique transversim angulato-tuberculatis punctatis obscura, macula frontali transversa, antennis tarsisque luteis. Long. lin. $2 \frac{t}{2}$.

Patria: Brasilia. Ex Museo Germar.

Simillima Chlam. tenebrosac ejusdemque staturae. Cuprea, obscura. Caput punctatum maculis tri- 
bus inter oculos fasciam transversam constituentibus labroque ferrugineis. Autennae compressae, obscure luteae. Thorax punctatus, norlosus, dorso quadrituberculatus, canaliculatus. Scitcllum triangulare laeve. Elytra tuberculata punctata tuberculis compressis lineas tres angulatas oblique transversas intermedias parallelas referentibus, punctis parvis subocellaribus. Margo internus denticulatus. P'cctus, abdomen, pedes ut in praecedentibus.

Aus Brasilien. Grüfse, Gestalt und Färbung dei Chlamys tenebrosa. Der Kopf ist flach punktirt: Zwischen den Augen stehen fast zusammenhängend als Queerbinde drei braunrothe Flecken. Von derselben Farbe ist die Lefze. Die Fühler sind zusammen gedrüclst und dunkel röthlichgelb. Das Rückenschild punktirt und durch weniger merkliche Erhabenheiten ungleich, hat den gewölnnlichen Höcker an welchem vier in einem Vicreck gestcllte erhöhcte Punkte and cine seichte Längsfurche zu bemerken sind. Rückenschildehen, Brust, Bauch und Bcine sind wic bei den vorhergehenden Arten. Dic Deckschilde sind durch Höcker und Eindrücke unglcich. Die ersteren sind zusammengedrückt, durch sic werden vornemlich drei zackigte Linien gebildet, welche schräg von aufsen nach der Nath hin die Decken durchschneiden. In den grubenförmigen Verticfungen stehen Punkte, die, wie bei den vorhergehenden $\Delta$ rten einen schmalen Ring und einen durch lebhafteren Glanz bemerkbaren Mittelpunkt haben. Die Nath ist mit feinen Zähnchen dicht besetzt. 
35. Chlamys purpurascens.

Tab. VIII, Fig. I1.

Chlamys thorace punctato - reticulato tuberculato, elytris reticulatis, fusco-aenea antennis tarsisque lu. teis. Long. lin. $2 \frac{x}{2}$.

H abitat in Brasilia, Dedit de VW in them.

Affinis praecedentibus subglobosa, obscura, nigro purpurascens, cupreo-micans. Caput subrugosum, vertice impresso, ore luteo. Antennae thorace breviores luteac. Thorax multituberculatus reticulatus, medio elevatus postice emarginatus. Scutellum lacve, utrinque productum. Elytra lineis eleva. tis concatenatis inaerualia reticulata loculosa, sparsimque in interstitiis punctata. Sutura distincte denticulata. Pectus abdomenque reticulata.

Aus Brasilien. $\frac{\mathrm{x}}{2}$ Linien lang. Den vorherge henden Arten ähnlich, doch im Verhältnifs etwas breiter. Die Farbe dunkelpurpurfarben, beinah schwarz, mit Kupferglanz. Der Kopf mit eingedrücktem Scheitel, unregelmälsig punktirt, runzlicht. Das Schildchen rothgelb. Die Fühler blafs röthlichgells. Das Rückensehild flach punktirt, die Punkte zum Theil durch Quecrstriche verbunden, die Mitte erhöhet, viclfach stumpfhöckerig. Das Rückenschildchen fast dreieckig, ziemlich glatt, tiefliegrend mit vorgezogenen Hinterwinkeln. Auf den Deckschilden in dor Milte einzelne gröfsere durch erhöhcte Iinien gebildete Vertiefungen deren Flächen weitliiuftig punktirt sind. Zwischen diesen und am Rande cin netrförmiges Gewebe dicht an einander gereiheter Grübchen. Die Nath deutlich gezahnt. Brust und Bauch durch erhöhote Linien und flach eingestochene Punkte 


\section{$-129$}

wie genetzt. Die Beine fast schwarz, die Fufsglieder rothgelb.

\section{Chlamys inaequalis.}

Tab. VIII. Fig. I2.

Chlamys capite thoraceque vage punctatis, multituberculatis aenea, obscura, labro, antennis tarsisque luteis. Long. lin. $2 \frac{\pi}{3}$.

Habitat in Brasilia. de Winthem.

Statura praecedentis. Caput punctatum, nigroaeneum clypeo obscuriori, labro palpisque luteis, mandibulis nigris. Antennae thorace breviores, subserratae luteae. Thorax vage punctatus multituberculatus, tuberculis lateralibus laevibus obtusis, intermediis elevatioribus angulatis submuricatis. Scutellum subquadratum immersum, laeve, lineola abbreviata elevata baseos. Elytra foveolata, oblique transversim angulato-rugosa subtuberculata, sutura crenata. Tarsi lutei.

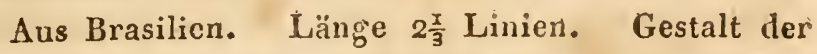
vorhergehenden Art. Schwärzlich mit mattem Med tallglanz. Der Kopf punlitirt, das Kopfschild dunkler; Lefze und Fühler röthlichgelb. Das Rückenschild einzeln punktirt, sehr höclirig, die Höcker ziemlich flach, an den Seiten gerundet, in der Mitte kantig. Das Schildchen fast vierecliig glatt, mit einer abge. brochenen erhöheten Linie am Grundtheil. Die Deckschilde voller Grübchen; von erhülıcten in Winkels żusammenstofsenden, schräg von aufsen nach der Nath verlaufenden Linien durehrogen. Wie Nath gezähnt. Die Beine mit Kupferglanz. Die Fufsulieder rütlilichgellb. 
37. Chlámys flavifrons.

Tab. IX. Fig. 1.

Chlamys thorace elytrisque punctatis, tuberculatis, aenea, capite, tarsis femorumque bagi Inteis. Long. lin. 2.

H a b i tat in Brasilia. Misit Dr. de Olfers.

Caput laeve luteum, labro ferruginco. Antennae thorace breviores, serratae, luteae, apice fuscae. Thorax sparsim punctatus, tuberculatus, medio gibbosus, gibbere quadrituberculato sulcato. Scutellum impressum laeve. Elytra sparsim impresso-punctata subtuberculata, tuberculis transversis diffusis. Sutura crenata. Pectus abdomenque punctis magnis impressis inaequalia, subreticulata. Pedes punctati. Femora anteriora ultra dimidium, postica basi nonnisi lutea. Tarsi lutei.

Aus Brasilien. Zwei Linien lang. Der Kopf flach, glatt, ruthgelb, mit rothbrauner Lefze. Die Fühler kürzer als das Rückenschild, gesägt, rothgelb, die letzten Glieder dunkler. Das Rückenschild nit Erhabenheiten besetzt, deren vier in ler Mitte deutlicher und zugespitzt und durch eine Längsfurche geschieden sind. Aufserdem hin und wieder eingedrückte Punkte. Das Rückenschildchen wie gewöhnlich. Auf den Deckschilden finden sich wellenförmig in die Queere verlaufend einige schwache Erhabenlueiten, zwischen diesen ein estochene Punlite. Die Nath ist deutlich gekerbt. Brust und Unterleib erscheinen wie genetzt durch flache eingedrückte Punkte. Die Beine sind punktirt., Die Schenkel an der Wur zel, die vordern bedeutender als die hintersten, rothgelb. Auch die Fufsglieder sind rothgelb. 
38. Chlaniys cupricollis.

Tab. IX. Fig. 2.

Chlamys punctata, tuberculato - reticulata obscura, capite thoraceque cupreis. Long. lin. $2 \frac{r}{4}$.

Habitat in Brasilie. Misit Dr. de Olfers.

Statura fere C. plicatae. Caput punctatum labro luteo. Mandibulae nigrae. Antennae vix thorace breviores serratac, luteac articulo primo dorso cupreo. Thorax sparsim punctatus, medio elevatus tuberculatus. Scutellum immersum. Elytra lineis elevatis reticulata ad basin tuberculata, sparsim punctata, obscura, atro-purpurea, lineis tuberculisque apice cupreis. Margo internus crenatus. Pectus abdomenque punctata obscura atro purpurea, lateribus anoque cupreis. Pedes obscuri cupreo - micantes. Plantae tomento pallido tectae.

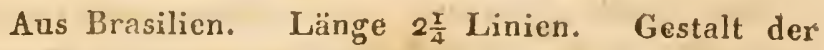
Chlamys plicata und der vorhergehenden Arten. Kopf lebhaft kupferroth glänzend, punktirt. Lefze rothgelb, Frefszangen schwarz. Fühler ein wenig kürzer als das Rückenschild, gesägt, rothgelb und nur das erste Glied oben mit kupfrigem Glanz. Das Rükkenschild einzeln punktirt in der Mitte bucklig und mit deutlicheren Hö̈clsern besetzt. Das Schildchen nur klein, eingesenkt und dunkel. Die Declischilde dunkel purpurfarben, einzeln punktirt, durch Linien genetzt, welche, besonders am Grundtheil in Höliker sich erheben und an der scharfen Kantc kupferroth glänzen. Die Nath ist gekerbt. Brust und Hinterleib sind flach punktirt, dunkel purpurfarben, die Seiten des Bauches and die Endspitzen des Hinter. leibes wie Kupfer glänzend. Die Bcine sind dunke! 
gefärbt; kupfriog glänzend und die Sohlen mit einem blafsgelblichen Filz bedeckt.

\section{Chlamys fuscipes.}

Tab. IX. Fig. $\mathbf{3}$.

Chlamys punctata, tuberculata, atropurpurea, thoracis dorso et lateribus, capite pedibusque ferrugineis. Long. lin. 3 .

Habitat in Brasilia. Dr. de 01 fers.

Statura fere C. monstrosae. Caput punclatum. Antennae serratae ferrugineae. Mandibulac nigrae. Thorax ferrugineus punctatus, medio elevatus rugosus bituberculatus sulcatus sulco longitudinali sulfusco, postice fuscus. Scutellum fuscum. Elytra punctis profunde impressis lineis elevatis obliquis, tuberculisque baseos inacqualia, fusco-nigra, cupreopurpurascentia sulura crenata. Pectus abdomenque reticulata fusca. Pedes ferruginei, postici obscuriores. Tibiae sulcatae, sulffuscae.

Aus Brasilien. Länge drei Linien. Gestalt der Chlamys monstrosa. Kopf punlitirt sammt Lefze und Fühlern rostfarben. Frefszangen schwarz, Rückenschild rostfarben, hinterwärts fast schwarz an den Seiten hell. Tief eingedrückte Punlte an den Seiten, in der Mitte Unebenheiten und zwei deutliche Höcker, welche durch eine dunkler gefärbte Längsfurche getrennt sind. Schildchen von dunkler Färbung. Deckschilde dunkel schwarzbraun mit purpurihnlichem Kupferglanz, cinzeln und stark punktirt, von erhabenen Linien schräg durchzogen, an dem Grundtheile höckeriog. Nath gekerbt. Brust und Hinterleib fein genetzt, dunkel schwarzbraun. Beine 


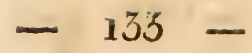

rostfarben, die hintersten so wic sämmtliche Schiencn dunkler gefärbt.

\section{Chlarnys rutila.}

Tab. 1X. Fig. \&.

Chlamys thorace rugoso, biclevato, elytris punctatis tuberculatis, ferruginea supra fusca: Long. lin. 5 .

Habitat in Brasilia. Misit Dr. de Olfors.

Magnitudine et statura praecedentis. Caput plaıum, punctatum, rufum, occipite fusco. Autennae serratae rufae. Mandilulac nigrae. Thorax lateribus punctatus, niedio elevatus rugosus bitubcrculatus, tuberculis sulculo divisis, antice ferrugineus postice subfuscus. Scutellum parvum postice utrinque productum, fuscum. Elylra punctato-rugosa, tuberculaia: tuberculis circa sedecim, aliis omnino fusca, apice ferruginea aliis ferruginea dorsu tuberculisque fuscis. Sulura crenata. Pectus abdomenquc reticulata vel fusca ano ferruginco, vel ferruginea tota, Pedes ferruginei.

Aus Brasilien. Länge: ggegen drei Linien. Geslallet wic die vorhergehende Art. Kopf flach punktirt gelbröthlich mit dunkleren Hinterkopf. Fühler gesägt, gelbruth. Frefszangen schwarz. Rüclsenschild punktirt, in der Mitte crhöhet und runzlich mit zwci Höcleru, die,durch cine Längsfurche geschicden sind. Vurdere Hälfte röiblich, hintere dunkelbraun ģefärbt. Schildchen von dunkelbrauner Farbe. Deckschilde durch Punkte gerunzell, mit etwa sechszehn Höckerchen in schrägen Queerreihen besetzt, bei einiggen dunkel gefärbt, und an der spitze röthlich, bei andern braunroth, selbst gelbruth, und dunkler 
nar der mittlere Raum und die Spitzen der Höcker. Nath gekerbt. Brust und Hinterleib genetzt, entweder dunkelschwarzbraun mit hellbrauner Spitze oder durchaus gelbbraun. Die Beine von brauner oder gelblbrauner Farbe.

\section{Chlomys rufa,}

Tab. 1X. Fig. 5.

Clythra thorace gibboso, punctulato, elytris punctatis tuberculatis, rufo-testacea, dorso tuberculisque purpurascentibus, Long. lin. 3 .

Habitat in Brasilia. Misit Dr. de Olfers.

Simillima praecedenti, Brevis, subquadrata. Caput planum rufum mandibulis oculisque nigris. Antennae thorace breviores, serratae, rufae. Thorax elevatus subtiliter punctatus, medio sulcatus litura utrinque media lineari obliqua maculaque postica purpurascentibus. Scutellum rufum basi purpurascens. Elytra-punctato-striata, tuberculata rufo-testacea, medio sanguineo - maculata, tuberculis in singulo elytro tredecin purpurascentibus, baseos duobus majoribus. Sutura crenata. Pectus abdomenque punctata rufa. Pedes concolores.

Aus Brasilien. Drei Linien lang. Selır ähnlich der eben beschriebenen Art; kürzer jedoch und von beinal viereckiger Form. Grundfarbe ein ins Gel'Jliche fallendes Roth. Der Kopf sammt den Fühlern einfarbig. Augen und Frefszangen schwarz. Das Rürkenschild dicht punktirt, fin einen IIöcker erhaben, den eine Längsfurche theilt, an den Sciten heller gefïrbt, nach linten jedoch jederseits dunkel pnrpurroth, aufserdem von oinem hellrothen Streifen, der you dem Miltolpunkt der Spitze yur Mitte des 
Seitenrandes scinräg verläuft durclizogen. Das Schildchen an seinem Grundtheil dunkler. Die Deckschilde in der Mitte dunkler, voll eingedrückter Punkte und mit spitzen dunkelrothen Erhabenheiten besetzt, deren jedoch nicht so viele, als bei der vorhergehenden Art, nur dreizehn etwa auf jeder Decike, unter ilnen zwei von ansehnlicherer Gröfse an der Vurzel unweit der Nath, anzutreffen sind. Dic Nath ist gekerbt. Brust, Bauch und Beine sind punktirt und gelbroth.

\section{Chlamys frenata.}

Tab. 1X. Fig. 6 .

Chlamys thorace elevato gibboso, elytris punclatis basi tuberculatis rufo-testacea, striis tuberculisque ferrugineis. Long. lill. $2 \frac{x}{2}$.

Il abitat in Brasilia. Misit Dr. de Olfers.

Statura praccedentis. Caput punctatum, rufotestaccum linea inter oculos angulari ferruginea. Mandibulae apice ferrugineae. Antennae breves, serratac rufac. Thorax subtiliter granulosus, medio valde elevatus tuberculo emarginato, testaccus dorso rufo-testaceus linea media transversa utrinque a tuberculi apice ad marginem later in ducta, macula baseos obliqua triangulari contigua, margineque postico ferrugineis. Scutellum rufo-testaceum. Elytra sparsim punctata, basi tuberculata apice tuberosa, rufo - testacea, tuberculis quinque, baseos duobus majuribus emarginatis, striaque obliqua transver6a ferrugineis, tuberibus tribus linearibus obtusis concoloribus. Sutura crenata. l'cetus ablomenque reticulatil rufo-testacea. Pedes rufo-testacci, anteriores forruginco - maculati. 
Vaterland: Brasilien. Länge: $2 \frac{x}{2}$ Linien. 'Rothgelb. Der Kopf punktirt; mit einer dunkelbraunen spitzwinklichten Zeichnung an der Stirn. Die Frefszangen mit dunkelbraunen Spitzen. Die Fühler gelbroth.' Das Rückenschild fein gekörnt, mit starkem in der Mitte ausgerandetem Höcker von dessen Spitze nach der Mitte des Seitenrandes, eine braune Linie herablïuft. Noch ist hinter dieser ein brauner schräg g dreieckiger Fleck. Auch ist der gamze hintere Rand dunkelbraun. Das Schildchen ist röthlich. Die Deck schilde punktirt und blassrothgelb, haben an der Spitze drei Beulen von derselben Farbe, ihre vordere Hälfte aber ist mit Höclserchen besetzt, von welchen drei kleinere nach der Mitte zu, die beiden gröfseren dunkelbraun gefärbten und an der Seite ausgerandeten, dem Nathwinkel nahe stehen. Die Nath ist fein 'yezahnt und durch die Deckschilde läuft schräg aufwärts dem Schulterwinkel za eine dunkelbraune Linie. Brust und Hinterleib sind fein genetzt, die Beine röthlichgeỉb, Schenkel und Schíenen des vorderen dunkler rọth gefteckt.

\section{Chlamys aurita.}

Tab. IX. Fig. 7 .

Chlamys punctata, tuberculata, fusca, luteo-masulata. Long. lin. 2.

Habit at in Brasilia. Donavit de Win them.

Elongata, subquadrata. Caput subtilissime punctatum, medio excavatum luteum, vertice macula fusca. Labrum ferrugineum. Mandibulae fuscac. Antenpae thorace breviores, subserratae fuscae, basi ferruginede. Oculi fusci. Thorax utrinque laevis luteus, medio punctato-reticulatus, scaber, fuscus dorso bi- 


\section{$-137-$}

tuberculatus macula media emarginata bascos sulbquadrata maculis duabus lateralibus oblongis, quatnorque ad marginem anticum minoribus obsoletioribus luteis. Scutellum subquadratum fuscum. Elytra punctata, tuberculata, lutea, macula majori flexuosa media,-minoribus lateralibus aliisque ad apicem fuscis. Sutura denticulata. Pectus reticulatum luteum, medio fuscum. Venter luteus, macula media, litura utrinque lineari punctisque ad apicem fuscis. Pedes lutei, femoribus tibiisque macula, tarsis omnino fuscis.

Vaterland Brasilien. Länge zwei Linien. Gestalt länglich viereckig. Farbe röthlichgelb. Der Kopf schwach punklirt, mit einer tiefen Stirngrubo und schwärzlich braunem Scleitelfleck. ' Die Lefze bräunlich, die Frefszangen dunliler. Die Fühler kürzer als das Riickenschild, gesägt, dunkel schwarzbraun, die ersten Glieder hellbraun. Das Rückenschild ist nur in der Mitte grob punktirt, braunschwarz, und dunkel braungelb gefleclit, an den Seiten fast glatt und in Gestalt grofser Flecken rothgelb. Der Rücken endigt in zwei kurze Spitzen mit welchen hinterwärts zwei kaum merkliche Hervorragungen zusammenhängen. Der braunschwarze mittlere Theil ist auf folgende Weise gefleckt: ein nach hinton ausgorandeter Fleck in der Mitte und unmittelbar vor den zugespitztén Rückendornen, ein fast viereckiger. Fleck hinter dem Rückenlü̈ker, ein länglichor zu jeder Seite des IIöckers, vier kleine undeutliche Flecken am vorderen Rande des Rückensclildes. Das Rükkonschildchen ist beinah viereckig und einfarbig braunschwarz. Die Deckschilde sind durch einzeln stchende, ziemlich spitzige Höcker ungleich, in den 
Vertiefungen und am Rande punktirt, rothgelb mit einem grofsen zwischen den Erhöhungen sich windenden grö̈fseren Mittelfleck und einigen kleineren rundlichen Flecken an der Seite und den Enden von braunschwärzlicher Färbung. Die Nath ist gezahnt. Brust und Bauch sind leicht genetzt, rothgelb, in der Mitte schwarzbraun, ein Queerstrich an der Seite des Unterleibes und ein kleiner Fleck ljederseits an der Spitze vor dem letzten, Bauchsegment sind von der nämlichen Färbung. Die Beine sind rothgelb, die Schenkel so wie die Schienen aufsen in der Mitte mit einem braunen Fleck bezeichnet. Die Fufsolieder sind schwärzlich,

\section{Chlamys echinate.}

Tab. IX. Fig. 8 .

Chlanys crocea, elytris, tuberculis ferrugineis. Long. lin. $2 \frac{x}{2}$.

Patria: Brasilia. Misit Dr. de Olfers.

Statura pracedentium. Caput punctatum nacula media mandibulisque ferrugineis. Antennae serratae, articulu primo dorso, ultimis quatuor ommino ferrugineis. Thorax sultilissime punctatus, dorso granulatus bielevatus. Scutellum breve. Elytra punctatostriata tuberculata, tuberculis in singulo elytro tredecim, illis baseos apicisque elevatioribus ferrugineis, intcrmediis minoribus concoloribus. Sutura subtilissime denticulata. Pectus abdomenque subtilissime reticulata lacte crocea. ledes crocei femoribus tibiisque puucto ferruginco.

Aus Brasilien. Lünge $2 \frac{r}{2}$ Linien. Farbe lebhaft saffrangelb. Der Kopt punlitirt nit brauncu Stirnfleck und Frefszangen. $\Lambda$ den lkurzen gesägten Fiih- 


\section{- $159-$}

lern sind die Endglieder durchaus, vom ersten Glicie nur die obere Seite dankelbraun. Der Rückenschild ist Isehr fein punlitirt, in der. Mitte körnicht, in zwei stumpfrunde Höcker auslaufend. Das Schildchen ist nur lkurz. Die Deckschildo laben Punktstreifen und etwa 3 Höcker, von welchen die beiden an der Wurzel und die an der Spitze durch ansehnlichere Gröfse und dunkle Färbung sich auszeichnen, die Höcker in der Mitte der Deckschilde dagegen, da sie kleiner und gleichfarbig sind, weniger auffallen. Die Nath ist sehr fein und kaum merlslich gezähnelt. Brust und Bauch sind höchst fein genetzt, hellgelb. Die Beine sind gelb, Schenkel und Schienen mit einem braunen Punkt bezeichnet.

\section{Chlanys porosa.}

Tab. IX. Fig. 9.

Chlamys punctata, rufo-testacea, ferrugincomaculata, elytris ferrugineis, tuberculis rufo-testaceis. Long. lin. 3.

II a b it a t in Brasilia. Misit Dr. de Olfers.

Habitus Chl. fuscipedis, rutilae et affiniun. $\mathbf{C a}$ put planum, macula media marginibusque ferrugineis. Labrum' emarginatum. Antennae breves luteae. Mandibulac ferrugineae. Thorax subglobosus ubique punctatus, dorso vix bituberculatus, ferrngineo-maculatus, margine postico fusco. Scutellum, ferrugineum macula media rufa. Ilytra ubique impressopunctata ferruginea, lineolis tuberculisque obtusis glabris rufo-testaceis variegata, basi fusco-marginata, margine interno subtiliter denticulata. Pectus abdomenque levissime punctata, ferrugineo-maculata. Pa des femoribus tiliisrque medio olsscmioribus. 
Aus Brasilien. Drei Linien lang. Gestaltet wie Chlamys fuscipes. Grundfarbe gelbroth. Der Kopf flach, kaum punktirt, ein Stirnfleck und der ganze sichtbare Rand rothbraun. Die Frefszangen braun, Die Fühler kürzer als das Rückenschild, einfarbig rothgelb. Das Rückenschild dicht punktirt, mäfsiog gewölbt, nach hinten in zwei kleine Erhöhungen auslaufend, überall dicht punktirt, rothbraun gefleckt, mit schwarzbraunem Hinterrande. Das Schildchen fast viereekig, braun mit rothgelbem Mittelfleck. Die Deckschilde voll tiefer eingestochener Punkte oder Grübchen, rothbraun, an Vorderrande schwarzbraun mit einem dicht anstofsenden Streif und auf der ganzen Fläche vertheilt mehreren theils linien - theils punktförmigen glatten Erhöhungen von rothgelber Färbung. Die Nath ist selır fein gezahnt, Brust und Minterleib sind fein genetzt, schwach gefleckt, die Beine gleichfalls gelbroth, nur Schenlicl und Schienen in der Mitte etwas dunkler.

\section{Chlamys 'corallina.}

Tab. IX. Fig. 10.

Chlamys rufescens capite thoraceque punctatis fusco-maculatis, elytris reticulato-tuberculatis. Long. lin. $2 \frac{x}{2}$.

Patria: Brasilia. Misit Dr. de Olfers.

Antecedentium habitu. - Color fere luteus. Caput planam, macula frontali mandibulisque fuseis. Antennae scrnatae luteae apice nigrae. Thiorax punctatus margine postico macnlisque fuscis. Scutellum parvun. Elytra rufa punctala punctis fuscis impressis, rugoga, tuberculata, tuberenlis transversis linearibus compressis aculis, uno ad basin pone medium, altero 


\section{$-141$}

ad suturam majoribus. Sutura acute denticulata. Pectus abdomen pedesque subtilissime reticulata Inteá.

Vaterland Brasilien. Länge $2 \frac{x}{2}$ Linien. Die Grundfarbe ist lebhaft rothgelb. Am Kopf ein Stirnfleck, die Frefszangen nnd Fühlerspitzen, am Rïkkenschild, welches gewölbt und seicht punktirt ist, der Ilinterrand und einige Flecken'schwarzbraun. Das Schildchen ist nur klein. Die Deckschilde sind dunkler roth, voll tief eingedrückter schwärzlicher Punkte, und ungleich durch Queerhöclier, welche zusammengedrückt und zugeschärft und von welchen der eine unweit der Mitte des vorderen Randes, der andere in der Mitte der Nath grörser als die übrigen sind. Die Nath ist fein, aber scharf und deutlich gezahnt. Brust, Hinterleib und Beine sind fein genetzt, und etwas heller gefärbt, als der übrige Körper.

\section{Chlamys exarata.}

Tab. IX. Fig. 11.

Chlamys rufa, thorace colcoptrisque rugosis, quadri-sulcatis. Long. lin. $2 \frac{2}{3}$.

Habitat in Brasilia. Misit Dr. de Olfers.

Statura fere praecedentium. Color fere sanguineus. Caput planum, punctatum, antennis apice mandibulisque nigris. Thorax gibbosus valde rugosus, snlcis quatuor apice coëuntibus nigris exaratus, dorso quadri-tuberculatus, tuberculis coacervatis obtusis. Scutellum concolor. Elytra lineis longitudinalibus elevatis lineolisque transversis reticulata, rugosa, bisulcata, sulcis longitudinalibus, exteriori interrupto, profundis nigris. Sutura denticulata. Pectus reticu= latum. Abdomen reticulatum apice punctatum. Pedes punctati, tibiis macula fusca. 
Aus Brasilien. Mehr als $2 \frac{x}{2}$ Linien lang. Hochroth, oben fast blutroth. Der Kopf punktirt. Fühlerspitzen und Frefszangen schwarz. Der Rücken gewölbt, sehr uneben, von vier in der Tiefe dunkelgefärbten vorn zusammenstofsenden Furchen 'durchzogen, die höchste Spitze auslaufend in vier dicht zusammengedrüngte stumpfe Höcker. Das Sciildchen einfarbig. Die Deckschilde gegittert, indem erlabene Längslinien durch Queerstriche verbunden sind, aufserdem gefurcht, zwei in der Tiefe geschwärzte Furchen auf jeder Decke, die auswendige dicht über der Mitte abgesetzt und unterbrochen. Der Innenrand ist deutlich mit scharfen Zähnchen besetzt. Die Brust ist leicht genetz.t. Der Hinterleib genetzt, an der Spitze punktirt. Auch die Beine sind punktirt und haben die Schienen einen schwärzlichen Fleck.

\section{Chlamys sellata.}

Tab. IX. Fig. 12.

Chlamys rufa, punctata, elytris linea elevata transversé divisis. Long. lin. 2.

Patria: Parà. Misit Sieber. Ex Museo Comit. de Hoffmannsegg.

Subquadrata. Caput planum, rufo-testaceum, antennis apice mandibulisque nigris. Thorax subtilissime granulatus gibbosus luteus dorso canaliculatus utrinque ferrugineus. Scutellum ferrugincum. Elytra lineolis elevatis punctisque impressis inaequalia obscure rnfa ad basin testacea, subtuberculata medio ferruginea lineaque elevata flexuosa obliqua divisa. Sutura denticulata. Pectus subtiliter reticulatum obscure rufum niedio nigrum. $\Lambda$ betomen reticulatum, apice punctatum, rufum. Peles ruf, tarsis ferrugincis. 


\section{$-145-$}

Von Parà in Brasilien. Zwei Línien lang. Ziemlich viereckig. Der Kopf Aach, gelbroth. Fühlerspitzen und Frefszangen schwarz. Das Rückenschild fein gekörnt, gelbroth, in der Mitte erhaben, der Höclier lebliaft rothgelb, durch eine Furche in der Mitte getheilt and neben dicser rothbraun gefïrbt. Das Schildchen klein und braun. Die Deckschilde voll eingedrückter Punkte und hin und wieder erhöheter Linien, in der vordern Hälfte auf blafs gelblichgrauem Grunde einige unbedeutende Höcker, durch die Mitte schräg vom Aufsenwinkel nach der Nath ein brauner Streif und vor demselben eine mehrfach gebogrene erhabene und scharfliantige Gränzlinie. Die Nath ist fein gezahnt. Brust und Hinterleib sind genetzt, röthlich, erstere in der Mitte schwarz, letzterer an der Spitze punktirt. Dic Beine sind gelbroth bis auf die Fúsglieder, welche dunkelbraun sind.

\section{9. 'Chlamys pellucida.}

Tab. X. Fig. 1.

Chlamys thorace granulato punctato elytris rugosis, punctatis, ochracea, rubro-maculata. Long. lin. $2 \frac{T}{2}$.

Patria: Para in Brasilia. Misit Sieber. Ex coll. Comit. de Hoff mannsegg.

Statura praecedentium. Laetc ochracea et sue. cini instar subpellucida. Caput adpressum subpunctatum, vertice sanguineo macula media nigricanti. Mandibulae ferrugineac. Antennae dorso apiceque fuscac. Thorax elevatus, fascia transversa media maculisque duabus posticis rubris. Scutellum ferrugineum. Elytra lineis subelevatis tuberculisque ob- 
tusis inaequalia, granulata, punctata vitta laterali maculaque dorsali communi rubris, punctis sparsim impressis nigricantibus, sutura denticulata. Pectus abdomenque subtilissime reticulata. Pedes punctulati. Vaterland Park̀. Länge $2 \frac{\pi}{2}$ Linien. Lebhaft bräunlichgelb, in manchen Richtungen durchscheinend wie Bernstein. Der Kopf flach, wenig punktirt, nach hinten dunkelroth mit einem schwärzlichen Scheitelfleck. Die Fühler sind oben und an den Spitzen schwärzlich, die Frefszangen schwarzbraun. Das Rülkenschild ist stark gewölbt, überall feinkörnicht, durchzogen von ciner breiten rothen, fast zimmetbraunen Binde, hinter welcher noch zwei Flecken von der nemlichen Fürbung und aufserdem überall auf der ganzen Fläche leicht eingestochene dunklere Punkte zerstreut sichtbar sind. Das Schildchen ist braun. Der Grund der Deckschilde ist wie bein Rückenschilde fein gekörnt, dann auch durch einige nur wenig erhabene bogenförmig verlaufende und zurücklaufende Linien ungleich. Die eingedrückten Punkte sind hier noch deutlicher und dunkler als auf dem Rückenschilde. Die Seiten sowohl als der Rüicken der Deckschilde sind dunkler roth und ganz so, wie die dunklen Stellen des Rückenschildes gefärbt. Die Nath ist fein und scharf gezahnt. Brust und Minterleib sind fein genetzt, die Beine punltirt.

\section{Chlamys reticulata.}

Tab. X. Fig. 2.

Chlamys thorace punctato, elytris punctato-reticulatis, basi tuberculatis, ochracca ferrugineo-macu= lata. Long. lin. $2 \frac{x}{2}$.

Habitat in Brasilia. Misit Dr, de Olfers.

Sta- 


\section{$-145$}

Statura praccedentium. Caput punctatum ferrugineum medio rufum. Labrum laeve rufum. Mandibulae ferrugineae. Antennae serratae fuscae basi ferrugineae. Thorax globosus, impresso-punctatus ochraceus, dorso ferrugineo-maculatus. Scutellum brevissinum ferrugineum. Elytra reticulata ubique punctata, sublineata, basi subtuberculata ochracea macula humerali, litura bascos, fascia maculari transversa apiceque ferrugineis. Pectus punctatum ferrugineum. Abdomen ochraceum ferrugineo - maculatum。 Pedes ferruginei.

Vaterland Brasilien. Länge $2 \frac{1}{2}$ Linien. Gestalt wie gewöhnlich. Hell roth - oder braungelb.' Dex" Kopf punktirt, an den Seiten rothbraun. Die Lefuc glatt, glänzend und hell gefärbt. Die Frefszangen dunkler. Die Fühler gesägt, fast schwarz, die beiden ersten Glieder braunroth. Der Halsschild ziemlich gewölbt, voll flach eingedrücliter Punkte, und oben in einander laufender braunrother Flecke. Das.Rükkenschildchen sehr kurz, rothbraun. Die Deckschilde fein genetzt, voll Vertiefungen, höckricht nur am Vorderrande und in der Mitte der Nath, braungelb mit rothen Flecken, von depen einer am Atursenwink el befindlich ist, die andern in Gestalt einer Binde dic Mitte der Deckschilde durchziehen. Aurerdem sind noch die Spitzen der Deckschilde und ein Schatten am vorderen Rande derselben rothbraun. Brust und Hinterleib sind fein punktirt, wie genetzt; erstere rothbraun, letzterer hell braungelb mit rothbraunen Flecken. Die Bcine sind einfarbig liraun. 


\section{Chlamys gुrranulata.}

Tab. X. Fig. 3 .

Chlamys thorace gibboso granulato, elytris t11berculatis reticulatis, rufa, antennis apice nigris. Long. lin. 2.

Il a bitat in Brasilia. De Winthem.

Elongata, subquadrata, rufo-ferruginea. Caput punctatum, punctis obiter impressis, labro luteo, mandibulis oculisque nigris. Antennae thoracis fere longitudine compressac, serratae, luteae, apice nigrae. Thorax ubique granulatus, dorso gibbosus gibbere rotundato obtuso. Scutellum parvum. Elytra tubera culis compressis linearibus acute carinatis reticulata, in interstitiis foveolata, sutura crenata. Pectus aldomenque obsolete reticulata, segmento anali punctulato testacco. Pedes rufo-testacei.

Ans Brasilien. Zwei Linien lang. Von länglicht viereckiger Gestalt und lebhaft rothbrauner Tärbung. Der Kopf ist seicht punlitirt, die Lefze gelbbräunlich, Augen und Mandibeln schwarz. Die Fühler, etwa so lang als das Rückenschild, sind zusammengedrückt, gesägt, rothgelb mit schwarzen Spitzen. Das Rückenschild ist übcrall fein gekörnt, in der Mitte in einen rundlichen Höcker erhöhet. Das Schildchen ist nur klein. Die Deckschilde erscheinen verschiedenariig genetzt, weitliiuftiger durch erhöhete Leisten, mil scharfen Kanten, welche in gerader oder schrïger Richtnng die Deckschilde durchziehen, und mehrentheils ìurch kürzere Queerleisten verbunden sind, enger durch grubenförmige Vertiefungen, welche sich in den auf eben angerebene Weise gebildeten Zellen, jeloch auch aufserden und 


\section{$-147-$}

zahlreich an den Spitzen der Decken finden. Die Nath ist fein gekerbt. Die untere Scite ist flach genetzt, die Endspitze des Hinterleibes gelblich mit schwach eingestochenen Punkten. Die Beine sind einfarbig gelblichroth.

\section{Chlamys maculata.}

Tab. X. Fig. 4.

Chlamys lutea, elytris reticulatis dorso sangui. neo-maculatis. Long. lin. $2 \frac{x}{4}$.

Habitat in Brasilia. Misit Dr. de Olfers.

Simillima praecedenti. Color laete fulvus. Ca* put planum, antennis apice mandibulisque nigris: Thorax subelevatus subtilissime punctulatus, lucidus dorso rufo-maculatus. Scutellum margine rufum. Elytra lineis elevatis reticulata, foveolata, nec tuber culata, basi apiceque sanguinolenta medio sanguineo. bimaculata. Sutura crenata. Pectus abdomenque subtilissime reticulata. Pedes punctulati femoribus tibiiscrue medio subrufis.

Aus Brasilien. Kaum länger als 2 Linien. Sehr ähnlich der vorhergehenden Art, nur ohne Höcker auf den Deckschilden. Grundfarbe leblaft rothgelb wie durchscheinend. Dor Kopf flach. ITandibeln und Fühlerspitzon scliwarz. Das Rückenschild etwas gewülbt, Iraum merklich punktirt, auf der Höhe und nach vorn etwas rothgefleclst. Das Schildchen klein mit dunlilerem Rande. Die Deckschilde leicht ge. netzt, voller Grübchen, vorn, besunders am Schul. terwinkel und an den Spitzen roth gefïbt, in der Mitte roth gefleckt. Fleclie sind zwei von lïnglich. runder Gestalt, einer noben dem endern in der Nähe der Nath, Diege iot foin gezalnt. Brust und IIIn. $10 *$ 
terleib sind fein genetzt, die keine Icicht punktirt, Schenkel und Schienen in der Mitte röthlich.

\section{Chlamys condita.}

Tab. X. Fig. 5.

Chlamys Intea, rufo-maculata, elyiris sparsim subtuberculatis. Long. lin. $2 \frac{\mathrm{T}}{2}$.

Ha bitat in Brasilia. Misit Dr. de Olfers.

Statura fere Chl.rutilae ac rufae. Caput planum punctulatum immaculatum. Antennae breves serratae unicolores. Mandibulae ferrugineae. Thorax subglobosus, subtiliter punctatus, dorso tuberculatus, tuberculis parum elevatis rufescentibus granulosis apice subrecurvis. Scutellum parvum. Elytra indislincte reticulata, impresso-punctata, punctis nigricantibus, medio apiceque tubérculata, pallida, macula magna axillari et suturali obliqua rufis. Sutura denticulata. Pectus abdomenque reticulata. Pedes punctulati.

Aus Brasilien. Länge $2 \frac{x}{2}$ Linien. Gestalt der Chlanys rutila. Rothgelb. Die Fühler einfarbig, die Frefszangen braun. Das Rückenschild fein punktirt, in der Mitte in einen doppelten jederseits rothen gekörnten Ilöcker mit etwas rückwärts gekrümmten Spitzen erhoben. Das Schildchen sehr klein. Die Deckschilde durch kaum merklich erhabene Linien genetzl, von der Mitte ab nach der Spitze zu mit kleinen spitzen Höckerchen besetzt, blafs röthlichgelb gefärbt voll eingedrückter schwärzlicher Punkte und geziert mit einigen rothen Flecken, von welchen eigentlich nur zwei, der eine am Schulterwinkel, der andere als ein schräg von der Nath aufwärts steigender Schatten in der Mitte der Deckschilde deutlich und, begräm» sind. Die Nath ist fein gezahnt. 
Brust und Bauch erscheinon fein genetzt, die Beine punktirt.

\section{Chlamys difformis.}

Tab. X. Fig. 6 .

Chlamys ferruginea, elytris reticulatis inaequalibus thoraceque fuscis, vitta media lateribusque forrugineis. Long. lin. $2 \frac{x}{2}-3$.

Chlamy's difformis O livier Entomologie VI. Suite du Nr. g6. p. 875. n. 2. pl. 1. f. 2.

Habitat in Brasilia. Misit Dr. de Olfers.

Elongata, elevata, medio compressa, apice truncata. Caput planum subpunctatum rufum, fronte linea longitudinali media elevata abbreviata. Labrum emarginatum. Antennae scrratae rufae, apice nigrae. Mandibulae nigrae. Thorax elevatus granulatus fuscus, sulco longitudinali medio lateribucque ferrugineis. Scutellum ferrugineum. Elytra valde reticulata, lineis elevatis versus apicem tuberculatis inaequalia, fusca linea elevata longitudinali obliqua lateribusque fusco-ferrugineis. Sutura crenata, l'ectus abdomenque subtilissime reticulata ferruginea. Pedes ferruginei.

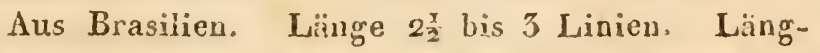
lich viereclig in der Mitte zusamnongedrückt, das Ende gerade abgeschnitten. Der Kopf flach punlitirt, braunroth, mit einer kurzen erhabenen Stirnlinie. Die Fühler roth mit schwarzen Spitzen. Die Frefszangen schwarz. Das Rückenschild erhaben, fein geliörnt, dunkel schwarzbraun; eine seichte Längsfurche in der Mitte and die Seiten sind braunroth. Das Schildchen braunroth. Die Deckschilde stark genctal, von erhöheten Linien besonderss der Länge 
nach durchzogen, die gegen die Spitze in stumpfe Höcker auslaufen. Di̊ Farbe der Deckschilde ist die des Rückenschildes, nur eine erhöhete Linie, die schräg von dem Schulterwinkel nach der Mitte der Deckschilde verläuft, die Seitenwand und die Spitzen sind braun. Die Nath ist deutlich gezalnt. Brust und Bauch sind fein genetzt und sammt den Bcinen braunroth. .

55. Chlamys cinnamomea.

Tab. X. Fig. \%.

Chlanys rufa, thorace elevato rugoso, elytris crenato-linealis punctato-reticulatis sanguineo-maculatis. Long. lin, $2 \frac{x}{2}-3$.

Habitat in Brasilia. Misit Dr. de Olfers.

Statura fere praecedentis. Caput planum, punctatum, medio impressum, macula ferruginea. IMandibulae fusco-ferrugineae. Antennae serratáe nigrae, articulis prioribus rufis. 'Thorax granulatus medio elevatus, utrinque sanguineus. Scutellum parvum obscure rufum. Mlytra ad marginem exteriorem et ad suturan sanguineo-maculata, elevato-lineata, in interstitiis punctala, lineis longitudinalibus subarcuatis dorso crenatis, nomullis in tubercula exeuntibus, partim apice coecuntibus. Sutura denticulata. Pectus subtiliter retioulatum, Abdomen reticulatum ultimo segmento lineis tribus elevatis longitudinalibus glabris abbroviatis. Pedes anicolores.

Aus Irasilien, Bis drei Linien lang. Beinah gcstaltet, wie die vorbeschriebeno Art, Farbe dunlielroth, dem Brałn sich nähernd. Der Kiopf punlitirt, tlach, fast oingedrückt, mit eincm dunklen Stirnfleck. Die Frefszangen schwarzbraun. Die Fühler deutlich 
gesägt, schwarz, die drei crsten Glieder roth. Das Rückenschild groblkürnicht, in der Mitte stark erhaben, an den Seiten dunkel- und fast blutruth. Das Schildcken klein und dunkel. Die Deckschilde, von crhabenen auf der Kante fein gekerbten, nicht ganz geraden sondern bogigten, mitunter, wic an der Nath, in Höcker sich erhebenden, zum Theil in einander ïbergehenden Linien der Länge nach durchzogen, sind iu den Zwischenräumen punktirt und sind sowohl diese ziemlich regelmäifsig eingestochene Punkte dunkler gefärbt, als auch die Zwischenräume überhaupt, besunders seitwärts und am Nathwinkcl, dunkelblutroth, wodurch die Deckschilde dunkel gefleckt erschcinen. Brust und IInterleib sind fein genctzt, letzterer an der Spitze dunkler, und das Endsegment selbst auf seiner Aufsenflïche von drei stump erhabenen glatten und liclleren Linien fast durchzogen. Dic lscinc haben dic Farbe des Kürpers.

\section{Chlanys lutcold.}

Tal. X. Fig. 8.

Chlamys subtuberculata sulphurca, thorace macula dursali, clytris punctis purpureis. Long. lin. 2.

Chlamy's 7uleole G erm. Ins. Spec. I. 1. 554, 11. 753.

Ilabilat in Brasilia. Misit Dr. de Olfers.

Statura fere C. maculatac. Caput planum, litura ad antemnarum insertionem macularge frontali purpurcis. Antennac vix thorace breviores luteac apice nigrae. Mandibulae ferrugineac. Thorax maculis utrinque tribus e punctis purpureis, melio a basi ad apicem usque purpureus, subgriblosus, postice subtuberculatus, tuberculis granulatis. Scutellum purpureo-marginatum. Elytra sparsim subtuberculata, 
punctis impressis purpureis. Sutura denticulata. Pectus abdomenque subtilissine reticulata, Pedes graciles. Tibiae lurido - annulatae.

Aus Brasilien. Zwei Linien lang. Gestaltet wie die mehrsten der Vorhergehenden. Duntrel schwefelgelb. Der Kopf an der Einlenkung der Fühler und mitten auf der Stirn purpurfarben. Die Fühler, fast so lang als das Rückenschild, gelb mit schwarzen Spitzen. Die Frefszangen dunkelbraun. Das Rückenschild punktirt, an den Seiten purpurroth gefleckt, die Flecken aus Punkten zusammengesetzt, in der Mitte kugelförmig erhaben, bis zum vordern Rande hin dunkel purpurfarben, nach hinten in zwei kleine körnichte Höclter auslaufend. Das Schildchen roth gerandet. Die Deckschilde hin und wieder nit seichten Höckerchen besetzt und mit eingestochenen purpurrothen Punkten übersäet. Die Nath fein gezahnt. Brust und Hinterleib sehr fein genetzt. Die Beine ziemlich dünn und läuger als gewöhnlich, die Schienen mit bräunlich - gelbem Ringe.

\section{Chlanys impressa.}

Tab. X. Fig. 9.

Chlamys atra, thorace elytrisque rufis atro-maculatis. Long. lin. $1 \frac{x}{2}$.

Clythra impressa Fabr. Syst. Elcuth. II. p.33.'n. 22.

Chlamys impressa S chönh er r Synonymia Ins.

11. p. 343.11 .5 .

Habitat in America meridionali. Habr. 1. c.

Specimen e Mtuseo de Sehestedt, nunc Regio Havmiensi ad describendum communicatum.

Statura C. foveolatac. Caput atrum labro antennisque nigro-piceis. Thorax clevalus rufus, maculi 
quatuor impressis, dorsalibus duabus majoribus sinuatis, punctoque utrinque atris. Elytra inaequalia rufa, maculis quatuor impressis, margine antico, suturaque vix denticulata atris. Pectus subtilissime reticulatum atrum. Abdomen atrum, macula utrinque fasciaque anali rufis. Pedes nigri.

Aus Südamerika. Länge $1_{2}^{\frac{x}{2}}$ Linien. Gestalt der Chlamys foveolata. Kopf mattschwarz. Lefze und Fühler bräunlich. Rückenschild roth, mit vier tiefschwarzen Flecken; die vorderen länglich bogigt und gröfser, die hinteren dicht dem Hinterrande anliegend. Aufserdem mitten im Seitenrande ein schwarzer Punkt. Die Deckschilde sind ungleich, roth mit vier eingedrückten tiefschwarzen Flecken. Auch sind die Schultern sammt dem vordern Rande, und eben so der innere Rand schwarz, letzterer undeutlich und sehr fein gekerbt. Die Brust ist fein 'genetzt und mattschwarz. Ebcn so der Hinterleib, nur zu jeder Seite vor dem letzten Abschnitt steht ein rother Fleck und das letzte Segment durchschneidet eine rothe Queerbinde. Die Beine sind schwarz.

\section{Chlanys labiata.}

Chlamys thorace elytrisque punctatis, plicatis, nitida, cyanea, labro antennisque rufis. Long. lin. $2 \frac{\pi}{2}$.

Patria: Brasilia. Misit Dr. de Olfers.

Nitidissima cyanea. Caput punctatum fronte foveola media impressa. Mandibulae nigrae. Antennae thorace breviores luteae apice nigrae. Thorax sparsim punctatus dorso utringpe tuberculatus, tuberculo obtuso, medio bicarinatus. Scutellum immersum. Elytra sparsim punctata, lincis arcuatis acute 
elevatis ruß̧osa, basi tuberculata, sutura crenata. Peclus abdumenque punclata. Pedes concolores.

Aus Brasilien. Länge $2 \frac{x}{2}$ Linien. Lebhaft blau. Der Kopf punktirt, auf der Stirn eine eingedrückte Grube. Lefze roth. Frefszangen schwarz. Tühler inesägt, gelbroth mit schwarzen Endgliedern. Das Rückenschild hin und wieder punktirt, in der Mitte zwei scharf erhabcne Linien, die durch eine glatte Furche getheilt sind, zu jeder Seite ein stumpfer und glatter IIöcker. Das Schildchen vertieft. Die Deckschilde einzoln punktirt, uneben durch gekrümmt verlaufende unter sich verbundene scharf erhabene Linien; einige IIöcker am Grundtheil; die Nath gelerbt. Brust und Bauch voll eingedrückter Punkte. Die Beine wie der Körper gefärbt.

\section{Chlamys puncticollis.}

Chlamys thorace punctato biclevato, elytris plicatis, tola cyanca. Loug. lin. $2 \frac{\mathrm{T}}{2}$.

Chlany's punclicollis Germ. Ins. Spec. I. p. 553. n. 752 .

Patria: Buhia, Misil Sello.

Similis pracceienti. Cyanea, nitida. Caput punctatum frunte fovcola impressa. Labrum masdibulacque nigra. Antennale compressae, serratae, nigrae, articulo primo pallido supra cyanco. Thorax sparsim punctatus, dorso bielevatus, tuberculis obtusis, medio sulcatus. Scutellum quadrangulare impiressum lacve. Nlytra sparsim punctata plicata, basi tuberculata, sutura crenaia. Pectus reticulatum. Abdomen lacve, lateribus punctatum. Pedes lacres cyanci. 


\section{- $155 \pi$}

Vón Bahia. Länge $2 \frac{T}{2}$ I Iinien. Glänzend blau und gestaltet wie dic vorhergehende Art. Auf der Stirn ein Grübchen. Lefze und Frefszangen schwarz. Dic Fühler gesägt, schwarz, das erste Glied blafs, oben blau. Der Rückenschild hin und wieder punktirt, in der Mitte gefurcht, zu jeder Seite eine stumpfo und glatte Erhabenheit. Das Rückenschildchen glatt, eingedrüclkt, viereckig. Dic Deckschilde leicht punktirt, faltig durch gebogene erhabene Quecrlinien, an der Wurzel höckrig. Die Brust 'genetzt. Der Hinterleib glatt, an den Seiten punktirt. Die Beine glatt.

\section{Chlamys smaragdina.}

Chlamys thorace elytrisque punctatis tulserculatis, viridis, labro luteo. Long. lin. $2 \frac{2}{3}$.

Il abitat in Brasilia. Dr. de Olfers.

Lacte viridis subaurata. Caput punctalum foveola inter oculus impressa. Mandibulac nigrae. Antennac breves scrratae, luteae apice nigrae, articulo primo supra viridi. Thorax punctatus, tuberculatus, medio sulcatus. Scutellum parvum. Elytra sparsin punctata, plicata, basi tuberculata, sutura vix erenata. Pectus abdomenque punctata. 'Tarsi nigri.

Aus Brasilien. Lünge $2 \frac{2}{3}$ Linien. Lebhaft hellgrün mit schwachom Goldglanz. Kopf punktirl, in der Mitte glatt mit einem Grübchen. Trefszangen schwarz. Lefzc rothgelb. Fühler lsurz, gesïgrt, rothgelb, Endylieder schwarz, Wur\%elglied oben grüı. Das Rückenschild einzelı punltirt und mit mehreren glatten, goldglinzenilen Hïclern besetzt. Schildehen 
klein. Deckschilde einzeln punktirt, ungleich durch erhabene Linien und Höcker. Brust und Hinterleib punktirt. Beine glatt mit schwarzen Fufsoliedern.

\section{Chlamys bicolor.}

Tab. X, Fig, Io.

Chlamys rufa, thorace elytrisque punctulatis atris: Long. lin. $2 \frac{x}{2}$.

Habitat in Brasilia, Misit Dr. de Olfers.

Statura fere praecedentium. Caput mineum macula triangulari occipitali mandibulisque nigris. Antennae vix thorace breviores rufae, apice nigricantes. Thorax subtilissime punctatus, cano-sericeus, medio gibbosus obtusus. Scutellum subquadratum, atrum. Elytra holosericea punctata sparsim tuberculata, tuberculis vix elevatis, obtusis. Sutura denticulata. Pectus abdomenque subtilissime reticulata, minea. Pedes concolores.

Vaterland Brasilicn. Länge $2 \frac{T}{2}$ Linien. Die untere Seite sammt Kopf und Beinen lebhaft mennigroth. Am Hinterkopf ein schwarzer dreieckiger Fleck. Die Frefszangen schwarz. Die Spitzen der Fühler schwärzlich. Rüclienschild und Deckschilde mattschwarz, etwas ins Grünliche spielend, seidenartig glänzend wegen dicht aufliegender weifslicher Härchen. Das Rüclzenschild fein punktirt, in der Mitte rund gewölbt. Die Deckschilde aufser eingestochenen Punkten mit stumpfen Höckerchen besctzt, die gewissermafsen einc Längsreihe ziemlich in der Mitte der Decken, doch nülıer der feingezahnten Nath bilden. 
62. Chlamys speculum.

Tah, X, Fig. 11.

Chlanys rugosa cupreo-fusca, elytris maculis duabus impressis holosericeis atris. Long. lin. 2.

Patria: Brasilia; Misit Dr. de Olfers.

Subglobosa, obscura, cupreo micans. Caput planum labro antennisque luteis. Mandibulae nigrae. Thorax vix elevatus subrugosus dorso canaliculatus. Scutellum minimum. Elytra reticulato-rugosa, medio maculis duabus rotundatis suboccllaribus atris. Sutura subtiliter denticulata. Pectus abdomenque re.ticulata. Pedes punctati. Tibiae striatae, basi apiceque luteae. Tarsi lutei.

Aus Brasilien. Zwei Linien lang. Von beinah kuglichter Gestalt und einer' dunkel schwärzlichen zum Kupferrothen, sichr "neigenden Färbung. Lẹfzen und Fühler sind rothgelb, die Frefszangen schwar\%. Das Rückenschild ist eben nicht gewölbt, überall schwach gerunzelt, in der Mitte gefurcht. Das Schildchen schr klein. Die Deckschilde sind netzartig gerunzclt, die Nath fein gezahnt. In der Mitte stehen neben einander $\mathrm{z}_{\text {wei }}$ runde, tiefer liegende, sammetschwarze, von einem kaum wahruelımbaren helleren Ringe umgebene Flecke. Brust und Bauch sind genetzt, die Beine punktirt, die Schenkel gestreift, an beiden Enden rothgelb, die Fufsglieder rothgelb. 


\section{$-158-$}

\section{Chlannys pilula.}

Tab. X. Fig. 12 .

Chlamys fusca globosa pedibus dilatatis compressis, tibiis subtrigonis. Long. lin. $2 \frac{T}{4}$.

Patria: Parà in Brasilia. Misit Sieber. Ex coll. Comit. de II of $\mathrm{fm}$ an $\mathrm{n}$ segg g.

Brevis, subglobosa, obscura, fusco-aenea. Caput punctatum, labro piceo. Mandibulae nigrae. Antennae breves serratae, luteac. Thorax sparsim punctatus, vix tuberculatus. Scutellum transversum, subquadratum, inter suturam paululum porrectum. Elytra punctato-striata, tubcrculata, tuberculis numerosis oblusis, margine interno integerrimo. Pectus utrinque ad pedes anticos recipiendos excavatum. Pleurae reticulatac. Abdomen punctatum. Pedes ssubtiliter punctati breves. Femora plana dila. tata, orbiculata. Tibiac apice crassiores dilatatae, truncatie. Tarsi-brevissimi.

Von Parà in Brasilien. Läng $2 \frac{x}{4}$ Linien. Fast kugclrund dunkel braunschwarz mit schwachem Kupferglanz. Kopf punktirt, Lefze glatt dunkelbraun, Frefszangen schwarz. Tïhler lurz, gesïgt und rothgelb. Das Riickenschild kaun erhaben punlitirt und hin und wieder liöckricht, die Höcker stumpf und kaum bemerkbar. Das Schildchen, nicht ganz vicreckig, lïnft zwischen der Nath in eine Spilze aus. Die Deckschilde tragen eine Menge-stmmper IÏikker und in Reilien eingestochener Punkle. Die Nath ist glatt. Die Brust ist zur Aufuahme der vordersten Beine tief ausggehühlt, die Brustseiten sind gुenetzt, der Hinterleib voll eingestochener lunlife. 
Die Beine sind nur kurz, deutlich fein punlitirt, dir Schenkel fiach, scheibenförmig erweitert, die Schicnen an der Spitze sehr erwcitert, abgeschnitten. Die Fufsglieder sehr kurz, an der innern Seite der Schienen eingelenkt.

\section{Chlamys (?) braccata.}

Tab. VI. Fig. 9.

Chlamys tuberculata brunnea, passim argenteosericea, antennis testaceis apice nigiris. Long. lin. $2 \frac{\pi}{2}$.

Patria: - - Ex Mrusco Comit: de Hoffmannsegg go

Brevis. Brunnea pilis brevibus aurato-argentatis undique fere arcte adjacentibus micans. Caput medio impressum, labro iransverso vix emarginato testaceo, mandibulis nigricantibus. Antennae corpore longiores testaceae, articulo ultimo apice nigro. Thorax ubique tuberculatus, tuberculis parum elevatis. Sctitllum subtriangulare apice elevato, subrellexo, truncato, subenarginato. Elytra rugosa, basi elevato-lineata, apice tuberculata, tuberculis clongatis, obtusis. Pectus abdomenque punctulata. Femora punctata, postica incrassata. T'ibiae basi pallidae, apice cum tarsis fuscae.

Vaterland unbekannt. Länge $2 \frac{T}{2}$ Linicn. Küirzer als die mehresten Chlamys und in der Gestalt beinah cinem Cryptocephalus älnlich. Blafshraun. Dicht aufliegende, kurze, silberfarlsene und zugleich wie blasses Gold gliinzende Hiirchen bedecken ihm theilweise. Ner Kopf, dicht anliegend, hat in der Mitte der Stirn ein Grübchen. Die Lefze ist schwach 


\section{$-160-$}

ausgerandet, blafs gelbröthlich. Die Frefszangen sinl schwärzlich. Die Fühler länger als der ganze Körper sind blafsgelb, die feinen Härchen womit das dritte, vierte, fünfte und sechste Glied unten besetzt sind, schwärzlich. Das Endglied ist an der Spitze schwarz.- Nas Rückenschild ist mäfsig erhaben und voll stumpfer, wenig erhabener Höcker, das Schildchen fast dreieckig, die Spitze abgestutzt, wie ausgerandet und in die Höhe gerichtet. Die Deckschilde sind fein gerunzelt, durchzogen von einigen stumpf erlı̈̈heten vor der Spitze verschwindenden Linien and besetzt nahe am Inde mit glatten läng. lich-runden Höckerchen. Brust und Hinterleib sind flach punktirt, die hintersten Schenkel verdiclit, die Schienen blafsgelblich an der Spitze schwärzlich, die Fufsglieder schwïrzlich. 
$\begin{array}{lllllllll}M & a & s & t & i & g & u & s .\end{array}$ 



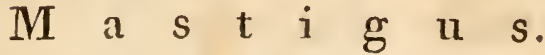

Mastigus Illiger (Magazin f. Inseltenk. I. u. III.) Latreille (Histoire natur. des Crust. et des Ins. IX. Gen, Crust. et Ins. I. Considerations gen. Cuvi er Regne animal). Schön. herr (Synonymia Insect.). Ptinus $\mathrm{Fabr}$. (entom. syst. Mant. Ins. Syst, Eleuth.). Olivier (Entomologie). Gmelin (Linn. Syst. Nat.). Notoxus Thunherg (Nov. Ins. Spec. Diss. acad. III.).

Eine Gattung, die wahrscheinlich nicht so arm an Arten ist als vielmehr nur wenige wegen ihrer geringen Gröfse und versteckten Aufenthalts bisher gefunden worden sind. Die Entleckung des Mastigus palpalis durch Herrn Grafen von Hoffmannsegg gab zucrst Veranlassung zur, Aufstellung und genaueren Untersuchung dieser Gattung, deren Trennung schon Olivier bei Gelegenheit der Erwähnung des Ptinus spinicornis Fabr. mit folgenden Worten an. gedeutet hatte: ,n'ayant pu examiner suffisamment cet insecte, nous le plagons ici, à l'excmple de $\mathrm{Mr}$. Fabricius, en attendant de pouvoir en former un genre particulier, d'après un examen plus exact." Olivier eritom. II. 17. 1\% 10. 11. 10. 
Latreille hat (a. a. O.) die Gattung ausitihlilich characterisirt, so dafs ich eine Beschreibung derselben hier für entbehrlich halte und lieber eine Uebersicht der Arten folgen lasse. Von mir selbst sind im Folgenden drei in der hiesigen Sammiung befindliche Arten beschrieben worden: der bekanute Mastigus palpalis und zwei neue Arten vom Cap. Aufserdem finden sich noch drei Arten eine von Fabricius, zwei von Thunberg beschrieben, so dafs die Zahi der jetzt bekannten Arten sich überhaupt auf sechs beläuft. Diese sind:

1. Mastigus palpalis Jll. Latr., welcher im Folgenden unter $\mathrm{Nr}$. 1. beschrieben ist.

2. MIastigns spinicornis (Ptinus spinicornis $\mathrm{F}$ a!) $\mathrm{r}$. Syst. Eleuth. I. p. 327. n. 12. Olivier Entom. II. 17. p. Ió. n. 10. Tab. I. Fig. 5. Linn. Syst. Nat. ed. Gmelin. I, IV. p. 1607. 11. 20.). Von den SandwichInseln.

3. Mastigus fuscus m. Ebenfalls hier beschricben und hat, wie der Mast. spinicornis einzelne lange Haare an den ersten Gliedern der Fühler. Dessen ungeachtet sind wohl beide Arten sicher verschieden, denn es passen die "elytra oblonga laevia pellucida “6 der Fabricischen Beschreibung nicht auf unsere Art und ist auch wohl die Verschiedenheit des Vaterlandes zu berücksichtigen.

4. Masligus deustus Schünh er (Syn. Ins. I. \&. p. 59. n. 2. Noloxus deustus Thun b. Nov. Ins. Spec. p. 101. diss, acad. III. p. 220.). Vom Kap. Hierher zählt Schönherr wohl mit Unrecht den Ptinus spiniconis Fabr. Ol. indem die Fabricische Beschrei- 
bung so wenig als Olivicr's Abbildung desselben auf deil Mastigus deustus zu passen scheint.

5. Mastigins favus Schönherr (Syn. Ins. I. 2. p.59. 1. 3. Notoxus flavus Thumberg Nov. Mns. Spec. p. 101. Diss.' acad. III. p. 220.). Auch vom Kap.

6. Mastigus glabratus m. Von mir hieruächst beschrieben. Ihm scheint der Mast. deustus nah verwandt, doch scheint in dein Verhäitnifs der Füh. ler ein Unterschicd vorhanden zu seyu, und wenu auf den Deckeu des Mast. glabratus Punktrcihen unverkenubar 'sind, so heil'st es in Thunberg's $\mathrm{Bc}$ schreibung des Mast. deustus von diesen Körpertheilen: absque punctis et striis.

\section{Mastigus palpalis.}

Mastigus ovatus, obsolete punctatus, fuscus, gyrisco-pubescens. Long. lin. $2-3 \frac{\pi}{2}$.

7hlastigus palpalis ILa $\mathrm{Lr}$. Hist. natur, des Crust. et des Ins. Tom. IX. p. 186. Gen. Crust. et Ins. I. 1. 281. 1. Tab. 8. Fi⿱⺈. 5. Schönherr Syu. Ins. I. 2. p. 59 . N. 66 . 1.

II a bitat in Lusitania. Com. de II offmannsc g g g

Corpus elongatum, postice aut rolundatum aut (in fenina) subacuminatum. Caput angustatum, punctatum, vertice impresso. Antennac apice rufescentes. Thorax subgibbosus punctatus. Elytra alutacca, obsolete punctata. Pedics dilute fusci.

Aus Portugal. Zwei bis $3 \frac{2}{2}$ Linicn lang. Lüngylich, (die Weibchen hinten zurespitzl) schwärzlich 


\section{$-\quad 166$}

mit greisen Haaren dünn besctzt, Kopf und Rückenschild deutlicher punktirt. Deckschilde mehr genarbt und lederähnlich, den Leib unten zum Theil umgebend, vorgezogen und spitz auslaufend bei den gröfsern, wahrscheinlich weiblichen, abgerundet und deutlich getrennt bei den klcinern Exemplaren. Die Scheitelgegend mit einem fast dreieckigen Eindruck. Die Fühler an den Spitzen röthlich. Die Beine hell bräunlich.

\section{Mastigus glabratus.}

Mastigus brunneus, capite pedibusque nigris elytris apice truncatis testaceis. Long, lin. $2 \frac{3}{4}$.

Habitat ad Prom. bonae spei, Distr. Uitenhagen; Krebs.

Statura breviore, thorace angustiore compresso, elytris brevioribus truncatis a Mast. palpali differt. Caput latitudine thoracis, subtilissime punctatum fuscum, vertice planum, impressum. Antennae thorace capiteque simul sumtis longiores fuscae, medio rufescentes. Palpi uigricantes. Thorax vix punctatus brunneus basi compressus. Elytra subtilissime transversim striata, lungitudinaliter punctato - striata, abdomine haud breviora, apice truncata, testacea. Pectus abdomenque brunnea. Venter medio fuscus. Pedes nigricantes.

Vom District Vitenhagen in der Cap-Colonic. Länge $2 \frac{3}{4}$ Linien. Vou der vorhergehenden Art durch einen lkürzern Kürper, mehr zusammengedrücktes hiückenschịld und abgestutzte Deckschilde vornehmlich zu unterscheiden. Der Kopf in Verhältnifs breitcr und wohl so brcit als das Rückenschild, 
höchst fein punktirt und schwärzlich. Dic Scheitelgruben wie bei den andern Arten. Dic Fühler von ansehnlicher Lïnge sind schwärzlich, in der Milte rüthlich. Das Rückenschild ist höchst fein nnd fast unmerklich punktirt, braun und matlglänzend, der hintere Theil etwas zusammengedrüclst, der vordere mit gewölbtem Rücken. Die Deckschilde höchst fein in der Queere gestrichelt, mit cinigen aus zusammengedrïngten Punkten bestehenden Längsreihen geziert, siud etwa so langr als der Ifinterleib, und an Ende abgestutzt, eben so wenig, wie bei den kleineren Exemplaren des Mast. palpalis zusammen verwachson. Brust und Bauch sind braun, letzterer in der Mitle dunkler. Dic Bcine sind schwärzlich.

\section{Mastigus fuscus.}

Mastirus ater, clytris abbreviatis rutundatis fus cis. Long. lin. $2 \frac{x}{4}$.

Patria: Promont. bonac spei, Distr. Uitenha a

Similis praccedenti. Niger, sericeus. Caput subtilissime punctatum, vertice plano sulcato, antennis basi passim pilosis palpisque nigris. Thurax subtilissime punctatus, dorso elevato. Elytra abdomine subbreviora, ovata, sublilissime transversim striolata, vix longitudinaliter punctato-striata, fusco-brunnea. Venter fuscus. Pedes nigri.

Ebenfalls von Vilenhagen. Länge $2 \frac{\pi}{4}$ Linien. Kürzer als die vorhergehende Art. Dunkel schwärzlich mit Seidenglanz. Der Kopf höchst feiu punk. tirt. Fühler und Frefspilizen, lotzlere anschnlich 


\section{$-168-$}

verdickt, erstere mit einzeinen ziemlich langen Haaren am Grundgelenk, von schwarzer Färbung. Das Rückenschild ebenfalls dicht und höchst fein punktirt, die Deckschilde nur kurz, an der Spitze abgerundet, überall sehr fein in die Queere gestrichelt, mit kaum merklichen Längslinien, dunkel kastanienbraun. Brust und Bauch sind schwärzlich, dic Beine sohwarz. 
Pach y losticta. 



\section{Pach y losticta n. g.}

Antennae breves clavatae, quinque-articulatae. Alae anticae ad apicem dilatatae, stigmate semilunari, areolis marginalibus duabus, submarginalibus tribus, submarginali secunda nervum recurrentem excipiente. Tarsorum posticorum articuli 2, 3, 4 brevissimi.

Fühler kurz, keulfürmig, fünfgliedrig. Vorderflügel erweitern sich vor der Spitze. Randmahl halbmondfürmig. Randzellen zwei, Unterrandzellen drei, in deren zweite ein zurücklaufender Nerv eintritt. Der hinterstert Fufsglieder 2tes, 3tes und fites, sehr kurz.

Beim crsten Anblick crscheinen die Blattwespen, welche die gegenwärtige Gattung [auf welche ich in meincr Beschreibung der Gattung Cimbex in den Verhandlungen der Ges. maturf. Fr. Bd. I. St. 2. p. 97. zuerst hingedeutet habc] ausmacìcn, als grofse blaue IIylotomen. Bald aber fällt neben der Kürze del Fïhler der Schnitt der Fliigel besonders auf, und eine genaucre Untersuchung lïfst noch so manche andere nerkwürdige Eigenschaften crkennen, welche ihro Vereinigungr zu einer besondern Gattung fordern.

Der Kopf, eher lilein als grofs, hat sehr grofse runde und hervorstehende $\Lambda$ ngen. Die Nebenaugen sind auf der Stirn in cin Dreieck dicht zusammengelriingrt. Jie Frefszangen sind liurz, gुckrïmut, zu- 
gespitzt, vor der Spitze scharf gezalnt. Der Bau der innern Mundtheile ist im Wesentliclien der der Blattwespen iiberhaupt. Nur scheinen die Frefsspitzen aus nicht so viel Gliedern zu bestehen. Die Laden sind inwendig gezahnt, der Zahn linienförmig, beinah so lang als die Lade selbst, ihre Taster fünf gliedrig, dic Glieder cylindrisch, kurz, das zweite lïnger als die übrigen. Die Lippe ist dreitheilig die Lappen sind linienfürmig und gleich lang. Die Lippentaster sind so lung als die Ladentaster und bestehen aus drei Gliedern, deren erstes kürzer als die übrigen ist, das letzte stumpfrund sich endigt. Die Fühler, im Verhältnifs nur kurz, haben-ein fast eirundes Grundgelenk. Dann folgt ein zweites kurzes Glied, das dritte ist nur wenig länger als das vierte, die Keule länger als das dritte Clied, länglicht, an der Spitze schrïgr. Das Rückcnschild ist hoch 'gewölbt, das Schildchen gerundet, die Brustseiten vorragend. Die vorderen Flügel sind bedeutend länger als die hinteren, an äufseren Rande dicht anı Anfang des Randmahls stark ausgebogen, darauf schnell schräg abgeschuitten. Dic Raucizcllen sind der Beschafenheit des Flügels gemiils im Verhailnifs kurz. Basselle gilt von den Uiitcrandzellen, die erste derselben ist dabei schmal, die zweite fast vierechig, die dritte lie grörste und offen. Ls tritt hier, wie bei cinigen Blattwespen die zu Allantus gehöres und anderen, welche Nematus zunächst stehen (Cladins III.) der Fall ein, daf's der Nerv, welcher die äufserste Zalle des mittleren Raumes nach innen begringat, mitten in dis wweite Unterrandzelle sich einm senkt, wie solches bei den Cimbex verwandten Gattungen bisher nicht bcobachlet worden. Das Rand- 
mahl ist von halbmondförmiger Gestalt, grofs und dick. Die hínteren Flügel sind besonders kurz. Die vorderen Beine sind sehr lurt, die Schienen mit dichtem fein- und kurzhaarigtem Ueberzug , die Fursoglieder mit langen Anhä̈nsseln versehen, die Klauen doppelt gelrrümnt und spitzig. Der Hinterleib ist ziemlich flach, der After trägt hervorstehende Zangen. Obschon von jeder der nachfolgend beschriebenen drei Arten uns mehrere Exemplare zugekommen sind, so waren sie doch siimmitich allem Anschein nach nur mönnlichen Geschlechts und die Weibchen wären in diesem Fall bisher unbekannt geblicben.

\section{Pachylosticta tibialis.}

Pachylosticta viridi-coerulca, tibiis tarsisque albis. Long. lin. 7 .

II abitat in Brasilia. Sello.

Caput coeruleum, nitilum, antennis mandibulisque nigris. Thorax glaberrimus, coeruleus, pleuris cyancis, margine postico testaceo. Scutellum viridicocruleum, nitidum. Grana albicantia. Alae fuscohyalinae, ante apicem obscuriores, nervis stigmateque nigro-fuscis. Pedes albidi capitulis femoribuscue cyancis, ungulis fuscis. Abdomen subtilissime punctatum viridi - coeruleum.

Aus Brasilien. Siebeñ Linien lang. Der Körper glänzend blaugrïn, Kopf und Rückénschild dunliler blau. Fühler und Frefszangen schwarz. Die Fliigel scliwärzlich, vor der Spilze dunliler, Nerven und Randmahl braunscliwarz. Beine weifs, Gelenkköllfe und Schenliel blau, Klauen braunschwar.. 


\section{Pachylosticta violacea.}

Pachyl. tota obscure - violacea. Long. lin. 6-7. Habitat in Brasilia. Dr. deOlfers et Sello. Praecedenti simillima, ejusdemque fere magnitudinis. Differt tantum pedibus nigro-violaceis. Thorax, caput pedes nig.o-violac : Antennate mandibulaeque nigrae. Alae fuscae, nervis stigmateque nigro-fuscis. $\Lambda$ bdomen viridi - coerulcum, ano violaceo.

Wohnort, Grörse und Gestalt der vorhergehenden $\Lambda$ rt. Kopf, Brustschild und Beine sind dunkel violetblau. Fühler und Frefszangen schwarz. Die Flügel, sclıwärzlich mit bläulichem Schiller, haben dunkel braunschwarze Nerven und Randmahl. Die glänzend grünlichblaue Farbe des Hinterleibes verliert sich an der Spitze in ein einfaches dunkelblau.

\section{Pachylosticta albiventris.}

Pachyl. violacea, ventre basi albo. Long. lin.5-7. Patria: Rio Jan. Mis. de Langsdorf et Sello.

Statura praecedentis. Differt nonnisi ventre albo, apice cyanco. Caput violaceum mandibulis solis nigris. Thorax violaceus. Grana alba. Abdomen violaceum, ventre late albido. Alae ut in praecedentibus. Pedes nigro-violacci, coxis posticis subtus albis.

Wohnort und Gestalt der vorher beschriebenen Arten. Doch kommen auch kleine Stïcke von nur 5 Linien Länge vor. Die Farbe ist dunkelvioletblau. Nur sind dic Frefszangen schwarz, die Riückeniörnchen weifs, der Bauch, die Spitze ausgenommen, so wic die untere Fläche der hintersten Hüftstüclien ebenfalls weifs, jedoch nicht so rein, sondern ins Gelbliche übergehend. 


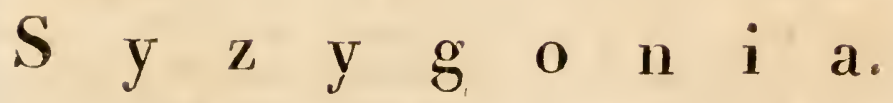





\section{S y z y g o n i a n. g.}

Antennae breves clavatae, articulis quinque aut quatuor ante clavam; clava solida. Areola marginalis unica appendiculata, snlomarginales quatuor.

Fühler kurz, keulfürmig, fünf oder vier Glieder vor der Keule, Keule ungegliedert. Vier Unterrandzellen. Eine Randzelle mit einer Nebenzelle versehen.

Eine andere merkwürdige Gattung aus der Familie der T'enthredinetae, mehr vielleicht als irgend eine geeignet, die Blattwespen mit keulförmigen Fühlern mit denen, welche ungeglicderte Fühler haben oder Cimbex mit Hylotoma zu verbinden. Manches Uebereinstimmende, wenn auch in Aeursern wenig $\Lambda$ ehnlichkeit mufs unsere Gattung mit der Neuholländischen Perga haben, welche Leach zuerst im 3ten Bande der zool. Misc. aufgestellt und monographisch bearbeitet hat. Bei dem ersten Anblick hält man die beiden bisher bekannten Arten für Arten von Cimbex, verwandt Leach's Abia. 'Nur bei genauerer' Betrachtung fällt sogleich und zuerst der Unterschied im Flügelgeäder auf, welches dem der Cimbex ganz fremd, dagegen von dem der Hylotomen kaum verschieden ist. Es ist nemlich die erste der Unterrandzcllen länglich und im Verhiiltuifs klein, die beiden folgenden unter "sich von igloicher Grölse sind lïng * 
lich viereckigg, die letzte offen und eben so grofs, wenn nicht grö̈ser als die vorhergehenden. Die Randzelle ist länglich, die Nebenzelle nur klein, doch deutlich, das Randmahl von keiner ansgezeiehncten Beschaffenheit. Hierneben sind die Fühler von mäfsiger Länge, kaum halb so lang als der Ilinterlcib, die beiden ersten Glieder schr kurz, die folgenden so ziemlich von gleicher Länge, oder das vicrte kaum merklich länger als das erste, das dritte ungefähr noch einmal so lang, und die Keule so lang als das dritte Glied. Der Kopf ist beinah wie bei Leach Abia, die Nebenaugen sind deutlich, die Augen grofs. Das Rückenschild ist mäfsig gewölbt, das Schildchen zicmlich grofs, erhaben und gerundet. Die Brustseiten stehen etwas hervor. Die Schicnen der hintern Beine haben auch in der Nitte èinen Dorn, die Fufsglieder haben die bei den Blattwespen gewöhnlichen Anhängsel. Der Hinterleib ist dick, fast eirund. Was den Mund betrifft, so haben die bisherigen Bcobachtungen gelehrt; dafs bei den Tenthredineten die innern Mundtheile nicht so bedeutenden und wesentlichen Abreichungen unterworfen sind, dafs Gattungskennzeichen von ihnen entnommen werden lö̈nten. Doch hat bei der Untersuchung der Mundtheile der Syzygonia sich gezeigt, dafs die schon bei Pachylosticia verminderte Zahl der Tasterglicder auch hier statt findet und der gewöhnliche zahnförmige Fortsatz am Anhange der Laden ist nicht vorgefunden worden, wie die nun folgende genauere Beschreibung der Mundtheile ergiebt: dic Frefszangen liurz, selir zusammengedrückt, gekrümmt, scharf zugespitzt, in der Mitte gezahnt; die Laden zusammengedrückt, mit breiten scheibenförmigen $\Delta$ nhängen, an welchen kcin zahnförmiger 


\section{- $179-$}

Fortsatz zu bemerken war. An den Kinnladentastern lionnten nur fünf, an den Lippentastern drci Glieder deutlich unterschieden werden. Letztere ragten so weit als die Lippe hervor, und erschien diese auf einem breiten ziemlich dreieckigen Kinn ruhend, weit vorgestreck: und in drei einander gleiche linienförmige Lappen gespalten. Diese Gattung, von deren im Folgenden beschriebenen zwei $\Delta$ rten bisher nur weib. liche Individuen uns zugeliommen, läfst sich, nach der Zahl der Fühlerglieder die sich vor der Keule befinden, wie solches bei Cimbex sehr zweckmärsig geschehen, ebenfalls in Familien eintheilen und werden sich dann bei den Arten der ersten Familie fünf, bei denen der zweiten nur vier Glieder bis zum kculfürmig verdickten Ende der Fïhler finden.

\section{Erste Familie.}

Fünf Glieder vor dem verdickten Ende der Fühler; antennae articulis quinque ante clavam.

\section{Syzygonia cyanopterc.}

Syz. violacea, capite thoraceque rufis. Long. lin. 7 . Habitat in Brasilia. Communicav. Bescke et de Langsdorf.

Caput magnum rufum mandibulis palpisque apice nigris. Antennae vix thorace breviores nigrae. Oculi fusci. Thorax rufus, scutello nigro - cyaneo. Abdomen lacte violacenm. Pedes nigro - cyanei. Nlae fuscae cyaneae apice dilutiores, nervis stignateque nigris.

Aus Brasilien. Sieben Linien lang. Der grofse und breite Kopf, so wie das Rückenschild, sind roth. Die Augen stehen stark hervor und sind-schwiir" lich, die Nebenaugen sehr deutlich. Mandibeln unil 


\section{$-180$}

Palpen sind an der Spitze schwarz. Die Fïhler, beinah so lang als das Rückenschild, sind ebenfalls schwarz. Das Schildchen ist blauschwarz. Der Hinterleib ist schön glänzend violet - blau. Die Beine sind schwärzlich blau, die Flügel blauschillernd, lebhafter und dunkler vor der Spitze, wo die Färbung mehr brïunlich ist. Nerven und Randmahl sind schwarz.

36. Syzygonia cyanocephata.

Syzygonia testacea, capitc viridi-aeneo, abdomine cyaneo, apice testaceo. Long. lin. $5 \frac{x}{2}$.

Habitat in Brasilia. Misit Sello.

Rufo-testacea, glaberrima, nitida. Caput nitidissimum, viriłi-cyaneum, labro palpisque pallidis, mandibulis magnis arcuatis acutis ferrugineis, oculis testaceis, ocellis succinei coloris. Antennae nigrucyaneae. Pleurae opalino - micantes. Abdomen dorso cyaneum apice lateribusque testaceum. Venter medio obscure cyaneus, segmentis apice testaceis. Tibiae posticae apice nigro-cyancae. Alae flavescentes ner$\checkmark$ is stigmateque testaceis.

Aus Brasilien. $5 \frac{x}{2}$ Linien lang und elwa so gestaltet wie C. sericea. Der Kopf glänzend blaugrün. Lefze und Frefsspitzen blafs, die stark gekrümmten Frefszangen braun. Die Augen grofs und blafsgelb, die Nebenaugen wie Bernstein glänzend. Die Fühler blauschwarz, das Rückenscìild gelbröthlich, die Brustseiten mnit hell blaulichem Schiller. Die Flügel hellgelblich, Nerven und Randmahl gelbrötblich. Die Beine wic das Rückenschild gefärbt. Die Spitzen der hintersten Schienen blauschwarz. Der Hinterleib oben blau, an den Seiten gelbröthlich, die Bauchsegmente bläulich, gelbröthlich serandet. 
T a r P a. 



\section{T a $r$ p a.}

Tarpa Fabr. (Syst. Piezat.). Panzer (entomulug. Vers, etc.). KIug (Blatıw. Mag. d. Ges. naturf. Fr.). Megalodonta L a tr. Ilist. natur. des Crust. et des Ius. Gen. Insect. Consider. gen. regne anirn. Nunveau Dict. d'Hist. natur.). Spinola (Ins. Lig.). Cophaleia Jurine (Hymenopt.). Diprion Schrauk (Fn. boica). Tenthrolo Fabr. (entom, syst.). Panz (Fn. Ins.). Coquebert (illustr. iconogr.), Rossi (Fn. Et.).

Im Magazin der Gesellschaft naturforschender Freunde habe ich versucht dic Blattwespen in Fanilien einzutheilen, auch viele Arten in einer Reihe von $\Lambda b$ handlungen beschrieben. Von diesen Abhandlungen sammelte ich einige besondere Abdrücke und vertheilte sie unter dem Titel: die Blattwespen nach ihren Gattungen und Arten zusammengestellt. Berlin, 1818.

Die Gattung Tarpa eröfnet die Reihe dieser kleinen Blattwespenmonographie. Nur dic beiden damals bekannten Arten: Tarpa ceplalotes und plagiocephala finden sich dort genannt und beschrieben. Die Gattung selbst ist aber ausfülnlich behandelt und vou T'enthredo gehörig unterschieden. Auch sind dic imneren Mundtheile auf der beigefighen 'I'afel abogebildet worden, Will ich daher nicht in WVickerho- 
lungen des dort Gesagten mich einlassen, so kanu ich gegenwärtig auf die, jener Abliandlung über Tarpa vorangeschickten allgemeinen Bemerkungen und die dort befindliche Gattungsbeschreibung mich beziehen und hiernächst gemäls dem Zweck der vorliegenden Blätter die Beschreibungen der jetzt bekannten Arten folgen lassen.

\section{Tarpa cephalotes.}

Tarpa atra, capite maculis, thorace lobo antico, macula dorsali, maculisque scutellaribus, abdomine panctis utrinque binis fasciisque flavis.

Tarpa cephalotes Fabr. syst. piez. p. 19. n. 1. Panzer entomol. Vers. p. 53. Klug Blattw. p. 6. n. 1. Magaz. d. naturt. Ges. II. p. 266.

Megaladontes cephalotes Latreille Gen. Ins. IlI. p. 233. Hist. natur. des Crust. et des Ins. XIII. p. 137. pl. 100. Fig. 1. Spinola insect. Lig. fasc. 1. p.50.

Cephaleia cephalotes Jurine Iymenopt. p. 67 .

Tenthredo cephalotes Panz. Fn. Ins. Germ. 62. t. 7. 8. Coquebert, illustr. iconogr. dec. 1. p. 16. Tab. 3. Fig. 8. S cha eff. icon. LVI. f. 1. Tossi Fna. Etr. II. p. 23. n. 707. ed. Ill. p. 33.

Habitat in Germania.

Caput lunula postica maculisque tribus inter oculos flavis. MTandibulae nigrac, apice ferrugineae. Antenuac rufescentes, articulo primo flavo. Collare flavum. Thorax macula utrinque pone scutellum flava. Lobus intermedius postice flavus. Plcurae macula sub alis flava. Squamae flavae. Alac flavescenies. Pedes flavi coxis nigris. Femora anteriora basi nigra. Abdomen macuils vtrinque tribus, fasciisque quinyuc flavis. 
Punktirt, etwas behaart. Grundfarbe sclitvarz. Gelb sind eine Linic an Hinterkopf, drei Flecke zwischen den Augen, Halsschild, am Rüickenschild ein Fleck zu jeder Scite neben dem Schildchen und der hintere Rand des mittleren Lappen, aufserdem ein Punkt unter den Flügeln und die Flügelschuppen, am Hinterleib aufser dem halbmondförmigen Ausschnitt drei Punkte an den Seiten der ersten und der hintere Rand der folgenden Segnıente. Die Flügel sind gelbiich mit dunkleren Nerven und dunkelm Schatten am vordern Rande. Die Beine gelb mit schwarzen Hüftstücken. Die vorderen Schenkel sind mit Ausnahme der Spitzen schwarz, die Fühler röthlich mit gelbem Grundgelenk, die Mandibeln schwarz, mit braunröthlichen Spitzen, bei den Männchen am äufscrn Rande gelb.

\section{Tarpa bucephala.}

Tarpa atra, capite thoraceque maculis, abdomine fasciis, prima interrupta, flavis.

Habitat in Lusitania. Ex Museo Comitis de H of fin annsegg.

Magnitudine Tarpam cephalotem fere superat, subhirta. Caput punctatum postice genis maculaque intermedia occipitali continua semilunari antice clypeo toto, facie inter antennas maculaque continua magna ante oculos adscendente utrinque arcuata flavis. Mandibulac flavae apice nigrae. Antennae articulo primo flavo, sccundo tertioque nigris, reliquis fuscis. Collare flavum. Thorax utrinque pone scutellum flavus. Lobus intcrmedius apice flavus. Metathorax utrinque flavo-punctatus. l'learae macula magna flava. Squamar flavac. Alac flavescentes, 
nervis stigmateque luteis. Pedes flavi. Coxae nigrac. Condyli macula flava. Abdominis segmentum prinum utrinque flavum reliquit omnia apice late flava. Segmenta ventralia nitida nigra, ultimis exceptis apice flavis.

In mare antennarum articulus prinus supra niger. Caput antice flavum. Genae nigro-terminatae. Subtus totus flavus.

Eine neue portugiesische Art, beinahe gröfser als Tarpa cephalotes. Schwarz, behaart. Der Hinterkopf sanmt der Wangeneregend gelb, in der Mitte eine halbmondförmige 'Zeichnung, deutlicher als bei 'Tarpa cephalotes. Der Vorderkopf grörstentheils gelb. Mit dem Kopfschild zusammenhängend ein fast viereckiger Fleck zwischen den Fühlern und zu jeder Seite ein Fleck vor den Augen, der halbmondförmig sich nach innen krümmt. Frefszangen gelb mit schwarzen Spitzen. Der Fühler erstes Glied gelb, zweites und drittes schwarz, die übrigeu bräunlich. Halsschild und Flügelschuppen gelb. Auf dem Rücken zu jeder Seite des Schildchen ein geclber Fleck. IIinterer Rand des miltleren Lappen gelb. Aưf dem Hinterrücken zwei gelbe P'unkte, Brustseiten mit einem grofsen gelben Fleck. Flügel gelblich, mit bräunlichen Nerven und Randmalı. Beine gुell, Hüftstïkke schwarz, Hüftorlieder mit gelbem Hleck. Am Hinterleib der erste Abschnitt zu jeder Seite, die übrigen Segmente sämmtlich am hintern Rande gelb. Männchen dem Weibchen ähnlich. Nur die Wiu. gengegend auswendig, das erste Fühlerglicel oben sehwarz, die Frefszangen gelb, die untére Scite des Körpers gुelb, die ersten Minaterleibsbinden in der Mitte unterbrochen. 


\section{$-187-$}

\section{Tarpa spissicornis.}

Tarpa atra antennis rufis ad apicem fuscis, capitis margine postico, thoracis antico, abdumine punetis fasciisque flavis.

Ilabitat in Germania (Ebersdorff); Grimm.

Nigra, punctata, nigro-pilosa. Caput maculis tribus inter oculos lineaque occipitali tenui arcuata flavis. Anteninac longius pectinatae, basi rufescentes. Mandibulae ad apicen ferruginae. Collare margine postico late tlavo. Thorax utrinque ad scutellum flavo-lineatus. Punctum ntrinque sub alis flavum. Squamae flavae. Alae hyalinae, ad marginem anteriorem late fuscae, nervis stigmateque fuscis. Pedes flavi coxis nigris. Femora anteriora basi nigra. Abdomen segmentis duobus prioribus ntrinque puncto, reliquis apice flavis. Segmenta ventralia apice flaves-. centia. Variat abdominis segmentis prioribus impunctatis. Maris mandibulae externe flavae; antennarum articuli priores subtus flavi, dorso nigri; venter fasciis distinetis transversis flavis.

Aehnlich der Tarpa cephalotes. Körper schwarz, punktirt, zum Theil schwarz haarigt. Fühler gelbroth, ausgenommen die eilf letzten Glieder, welche sammt den aus ihnen hervorgehenden langen Kammspitzen schwïrzlich sind. Erefszangen schwarz, vor der Spitze rothbraun. Zwwischen den Augen drei gelbe Punikte. Fine gelbe Linie im Halbcirkel am Hinterkopf. Halsschild am hinteren Rande breit gelb. Eine schrägre gelbe Linie zu jeder Seite am Rückenschildchen. Gelber l'unkt unter den Flïgeln und gelbe Flügelschuppen. Die Ilügel durchscheinend, iufscrer Raud in auschulicher Breite brä̈unlich. Ner- 


\section{- $188-$}

ven und Randmahl braun. Beine gelb, Schenkel röthlichgelb, vordere an der VVurzel schwarz. Hüftstüche schwarz. Die ersten Hinterleibssegmente haben zu jeder Seite einen gुelben Punkt, oft sind sie ungefleckt. Dic letzten fünf Abschnitte sind gelb gerandet.

An den Männchen ist die auswendige Seite der Mandibeln rothgelb, die seliwarze Fühlerwurzel aufserhalb gelb, und die Bauchsegmente sind fast zur Hälfte gelb.

\section{Tarpa spiracae.}

Tarpa atra abdomine fasciis, capite thoraceque maculis, antennis mandibulisque flavis.

Tenthredo spiraeae. Pall. mscrpt.

II abitat in Tauria. Pallas.

Simillima Tarpae spissicorni. Caput punclatum, macula utrinque ante oculos, lineaque vccipitali semicirculari flavis. Mandibulae nigrae cxtus flavae. Antennae longius pectinatae, pectinibus fuscis. Thorax punctatus, macula lineari obliqua utrinque ad scatellum, puncto sub alis, collaris margine pestico squamisque alarum flavis. Alae hyalinae, margine anteriori obscuro, nervis stigmateque fuseescentibus. Pedes lutei coxis nigris. Abdomen fasciis quatuos flavis. Venter flavo-lineatus.

Maris caput antice flavum. Mandibulae, flavac. Jugulum maculaque magna semilunaris sul alis fliva. Coxae omnes, fasciae ventrales quinque anusque flava.

Jer Tarpa spissicornis sehr ähnlich, besonders in Hinsicht der ebenfalls mil längerm Kamm versehenen Fühler. Körper schwarz, Kop£ und Rückenschild punktirt. Auf jeder Scilc vor den $\Lambda u g e n$ eiu 


\section{- 189}

gelber Fleck. Am Hinterkopfe eine gelbe Linie in Gestalt eines halben Cirkels. Mandibeln schwarz, aufsen gelb. Fühler röthlichgelb mit schwärzlichem Kamm. Halsschild, Flügelschnppen, cin Punkt unter der Finlenkung der vorderen Flügel, eine schrïge Linie zu jeder Seite des Schildchen sind an Rückenschild gelb. Die Flügel sind hell, am rorderen Rande dunkel, Nerven und Randınahl bräunlich. Beine rüthlichgelb mit schwarzen Hüftstücken. Am Hinterleibe vier gelbe Binden.

Beim Männchen ist dic untere Hälfte des Kopfes, oder das eigentliche Gesicht, nebst Kopfschildchen, Frefszangren und Fühlern gọelb. Halsschild und Unterhals, Fliigelschuppen und ein grofser halbmondoder nicrenfürmiger Fleck unter den Vorderflügeln, die Hüftstücken, fiinf breite Binden am Bauche, wie die Aftergegend sind von der nemlichen Farbe.

\section{Tarpa plagiocephala.}

Tarpa atra capite thoraceque maculis, abdomine fasciis alarumque squamis pallidis.

Tarpa plagiocephala F a b r. syst. piezat. p. 20. n. 2. Klug Blattw. p. 7. n. 2. Magaz. d. Berl. Ges. waturf. Fr. II. Jahrg. p. 267. Scha eff. elem. entom. T. CXXV. f. g. 10.

Habitat in Germania.

Caput punctatum, nimro-subpilosum, maculis tribus inter oculos, lineaque postica pallidis. Mandibulae vix apice ferrugincae. Antennae rufescentes, articulo primo secundoque nigris. Collare pallidum. Thorax punctatus, maculis ad scutellum binis punctoque sub alis fallidis. Alae ad costam obscuriores. Pedes lutei coxis nigris. Abdomen fasciis quinque 
pallidis. In nonnullis segmentum secundum utrinque albo-punctatuns. Venter pallido-bifasciatus.

Maris mandibulae margine exteriori flavac, thorax fere immaculatus, abdomen unifasciatum, lateribus albo-punctatum. Venter fasciis quinque anoque. pallidis.

Schwarz, punktirt, am Kopf schwarz bchaart. Zwischen den Angen drei gelblichweifse Flecke, am Hinterkopf eine dergleichen gebogene Linie. Die Frefszangen siod schwarz, kaum an der Spitze bräunlich, die Fühler gelbroth, das erste und zweite Glied schwarz. Halsschild, ein Fleck zu jeder Seite des Rückenschildchen, ein Punkt unter den Flügeln und die Flügelschuppen sind gelblichweifs. Die Flügcl hell, sind am vorderu Rande dunkeler, Nerven und Randmahl wie gewöhnlich. Die Fürse rothgelb mit schwarzen Flüftstücken. Der Hinterleib hat fünf, der Bauch zwei gelbweifse Binden.

Bei einigen findet sich noch ein weifser Punkt zu jeder Seite am zweiten Hinterleibssegment. Auch trifft man die Fühler durchaus röthlich.

Beiun Männchen sind die Mandibeln am Aursenrande gelb. Die Flecke neben dem Rückenschildchen fehlen gewöhnlich. Am Hinterleib ist nur cine Binde deutlich vorhanden, die übrirgen sind an den Sciten durch Punkte angedeulet. An Bauch sind fünf deutliche Binden und dic Aftergegend gelbweifs, Ganz von dieser Beschaffenheit ist das Exemplar in der Fabricischen Sammlung.

\section{Tarpa megacepliala.}

Tarpa atra capite thoraceque maculis, abdomine fasciis pallidis. 
Tentleredo redimila Pall. mserpt.

II abitat in Germania; in Tauria. Pallas.

Simillima praecedenti. Caput punctatum nïgro. pilosum, maculis tribus inter oculos lineaque arcuata postica albis. Antennae rufescentes, primo secundoque articulo nigris. Mandibulae nigrae vix apice ferrugineae. Collaris margo posticus, medio interruptus, albus. Punctum sub alis naculaque utrinque ad scutellum alba. Squamae alarum nigrae. Alae hyalinae, ad costam fuscescentes, nervis stigmateque fuscis. Pedes lutei coxis nimris. Abdomen fasciis quinque albis. Venter albido-bifasciatus.

Mas a mare praccedentis speciei differt statura majore, mandibulis, sicuti in femina nigris nec margine exteriori flavis, macula utrincuc ante oculos, nec inter oculos tribus, capitis lunula postica late interrupta albis, thorace ad scutellum distincte albo bimaculato, abdominis segmentis secundo sex́loque immaculatis, quarto vero quintoque macula utrinque majori, septimo toto albis.

Das Veibchen kaum von der vorhergehenden Art verschieden. Schwar\% glïnzend, Kopf und Rükkenschild schwarz behaart. Zwischen den Augen drei gelbweifse Flecke, cine halbmondförmige weifse Linie am Hinterliopf. Fühler röthlich, das erste und zweite Glied mehrentheils, doch nicht immer schwarz, Mandibeln schwarz, liaum vor der Spitze bräunlich. Halsschild weifs, doch in der Mitte unterbrochen. Ein Fleck zu jeder Seite am Schildehen und ein Punlit unter den Flügeln weifs, die Schuppen jedoch schwarz, nicht weifs, wie gewöhnlich bei der Tarpa plagiocephala. Flïgel hellgelblich, dunliler am vordern Rande. Nerven und Randmahl wic gewöhnlich. Beine rotl- 
gelb mit schwarzen Hüftstücken. Am Hinterleib fünf, am Bacch zwei weifse Queerbinden.

Das Männchen ist von dem Männchen der vorhergehenden Art deutlich unterschicden. Es hat wie sein Weibchen einfarbig schwarze Frefszangen, zwischen den Augen nur zwei, nicht drei weifse Flecke. Es ist neben dem Rückenschildchen deutlich, wie sein Weibchen, gefleckt. Am Hinterleib sind der zweite und scchste Abschnitt ungefleckt, der vierte und fünfte zu jeder Seite mit einem grofsen weifsen Fleck bezeichnet.

\section{Tarpa Alavicornis.}

Tarpa atra mandibulis antennisque rufescentisus, capite thoraceque maculis, abdomine maculis fasciisque pallidis.

Habitat in Germania.

Tarpa plagiocephala major. Caput punctatum, maculis tribus inter oculos lunulisque posticis albis. Antennae dorso flavescentes, arliculo primo flavo. Collare fascia postica, medio interrupta alba. Thorax macula utrinque ad scutcllum punctoque sub alis albis. Squamae albae. Alae flavescentes liyalinae, ad costam obscuriores, nervis stignateque ferrugincis. Pedes lutei coxis nigris. Abdominis segmentum primum et secundum utrinque albo-maculata, reliqua segmenta albo-marginata. Venter albo-bifasciatus.

Gröfser als Tarpa plagiocephala. Körperfarbe schwarz. Kopf punktirt. Zwischen den Augen drei Flecken. Am Hinterkopf die gewöhnliche Bogenlinie von gelbweifser Farbc. Die Fïhler rothgelb, sind auf der obern Seite heller. Gelb ist besonders das 


\section{$-103-$}

erste Glied: Die Frefszangen sind rüthlichgelb, an den äufsersten Spitzen schwarz. Das Halsschild, zu jeder Seite am Rückenschildchen ein Fleck, ein Punkt unter den Flügelı und die Flügelschuppen sind weifs. Die Flügel gelblich - durchscheinend, sind am vordern Rande etwas dunkler, Nerven und Randmahl wie gewöhnlich. Beine sind rothgelb mit schwarzen IIüftstücken. Der erste und \%weite Abschnitt des Hinterleibes haben zu jeder Seite jeder einen gelbweifsen Fleck, die übrigen Segmente sind am Rande weifs. Am Bauch finden sich zwei gelbweifse Queer. binden.

\section{Tarpa quinquecincta.}

Tarpa atra mandibulis antennisque rufescentibus, capite thoraceque maculis, abduminis segmento primo utrinque puncto, reliquis apice albis.

Tenthredo quinquecincta Pall. Mpt.

Ha bit at in Tauria; Pallas.

Affinis praecedenti. Magnitudine Tarpam plagiocephalam aequat. Caput punctatum, maculis tribus magnis inter antennas lineaque semilunari occipitali. albis. Mandibulae vix apice nigrae. Antennae fuscopectinatae. Collare album. Thoracis lobus anticus utrinque albo-marginatus. Maculae ad scutellum punctumque sub alis alba. Squamae albae. Alae hyalinae ad costam flavescentes. Pedes lutei coxis fuscescentibus.

Aus Taurien von Pallas. Von der Gröfse der Tarpa plagiocephaia. Grundfarbe schwarz. Kopf punktirt. Zwischen den Auren drei weifse Flecke, am Hinterkopf eine breite weirse Bogenlinie. Fül. 


\section{$-194$}

ler röthlich doch kürzer als bei der vorhérgehenden Art, zugleich stärker und dunkler gekämmt. Frefszangen röthlichgelb, an den äufsersten Spitzen schwärzlich. Halsschild und Flügelschuppen weifs. Der vordere Lappen'des Rückenschildes zu jeder Seite weifs gerandet. Jederseits neben dem Rückenschildchen ein weifser Fleck und ein weifser Punlst an der Einlenkung der Vorderflügel. Die Flügel hell durchscheinend, an vordern Fiande gelblich, Nerven und Randmahl etwas dunkler. Die Beine röthlichgelb mit schwärzlichen Hüftstücken. Am Hinterleib der erste Abschnitt mit einem weifsen Punkt zu jeder Seite, die übrigen Segmente sämmtlich weils gerandet. Am Bauch zwei gelblichweifse Queerstriche.

\section{Tarpa pectinicornis.}

Tarpa atra, pedibus antennisque rufis, his nigro-pectinatis, maculis in fronte tribus, linea semicirculari occipitali, lobo antico thoracis, fasciisque in abdomine quatuor albis.

Patria: Barnaul Sibiriae. Dedit Germar qui a Dre. Gebler illan accepit.

Simillima Tarpae plagiocephalae $F$, cui paullo major, antennarum forma Tarpae spissicorni propius accedens. Caput punctatum nigro-pilosum; macula utrinque triangulari ante oculos, punctoque inter antennas pallidis. Mandibulae nigrae, latere externo late ferrugineo. Antennae thorace breviores luteae, articulo secundo nigro, reliquis nigro-pectinatis. Thorax punctatus nigro-pilosus. Collare, linea ntrinque obliqua juxta scutellum, squamae alarum, 
punctumque parvam lineare prope inserliones alarum anticarum pallida. Abdomen nitidum nigerrimum, scymento primo macula media semilunári excisa, ultimis quatuor margine late pallidis. Punctum pallidum etiam utrinque ad apicem segmenti tertii nonnunquam adest. Venter pallido-bistriatus. Alae hyalinae, anticac ad costam late fuscae, nervis stigmateque forrugineis. Pedes lutei unicolores.

Von Barnaul in Sibirien. Aehnlich der Tarpa plagiocephala, doch sind die Fühler beinah wie bei der Tarpa spissicornis, Dic Grundfarbe ist schwarz. Kopf und Rückenschild sind stark punktirt und scliwarz behaart. Die Beine sind gelbroth, die Flügel durchscheinend, die vordern am Aufsenrande breit bräunlich mit gelbrothem Randmahl und Nerven, letzteren jedoch in der Spitze der Flügel mehr schwärzlich, Die Fühler sind von märsiger Länge, das erste Glied gelbroth, das zweite fast schwarz, die folgenden dreizehn bräunlich, an der inwendigen Seite mit sehr verlängerten schwarzen Fortsätzen, wodurch sie deutlich gekämmt erscheinen. Die stark gekrümmten und gezahnten Mandibeln sind an dem äufseren Rande breit braunroth. Von blafsgelber oder gelblichweifser Färbung finden sich folgende Theile und Zeichnungen: an der Stirn vor den Augen ein dreieckiger und zwischen den Füllern ein lileiner runder Fleck. Am Hinterkopf eine schmale Cirkellinie, am Rückenschild der Halskragen, die Flügelschuppen und ein Punkt dicht unter der Einlenkung der Vorderflügel, so wie neben dem Schildchen in schräger Richtung eine abgebrochene oben etwas breitere Linic und 
der hintere Rand der Rückenkürnchen, am Hinterleib endlich der ausgeschnittene halbmondfömige Fleck im, ersten Abschnitt und ein breiter Saum am hintern Rande der vier letzten Abschnitte, oder des vierten, fünftèn, sechsten und siebenten, zuweilen noch ein Punkt zu jeder Seite des dritten Abschnitts. Endlich sind dic beiden vorletzten Bauchsegmente schmal blafsgelb gerandet. 
C r y p t 


\section{Cryptocerus.}

Cryptocerus Fabricii (Syst. Piez.). Latreille (Hist. natur. des $\mathrm{Cr}$. et des Ins., Gen. Crust, et Ins., Considerations geu., Regne animal., Nouveau Dict. d'Iist. natur.). D n meril (Diction. des Sciences natur.) Formica Linn. (Syst. Nat.). Fabr. (Entom. syst. etc.). De Geer (Ins.). Christ (Ins.). Olivier iEncycl.). Latreille (Hist. natur. des Fourmis.).

Unter allen Ameisen bieten die der gegenwärtigen Gattung in ihrer Körperform die auffallendsten Verschiedenheiten dar. Aufser daf's bei ihnen der dem kurzen aus zweien Segmenten bestehenden Hinterleibsstiel folgende Abschnitt des Hinterleibes die folgenden beinah versteckt, deckt noch der grofse viereckige Kopf mit seinem hervortretenden Seitenrande die ziemlich kurzen Füller, und nimmt deren Wurzelglieder in einer eigenen Rinne auf. Dic Gattung Cryptocerus zählte bisher nur selır wenigge Arten. Fabricius führt deren, da man den Cryptocerus marginatus als Weibchen des Cryplocerus atratus nicht mitzählen kann, nur vier auf, die sich auch in der hiesigen Sammlung befinden and im Folgyenden, nebst noch sechs andern beschrieben sind. Aufser diesen sind noch folgrende drei Arten durch Latreille belsannt gemacht worden, nemlich: 
Cryptocerus granulatus (Formica granulata, Hist. nat. des Fourmis p. 275. PI. XII. fig. 75.); Cryptocerus haemorrhoidalis (Formica haem., Hist. nat. des Fourmis p. ${ }_{7}{ }^{6 .}$ ) ; Cryptocerus Pavonii (Gen. Crust. et Ins. IV. p. 132.), so dafs die Gattung Cryptocerus jetzt überhaupt aus dreizehn bekannten Arten besteht.

\section{Cryptocerus atratus.}

Cryptocerus thorace quadrispinoso, capite depresso marginato, postice utrinque bispinoso, totus aterrimus. Long. lin. $4 \frac{x}{2}-8$.

Formica atrata Linn. Syst. Nat. ed. X. p. 58 . n. 15. ed. XII. II. p. 965 . n. 16. ed. Gmelin. I. 5 . p. 2803. n. 16. Fabricii Syst. entomol. p. 3y5. n. 24. Spec. Ins. 1. p. 493. n. 33. mant. ins. I. p. 510. n. 40. Entom. syst. 11. p. 363. n. 54. Christ. Naturg. d. Ins. p. 516. Olivier Encycl. méth. Hist. nat. T. 6. p. 50o. Latreille Hist. nat. des fourmis p. 272. tab. XII. f. 7 .

Formica quadridens De Geer Ins. Ill. p. 60g. $n$. 7. tab. 31. fig. $17-20$.

Tapiiai M a rcgr. Brasil. 252. S eb a thes. IV. Tab. 99. fig. 7 .

Cryplocerus atratus Fabr. Syst. piez. p. 418. n.'x. liatreille Hist. natur. des Crust. et des Ins. Tom. XIII. p. 260. Gen. Crust. et Ins. IV. p. 132. Nouveau Dict, d'Hist. natur. VI. p. 582.

Fem. Cryptocerus marginatus $\mathrm{F}$ a b r. Syst. piez. p. 4ı. n. 2. (Sec. specim. in museo Lundii nunc. Regio Havniensi).

Nabitat in America meridionali; in Brasilia frequentissimus. 
Medins, glaber, punctatus, totus aterrimus. Petioli segmenta utrinque tuberculata.

Fenninae caput postice utrinque bituberculatum. Thorax antice utrinque mucronatus, sub scutello bispinosus. Abdomen ovatum, magnum. Alae testaceae, hyalinae, ad costam obscuriores, nervis ferrugineis, stigmate fusco.

In mehreren Ländern von Südamerika, namentlich in Brasilien gemein. Der Körper $4 \frac{x}{2}$ bis 8 Linien lang, punktirt, unbehaart und ganz schwarz. Kopf vierec $2 \mathrm{ig}$, an den Seiten mit aufgeworfenem Rande, hinten zu jeder Seite mit zwei spitzigen Dornen. Rückenschild in der Mitte schmal, vorn breiter, vorn und hinten jederseits mit starkem, langem Stachei bewaffnet. Des Hinterleibsstiels beide Abschnitte etwas höckriq.

An den Weibchen, welche gröfser, und fast noch einmal 80 grofs als die kleinsten Exemplare der Geschlechtslosen sind, finden wir nur die Hervorragungen schwächer und statt der langen Stacheln an Kopf und Rückenschild Dornen, von denen nur die beiden unter dem Schildchen sich etwas verlängern und als Spitzen ausiaufen; die Fliigel sind blafsbräunlich, am vordern Rande dunkler gefärbt, die Nerven braun und das Randmahl dunkler. Die Flügel fallen, wie iiberhaupt bei den Ameisen, schon den lebenden Weibchen ab, und wir finden daher auch die Weiber des Cryptucerus atratus oft nur mit einem oder cinigen Flügeln, oft uneeflügelt. Die Weibchen kounmen selten, die Geschlechtslosen dagegen in Ueberflul's gu uns. 


\section{Cryptocerus pusillus.}

Crypt. thorace subspinoso postice bispinoso ater capite ante oculos dilatato utrinque testaceo. Long. lin. $2 \frac{1}{2}$.

Habilat in America meridionali; ex Museo Regio Havniensi. Parà Brasiliae ex Museo de II offmannsegg. Rio Janeiro. Misit Dr. de Olfers. Demerary. Communicavit $\mathrm{He}$ m merich.

Parvus depressus. Statura Cryptocero atrato proximus, punctatus, aterrimus pilis argenteis rariuribus adjacentibus micans. Caput antice emarginatum, utrinque testaceum, postice utrinque oblique truncatum angulatun. Mandibulae brevissimae. Antennae breves, apice rufescentes. Thorax planus lateribus quinque-spinosus, spinis duabus posticis longioribus acutis, reliquis brevissimis. Abdomen cordatum subtilissime punctatum, submarginatum basi utrinque testaceum. Petioli segmenta brevissima, antice utrinque in spinulam dilatata. Pedes unicolores.

In Süd-Amerika, namentlich Brasilien und Demerary einheimisch. Viel kleiner als der Cryptocerus atratus', und nicht länger als $2 \frac{\mathrm{r}}{2}$ Linien, jedoch in Rücksicht der Gestalt ilm nahe verwandt. Der Körper ist mattschwarz, den Ifinterleib ausonenommen, deutlich punktirt. An einigen Stellen sieht man dicht aufliegende, wie Silber glänzende Härchen. Der Kopf ist, besonders hinter den Augen breit, vorn ansgerandet, zu den Seiten brïunlich, hinten auf jeder Seite schräg abgeschnitten. Die äufsersten Spitzen dẹr Fühler sind röthlich. Das Rückenschild ist an den Seiten gedornt. Drei kurze, doch zugespitzte Dornen befiuden sich zu jeder Seite an der vordern, 
zwei dergleichen an der hintern Hälfte des Schildes, der letzte Dorn jeder Seite ist ansehnlich verlängert. Der Hinterleib ist herzförmig, an der Einlenkung deutlicher gerandet, der Rand blafsbräunlich. Beide Abschnitte des Stiels sind kurz, jederseits in einen kurzen flachen Dorn sich endigend. Die Beine sind einfarbig schwarz.

\section{Cryptocerus minutus.}

Cryptocerus thorace spinoso, ater capite ante oculos utrinque testaceo, antennis, pedibusque rufescentibus. Long. lin. 2.

Cryptocerus minutus Fabr. Syst. piez. p. "420. n. 5. (sec. specimen Mus. Dom. de Sehes ted t nunc Regii Havniensis).

Il abitat in America meridionali; Rio Janeiro; misit amicissimus de Olfers.

Praecedenti simillimus, subtilissime punctatus, aterrimus, pilis argenteis adjacentibus micans. Caput vix thorace latius, antice emarginatum, ante oculos utrinque testaceum, postice oblique truncatum, angulatum. Mandibulae vix exsertae. Antennae breves rufescentes. Thorax planus, sulco medio transverso, divisus, utrinque quinque-spinosus, spinis anterioribus minoribus acntis, posticis duabus validioribus apice rufescèntibus. Abdomen cordátum basi sinuatum, utrinque marginatum testaceum. Petioli segmenta brevia, utrinque spinosa. Pedes ferruginei, fentoribus nigris.

Specimen Musei Havniensis nostro duplo fere minus minime tamen specie distinctum.

Yon Rio Janeiro in Brasilien. Kleiner als der Cryptocerus pusillus. "Der Körper flach, schwarz, 
punktirt, durch einzeln aufliegende silberglänzende Härchen, besonders am Rücken, der vordern Hälfte des Hinterleibes und den Schenkeln der Beine schillernd. Der Kopf, kaum breiter als das Rückenschild, ist vorn ausgerandet, an den Seiten blafsbräunliclr. Sehr kurze Mandibeln und kurze braunröthliche Fühler. Das Rückenschild durch eine Queerrinne getheilt, in der Mitte verengt, an den Seiten gedornt. Füní Dornen zählt man auf jeder Seite, die vorderen sind kürzer, doch zugespitzt, die hintersten nach aufsen schräg aufsteigend, etwas länger und an den Spitzen röthlich. Der Hinterleib herzförmig, wie bei der vorhergehenden Art, ist besonders an seiner Basis deutlich gerandet und an den Seiten blafsbräunlich. Die letzten Segmente schillern röthlich. Beide sehr kurze Abschnitte des Stiels dehnen sich Seite in einen flachen, spitzen Dorn. Die Dornen des ersten Abschnitts sind im Verhältnifs lang und hakenförmig nach hinten gekrïunmt. Schienen und Fufsglieder sind braunroth, Schenkel und Hüftglieder schwarz.

\section{Cryptocerus clepressus. n. sp.}

Cryptocerus ater thorace petioloque spinosis, capite postice bispinoso, antice utrinque testacev. Long. lin. 2.

Patria: hio Janeiro; collegerunt Dr. de Olfers et Sello.

Statura Crypt. pusilli. Punctatus aterrimus, pilis argenteis adjacentibus ubique micans. Caput vix thorace latius, depressum, postice dilatatum marginatum utrinque bispinosum, spinis brevissimis depressis, ante oculos utrinque testaceum. Mandibulae breves 


\section{- 205}

ferrugineac. Antennae apice rufescentes: Thorax brevis lateribus planus et quinquespinosus, spinis anterioribus majoribus depressis apice truncatis posticis brevioribus acutis recurvatis. Abdomen cordatum basi emarginatum, utrinque marginatum margine testaceo. Segmenta petioli brevia basi utrinque spinosa, spinis depressis acutis, recurvatis, anterioribus longioribus. Femora clavata, compressa, postica angulata et medio subspinosa, apice ferruginea. Tibiae anticae ferrugineae. Tarsi rufescentes.

Grörse und Gestalt des Cryptocerus pusillus, schwarz, iiberall dicht punktirt, durch kurze einzeln dicht aufliegende silberğlïnzende Härchen schillernd. Der Kopf, breiter als das R̈ückenschild, erhebt sich jederseits über den Augen und bildet dort, doch aufserdem nirgend einen aufgeworfenen Rand, dann verschmälert sich der Kopf, tritt vorn, wo er blafsbräunlich ist, anf jeder Seite hervor. In der Bucht, welche so in der Mitle entsteht, findet man die Frefsgangen, liurz und breit, doch zugespitzt und von dunkelbrauner Farbe. Von den beiden Spitzen zu jeder Seite hinter den Augen ist die inwendige die längere. Die Fühler sind schwarz, an den Spitzen röthlich. Das Rückenschild ist kurz, an den Seiten mit flachen Dornen bewaffnet, von denen die beiden vordern gröfser, breit und an der Spitze abgeschnitten, die folgenden zugespitzt, die mitleren die kleinsien sind. Beide Abschnitte des Hinterleibsstiels sind kurz, flach, an den Seiten in rückwäris gekrümınte spitzigge Dornen verlïngert. Der erste Abschnitt hat die längeren Spitzen. Der Ilinterleib selbst ist herzförmig, wio bei den vorhergelsenden Arten. Die Schenkel sind liurz, etwas zusammengedrüclit, in der Mitte verdickt, 
die hintersten am obern Rande gerade in der Mitte mit einem kurzen spitzigen Dorn bewaffnet. Die Schieneu sind kurz, zusammengedrüclit, die vorderen beinah durchaus, die hintersten am Rande braun. So sind anch an den vorderen Beinen die Fufsglieder sämmtlich, an den hintersten nur die letzten Glieder röthlich.

\section{Cryptocerus pallens.}

Cryptocerus capite thoraceque angulatis, petiolo brevissimo subspinoso, depressus pallidus. Long. lin. $1 \frac{\pi}{2}$.

Patria: Brasilia; misit $\mathrm{S}$ wains on.

Corpus pallidum. Caput quadratum, punctatum, utrinque marginatum, apice emarginatum, rufescens. Mandibulae breves ferrugineae. Antennae ferrugineae, apice pallidae. Oculi nigri. Thorax elongatus, apice profunde sinuatus, linea impressa media transversa divisus, utrinque marginatus, margine rufescenti basi in angulum obtusum producto, ante apicem crenato. Petiolus articulis brevissimis transversis, primo in spinam ntrinque acutam dilatato. Abdomen elongatum, cordatum, basi emarginatum, marginatum, marginibus ferrugineis. Pedes compressi breves, tibiis basi rufescentibus.

Aus Brásilien. Nur $1 \frac{T}{2}$ Linien lang. Flachgedrückt, blåssolb, punktirt, durch einzelne kurze und sehr zarte, wie Silber glänzende Härchen in den Punkten schillernd, der Rand überall röthlich alggesetzt. Der Kopf fast vierechig vor den kleinen schwarzen Augen gerandet, an der Spitze ausgerandet mit braunröthlichen Mandibeln und röthlichen 
an den Spitzen blassgelben Fühlern. Das Rüclienschild länglich viereckig, ist in der Mitte durch eine eingedrückte Queerlinie gुetheilt, läuft vorn zu jeder Seite in einen stumpfen Wiskel aus, und hat vor dem hintern Ende, welches tief bogigt ausgeschnitten ist, einige stumpfe Zähnchen. Der Hinterleibsstiel besteht aus zwei sehr kurzen Gliedern, deren erstes breiter ist und in cine scharfe Spitze an den Seiten sich endigt. Der Hinterleib ist länglicht herzfürmig, dentlich gerandet. Die Beine sind zusammengedrüclit, liurz, die Schienen an ihrer Verbin: dung mit den Schenkeln rüthlich.

\section{Cryptocerus clypeatus.}

Cryptocerus depresius, laevis, testaceus capite thoraceque spinis, abdomine margine elevato pallidis, membranaceis. Long. lin. 4.

Cryplocerus clypeatus Fabr. Syst, piez. p. 420. n. 3. (Sec. specimen Mus. Regii Havn. ex Mrusco de Sehestedt).

II a itat in America meridionali; Parì in Brasilia. Misit Sieber; Mius. berolinense ex Mus. Comit. de Hoffnan $\mathrm{nsegg}$.

Cryplocero atrato minor, depressus, nitidus, quasi pellucidus. Caput dilatatum, férrugineum, lateribus'pallidum membranaceum, antice emarginatum, postice utrinque subspinosum. Mandibulae breves, pallidac, apice ferrugineac. Oculi parvi glubosi nigri. Antennae ferrugineae, basi pallidae. Thorax ferrugineus, marginibus elevatis membranaceis pallidis, medio angustatns, antice ulrinque dilatatus spinosus, spina valida depressa recurı́, postice subspinosus 
spina brevissima obtusa. Petiolus articulis brevissimis ferrugineis utrinque unispinosis, spinis anterioribus brevioribus acutis incurvis, posterioribus longioribus recurvatis obtusis. Abdomen subcordatum, marginatum, margine onıni elevato, albido-hyalino, medio ferrugineum glaberrimum inflatum et pellucidum. Pedes ferruginei.

Aus Süd-Amerika; die Exemplare der hiesigen Sammlung von Parà in Brasilien. Kleiner als Cryptocerus atratus, und vier Linien lang, flach gedrückt, gelbbraun, an den Seiten blafs, hautähnlich und wie darchscheinend. Der Kopf erweitert, vorn ausgerandet, am hintern Winkel in eine stumpfe Spitze auslaufend. Die Fühler mäfsig lang, dunkel mit hellem Wurzelglied, die Augen klein, rund und schwarz. Das Rückenschild in der Mitle verengt, vorn zu jeder Seite in einen hakenfürmigen rückwärts gekrümmten Dorn erweitert, hinten ebenfalls, doch in geringerem Grade erweitert, breit aufgeworfen und stumpfspitzig. Die Aüschnitte des Hinterleibsstiels sind sehr kurz, jeder an den Seiten mit einem, der erste mit einem flachen zugespitzten, der zweite mit einem längern, stumpfen nach vorn gelirummten Dorn versehen. Der Hinterleib fast herzförmig, hat einen aufgeworfenen blassen und durchsichtigen Rand. Die Beine sind von der Grundfarbe des Körpers.

\section{Cryptocerus membranisceus.}

Cryptocerus depressus, brunneus, punctatus, capite thoraceque spinis, abdomine margine membranaceis pallidis. Long. lin. 3 .

Pa ıria: Brasilia. Misit Dr. de Olfers: 
Fraecedenti valde afñnis, brunneus, punctatus, punctis piliferis, pilis brevissimis argenteis. Caput longitudine thoracis, antice emarginatnm, late marginatum, margine membranaceo, postice utrinque in spinam obtusum productum. Mandibulae breves ferrugineac. Antennae ferrugineae, apicc fuscae. Oculi rotundati prominentes, ferruginei. Thorax medio coarctatus, utrinque bispinosus, spinis depressis membranaceis, anticis majoribus rectirvis, posticis brevioribus reflexis. Petiolus abdominis distincte binodis, articulis utrinque unispinosis, spinis membranaceis recurvatis obtusis. Abdomen basi late, apice acule emaryinatum, marginatum, margine membranaceo. Pedes ferruginei.

Aus Brasilien: drei Linien lang. Der eben beschriebenen Art sehr ähnlich und eben so flach gedriickt und braun gefärbt, doch ist der Körper überall mit Punkten, aus welchen sehr kurze, silberglänzende Härchen entspringen, hesetzt und erscheint daher weder so glänzend, noch so durchsichtig als der des C. clypeatus. Der Kopf von ansehnlicher Gröfse, hat etwa die Breite des Rückenschildes, ist vorn weit ausgerandet zur Aufnahme der kurzen dreieckigen Mandibeln. Derselbe läuft zu jeder Seite linten in einen flachen stumpfen Zahn aus, vor den Augen scheint er einen breiten durchsichtigen Rand zu haben. Die Fühler sind von ziemlicher Länge, brauı, an den Spitzen dunkler, die Augen hervorstehend, rund, dunkelbraun. Das Riickenschild ist, wie bei der vorhergehenden Art, in der Mitte eingeschnürl, vorn zu jeder Seite in einen grö́sern gelirümmten, hinten in einen stumpfen aufwärts gebogenen flachgedrückten, hautïhnlichen Zahn auslaufend. Dex 
Hinterieibstiel hat dentlich abgesetzte Glieder, deren jecies an den Seiten in einen linicnförniggen nicht zugespitzten Zahn auslänft. Der Dinterleib ist an seinem Ursprung weit ausgeschniten, an der Spitze eivogekerbt und von einem gleich einer zarien Haut durchsichtimen schmalen Rasde überạll umgeben. Diè Beine sind braun.

\section{Cryptocerus umbraculatus.}

Cryptocerus thorace subspiuoso, ferrugineus abdomine flavo-maculato. Long. (feminac) lin. $4 \frac{9}{2}$.

Cryplocerus umbraculatis Fa b r. Syst. piez. p. 420 . 1. 4. (Sec. spec. Lundii in Museo Regio Havniensi).

Habitat in America mericionali; Bahia Brasiliae; Mas. Reg. Berol. ex Musco Comit. de Hotfmannsegr.

Neutrum Cryptocero clypeato fere minor. Caput depressum medio ferrugiueum, pilis brevissinis rarioribus adjacentibus anreo-punctatum, lateribus elevatum, postice truncatum, angulatum, pallido-narginatum, antice utriuque rotundatum pallidum. Mandibulae breves pallidae, apice ubscuriores. Antennae ferrugincae, scapo pallido. Oculi globosi ferruginei. 'Thorax ferrugineus, pilis aneis intermixtis punctatus, lateribus denticulatus, antice spinosus, spinis brevibus depressis acutis pallidis subjellucidis. Petioli segmenta ferruginea, sparsin punclata, brevia, utriuque spinosa, spinis subaequalibus depressis recurvatis acatis, posticis margine superiori dilatatis membranaceis. Abdumen cordatum, ferrugincum, antice utrinque marginatum, marginibus elevatis membranaccis albo-hyalinis, basi, fascia intermedia medio nterrup:a apiceque testaceis, subtus testaceum. Pe- 


\section{$-211$}

des ferruginei pilis aureis rarioribus adjacentibus submicantes. Femora subincrassata, postica margine supero subdentata. Tibiae posteriores basi annulo pallido.

Femina major, capite thoraceque punctatis ferrugineis, lateribus testaceis. Caput marginatum postice truncatum obtusum margine elevato, crenato. Antennae breves ferrugineae. Oculi fusci. Ocelli in capitis vertice distincti. Collare lineà elevata transversa a thorace distinctum, marginatum, margine crenato. Pleurae pallido-maculatae. Metatiorax utrinque bispinosus, lateribus pallidus. Alae testaceas, hyalinae, ante apicem subfuscae, nervis prope insertionem pallidis, reliquis stigmateque ferrugineis. Petioli segmenta ferruginea, punctata, lateribus vix spinosa. Abdomen magnum vix punctatum olscure ferrugineum et fere nigrum, pallido-quadrimaculatum, ano ferrugineo. Venter ferrugineus basi pallidus. Pedes ferruginei.

Das Geschlechtslose !der Föniglichen Sammlung in Kopenhagen stammt aus Süd - Amerika, das Weibchen in hiesiger Sammlung, dessen Länge $4 \frac{\mathrm{T}}{2}$ Linien betrügt, erhielt der Graf v. Hof fmannsegg von seinem Freunde Gumes in Bahia.' Das Geschlechts. lose der genannten Sammlung ist kleiner als der gewöhnliche Cryptocerus atratus, von Farbe braun, Kopf, Rückensclild und Hinterleibssticl punktirt und erscheinen diese Theile, wie die Beine, durch aufsitzende kurze glänzende Härchen wie mit Goldpünktchen besäet. Der Kopf ist flach, gerandet, der Rand etwas aufgeworfen, scharf, vor den Augen von hel. ler Farise und einer dünnen Haut ähnlich. Hinten

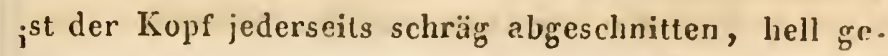
14 * 
randet, die Ecken wenig hervorstehend, kaum Dornen ähnlich. Die Fühler sind braun mit blassem Wurzelgliede, die Augen rund und dunkel. Am Rückensehild ist. besonders der vordere Rand zu jeder Seite mit einem flachen, kurzen, doch scharf zugespitzten, nach hinten ggekrümniten hell gefürbten Dorn bewaffuet. Die hintere Hälfte ist an dcn Seiten ku:z gezahnt. Die Zähnchen sind ebenfalls von heller Farbe, flach und fast durchsichiig. Beide Abschnitte des Hinterleibstiels stimmen in ihrer Gestalt und Eeschaffenheit beinah überein. "Jedes derselben lïuft, an den Seiten in cinen flachen, zugespitzten, riickwärts gekrümmten, am Rande hellen und durchscheinenden Zahn aus. Der Hinterleib ist herzförmig, dnnkelbraun. Der Grundheil blafsgelb, durch die Mitte zielst sich eine unterbrochene Binde, die Spitze ist hellbräunlich. $Z u$ jeder Seite neben der Einlenkung des Stiels hat der Finterleib einen schmalen durchsichtigen Tand in Gestalt einer dünnen Haut. Der Bauch ist blass. Die Beine sind wie der übrige Kürper gefürbt, die hinteren Schienen blafs geringelt, die hinterston Schenkel etwas verdickt und am oberen Rande in der Mitte stumpf gezahnt.

Das Veibchen im hiesigen Museum zeigt ungefähr dieselben Verhältnisse, wie beim Cryptocerus atratus. Es ist ansehnlich gröfser und erreicht fast an Grörse die Geschlechtslosen des Eryptocerus airatus. Kopf und Rückenschild sind punktirt. In den eingedrückten Punkten finden sich die kurzen golänzenden Härchen, welche den Geschlechtslosen ein goldschillerndes Ansehen ertheilten. Der Kopf ist nicht breiter als das Rückenschild, nach vorn anf- 
geworfen und blafs, seitwärts mit cinem gekerbten aufoworfenen Rande versehen, das Ilinterhaupt noch hesonders gerandet und auch dieser Rand dunkler und grekerbt, jederseits in einen stumpfen Winlrel auslaufend. Die Mandibeln sind kurz und breit, die Fïhler kurz mit kürzeren hellen Vurzelngliede, dic Augen rund, dunkel, dic Nebenaugen sehr deut. lich. Voun Rückenschild ist das Halsschildchen dentlich getrennt, queer durch dasselbe zieht sich dicht am Rückenschilde ein feiu gekerbter Kannm und vorn wird es durch einen ebenfalls gelierbten Rand begränzt. An den Seiten ist dieser vordere Rand kaum merlklich in einen stumpfen Winkel vorgezogen. Der Rïcken ist dunkel, die Brustseiten sind höckrig, punktirt, blars gefleckt, fein behaart. Das Schildchen ist durch zwei eingedrückte geschwungeno Queerlinien geschiedęn, der Hinterrücken zu beiden Seiten mit zwei kurzen hellen Dornelı, von welchen der letrte spitz auslïuft, bewafnet. Die Segniente des Hinterleibsstiels sind lkurz, dunkelbraun, punktirt, an den Seiten hückerig. Der Hintcrleib, gröfser als beim Geschlechtslosen, ist dunkel schwarzbraun, ge ziert mit vier hellgelben Flecken, zwei zu jeder Seite, von denen die beiden am Grundtheil des Hinterleibes gröfser und beinah vereinigt, die beiden mittleren deutlich getrennt sind. Die Spitze ist hell röthlichbraun, der Bauch eben so gefärbt, mit einem grofsen gelben Fleck an der Finlenkung des Stiels. Die Flügel sind grelblich, durchscheinend, vor der Spitze dunkel, die Nerven an der Vurzel bla「sgelb, die übrigen sanmit dem Randmahl dunlielbraun. Die Beine sind ciafarbig braun. 


\section{Cryptocerus elongatus.}

Cryptocerus thorace antice posticeque spinoso, elongatus, aterrimus. Fem. long. lin. 5 .

Patria: Parà in Brasilia. Misit Sieber; ex Museo Com. de Hoffmannsego. Rio Janeiro; misit Sello. Demerary. Comm. Hemmerich.

Cryptocero atrato vix brevior at valde elongatus, cylindricus et angustissimus. Aterrimus. Caput punctatum globosum, margine ante oculos utrinque elevato, postice utrinque subtuberculatum. Clypeus parvus, albido - tomentosus. Mandibulae apice biden; tatae. Antennae brevissimae fuscae. Oculi globosi fusci. Ocelli distineti. Thorax abdomine brevior, punctatus, lobo antico utrinque tuberculato, tuberculis brevibus aculis. Metathorax dorso scaber, apice bispinosus. Segmenta petioli brevia, transversa, punctisque impressis scabra. Abdomen elongatum, subtilissime transversim striatum et sparsim impressopunctatum, segmentis marginibus tenuissime sanguineis. Pedes simplices, femoribus vix apice ferrugineis. Alae fumigatae, hyalinae, nervis stigmateque fuscis.

Von Parà und Rio Janeiro in Brasilien und von Demerary. Weibchen, fünf Iinien und beinah so lang als der Cryptocerus atratus, nur'schmal und cylindrisch. Kopf und Rückensclild sind punktirt; der Kopf lkugelrund, der Rand an jeder Seite vor den Augen aufgeworfen. Hinter den Augen befindet sich ein fast unmerklicher spitziger Höøker. Das kleine Kopfschild ist mit weifslichen Härchen diclit bedeckt, die Frefszangen sind an der Spitze zweigezahnt, die Fühler kurz und dunkelbraun, die $\Lambda$ ugen 


\section{$-\quad 215$}

rund, die Nebenaugen deutlich. Am Rückenschild befindet sich vorn zu jeder Seite ein spitzinger IIöklser. Der lïinterrücken, rauh durch tief eingedrüclite Punlute, endight sich in zwei spitze Dornen. Die Abschnitle des Minterleibstiels sind kur\%, und durch eingedrüclste Punlite, wie der Hinterrüclsen ungleich. Der Finterleib ist schmal und lang, höchst fein in die Queere gestreift und hin und wieder punkirt. Die Abschnitte schillern an den Rändern braunruth. Die Flïgrel sind dürchscheinend, düch etwas dunkel, bräunlich angeflogen. Nerven und das sehr deutliche Randmahl sind dunkel braunschwarz. Jie Beine sind kurz, dis Schenkel an de: Spitze braun.

\section{Cryptocerus quadrimaculatus.}

Cryptocerus elongatus, aterrimus, abdomine flavo-quadrimaculato. Fem. Long. lin. $3 \frac{1}{2}$.

Patria: Brasilia; Sello. Parà misit Sieber; ex Níuseo Com. de H off mannsegg.

Praecedenti similimus ejusdemqne magnitudinis et s:aturae. Caput punctatum globosum arte oculos utrinque marginatum, elevatum, postice rotundatum. Mandibulae breves, acutae, nigrae. Antennae brevissinae fuscae, apice rufescentes. Oculi globosi. Ocelli distincti. Thorax punctatus, antice utrinque subspinosus. Minetathorax punctis impressis scaber, basi utrinque tuberculatus, i:pice bispinosus. Segmenta petioli brevia, punctis impressis scabra, utrinque tuberculata. Abdomen cylisdrisum, segmento primo maximo, basi et ad apicem utringue flavo-maculato. Segmenta omnia tenuissime sanguincu - marginata. Alac obscurae, hyalinae, nervis stignateque fuscis. ledes breves, femoribus apice tibiis tarsisque ferrugrineis. 
Aus Brasilien. Ebenfalls nur Weibchen, im Körperbau der vorhergehenden Art höchst ähnlich, doch etwas kleiner und nur $3 \frac{x}{2}$ Linien lang. Der Kopf punktirt, kugelrund, vorn mit anfgeworfenem Seitenraude, hinten gerundet. Die Frefszangen zu. gespitzt. Die Fühler kurz, braun, an der Spitze röthlich, die Augen rund; die Nebenaugen deutlich. Das. Rückenschild, dicht punktirt, liat vorn zu jeder Seite einen spitzigen Höcker. Der Hinterrücken endigt sich in wwei Dornen und ist an den Seiten höckrig. Die $\Lambda$ bschnitte des Iinterleibsstiels sind dicht punktirt. Der erste Abschnitt ist nicht ganz so breit als der zweite, an den Seiten höckerig, der zweite zu jeder Seite in einen stumpfen Dorn auslaufend. Am Hinterleib, welcher schwach punktirt ist, ist der erste Abschnitt sehr grofs und mit vier gelben Flecken bezeichnet, von welchen zwei am vordern Rande, zwei unweit der Spitze, dicht an den Seiten, befindlich sind. Sämmtliche Abschnitte haben einen sehr schmalen rothen Ritnd. Die Flügel sind dunkel, durchsichtig, mit dunkelbraunen Nerven und Randmahl, die Beine kurz, die Schenkel an der Spitze braun, Schienen und Fufsglieder braun. 
C $\quad$ e $\quad r \quad a \quad m \quad$ i $\quad$ u $\quad$ s. 



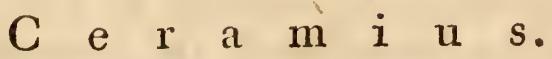

Ceramius Latreille, (Considérations etc. Cuvier-regne animal). Gnatho Klug (Magaz. d. Gesellsch, naturf. Fr, zu Berlin IV.).

Im Jahrgange 1810. des INagazins der Gesellschaft naturforschender Freunde siellte ich "(pag. 36 u. f.) eine merkwürdige neue Wespengattung unter der Benennung Gnatho auf. Ich kannte damals von dieser so anffallend verschiedenen Gattung nur eine Art, welche Herr Professor Lichtensteiri in Afrika entdeckt hatte, und die ich nach ih:n Gnatho Lichtensteinii nannte, auch auf einer beigefügten Tafel (I. Fig. 3.) abbilden und eben daselbst (Fig. e. f.) einige Umrisse der wie es schien, sehr nerkwürdiog gebildeten inneren Mundtheile gebin liefs. Späterhin indefs überzeugte ich mich, dafs der Gattungsname Guatho schlecht gewählt sey, weil schon von unserm verewigien Llliger in dessen Magazin der Inselitenkunde Band VI. pag. 548. dieselbe Benennung zur Bezeichuung einer Käfergattung, die Latreille Megacephala nennt, angewendet worden ist; dann aber lehrte mich eine genauere Untersuchung, dafs ich die Structur der Lippe und ihrer Theile nur an einem verstünmelten Stücle und unrichtig beobachtet und demgenäl's 
falsch und mangelhaft heschrieben und in der Abbildung vorgestellt hatte.

Beide von mir beģangene Fehler zu verbessern, und was sonst liickenhaft in meiner frühern Arbeit erscheint, zu ergänzen, war, indem iç die folgenden Zeilen niederschrieb, meine haupisächlichste $A \emptyset$ sicht, wobei nun aurserdem diese Gelegenheit von mir benutzt worden ist, um auch die iibrigen aufser dem Ceramius Lichtensteinii nun bekannten Arten dieser Gattung zu beschreiben.

Was die Gattungsbenennung Gnatho betrift, 'so ist diese sehr leicht und zweckmälsiog durch $L$ ao treille's Gattungsnamen Ceramius ersetzt, unter welcher Benenuung dieser so berühmte als verdicnte Soluriftsteller dieselbe Gattung auf den Grund der Untersuchung einer andern und zwar Europäischen Art in seinen im Jahr 1810. zu Paris erschienenen "Considérations générales sur l'urdre naturel des Crustacés, des Arachnides et des Insectes (p. 52g. C. 502.) zuerst aufgestellt hat.

Der zweiten Anforlerung genügt züörderst nachstehende geuaue, und unständliche Beschreibung der. Lippe, wie ich sie an meinem Ceramius Lichtensteinii leobachtet habe:

Das Ganze der Lippe, weit entfernt von der ihm im Magazin IV. p. 36. angeschuldigten Dürftigkeit, ist viel cher zilsammengesetzter als bei den übrigen Wespen. Wie im Kürper des Thieres übcrhaupt eine gewisse Annäherung eines Theils an die bienenartigen Insekten, andern Theils an Latreilles Crabronites sich verrathen will, so enthält auch der Apparat, den man gewöhnlich Lippe nennt, Einzelheiten, die sonst nur in veränderter Form und Ver- 
hältnifs dem Bienenmunde gehören. Ich fange mit der Lippenscheide an und bemerlio von ihr zuerst, dafs sie ihrer Furm rach beinah eisen Kubus darstellt und in ihrer Substanz melir lederartig als hornähnlich ist. Iir Inneres verbirgt einen ansehnlichen Vorrath ron musliulösen und sehnigten Gebilden zur Lenkung der verschiedenen aus ihr hervorgebenden, zum Saugen, zum Tasten oder zur Unterstitzung der saugenden Theile dienenden VVerlizeuge. Jhre untere Fläche schütat die hornharte Belkleidung, ihre obere Fläche erhebi sich in einem doppelten zweispaltigen, ebenfalls hornharten Streifen mi: abweichenden Spitzen. Unter diesem finden wir eine gewölbte aus einer feinen Membran gebildete Schuppe angeheftet und durch diese als zartere Fortsetzung der Lippenscheide eine Verbindung zwischen dem Kubus der Lippeascheide nud den aus ihm entspriugenden, nach aufsen hervortrctemlen, nun näher zu beschreibenden Theilen jewerkstelligt.

Von dicsen Theilen gedenise ich zuerst zweier garten hïuliģen, im Aufaug scheibenförmigen, dann plötzlich sich verengenden und in einen linienförmigen Fortsatz ausiaufenden Seitenlappen, die mit grofsem Rechte Nebenzungen (paraglossae) genannt werden könnten. Sie sind die $\Delta$ ưsentheile der Lippe und dienen zum Schutz der innen gelegenen doppelten Zunge. Weiter erwihne ich einer schmaleis, feinen und häutigen Schuppe, deren eine zu jeder Seite unter der schon beschriebenen Lippenschcile hervortritt und der Zunge von oben Schut\% gewäht. Besonders aber und als vorzüglich merkwürdig-nenne ich die zwischen deu scheibenartigen Nebenzungen verborgene, diese an Läıg liatu ibertreffende fich- 
ren ähnliche, sehr fein geringelte doppelte Zunge. Endlich füge ich dem noch bei, dafs die Frefsspitzen der Lippe zwar viergliedrig sind, das letzte Glied indessen ausgereichnet kiein isi, so dafs es bei einer wenigger genauen Untersuchurgg leicht übersehen werden kann.

Dies war, was in Hinsicht meiner früheren Angaben über die Gattung Gnatho (nunmehr Ceramius) nothwendig berührt und berichtigt werden mufste. Jetat folgt das Resultat der spätern Untersuchungen der Europäischen Art oder des Ceramius Fonscolombii Latr. und der Vergleichung seiner Theile mit denen des Ceramius Lichtensteinii.

Die Lippe, als derjenige Mundtheil des Ceramius, welcher der vorzüglichsten Aufmerksamkeit werth scheint, ist beim Ceramius Fonscolombii überhaupt mehr zukammengedrückt, besonders aber nähert sich die Lippenscheide in ihrer Gestalt mehr diesem Theile wie $e r$ bei andern Hymenopteren und namentlich auch den Vespariae gewöhnlich angetroffen wird. Undeutlicher sind hier die hornartigen Streifen, welche divergirend auf der obern Fläche der Lippenscheide des Ceramius Lichtensteinii angetroffen wurden. Dagegen sind, um vieles deutlicher und in grö̈fserer Vollkommenheit die Hautschuppen an der Spitze der oberen Seite der Lippenscheide vorhanden, und wir sehen, dafs eine derselben zu jeder Seite den Ursprung der Seitenlappen oder Nebenzungen declit, eine doppelte hingegen in der Milte zwischen diesen von oben her den Saugrpparat schützt. Die Nebenzungen selbst sind wie bei der Afrikanischen Art gestaltet. Nur sind die linienförmigen Fortsütze in welche sie auslaufen, verhältnifsmälsigg kürzer, auch in ihren Spi- 


\section{$-223$}

tzen mit einem lunkeln Punlite bezeichnet. Eine doppelte Zungre ist anch hier zwischen den äufseren Lappen versteckt, nur ist sie breiter und kürzer, zugleich ist jede der einzelnen Röhren auf der inwendigen Seite etwas geftïcht, am obern Rande leicht gefranzt, ïberbaupt undeutlicher geringelt. Dín Lippentaster endlich sind deutlich viergliedrig, das letzte Glied nur wenig liürzer, als das vorhergehende.

So wie aber bei diesen beiden Arten der Gattung Cerainius Verschiedenheiten geringerer Bedeutung in der Lippe und dem Verlältuils der Tasterglieder obwalten, eben so trefen wir, wenn auch nicht wesentliche, doch bemerisenswerthe Abweichungen in der Structur der Laden und vorzüglich der ihnen gehörenden Tastcr an. Luetztere sind nemlich zwar auch auf den ersten Anblick und bei oberfächlicher Hetrachtung mit einer gewöhnlichen Lupe nur einglied̉rig, erscheinen jeduch bei ciner stïrkern Vergrö̈fserung mittelst einer einfachen Linse schon deutlich dreigiiedriog, so dafs wir ein kurzes rundes Wurzelglied, eis darauf folgendes längeres und ein woll doppelt so langes Endglied olme Miihe unterscheiden, und selbst dieses Endorlied ist unweit der Spitze durch eine besondere Einschnürung getheilt, so dafs einem gut bewâñneten Auge die Kinnladentaster des Ceramius ronscolombii vieroglicdrig erscheinen.

Ganz wie bei dem Ceramius Forscolombii sind auch die Mundthei'e einer höchst ähnlichen Art, welche sich in der Sammlung des Grafen v. H iffmannsegg fand und als Ceramius lusitanicus späterhin beschrieben worden ist, gebildet. Dagegen findet sich bei einer neuen und merkwürdigen $\Lambda$ frikanischen Art, dem ebenfalls nachher beschriebenen 


\section{$-224$}

Ceramius linearis, in Uebereinstimmung mit einem sehr schmalen Körperbau eine so auffallende. Verengung und linienförmige Verlängerung sämmtlicher innerẻn Mundtineile, dafs mit demselben Rechte, wie die Trenuung einiger Vespariae und Sphegimae mit sehr verlängerten Mundtheilen geschelıen, auch der Ceramius linearis als eigene Gattung hätte aufgestellt werden können, welches aber, da besonders nur ein einziges Insekt von dieser Art bisher bekannt geworden ist, nicht zu rechtfertigen seyn würde.

Ueberhaupt habe ich die eben gedachten Abweichungen vorzüglich darum aufgezeichnet, weil es mir der Mühe werth schien, sie zu kennen, nicht, dafs sie einmal einen Grund abgeben könnten, çie verschiedenen Arten von Ceramius danach als Gattungen zu trennen. Jch halte diese $A b w e i c h u n g e n$, vielleicht mit Ausnahme der Mundbildung des Ceramius linearis, nur für unwesentlich und bin der Meinung, dafs sie in einem Systemı nach F a b r i ci schen Grundsätzen gremeinschaftlich die Naterialien zu einem sehr guten künstlichen Gattungscharakter etwa in folgender Art hergeben könnten :

Palpi quatucr: labiales longiores, quadriarticulati, articulis cylindricis, subaequalibus, ultino brevissimo; maxillares breviores, articulis indisiinctis.

L abium tubo affixum coriaceo, brevi, subcompresso, apice subtus integro, supra squamis meimbranaceis utrinque tecto, bilaciniatum; laciniis membranaceis, semiorbiculatis, in processum brevem linearem exeuntibus, linguum (s. glossarium) duplicem obtcờcentibus. 


\section{$-225$}

Maxillae compressae, basi corneae, apice mem.

branaceae, subintegrae.

Der wesentliche Character aber würde in der Beschaffenheit der Lippe zu suchen, und mit den Worten ausgesprochen seyn: Labium bilaciniatum, laciniis lingrean duplicem obtegentibus.

Ehe ich dis Betrachtung der Gattung verlasse, kann ich nicht umhin noch der Kinnbacken (mandibulae) zu erwähnen, die bei den verschiedenen Arten abweichend geformt, bei dem Ceramius Lichtensteinii an der Spitze zweizahnig sind und vor der Mitte nichts als eine geringe Erhabenheit als unbedeutende Anlage zu einer zahnförmigen Erhöhung zeiğen, dagegen beim Ceramius Fonscolombii nicht allein unweit der Wurzel mit einem im rechten Winkel einwärts vorspringenden starken Zahne bewaffnet sind, sondern anch nach diescm aufser dem scharfen Zahne der Spitze, zwei in derselben Richtung abwärts geführte scharfe und ziemlich lange Zähne haben. Auch bemerke ich beiläufig, dafs ich Exemplare des Ceramius Lichtensteinii erhalten habe, welche die Flügel nach $\Delta$ rt der übrigen Wespen grefaltet trugen, so dafs, wenn auch dasselbe in Hinsicht des Ceramius Fonscolombii, nach Latreille's Versicherung nicht statt finden sollte, dennoch Latreilles, ,ailes étendues" (Considérations ctc. 1. c.) die Gattung Ceramins zu unterscheiden nicht geeignet seyn würden.

Die Arten sind:

\section{Ceramius Lichtensteinii.}

Ceramius ochraceus, vertice, thoracis durso, abdominis segmentis macula bascos nigris. Long. lin.8. 
Gnatho Lichtensteinii Klug Mag. d. Ges, naturf. Freunde. IV. p. 38. Tab. 1, Fig. 3.

Patria: Prom. bonae spei.

Facies Crabronis. Caput magnum ponctatum nigrum, oculorum cantho, macula frontali'duplici, genis, clypeo labroque luteis. Antennae vix capite longiores ferrugineae. Mandibulae ferrugineae apice nigrae. Collare luteum, antice nigrum, lateribus ferrugineum. Thorax dorso punctatus niger. Metathorax supra ochraceus. Scutellum basi nigrum. Squamae ochraceae. Pleurae nigrae macula semilunari pallida. Abdomen ochraceum, segmentis quatuor prioribus macula magna media baseos nigra. Alae hyalinae nervis stigmateque ferrugineis. Pedes ochracei.

Vom Vorgcbirge der guten Hoffnung. Acht Linien lang und vom Ansehen eines Crabro oder Philanthus. Der Kopf grofs, punktirt, schwarz; ochergelb: Schild und Lefze, der Winkel vor den Augen, ein doppelter Fleck an der Stirn zwischen den Augen und die Wangengegend. Fühler und Mandibeln sind braun, letztere mit schwarzen Spitzen. Der Halskragen oder vordere Lappen des Rückenschildes ist gelb an den Seiten mit einern brannen Schatten, die vordere untere Seite aber schwarz. Das Rückenschild selbst ist stark punktirt und schwarz, der Hinterrücken hell ochergelb, das Schildchen entweder ganz oder doch zur grö̈lsern hintern Hälfte gelb. Die Brustseiten haben einen blafsgelben, mondförmig gebogenen Fleck. Die Flügelschuppen sind ochergelb, die Segmente des Hinterleibes von der nemlichen Farbe. Nur die ersten vier haben einen mattschwarzen, grofsen und halbrunden Fleck, welcher z.noleich die ganze Breite des vordern Randes ein. 


\section{$-227$}

nimmt. Die Flügel sind durchscheinend, wenig bräunlich getrübt, mit braunen Nerven und Randmahl. Die Beine sind durchaus ocherfarben.

\section{Ceramius linearis.}

Ceramius elongatus niger, thorace maculis', abdomine fasciis sex anoque flavis. Mas long. lin. 7 .

Patria: Prom. bonae spei; Distr. Vitenhagen. Krebs.

Corpus elongatum, angustissimun, nigrum. Caput punctatum, linea utrinque ante oculos flexuosa, semicirculari frontali ad clypei basin intermedia, punctoque utrinque in medio genarum flavis. Clypeus flavus, utrinque ad basin niger. Labrum flavum. Mandibulae flavae, apice nigrae. Antennae thorace fere duplo longiores, filiformes, apice incurvatae luteae, articulo primo flavo, dorso nigro. Rostrum lineare flavum. Thorax elongatus; lobo antico, apice valde sinuato, flavo, macula utrinque triangulari nigra, intermedio lineola dorsali abbreviata, lineolis lateralibus obliquis, punctisque duobus versus marginem anteriorem flavis. Squamae luteae, flavo-marginatae. Pleurae macula triangulari flava. Scutellum flavum, basi nigrum, puncto utrinque flavo. Netathorax utrinque flavo-maculatus. $\Delta$ bdomen apice bidentatum nimrum, segmentis quinque prioribus margine postico late, sexto fascia bisinuata, ultimo apice flavis. Venter in ultimo segmento dentatus, dente brevi recurvo, medio flavo-maculatus, macula transversa biloba. Alae hyalinac, apice obscuriores nervis stigmateque ferrugineis: Pedes flavi coxis pallidis. 
Von Vitenhagen. Nahe an 7 Linien lang. Ein einzelnes männliches Exemplar. Der Kürper sehr schmal, fast linienförmig. Die Grundfarbe schwarz. Am Kopfe finden sich vor den Augen ein etwas gebogener Strich, cine Zirkellinie dazwischen in der Mitte nahe dem Grundtheile des Konfschildes und hinter den Augen in der Nitte der Wangen ein Punkt vón gelber Earbe. Das Schildchen ist scchsseitig, gelb, die hinteren Seiten schwarz gerandet. Die Lefze und der linicnförmig vorgestreckte Rüssel sind gelb, die Frefszangen gelb mit schwarzen Spitzen. Die fałenförmigen Fühler mit gekrümmten Spitzen, wohl doppelt so lang als das Riickenschild, sind röthlichgelb, das Wurzelnglied gelb, oben schwarz. Das längliche Rückenschild ist wie der Kopf punktirt, das Halsschild, an der Spitze ticf ausgeschinitten, ist gelb mit einem schwarzen drcieckigon Fleck an den Seiten. Die Mitte des Rückenschildes dagegen ist schwarz und die gelben Zeichnungen auf demselben bestchen in einer abgekürzten Mittellinie, zwei dergleichen schrïgen Seitenlinien und zwei lilcinen Punkter. Die Punkte stehen nicht weit von dem vorderen Rand zwischen den Seitenfortsützen des Halsschildes. Die Linien berühren die Basis des liückenschildchen. Dieses ist schwarz mit gelber Spitze und hat einen gelben Punlt zu jeder Seite, da wo es sich mit dem Rückenschild verbindet. Der Hinterrücten hat auf jeder Seite cinen gelben Fleck. Der IIinterleib ist, wie der ganze Körper sehr sclımal, endigt sich in zwei kurze, hakenförmig gelsrümmte Spizzen und hat zwischen diesen auf der untern Seite noch einen breiteren Dorn, wie dergleichen anch bei den männlichen Bembex wahrgenonmen wird. An den 
fünf ersten Abschnitten ist die vordere Hälfte schwwarz, die hintere gelb, und dasselbe findet sich auch bei dem sechsten Abschnitt, nur dafs hier die gelbe Binde, wie bei dem folgenden Cer. Fonscolombii auf jeder Seite einen Ausschnitt hat. Der letzte Abschnitt ist an der Spitze gelb. Aut dem Bauch sieht man einen breiten, zweilappigen, gelben Fleck. Die Beine sind dunkelggelb mit blafsgelben Hüftstücken, die Flügel durchscheinend, an der Spitze etwas getrübt, mit braunen Nerven und Randmahl.

\section{Ceramius Fonscolombii.}

Ceramius ater, capite thoraceque punctis, abdumise fasciis utrinque sinuatis flavis. Long. lin. 7 .

Ceramius Fonscolombii Latreille Considérations etc. p. 32 g. u. 438.

Habitat in Gallia meridionali.

Statura fere Vespae grallicac. Corpus subpubescens. Caput clypeo, linea ante oculos et puncto ver. sus marginen posticum genarum flavis. Mandibulac ejusdem coloris, apice nigrae. Antennae vix capite longiores, articulo primo subtus flavo. Collare nigrum, medio flavum. Macula utrinque ad basin pleurae, puncta tria linearia parva in dorso thoracis, lineola in scutelli medio longitudinaris et altera sub scutello minor, transversa, punctum denique utrinque in metathorace, flava. Abdominis segmentum primum maculam utrinque flavan, segmenta quinque insequentia fascias totidem utrinque profunde sinuatas habent, septinum seginentum macula media flava ormat. Venter planus niger, basi ferrugineus, segmento secundo puncto utrinque, tertio quartoque maculatransversa bisinuata flavis. Pedes subtus lu- 
tei, dorso flavi sunt, exceptis coxis femoribusque ultra basin nigris apice tamen flavis. Alae hyalinae, apice fuscescentes, nervis fuscis, costa sligmateque ferrugineis. Alarum squamae flavae puncto medio luteo notatae.

Aus dem südlichen Frankreich: Sieben Linien lang. Tiefschwarz, Kopf und Rückenschild punktirt. Gelb sind ein Saum am inwendigen Rande der Augen, ein Fleck in der hintern Wangengegend, die untere Seite des Fühlerschafts, das Kopfschild und die Fühler bis zur Spitze, ferner der mittlere Theil des Halsschildes, ein Fleck an den Brustseiten, drei linienförmige Punkte auf dem Rücken dicht am vorderen Rande des Schildchen, auf diesem eine Längslinie, unter ihr eine kleine Queerlinie und ein Punkt zu jeder Seite am Hinterrücken. Die Flügelschuppen sind gelb mit einem dunkleren Mittelpunkt. Der Hinterleib ist schwarz. Der erste Abschnitt hat auf jeder Seite einen Fleck, der letzte einen Mittelpunlst, die übrigen haben eine zweimal tief ausgebogene, den hinteren Rand ganz einnehmende Queerbinde von gelber Farbe. Die ersten Segmente am Bauch sind braun, das zweite hat zwei gelbe Punkte, auf dem dritten und vierten findef sich in älnnlicher Art wie oben ein doppelt ausgerandeter Queerfleck. Die Flügel sind durchscheinend, an den Spitzen dunkler, mit dunklen, fast schwarzen Nerven, wogegen die Nerven in der VVurzel und am vordern Rande der Flïgel wie das Randmahl bräınlich gelb sind.

\section{Ceramius lusitanicus.}

Ceramius ater, abdomine fasciis flavis repandis. Ha bi tat in I dusitania; Com. de If of $\mathrm{manh}$ e g g g. 
Simillimus praecedenti ejusdemque magnitudinis et staturae. Differt praesertim antennis multo Jongióribus, fasciisque abdominalibus utrinque emarginatis quidem, minime tamen profunde sinuatis. Caput punctatum, atrum, fusco-pilosum, genis macula postica flava. Cantlius oculorum vix flavo-marginatus. Clypeus flavus, margine omni nigro. Labrum fuscum apice flavum. Mandibulae flavae, apice nigrae. Antennae thorace longiores nigrae, apice involutae, ferrugineae, articulo primo subtus flavo. Thorax punctatus ater, fusco-pilosus. Collare antice ntrinque flavum. Scutellum macula dorsali flava. Pleurae puncto flavo. Squamae ferrugineae. Aldomen macula utrinque ad apicem primi segmenti, fasciis quinque medio repandis utrinque dilatatis maculaque dorsali in segmento septimo flavis. Segrmenta ventralia flava, macula triangulari nigra. Alae apice fascescentes nervis stigmateque fuscis. Pedes lutei, femoribus basi nigris, coxis subtus flavis.

Aus Portugal. Gröfse und Gestalt der vorhergehenden Art. Schwarz., Kopf und Rückenschild punktirt und dunkel behaart. An den Wangen findet sich ein kleiner Punkt, vor den hugen eine kaum wahrnehmbare Gränzlinie von gelber Farbe. Das Kopfschild ist gelb, iiberall schwarz gerandet. Die Lefze ist dunkel mit gelber Spitze, die Mandibeln sind gelb mit schwarzen Spitzen. - Das Rüclienschild ist fast einfarbig schwary. Nur der Halsschild hat vorn zu jeder Seite einen gelben Fleck, das Schildchen einen gelben Mittelpunkt und ein sehr kleiner Punkt steht seitwärts unter jedem Vorderflügel. Die Flügelschuppen sind braun, die Flügel an der Spitze cunkel, Nerven und Randusal braunschwarz. $\Lambda \mathrm{m}$ 
Hinterleibe bemerken wir zu jeder Seite des ersten Abschnitts einen Fleck, auf dem letzten Segment einen Mittelfleck von gelber Farbe. An den übrigen Seymenten ist der hintere Rand gelb, so dafs er eine sclimale gebogene, zu jeder Seite breitere Queerbinde bildet. Die Schilder des Bauchs sind, die letzten ausgenommen, blafsgelb mit einem kleinen schwarzen Dreieck in der Mitte am vordern Rande. Die Beine sind dunkelgelb, die Schenkel an der Wúrzel schwarz, die Hüftstïcken unten blafsgelb. 


\section{$\mathrm{Z}$ u r}

Monographie der

Gat tung: C h l a m y s. 
Zur Auseinandersetzung der Gattung Chlamys verleitete mich die, wie es mir damals schien, grofse Menge der Arten dieser Gattung, welche, neben einer bedeutenden Anzahl anderer Insecten, vorzïglich auf seiner letzten gröfseren Reise in Brasilien der Herr Legationsrath Dr. von Olfers, und sein fleilsiger Begleiter Sellow gesammelt und nach Europa gesendet hatten. Gleiche Umstände waren es, welche zur nemlichen Zeit Herrn Vinc. Kollar in Wien zur Bearbeitung einer Monographie derselben Gattung und Herausgabe seiner: Monographia Chlamydum. Cum tabulis aeneis coloratis duabus. Viennae. Impensis Heubneri 1824. fol, vermochten. Wäro diese Monographie vor der Vollendung der meinigen erschienen, so würde die Bekanntmachung der letztern wahrscheinlich unterblieben seyn. Jedoch künnen beide, nach meiner jetzigen Ueberzeugung auch recht wohl neben einander bestehen, da in jeder derselben eine nicht unerhebliche Menge neuer Arten beschrieben ist. Nur etwa die Hälfte derer, welche die Monographie des Herrn Kolla r enthält, ist mir oder sonst bekannt gewesen, so dafs die Gattung Chlamys, früher von so geringem Umfange, hierdurch eben so schnell als bedeutend gewonnen hat. Wo in beiden Monographieen, wie einigemal der Fall ist, dieselben 
Arten unter verschiedenen Benennungen vorkommen, müssen, in sofern nicht ältere Artbezeiclinungen schon vorhanden und von mir benutzt waren, die von Herrn Kollar gewählten Bezeichnungen den Vorzug behalten. Die von Herrn Kollar geschehene Eintheilung der Gattung in zwei Familien, je nachdem die Nath der Deckschilde entweder fein gezahnt oder glatt ist, erleichtert dí Anordnung und das Aufsuchen der Arten. Ich hatte diese Verschiedenheit zwar ebenfalls wahrgenommen und bei den Artbeschreibungen jederzeit angegeben, wollte aber, da dic Zahl der-Arten mit glatiom Nathrando in Verhältnifs gering ist, hierauf keine Eintheilung in Familien stützen. Herr Kollar hat in seiner Monographie überhaupt 45 Arten beschrieben, von welchen vier zur zweiten Familie gehören. Folgende Veräuderungen würden in Beziehung auf gedachte Schrift in meiner Monographie vorzunehmen und zunïchst als Synonyme zu früher bekannten Arten nachzutragen seyn:

2u Chlamys monstrosa p. 8g. n. 1., Kollar Monogr. Chlanyd. p. 5. מ. 1. Tab. I. Tig. 8.; zu Chlusny's bacca p. 93. n. 3., Koll. Monogr. p. 6. n. 2. Tab. I. Fig. 9.; unter der dorterwähnten $\Lambda$ bart ist wahrscheinlich Chlaniys cuprea (p. 94. n. 4.) verstanden. Zu Chlamy's arcula p. 99. n. 7., Chl. Schreibersii Koll. Monogr. p. 9. n. 5. Tab. I. Fig. 12.; zu Chlamy's capricornis p 113. n. 21., Chl. Dejeani Koll. Monogr. p. 14. n. 10. Tab. I. Fig. 17.; zu Chlamys plicala (tuberesa Knoch), Koll. Monogr. p. 12. n. 8. Tab. I. Fig. i5.; zil Chlamys cistclla p. 125. 11. 35., Chl. Mikani Koll. p. 25. n. 21. Tab. II. Fir. 28.; zu Chlamy's luteola p. I51. n. ¿6., Chl. signata Koll. p. 4ú. n. 40. Tab. II. 
Fig. 47.; zu Chlamys puncticollis p. 154. n. 59., Chl. Mühlfeldí Kull. p. 19. n. 15. Tab. I. Fior. 22.

Dagegen würden folgenden von mir beschriebenen Arten nachstehende in der Monographie des Herrn Kollar vorkommende Benennungen an der Stelle der meinigen beizulegen seyn:

Chlamy's spinosa Koll. (Monogr. p: 8. n. 4. Tab.I. Fig. 11.) der Chl. muricata p.97. n. 6.; Chlamys Langsdorfii Koll. (p. 10. n. 6. Tab. 1. Fir. 13) der Chl. ru. gosa p. 104. n. 11.; Chlamy's varians Koll. (p. 2g. n. 25. Tab. II. Fig. 52.) der Chl. diadema p. 109. n. 16.; Chlamys Germari Koll. (p. 33. 11. 29. Tab. II. Fig. 36.) der Chl. scoriosa p. 120. n. 28.; Chlamy's maculata Koll. (p. 4x. n. 37. Tal, II. Fig. 44.) der Chl. favosa p. 121. n. 2y.; Chlamy's Olfersii Koll. (p. 23. n. 26. Tab. I. Fig. 26.) der Chl. tenebrosa p. 124. n. 32.; Chlamys globosa Koll. (p. 22. n. 25. Tab. I. Fig. 25.) der Chl. purpurascens p. 128. n. 35.; Chlamys KKnochii Koll. (p. 26. n. 22. Tab. II. Fig. 29.) der Chl. fuscipes p. 132. n. 39.; Chlamy's Nattereri Koll. (p. 17. n. 13. Tab. I. Fig. 20.) der Chl. rufa p. 134. n. 41.; Chlamy's dromedarius Koll. ( $p .16$. n. 12. Tab. I. Fio. 19.) der Chl. frenata p. 135. n. 42.; Chlamy's vuricgata Koll. (p. 27. n. 23. Tab. II. Fig. 30.) der Chl. porosa p. 139. n, 45.; Chlamy's sulcata Koll. (p. 38. n. 34. Tab. II. Fig. 4I.) der Chl. cinnamomea p. 150. n. 55.; Chlamy s hicroglyphica Koll. (p. 18. n. 14. Tab. I. Fig. 21.) der Chl. labiata p. 153. n. 58.; Chlamys olivacea Koll. (p. 45. n: 41. Tab. II. Fig. 48.) der Chl. bicolor p. 166. n. 61.; Chlamy's cyanca Koll. (p. 46. n. 42. Tab.II. Fig. 49.) der Chl. cyanella p. 108. n. 15., and Chlamys morio Koll. (p. 47. n. 43. Tab. II. Fig, 50.) der Chl. globosa p. 129. n. 27 . 
Als neu sind folgende Arten der Kollarschen Monographie nachzutragen:

a. aus der ersten Abtheilung:

Chlamys hirta (p. 7.n. 3. Tab. 1. Fig. 10.), Chl. intricata (p. 11. n. 7. Tab. I. Fig. 1/4.), Chl. Latreillii (p. 13. n. 9. Tab, I. Fig. 16.), Chl. adspersa (p. 15. n. 11. Tab. I. Fig. 18.), Chl, Kammerlacheri (p. 20. n. 16. Tab. I. Fig. 23), Chl. Schottii (p. 21. 1, 17. Tab. I. Fig. 24.), Chl. hybrida (p.24. n.20. Tab. I. Fì. 27.). Vielleicht jedoch Chl. tarsata P. z02. n. 9. der Monographie, doch hat sich die Art die zu den gewöhnlichsten in Brasilien gehören soll, mit Sicherheit nicht ermitteln lassen. Chl, elongata (p. 28. n. 24. Tab. II. Fig. 31.), Chl. Schüchtii (p. 3o. n. 26. Tab. II. Fig. 33.), Chl. affinis (p. 32. n. 28. Tab. II. Fig. 35.), Chl. exarata (p. 34. n. 30. Tab. II. Fig. 37.), Chl. quinquesulcata (p. 35, n. 31. Tab. II. Fig. 38.), Diese scheint der Chl. cristata F. sehr. ähnlich zu seyn; doch ist bei der letztern der inwendige Rand der Deckschilde glatt. Chl. thoracica (p. 36. n. 32. Tab. II. Fig. 39.), Chl. haemorrhoidalis (p. 37. n. 33. Tab. II. Fig. 40.), Chl. rulgicunda (p. 39. n. 34. Tab. II. Fig. 42.), Chl. Selowi (p. 40. n, 36. Tab. II. Fig. 43.). Diese Benennung dürfte zu ändorn seyn, da vermuthlich die Art, nach dem in den vorstehenden Monographieen oft erwähnten, um die Vermehrung der hiesigen Sammlungen so verdienten, Sellow genannt ist und dann Sellovii heifsen müfste. Chl. Pohlii (p. 42. n. 38. Tab. II. Fig. 45.), Chl. Gysselinii (p. 43. n. 39. Tab. II. Fig. 46.).

b. aus der zweiten Abtheilung.

Chl. dubia (p. 48. n. 44. Tab. II. Fig. 51.) und Chl. sinuata (p. 49. n. 45. Tab. II. Fir. 52.). ... 
Hiernach würde die erste Abtheilung der Chlamys durch Herrn Kollar's Monographie um 18, die andere um zwei Arten vermehrt, die Zahl der nun beschriebenen Arten überhaupt auf 84 gebracht worden seyn. Zur zweiten Familie gehüren von den in meinen Monographieen zuerst beschriebenen Arten: Chl. galeata, umbrosa, pilula und braccata, und aufserdem die von Fabricius beschriebene Chl, cristata. Endlich machen noch einige in der.Koll ar schen Monographie gebrauchte Benennungen die Aenderung derselben Namen in der meinigen nothwendig. Dieses sind: Chl. affinis, p. 115. n. 23. welches in Chl.assimilis umzuändern, Chl. exarata. p. 141. n. 47. wofür Chl. exasperata zu setzen und Chl. maculata p. 147. n. 52. welche Benennung mit Chl maculosa zu vertauschen seyn würde. Bei dem, ehe mir die Monographie des Herrn Kollar zu Gesicht kam, schon vollendeten Abdruck der meinigen, hat die Zahl der Abbildungen auf welche bereits Bezieliung.genommen worden, nicht füglich ferner vermindert noch verhütet werden lrönnen, dais nicht mitunter eine dort schon vorgestellte Art noch einmal abgebildet wurde. Dieses hat sich indefs nur selten gesroffen. Um die Richtigkeit der Abbildungen bin ich möglichst besorgt gewesen. Nicht alle gehören zu den gelungensten, doch mügen leicht die Arten von Chlamys sowohl in Bildern, als durch Beschreibungen, sehr schwer richtig und vollkommen genügend darzustellen seyn. 


\section{R e gister.}

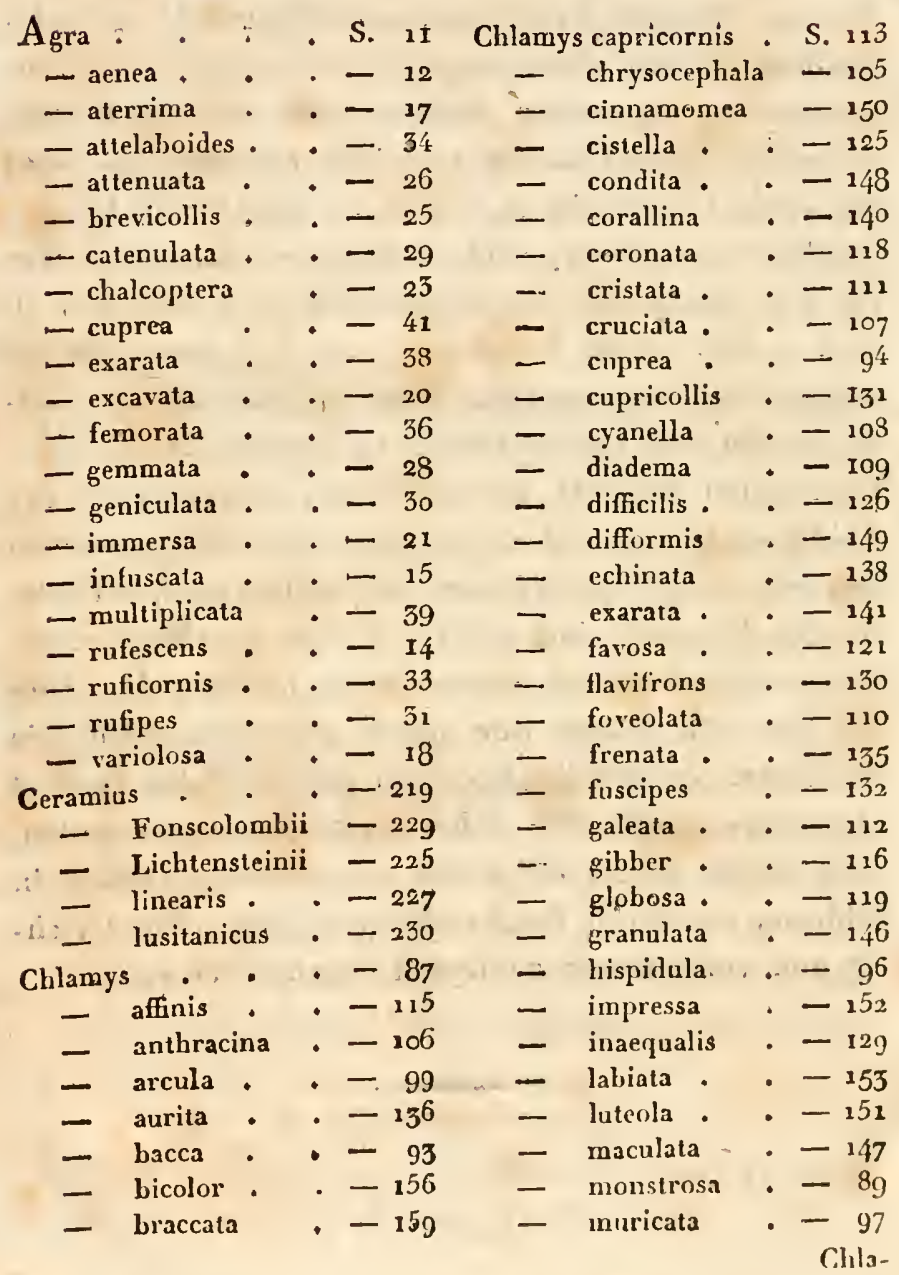


Chlamys nodosa . : S. 100

$$
\begin{aligned}
& \text { - obscura . : - Io3 } \\
& \text { - pellucida . - } 143 \\
& \text { - pilula . . }-15^{8} \\
& \text { - plicata. . - } 114 \\
& \text { - porosa. . - } 139 \\
& \text { - puncticollis . - 15t } \\
& \text { - purpurascens - } 128 \\
& \text { - reticulata - - } 144 \\
& \text { - rufa . . - } 132 \\
& \text { - rugosa. . - } 10 \text {. } \\
& \text { - rutila . . }-133 \\
& \text { - scoriosa - }-120 \\
& \text { - sellata. . - } 142 \\
& \text { - smaragdina . }-155 \\
& \text { - speculum . }-157 \\
& \text { - suberosa . - } 113 \\
& \text { - subspinosa . - } 123 \\
& \text { - tarsata . . - } 102 \\
& \text { - tenebrosa . - } 124 \\
& \text { - tuberculata . }-117 \\
& \text { - umbrosa . - } 122 \\
& \text { - violacea. . }-92
\end{aligned}
$$$$
\text { Cryptocerus • . }-199
$$

- atratus . -200

$$
\text { - clypeatus . - } 207
$$$$
\text { - depressus. - } 204
$$$$
\text { - elongatus . - } 214
$$

- membranaceus - 208

- minutus . -203

- pallens . -206

- pusillus . -202

- quadrimacula-

$$
\text { tus . . }-215
$$

- ũmbraculatus - 210

Ctenostoma - . . - 3

- formicarium - 4

- rugosum - 7

- trinotatum. - 5

Mastigus . . . - 163

- deustus. . -164

- 1lasus . . -165

- fuscus . . -167
Mastigus glabratus - S. 266

- palpalis . $\therefore-165$

- spinicornis . -164

NIegalopus . . . -45

- abdominalis - 78

- ater. . - 67

- analis. . 59

- bicolor . - $7^{6}$

- bifasciatus. - 53

- binotatus . - 74

- bipunctatus - 78

- cruralis . - 64

- curvatus . - 82

- curvipes - - 79

- dentatus . -73

- depressus. - $7^{1}$

- dimidiatus. -77

- discoideus. - 49

- egregius . - 50

- fasciatus - -58

- flavo - macula-

tus . - -57

- trontalis. -75

- hirtipes . -65

- inscriptus. - 61

- marginatus . - 51

- nigricornis - 65

- obliquus . -83

- ruficornis. - 60

- sellatus - - 47

- signatus $\cdot 54$

- subfasciatus - 52

- testaceus . $-5^{6}$

- tibialis. . $-8 \mathrm{I}$

- variegatus . - 69

- vittatus . -70

Pachylosticta . . -171

- albiventris . -174

- tibialis $\cdot-173$

- violacea.$-17^{4}$

Syzygonia . . . -277

- cyanocephala - 180

- cyanoptera . - 179

$$
16
$$




\section{- 242}

Tarpa S. 183 Tarpa pectinicornis . S. 194

- bucephala. $\quad-185:$ plagiocephala -189

- cephalotes . - 84 - quinquecincta .' 193

- Havicurnis. . - 192 - spiraeae . . - I88

- megacephala : - 190 - spissicornis - 187

Werichtigungen.

Seite 180 Zeile 8 von oben, lies 2 statt 36.

- $189-15$ - unten, - 5-56. 
Tab.I.
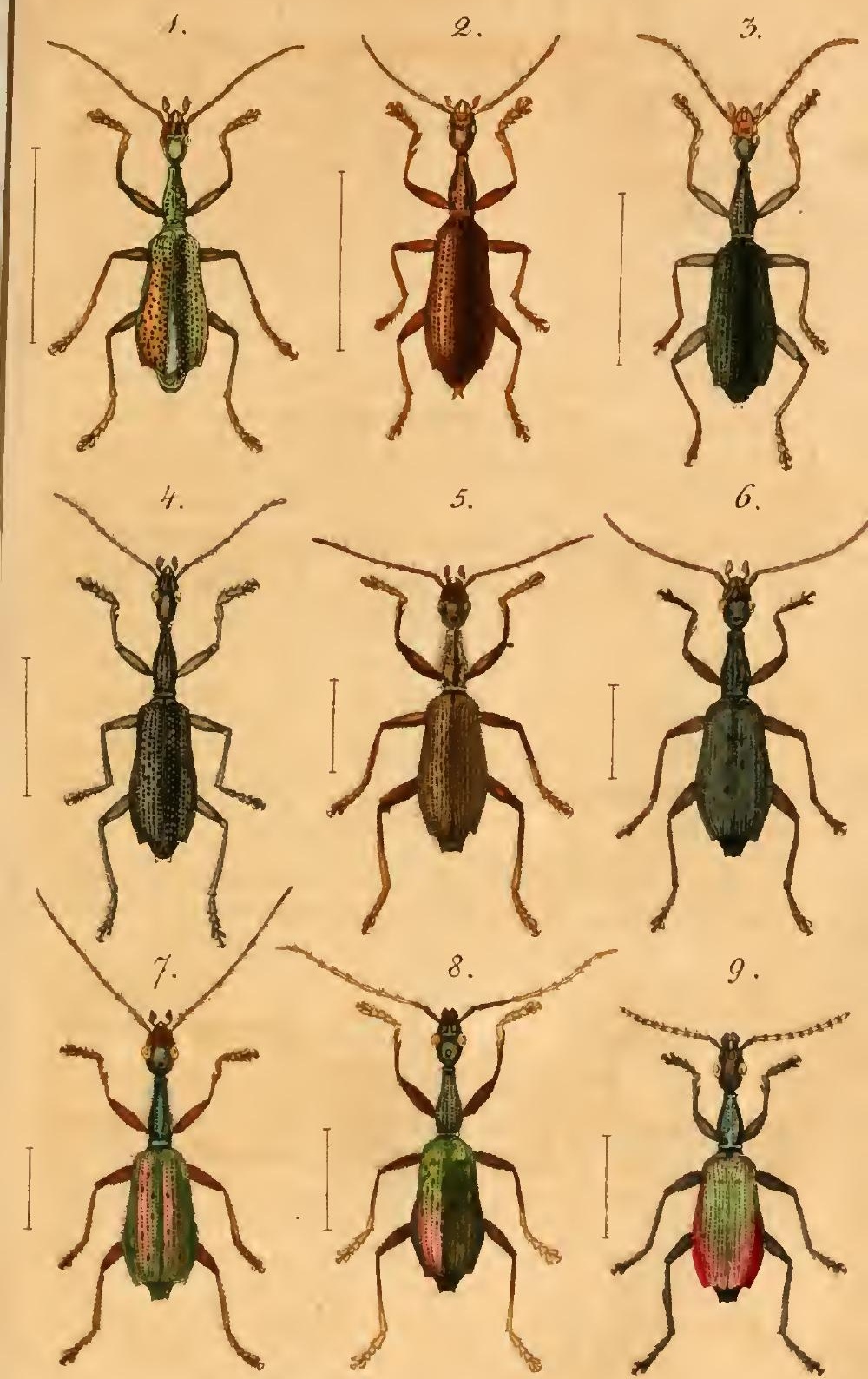

$T a b, I I$.
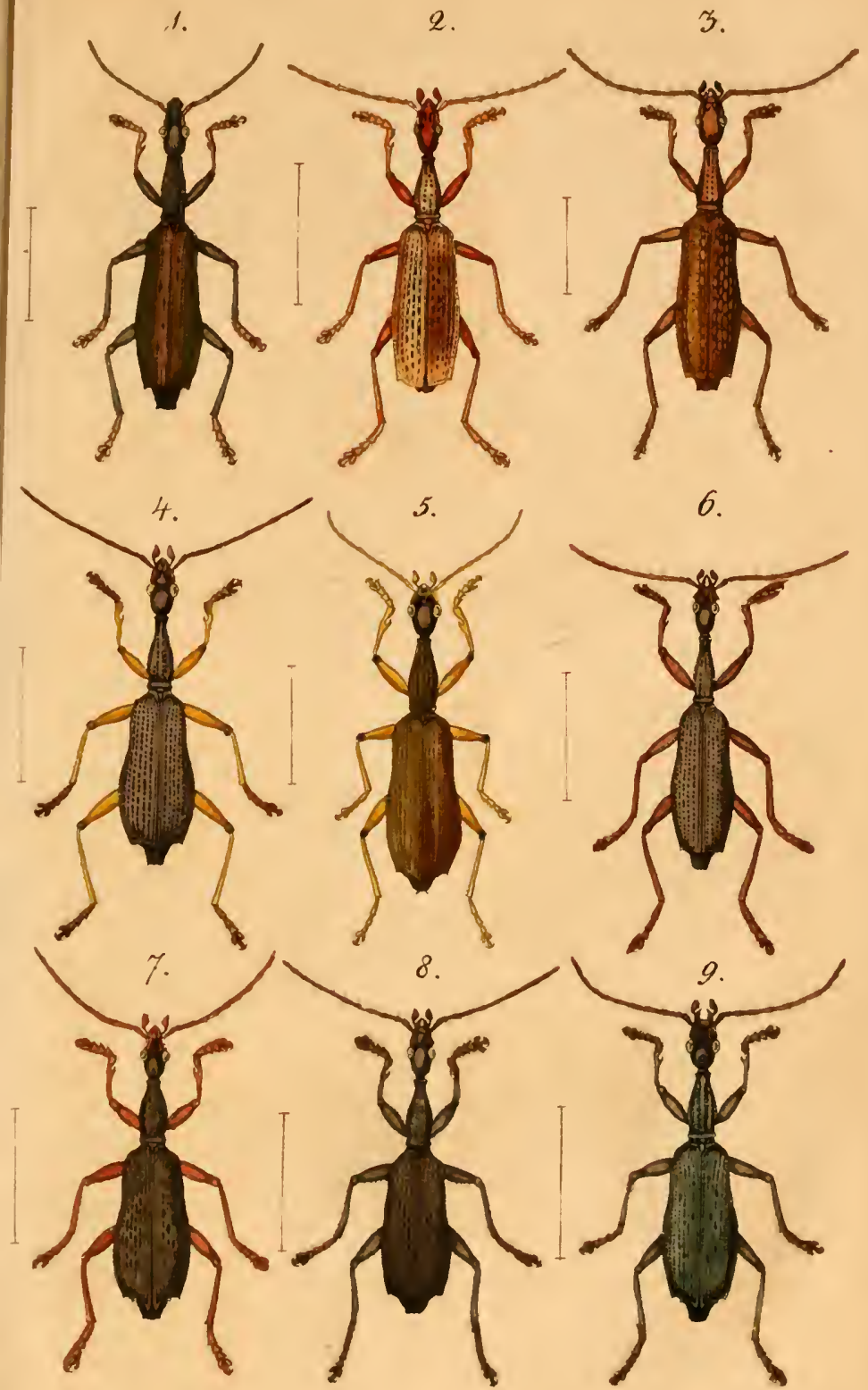

Klug Ilosengr. 
Yab.III.
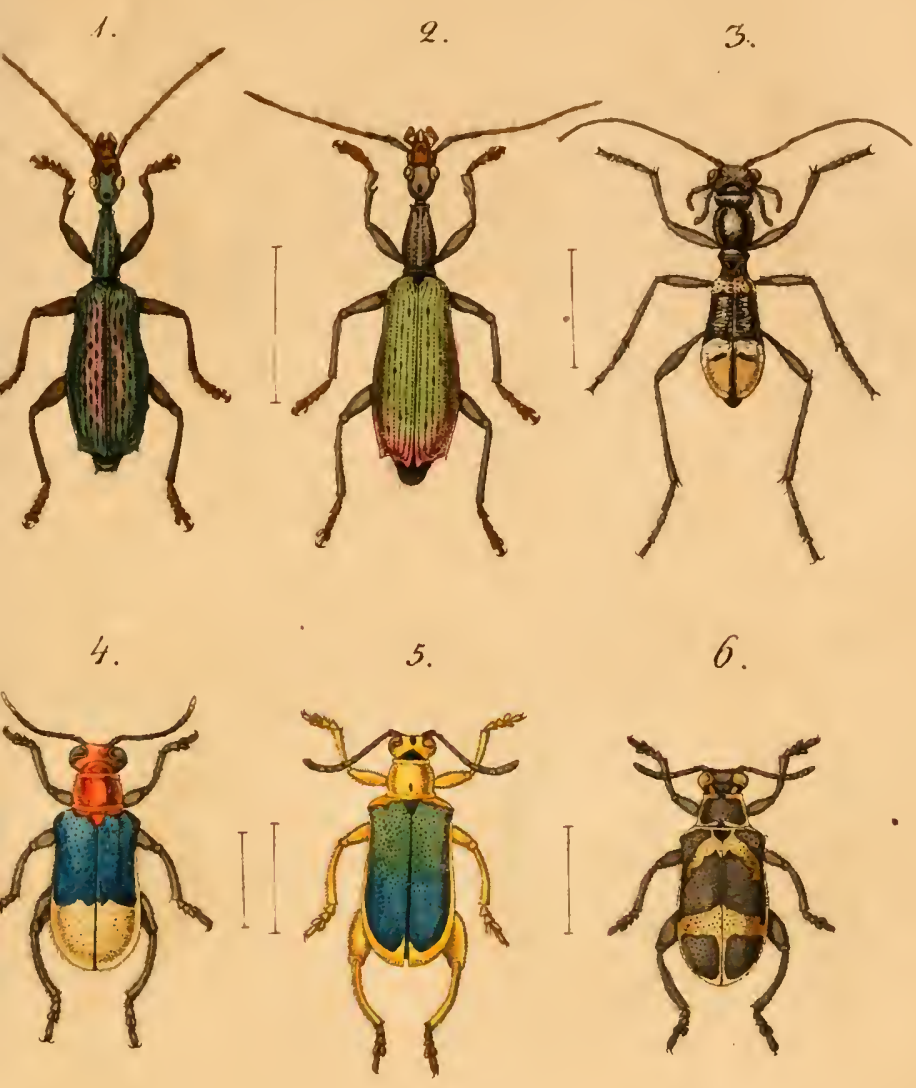

7.

8.
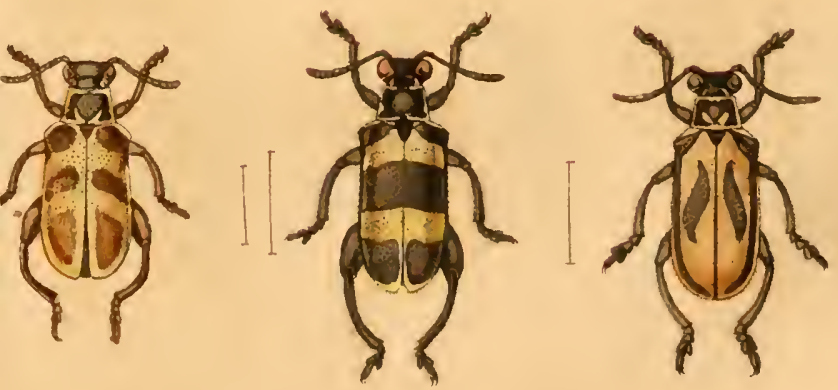

Klug-IIonour. 

Trbbsi.

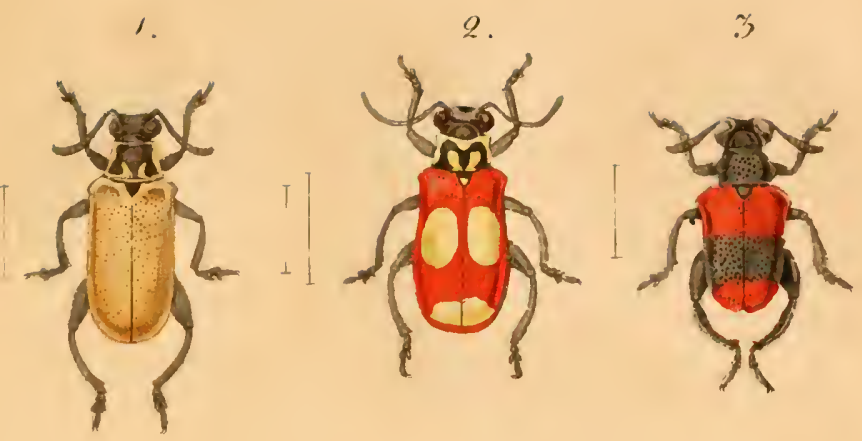

4.

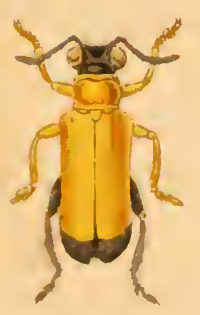

$\tilde{\pi}$

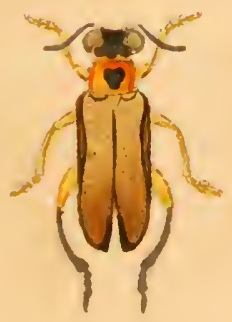

5.

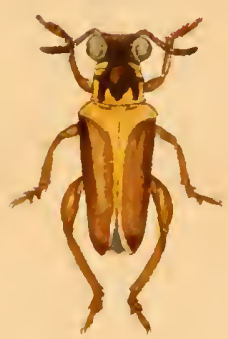

8.

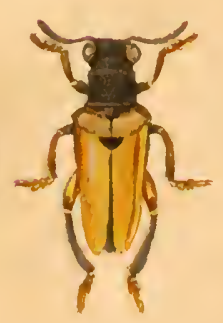

6

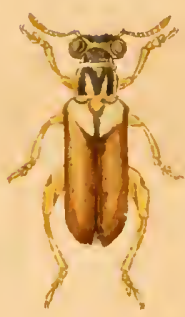

9.

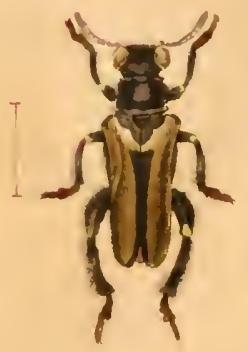



1.

$\tilde{3}$
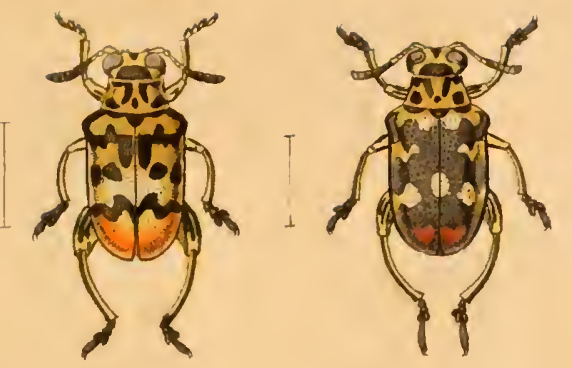

4.

5.

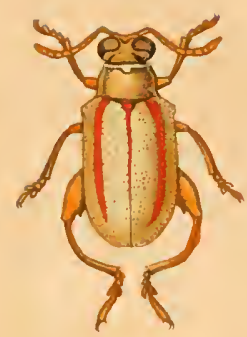

6.
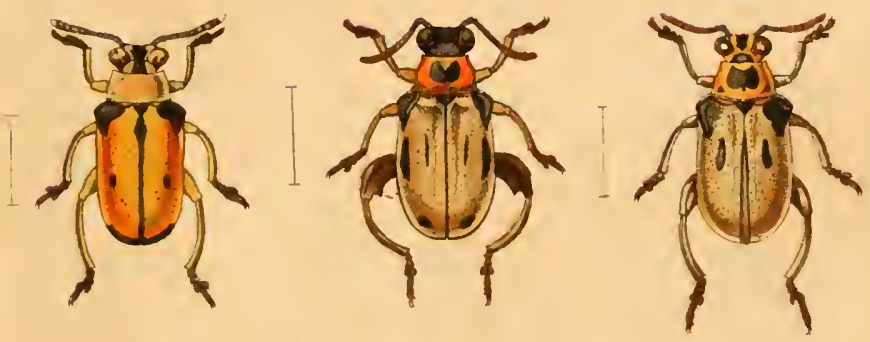

7.

8.

9.
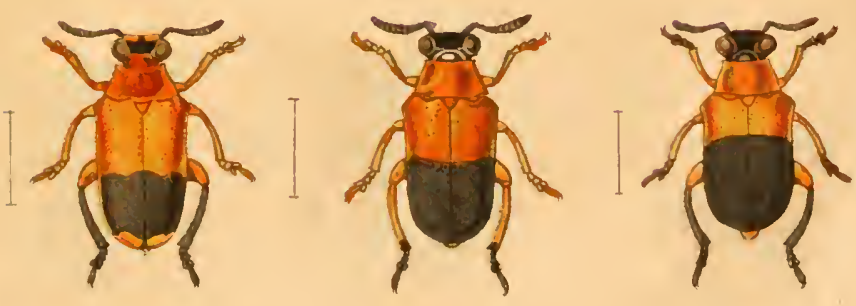

Kilug. Ilonngr: 

Tab.1\%.

1.

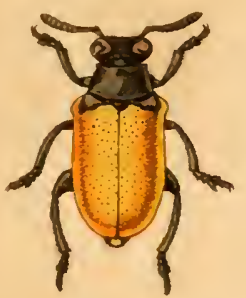

4.

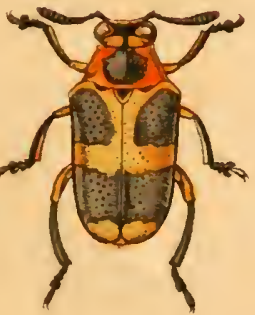

7.

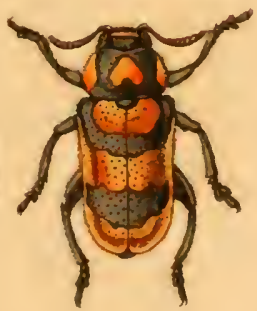

2.

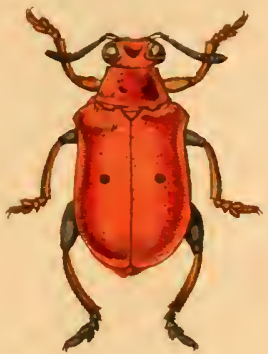

5.

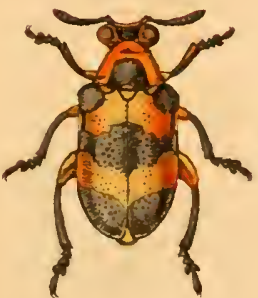

8.

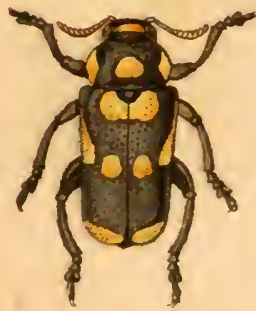

3

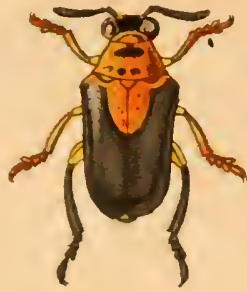

6.

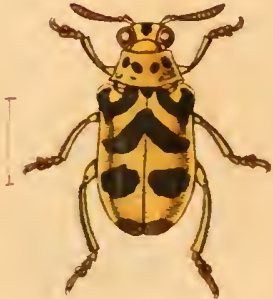

9

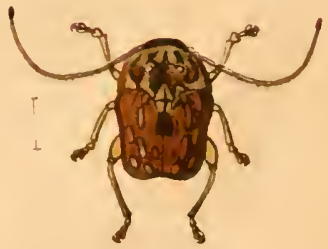

\section{Rlugullonogr.}



1. 2.

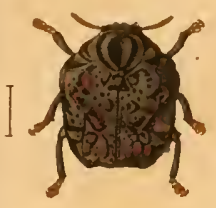

4.

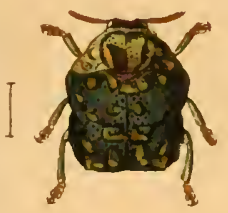

7.

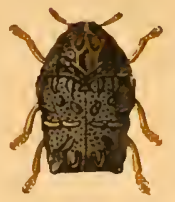

10.

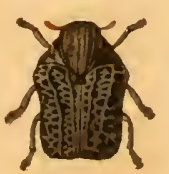

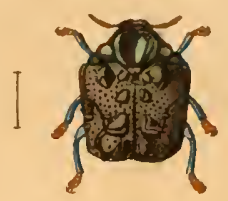

5.

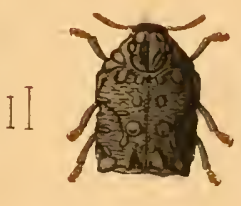

8.

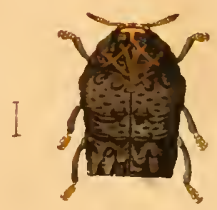

II.

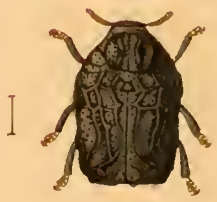

3.

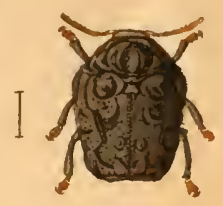

6 .

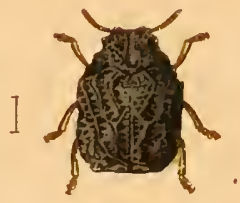

9.

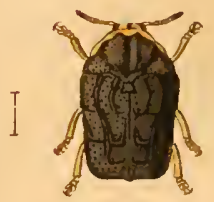

12.

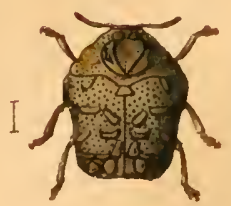

Klug Vonegr: 

1.

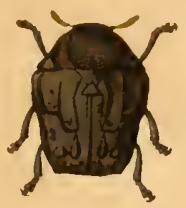

4.

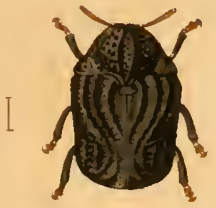

I

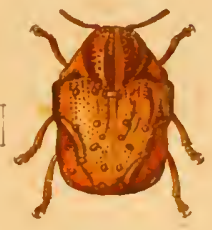

10.

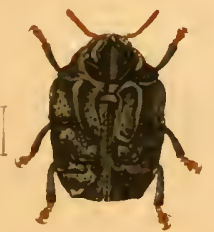

$2 \ldots$

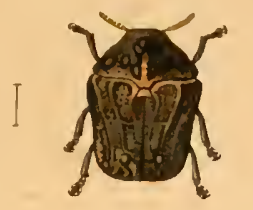

5.

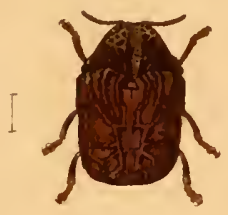

2.

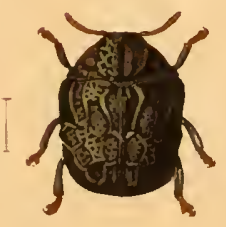

II.

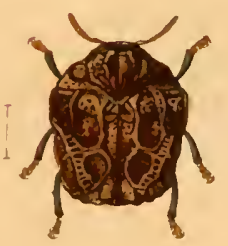

3.

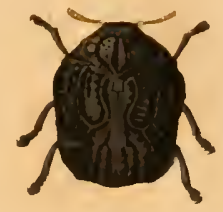

6.

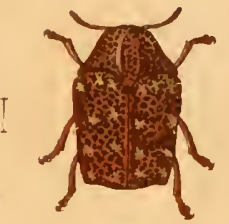

$\Omega$

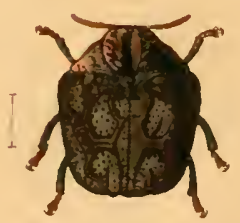

12.

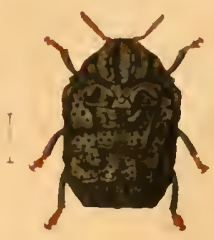

Klug. Nonegr: 

I.

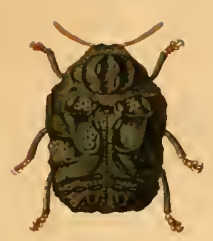

4

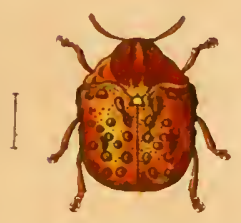

$$
7
$$

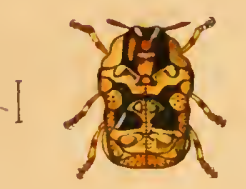

10.

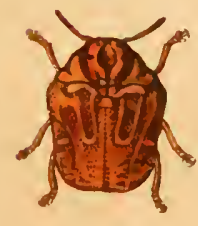

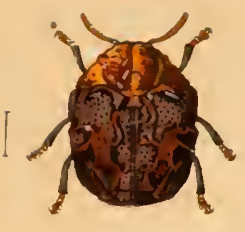

5.

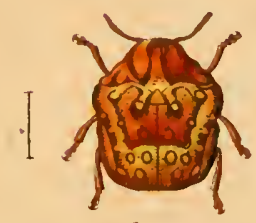

8.

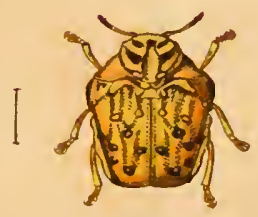

II.

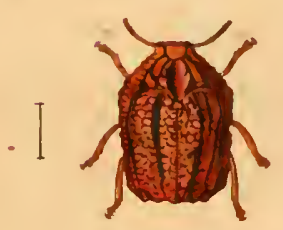

3.

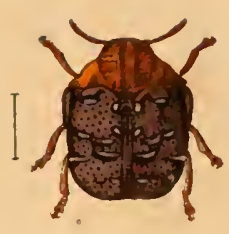

6.

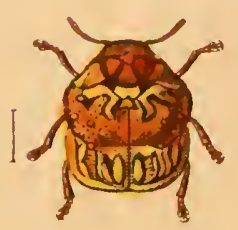

9.

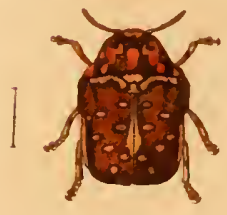

12.

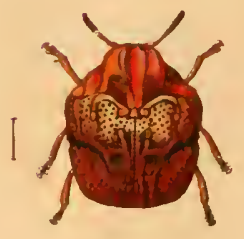

Klug. Nlonogr. 



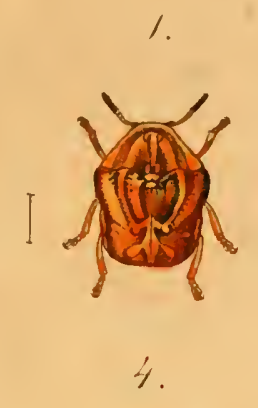

2.

$j$.
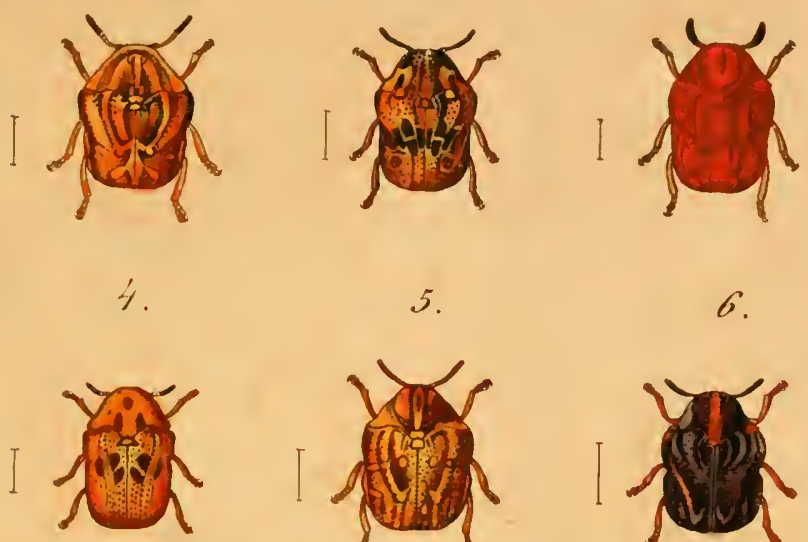

5.

6.
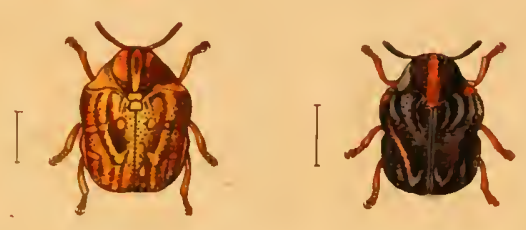

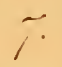

2.

9
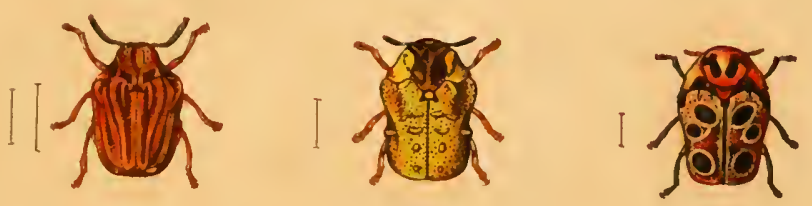

10.
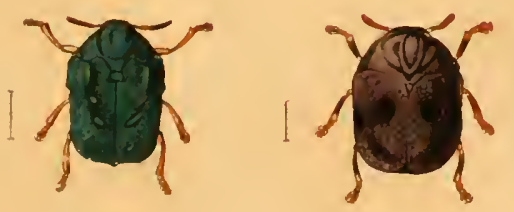

12.

II.

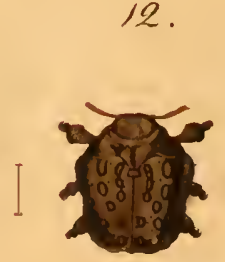

Klun Honny. 




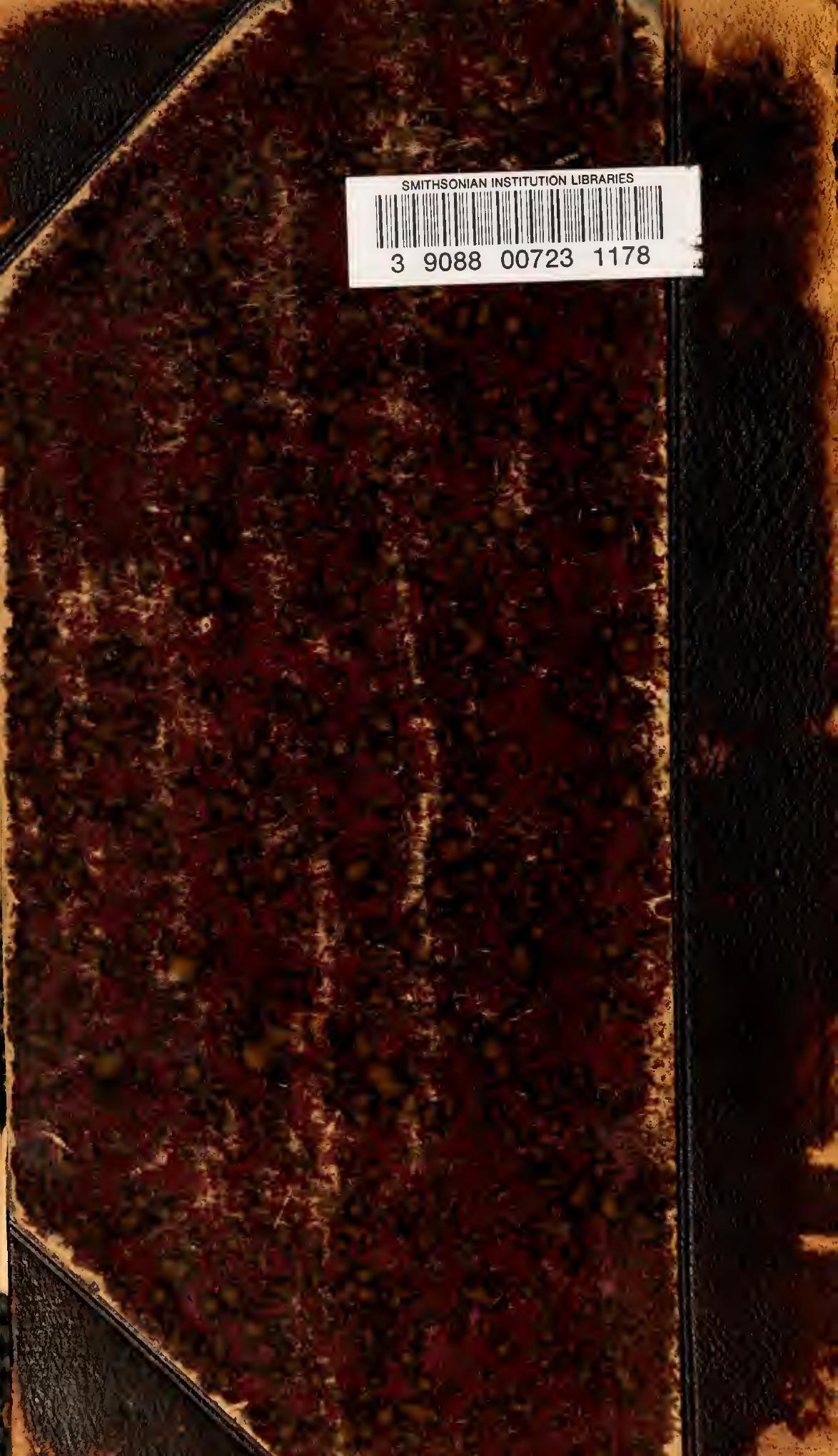

